\title{
WEATHERING THE STORM: \\ THE DEMAND FOR AND IMPACT OF MICROINSURANCE
}

\section{DISSERTATION}

to obtain

the degree of doctor at the University of Twente, on the authority of the rector magnificus, prof.dr. H. Brinksma, on account of the decision of the graduation committee, to be publicly defended

on Friday 14th of September 2012 at 16.45 hours

by

Karlijn Morsink

Born on the 13 January 1984,

Hengelo, The Netherlands 
This thesis is approved by:

Promotor: prof.dr. J.C. Lovett

Assistant-promotor: dr.ir. A.L. Kooijman-van Dijk

Assistant-promotor: dr. P.A.T.M. Geurts 
Members of the Committee:

$\begin{array}{lll}\text { Chair: } & \text { Prof.dr R.A. Wessel } & \text { University of Twent - MBe } \\ \text { Secretary: } & \text { Prof.dr. R.A. Wessel } & \text { University of Twente - MB } \\ \text { Promotor: } & \text { Prof.dr. J.C. Lovett } & \text { University of Twente - MB } \\ \text { Co-promotor: } & \text { Dr. ir. A.L. Kooijman-van Dijk } & \text { University of Twente - TNW } \\ \text { Co-promotor } & \text { Dr. P.A.T.M. Geurts } & \text { University of Twente - MB } \\ \text { Member: } & \text { Prof.dr. G.W. Harrison } & \text { Georgia State University, } \\ \text { Member: } & \text { Prof.dr. B.W. Lensink } & \text { University of Groningen } \\ \text { Member: } & \text { Prof.dr. J.Th.A. Bressers } & \text { University of Twente - MB } \\ \text { Member: } & \text { Prof.dr. A. van der Veen } & \text { University of Twente - ITC }\end{array}$

Having heard the defence of this dissertation on 14 September 2012 the committee has decided to admit Karlijn Morsink to the degree of doctor, awarded "Cum Laude". 


\section{Colofon}

(C) 2012 Karlijn Morsink, University of Twente, MB/ CSTM

No part of this publication may be reproduced, stored in a retrieval system, or transmitted, in any form or by any means, electronic, mechanical, photocopying, recording or otherwise, without prior written permission of the author.

ISBN: 978-90-365-3425-3

DOI: $10.3990 / 1.9789036534253$ 


\section{Content}

List of Tables and Figures

Foreword vii

Chapter 1 Introduction

1.1 Background: Demand and impact 1

1.2 Problem definition 2

1.3 Theoretical embedding 3

1.3.1 Insurance demand and utility maximization 3

1.3.2 Insurance demand and market failures 5

1.3.3 Insurance as a complement to consumption smoothing activities 6

1.3.4 Insurance as substitution for income- and consumption smoothing 6

$\begin{array}{lll}1.4 & \text { Research question } & 7\end{array}$

1.5 Structure of the thesis 8

Chapter 2 A review of microinsurance demand

2.1 Introduction 11

2.2 General theoretical framework 12

2.2.1 Expected utility 12

$\begin{array}{ll}2.2 .2 \text { Actuarially fair insurance } & 13\end{array}$

2.2.3 Credit-constraints 14

$\begin{array}{ll}2.2 .4 \text { Asymmetric information } & 14\end{array}$

2.2.5 Behavioral explanations 15

$\begin{array}{ll}\text { 2.2.6 Understanding of insurance } & 16\end{array}$

$\begin{array}{ll}\text { 2.2.7 Demand versus decision-making } & 17\end{array}$

$\begin{array}{ll}\text { 2.2.8 Trust, social capital and network explanations } & 17\end{array}$

$\begin{array}{ll}2.2 .9 \text { Conclusion } & 19\end{array}$

2.3 Method for analyzing empirical studies $\quad 19$

2.3.1 Criteria for inclusion and exclusion of studies 20

2.4 Microinsurance demand determinants 21

2.4.1 Price, subsidies and discounts $\quad 22$

2.4.2 The insured risk and household risk situation $\quad 24$

2.4.3 Prevention, self-insurance and formal risk-sharing 26

$\begin{array}{ll}2.4 .4 \text { Marketing treatments } & 27\end{array}$

$\begin{array}{ll}2.4 .5 \text { (Risk)preferences } & 29\end{array}$

2.4.6 Credit-constraints $\quad 32$

2.4.7 Understanding insurance 32 
2.4.8 Social capital, networks and trust 34

2.5 Exploration of other explanations 38

$\begin{array}{lll}2.6 & \text { Conclusion and discussion } & 40\end{array}$

Chapter 3 The trusted neighbour effect: Peer experience and demand for microinsurance

3.1 Introduction 43

3.2 Results from previous studies $\quad 44$

3.3 The trusted neighbour effect in insurance transactions 45

3.4 Domain, research design and measurement 48

3.4.1 Domain 48

$\begin{array}{ll}3.4 .2 \text { Research design } & 49\end{array}$

3.4.3 Measurement $\quad 51$

3.5 Sample characteristics $\quad 53$

3.6 Results: Knowing peers with claims and take up of PAID plan 56

3.7 Discussion $\quad 58$

3.8 Conclusion 61

Chapter 4 Understanding and measuring the impact of microinsurance on poverty reduction

$\begin{array}{lll}4.1 & \text { Introduction } & 65\end{array}$

4.2 Theories about microinsurance impact 66

$\begin{array}{ll}\text { 4.2.1 Demand and impact } & 67\end{array}$

4.3 Current evidence of the impact of microinsurance 69

$\begin{array}{lll}4.4 & \text { Valid research designs } & 72\end{array}$

4.4.1 Four validities in microinsurance impact research 73

4.5 Considerations when designing microinsurance impact studies 75

4.5.1 Research designs for studying microinsurance impact 76

$\begin{array}{lll}4.6 \text { Conclusion } & 78\end{array}$

Chapter 5 Impact of microinsurance on consumption smoothing activities

$\begin{array}{lll}5.1 \text { Introduction } & 79\end{array}$

$\begin{array}{lll}5.2 & \text { Microinsurance and consumption smoothing activities } & 80\end{array}$

5.3 Domain, research design and measurement 83

$\begin{array}{ll}\text { 5.3.1 Domain } & 83\end{array}$

$\begin{array}{ll}\text { 5.3.2 Research design } & 84\end{array}$

$\begin{array}{ll}\text { 5.3.3 Measurement } & 88\end{array}$

$\begin{array}{lll}5.4 & \text { Descriptives } & 90\end{array}$

5.5 Consumption smoothing activities and their determinants 92 
$\begin{array}{llr}5.6 & \text { Discussion } & 99\end{array}$

$\begin{array}{lll}5.7 \text { Conclusion } & 100\end{array}$

Chapter 6 Conclusions and discussion

$\begin{array}{lll}6.1 & \text { Introduction } & 103\end{array}$

$\begin{array}{lll}6.2 & \text { Research question } & 104\end{array}$

$\begin{array}{ll}\text { 6.3 Conclusions from chapters } & 104\end{array}$

6.4 Discussion and recommendations for future research 109

$\begin{array}{ll}\text { 6.5 Contributions to policy and practice } & 113\end{array}$

$\begin{array}{ll}\text { Dissemination of the research } & 117\end{array}$

$\begin{array}{ll}\text { References } & 121\end{array}$

$\begin{array}{lr}\text { Appendix Chapter 2 } & 139\end{array}$

Appendices Chapter $3 \quad 141$

Appendices Chapter $4 \quad 145$

Appendices Chapter 5 149

Appendices Chapter $6 \quad 153$

$\begin{array}{ll}\text { Samenvatting } & 171\end{array}$

About the author $\quad 181$ 


\section{List of tables and figures}

\section{List of tables}

Table 2-1 Overview of papers included in the study 21

Table 2-2 Studies classified by insured risk and demand factor category 22

Table 2-3 Health and agriculture characteristics 25

$\begin{array}{lll}\text { Table 2-4 Preferences } & 29\end{array}$

Table 2-5 Financial literacy, education and insurance experiences 32

Table 2-6 Social capital, networks and trust 36

Table 2-7 Overview of qualitative studies investigating insurance demand 39

Table 3-1 Proportions, means and standard deviations of determinants of PAID plan insurance uptake, all households, households with PAID plan and CARD member households. 55

Table 3-2 A logistic regression analysis of the determinants of PAID plan insurance uptake $\quad 57$

Table 3-3 A logistic regression analysis of the determinants of PAID plan insurance among CARD members $\quad 59$

Table 5-1 Consumption smoothing activities according to focus groups 90

Table 5-2 Potential categorization of dependent variable 'consumption smoothing'

Table 5-3 Proportion consumption smoothing activities for all households with and without payout and for households in heavy shock villages

Table 5-4 Differences in characteristics between insured and non-insured (t-test) and differences in mean damage per characteristic (F-test)

Table 5-5A Payout and Consumption smoothing activities (Sideline, Eastless and Savings)

Table 5-5B Payout and Consumption smoothing activities (Informal, Moneylender and Sellcons)

Table 5-5C Payout and Consumption smoothing activities (Child, Sellprod, Moveout)

Table 5-6 Combined consumption smoothing variable

\section{List of figures}

Figure 1-1 Graphic representation structure of thesis 10

Figure 2-1 Shape of the utility function for different risk preferences 12

$\begin{array}{ll}\text { Figure 2-2 Prospect Theory } & 16\end{array}$

Figure 5-1 Mural by Carlos 'Botong' Francisco depicting Bayanihan 87

Figure 5-2 Insurance, Typhoon and Consumption smoothing activities 88 


\section{Foreword}

More than 850 low-income households from rural areas in India, Kenya, the Philippines and Ethiopia I have personally interviewed during more than one and a half years of field work in my life as a researcher. I lived with the people in these communities, often far away from electricity, running water and modern means of communication. These interviews were more than questionnaires; they were conversations, giving me the opportunity to get an in-depth understanding of the choices these low-income households make in their lives. The hours spent fetching water with a group of women from a nearby water-source in the morning; the preparations of a bride before she is taken away from her home-village to marry an unknown husband and live with his family; and the nightly sessions where elderly villagers call on the 'spirits' to cure the sick have provided the much-needed context. Through these experiences I have so well understood what uncertainty and insecurity mean for people's capability to grab lives' opportunities. And in my opinion inequality in uncertainty is a central element of persistent poverty. This thesis reflects the scientific representation of this problem. By contributing to increased access to valuable insurance by the uninsured I hope to reduce the negative consequences of this uncertainty so that low-income people in developing countries are 'free' to achieve their aspirations. This thesis is my 'freedom' to contribute to a more equal society which I aspire to be a part of.

I am grateful to: The more than 850 low-income people which took the time to spend at least an hour to answer all my questions to contribute to my aspirations; My research assistants, Sonu, Renuka, late Imara and Joy, for living with me in these communities for months and putting everything in perspective; My supervisors Jon, Peter and Annemarije who taught me to be a 'scientist' and pushed me to the highest level; My colleagues at CSTM, ITC and IGS, who believed in me and gave me the 'freedom' to grab my opportunities; My colleagues from the Microinsurance Network, the ILO Microinsurance Innovation Facility, the Dutch Ministry of Foreign Affairs and the inspiring people from the academic community for unlimited support, critical reflections and never-ending debates; My friends for understanding that friendship is not bound by time or space; My family for defining my aspirations and thus making me who I am; and finally Jasper who made me belief that I could reach the stars and had the ever-lasting patience for me to figure it out. Thank you. 


\section{Chapter 1}

\section{Introduction}

\subsection{Background: Demand and impact}

Microinsurance has the potential to assist poor people in developing countries in coping with shocks such as health shocks, death, crop loss and natural hazards (Dror and Jacquier, 1999; Dercon, 2005; Barnett, Barrett and Skees, 2007; Giné, Townsend and Vickery, 2008). Poor people often lack the financial reserves to cope with these risks and its consequent shocks. Uninsured risk has welfare implications which go well beyond consequences for short-term consumption; and is a cause of persistent poverty (Townsend, 1994; Dercon 2004; Carter, Little, Mogues, Negatu, 2006). The inability to deal with these shocks may reduce a society's capacity to accumulate, innovate and develop (Fafchamps, 2003: 146).

Large-scale environmental variability, with time, rapidly increases the need for additional risk management options. Changes in the strength and frequency of natural disasters, such as typhoons, are already a problem for many regions (Wisner, Blaikie, Cannon and Davis, 2004). Moreover, the nature of climate related risks, often being systematic and recurring, means that the poor cannot rely on informal insurance arrangements alone to successfully cope with them. This is especially relevant with shocks like natural hazards because these are geographically covariant thus resulting in many households being impacted in the same direction at the same time. Furthermore, factors such as globalization, urbanization and increased mobility may change family and social structures, which are necessary for informal risk-sharing, and render these less powerful and less reliable. This is further exacerbated by the inability of governments of many developing countries to provide adequate risk management to its population.

In recent years microinsurance has been introduced as a mechanism with the potential to assist the poor in dealing with risk. The International Association of Insurance Supervisors (2007: 10-11) describes microinsurance as:

"....insurance that that is accessed by low-income population, provided by a variety of different entities, but run in accordance with generally accepted insurance practices.......the risk insured under a microinsurance policy is managed based on insurance principles and funded by premiums.... Microinsurance therefore does not include government social welfare...Microinsurance is neutral in terms of the size of the risk carrier - it can be small and informal, while others are large mutual insurers or insurance companies..... Microinsurance covers a variety of different risks, including illnesses, accidental injuries, and death and property loss - basically any risk 
that is insurable, and is designed to be appropriate in terms of affordability and accessibility to low-income households. They can be offered as a single risk product or as a bundled risk product. Coverage can also be provided on an individual or group basis....One key difference between microinsurance and other insurance is how it is made accessible to the low income market. "

For example low-income people often have irregular cash flows, no experience with insurance, and no bank accounts. These characteristics of microinsurance clients imply that premium payments are often regular and flexible, in cash and linked to other transactions (such as loan payments) (McCord and Churchill, 2005).

Microinsurance as a mechanism to assist the poor in coping with risk is receiving increasing attention among governments, donors, policymakers and NGOs. This is demonstrated, for example, by the publication of microinsurance regulations by the Insurance Regulatory and Development Authority (Micro-Insurance) Regulations, 2005 of the government of India ${ }^{1}$. Mention of insurance in article 4.8 and decision 5/CP.7 of the United Nations Framework Convention on Climate Change (UNFCCC): "...insurance... to meet the specific needs and concerns of developing country parties arising from the adverse effects of climate change.” It is also shown by the participation of Oxfam America in a partnership with Swiss Re and International Research Institute for Climate and Society (IRI) in the Horn of Africa Risk Transfer for Adaptation (HARITA) microinsurance program through which 13,000 Ethiopian small scale farmers insured themselves in 2011 (Swiss Re, 2011).

At the same time investments in microinsurance by the commercial sector are increasing. It has been suggested that the global micro insurance market is worth USD 40 billion to the insurance industry and that it has the potential to reach out to 2.6 billion low-income people worldwide in the future (Swiss Re, 2010). Lloyds sees microinsurance as an opportunity to reach an under-served target-market (Lloyds, 2009: 6). A recent estimation of the outreach of microinsurance suggests an increase from 78 million risks insured in 2006 to approaching 500 million risks insured in 2011 (Churchill and McCord, 2012).

\subsection{Problem definition}

The interest of policy makers in microinsurance fits with a focus on market-based development policies that attempt to include the poor, as producers or consumers, in globally linked markets. Examples of such market-based innovations are micro credit in which the credit constraints of poor (potential) producers are addressed (Yunus, 2008); or base or bottom of the pyramid activities in which the poor are viewed as potential clients of a variety of products (Prahalad, 2004). Similarly, the vulnerability of the poor to risks may be reduced by introducing microinsurance. However, for microinsurance to contribute to poverty reduction there needs to be sufficient and sustainable demand in the long run. In addition there must be a demonstrable link between microinsurance take up, welfare improvements and eventually poverty reduction. Insurance has been offered

\footnotetext{
${ }^{1}$ Published in The Gazette of India, New Delhi, 10 November 2005
} 
to households in developed markets for decades. However, the insurance products and business processes in these markets have been adapted to the needs of these clients and the insurance markets have been shaped by the context in which the clients and insurance companies operate. This context includes factors such as legal and regulatory frameworks, communication channels, infrastructure, standards, social structures, social security, financial status, education and exposure. To many developing countries the concept of insurance is new, especially in rural areas and the context in which it develops is different. Therefore it is still uncertain if there is demand for microinsurance, how it will evolve, how product design and business processes create value for low-income people in developing countries and if it will contribute to poverty reduction.

\subsection{Theoretical embedding}

\subsubsection{Insurance demand and utility maximization}

Risk is uncertainty about future states of the world (rain or dry, sick or healthy, typhoon or no typhoon). When the risk materializes with a negative consequence there is a shock (drought, sick, typhoon damage). Both the risk and a shock have the same distribution but risk is the ex-ante probability while the shock is the materialized event. How do households make choices under circumstances of uncertainty about future states of the world?

Let us look at an example to explain this (adapted from Eeckhoudt, Gollier and Schlesinger, 2005:4-5):

'Sempronius owns goods at home worth a total of 4000 ducats and in addition possesses 8000 ducats worth of commodities in foreign countries from where they can only be transported by sea. However, our daily experience teaches us that of two ships one perishes.'

The total value of this lottery $x$ of his wealth will be 4000 ducats if the ship is sunk (probability of .5) and 12000 ducats if the ship makes it to his home (probability of .5). The expected value of this lottery is:

$\mathrm{Ex}=4000 * .5+12000 * .5=8000$ ducats

Now Sepronius has an idea. Instead of putting all 8000 ducats in one ship he spreads them over two ships. Now there are four states of the world. One in which two ships sink, one in which no ship sinks and two states in which one of the ships sinks. The total value of this lottery $y$ is:

$\mathrm{Ey}=4000 * .25+8000 * .25+8000 * .25+12000 * .25=8000$ ducats

Even though both lotteries have the same expected value, most people would choose the latter option because it diversifies the risk over different states of the world. This implies that the expected value does not provide a good representation of the manner in which most people make decisions when confronted with risk. Therefore theory about 
decision-making under uncertainty uses expected utility and the expected utility of both lotteries mentioned above depend on an individuals' utility function.

The expected utility theory is also used to understand decision-making about insurance. Insurance also spreads the risk of loss over different states of the world. The extent to which an individual is willing to do so depends on his or her preferences and is therefore subjective and specific to each decision maker and is reflected in his or her utility function. Most people are assumed to have a preference for avoiding at least some level of risk (Eeckhoudt et al., 2005:5). Uncertain expenses to which households are exposed prevent households from maximizing utility and therefore, under specific conditions, it is optimal for households to insure against them (Arrow, 1964; Mossin, 1968; Feldstein, 1973). Economic theory assumes that rational individuals try to maximize their expected utility of scarce resources. In this respect it looks at utility in economic or monetary terms.

One important element of the expected utility theory is that it assumes that individuals who are risk averse will have a concave utility function and purchase full insurance at an actuarially fair price to maximize their expected utility (Pratt, 1964; Arrow, 1965). Under the assumption that there is perfect information, if there was insurance of premium $m$ that would equal the expected utility and individuals were risk averse, they would be willing to buy this insurance because it would maximize their utility. In practice, actuarially fair insurance is not attainable because the administration cost and the risk premium for the shareholders have to be added to the actuarially fair rate. Administration costs are expenses made by the insurance company. The risk premium is a premium to the shareholders of the insurance company as payment for the risk they take in offering the insurance. In this way the premium that has to be paid is higher than the actuarially fair premium. In this case, if all other factors are constant the optimal level of demand is lower and the household will partially insure according to its personal risk preferences (Mossin, 1968; Doherty and Schlesinger, 1990). Under the assumption that wealth is inversely correlated with risk aversion, low-income households, who are the targeted clients of microinsurance, are assumed to be more risk averse and purchase more insurance to avoid the risk of loss (Laffont and Mantoussi, 1995; Guiso and Jappelli, 1998).

To cope with shocks, poor households often rely on a diversity of existing strategies such as risk diversification, borrowing, using savings, depleting production assets and informal risk-sharing between households. Such activities, like insurance, have the objective of smoothing income and smoothing consumption (Alderman and Paxson, 1994 and Morduch, 1995). Income smoothing or so-called ex-ante efforts to reduce risk exposure refer to activities which households undertake to protect themselves from adverse income shocks before they occur, such as combining farm and non-farm income activities or diversifying crops and production techniques (Alderman and Paxson, 1994). Consumption smoothing activities occur after shocks with the objective of protecting the variability of the consumption pattern and consist of risk coping and informal risk-sharing arrangements. (Morduch, 1995; Barnett, Barrett and Skees, 2007). 
Since households already have existing mechanisms for dealing with uncertain expenses, what does this mean in the light of the demand for an external insurance mechanism such as microinsurance? Research shows that the level of consumption smoothing which poor households achieve in the light of idiosyncratic shocks through existing activities is not sufficient to allocate risk within communities or provide permanent income over time (Alderman and Paxson, 1994, Townsend, 1994, Fafchamps and Lund, 2003; Kazianga and Udry, 2006). Idiosyncratic shocks are shocks that are specific to a household and not correlated to shocks that other households experience such as breaking a leg or getting a heart attack. However, since natural hazards are correlated and households are assumed to be risk averse, this would imply that there is an opportunity for a complementary mechanism for coping with uncertain expenses in the wake of covariant shocks. This implies that if low-income households would be utility maximizers and could afford the insurance premium, that they would take up at least a certain level of microinsurance, if it were available to them.

\subsubsection{Insurance demand and market failures}

However, even if microinsurance is supplied, the demand for microinsurance in developing countries is low in comparison to expected demand based on expected utility theory. Furthermore, an increasing number of empirical studies investigating microinsurance demand in developing countries find that risk aversion leads to less, instead of more, take up of microinsurance (Giné et al., 2008; Cole et al., 2009; Ito and Kono, 2010; Clarke and Kalani, 2011; Dercon, Gunning and Zeitlin, 2011). This contradicts assumptions underlying expected utility theory namely that demand for insurance is higher for risk averse individuals who use insurance to avoid the risk of loss (e.g. Arrow, 1963, 1965; Pratt, 1964; Mossin, 1968; Feldstein, 1973; Schlesinger and Doherty, 1985).

How, since we assume households attempt to maximize their expected utility and existing consumption smoothing activities are insufficient, can we explain this relatively low demand? There are several assumptions underlying the application of expected utility theory to insurance demand, which in the reality of microinsurance markets may not exist, such as, perfect information and an individuals' ability to objectively assess probabilities of risk (Pauly, 1968; Kahneman and Tversky, 1979). Market imperfections are typically given as explanations for less than optimal insurance demand (Arrow, 1963, 1965; Holmstrom, 1979; Arnott and Stiglitz, 1991). How does the inability to offer insurance at actuarially fair insurance rates influence microinsurance demand? What happens to microinsurance demand if low-income households in developing countries are credit-constrained? Are households capable of objectively assessing probabilities of risk? Recent empirical investigations suggest the role of trust (Cai, Chen, Fang and Zhou, 2010; Gunning, Dercon and Zeitlin, 2011) as an explanation for relatively low insurance demand. Especially uncertainty about the insurance product itself (Karlan and Morduch, 2009) and the role of trust as an uncertainty reduction mechanism may play an important role in explaining why insurance demand is especially low for the risk averse. All these factors may lead to less than optimal insurance demand and if full insurance is not attained this means that welfare is not optimally distributed, which has impoverishing welfare effects (Townsend, 1994). 


\subsubsection{Insurance as a complement to consumption smoothing activities}

Up to now the impact of microinsurance has been described in terms of welfare effects through utility maximization in terms of smoothing consumption. It was assumed that low-income households are not fully insured in the wake of covariant risks and microinsurance would therefore provide complementary insurance leading to increases in welfare. However, microinsurance does not necessarily only have a complementary role to existing consumption smoothing activities, but these existing activities and microinsurance may also substitute each other (Arnott and Stiglitz, 1991). If microinsurance was actuarially fair and would fully substitute existing consumption smoothing activities, there would not be a change in the level of insurance achieved and there would not be changes in expected utility due to microinsurance. However, if there is no full insurance and existing consumption smoothing activities are crowded out, may this even have negative welfare effects?

Arnott and Stiglitz (1991) and Lin, Liu and Meng (2011) show that this partly depends on the asymmetry of information about the probability and level of expected losses of the insured. However, it may be possible that microinsurance also has welfare enhancing effects that are not captured by considering welfare effects in terms of single period decisions.

\subsubsection{Insurance as substitution for income- and consumption smoothing}

Consumption smoothing and income smoothing activities themselves may have costs in the light of economic growth paths (Morduch, 1995). Income smoothing activities by reducing risk or diversifying risk typically also yield lower profits and thus reduce welfare effects. This effect is especially strong for low-income households which are already risk averse by their nature (Alderman and Paxson, 1994). Consumption smoothing activities may also have significant costs for households if assets needed for future income, such as production or human assets, are depleted (Dercon and Hoddinott, 2005; Kazianga and Udry, 2006; Barnett, Barrett and Skees, 2006). If microinsurance indeed has a substitution effect it may not have a direct or even negative effect on the expected utility with respect to a single period decision about an uncertain expense; but it may have positive impact for future income. For example, microinsurance, by providing security through ex-ante premium payments against possible future uncertain expenses, may not only provide an incentive to households to invest in higher risk and higher return activities. Without the insurance they might have tried to smooth their income by investing in secure, low risk and low return activities. In addition, microinsurance, by providing a payout in case of uncertain expenses, may prevent households from engaging in consumption smoothing activities that have negative consequences for future income such as selling production assets. However, in the same way that microinsurance may have positive impacts on income or consumption smoothing activities, it may also have negative consequences. For example it may prevent households from adequately managing risk in anticipation of a future shock or it may prevent them from investing in traditional risk-sharing arrangements that they may need in instances where the insurance does not provide cover. 


\subsection{Research question}

Despite the potential of microinsurance to lead to welfare improvements, the demand for microinsurance is at a relatively low level. In addition, it is largely unknown what impact it currently has, either as complement to or substitution for existing income- and consumption smoothing activities. This leads to the following dual research question:

Why do low income households demand microinsurance and does it impact poverty reduction?

This research question consists of two parts. The first part is concerned with understanding why individuals take up microinsurance. This is deemed important to know, given the assumption that increased insurance uptake contributes to increases in welfare, especially in the case of natural disasters with covariant risk. Understanding demand is instrumental in designing the correct products and offering them through the appropriate business processes. In addition, market imperfections can be corrected through legal and regulatory frameworks with the objective of increasing welfare. The second part of the question is different as it considers the impact of microinsurance interventions in terms of poverty reduction, taking into account the potential of different impacts for different (groups of) households.

To answer these questions the thesis is divided into two parts: a part focusing on demand and a part focusing on impact. In the first part the following question will be addressed: Which factors influence the demand for microinsurance by low income households? To answer this question a review of literature on insurance demand and empirical studies that have investigated microinsurance demand is conducted. This review will show that social capital and networks significantly affect insurance demand. In addition, it will show that the role of uncertainty about the insurance, and trust as a potential mechanism to reduce this uncertainty, are under-researched. Therefore it is hypothesized that trust, built through knowing peers with claims, positively affects the demand for microinsurance. To empirically test the role of trust as a mechanism to reduce uncertainty about the insurance product a study is conducted in which demand for a natural disaster indemnity insurance is investigated through data collected from focus groups and a household survey sample of 200 Filipino households.

In the second part of the thesis, a literature review is used to explore theories about potential impacts of microinsurance in the light of poverty reduction. This review is complemented by a discussion of research methods for studying microinsurance impact. This review will show the relevance of research on the impact of microinsurance on consumption smoothing activities, especially in a context of poverty reduction. It is hypothesized that households with microinsurance are relatively less likely to use consumption smoothing activities which have consequences for future income and productivity outside of the single period setting. To empirically test the impact of microinsurance on these smoothing activities the same focus groups and sample of 200 households is used to create a link between the model explaining the demand for this particular insurance product and the explanation of its impact on poverty reduction. 


\subsection{Structure of the thesis}

Chapters 2 and 3 cover the part of the research question dealing with demand; and the part on impact will be covered in Chapters 4 and 5. Chapter 6 provides the conclusions. In Figure 1-1 a graphic representation is presented of the structure of the thesis.

Chapter 2 starts with a literature review aimed at understanding why low income households demand microinsurance. Expected utility theory will be taken as the starting point as it is typically used for understanding decision-making about insurance. Critical assumptions underlying the application of expected utility theory will be compared with the actual situation in microinsurance markets, leading to a general theoretical framework identifying factors potentially influencing insurance demand. Based on this framework a total of 31 empirical studies are analyzed and compared.

This review leads to the observation that even though the effect of some factors is consistent over the different studies, the mechanisms underlying their effect are still understudied. In addition, many studies compare take-up versus no take-up of microinsurance. This makes sense when households have been properly informed and thus are aware of the insurance. However, as soon as adopters are compared to nonadopters, while these non-adopters can be households without insurance awareness knowledge or households which are still in a persuasion stage ${ }^{2}$ before they actually make their decision, it is difficult to attribute observed effects to the correct mechanisms. Another observation is that most studies include indicators for social capital or networks or include location dummies. The interpretation of their often significant and substantial effect is lacking. What are the mechanisms underlying these observed effects? Some studies suggest uncertainty about the insurance as an explanation. How can this uncertainty be reduced? Is there a role for trust?

Chapter 3 starts with a consideration of the specific developing country context where, especially in rural areas, low-income people often have no or negative experiences with insurance. Uncertainty in the insurance transaction is therefore hypothesized to be relatively high for low-income people in rural areas in developing countries in comparison to people in developed countries. The findings about trust, network, social capital and non-adoption in Chapter 2 lead to an exploration of literature about uncertainty, trust and literature about the diffusion of innovations. This literature suggests that trust in transactions can be built through formal and informal mechanisms and that, in particular, informal mechanisms play an important role at local levels. In addition, this literature suggests that trust-building mechanisms can substitute each other. What does this imply for understanding the role of trust in enhancing microinsurance demand? Firstly, it is hypothesized that, because formal mechanisms for building trust in microinsurance are often not accessible, reliable or existent, households need to rely on informal trust-building mechanisms. Out of informal trust-building mechanisms, experiences of peers are suggested to play an important role because microinsurance is an innovation, which may or may not provide a benefit in the future, a

\footnotetext{
${ }^{2}$ The 'Persuasion stage' is one of the stages in the decision-making process about an innovation and comes from Rogers (1973), The Diffusion of Innovations, and refers to the stage in which an individual forms a favorable or unfavorable attitude towards the innovation.
} 
so-called 'preventive innovation'. Literature about the diffusion of preventive innovations has found that peer experiences with the innovation play an important role in the take up of the innovation. This hypothesis is tested in Chapter 3 by studying the demand for a natural disaster re-housing insurance on a sample survey of 200 rural households in the Philippines.

What is being ultimately addressed is the impact of microinsurance on welfare and poverty reduction, both through the effects of understanding insurance demand, as studied in Chapter 2 and 3, and through the impact of microinsurance on (groups of) households. Firstly, the fourth chapter will start by discussing the consumption smoothing effect of microinsurance but will also discuss theories about ex-ante effects of microinsurance on changes in behavior and impacts outside of single-period utility maximizing decisions. Furthermore, in terms of poverty and inequality, the distributional impact of microinsurance is considered, providing a link with findings from Chapter 2 and 3. Secondly, it provides an overview of current microinsurance impact research and concludes that the current state of the art still provides little information about microinsurance impact, other than the impact of health insurance on out-of-pocket payments and health care utilization. What is the impact of microinsurance on poverty reduction in the light of relatively low levels of demand? The second part of Chapter 4 considers methods for studying microinsurance impact in the light of relevant questions and characteristics of microinsurance products. It discusses experimental, quasi-experimental and qualitative designs in terms of different validities; and thus the type of questions these designs are appropriate for. It concludes that although experiments (especially randomized control trials) have the potential to achieve internal validity about average effects, they may not be appropriate for studying certain impacts of microinsurance in the light of pay-outs for infrequent shocks. Since insurance is a preventive innovation there is often a long time period between premium payment and risk event with pay-out which prevents impact from being easily observed. In addition, the chapter addresses the importance of understanding factors that influence demand, especially in the light of distributional effects of microinsurance.

In the fifth chapter the model developed for studying demand in Chapter 3 will be used to study the impact of natural disaster re-housing insurance on consumption smoothing activities of households in the wake of natural disasters. The first question addressed in this chapter is: what kind of impact can be expected from microinsurance on smoothing activities? Literature about stressfulness of coping strategies is used to derive hypotheses about stressfulness of certain consumption smoothing activities with respect to impacts on future income and productivity. It is hypothesized that households with microinsurance are less likely to use higher stress consumption smoothing activities than households without micro insurance.

To empirically test this hypothesis, the same sample is used as for the estimation of the demand model in Chapter 3, because it is deemed important to link the model explaining the demand for this particular insurance product to the explanation of its impact. Studying the impact of the insurance product on consumption smoothing activities ex-post a disaster cannot, reasonably, be done through a randomized design for reasons which are discussed in Chapter 4. However, by having a relatively strong model for explaining demand we can control for confounding variables. The advantage 
of using the same demand model also allows for studying the impact of factors explaining demand, which may be indications of market imperfections, on the impact that is observed.

Finally, Chapter 6 presents the conclusions, discussions and recommendations for future research and for policy makers and practitioners.

Figure 1-1 Graphic representation structure of thesis

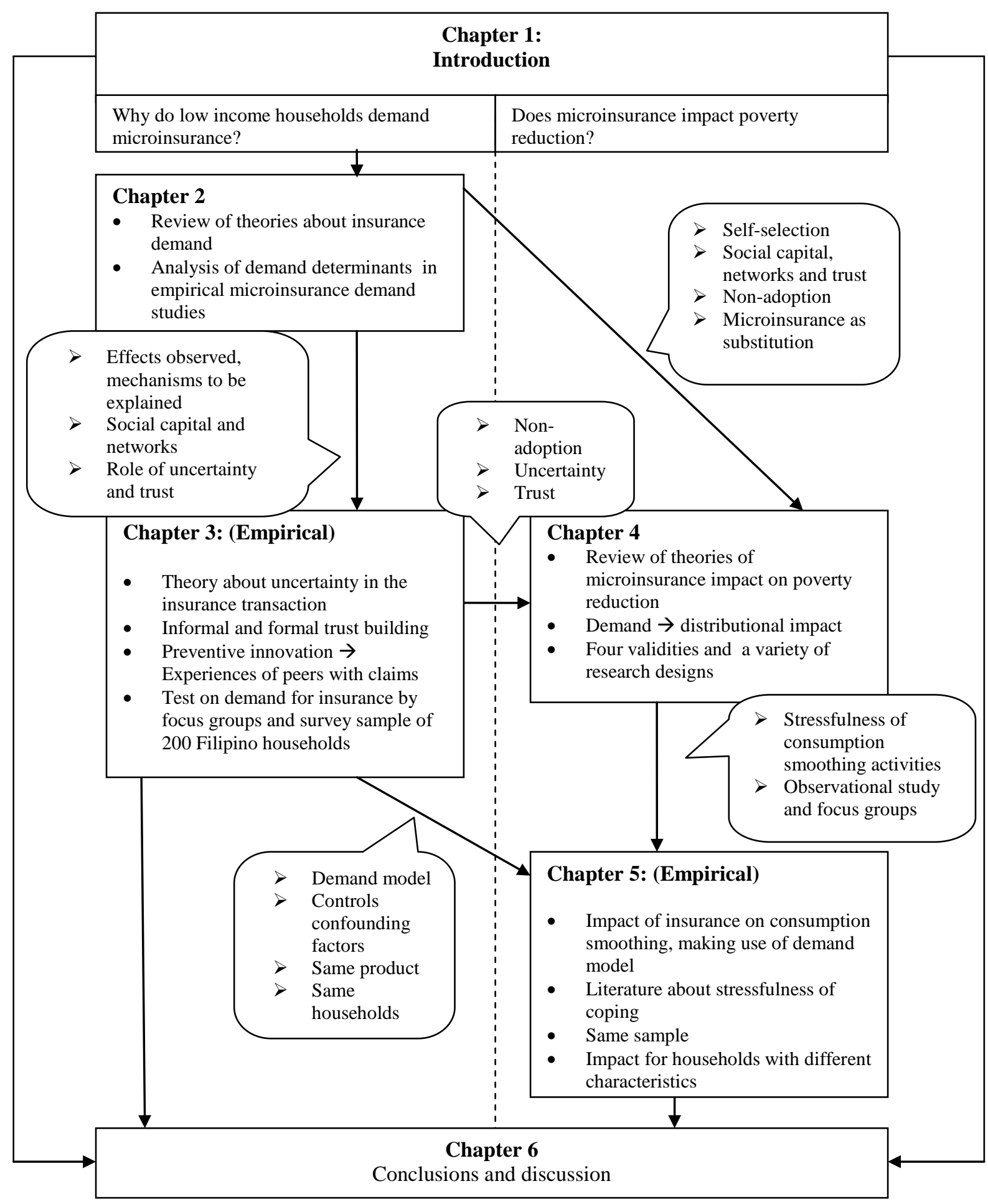




\section{Chapter 2}

\section{A review of microinsurance demand}

\subsection{Introduction}

Even if microinsurance is supplied, the demand for microinsurance in developing countries is low in comparison to expected demand based on expected utility theory. Furthermore, an increasing amount of empirical studies investigating microinsurance demand in developing countries find that risk aversion leads to less, instead of more, take up of microinsurance (Giné et. al., 2008; Cole et al., 2010; Ito and Kono, 2010; Clarke and Kalani, 2011; Dercon, Gunning and Zeitlin, 2011). This also contradicts assumptions underlying expected utility theory, which are that demand for insurance is higher for risk averse individuals who use insurance to avoid the risk of loss (e.g. Arrow, 1963, 1965; Pratt, 1964; Mossin, 1968; Feldstein, 1973; Schlesinger and Doherty, 1985). Potential explanations being investigated to explain this contrast between theory and empirical observations include: low levels of wealth of targeted clients, credit-constraints and low levels of financial literacy. Others suggest that behavioral explanations such as cognitive, emotional factors or even social explanations may elucidate the apparent contradiction (Schneider, 2004a, Giné et al., 2008, Cole. et al., 2010;).

However, to date there is no conclusive answer that can explain the relatively low level of insurance demand and inverse effects of risk aversion. A substantial quantity of empirical studies on microinsurance demand have recently been published and it is now pertinent to analyze what contributions this empirical literature can make to theory, policy and practice concerned with microinsurance demand. For policy makers and other professionals it is essential to know firstly which factors explain demand and secondly which factors can be influenced to support effective policy making. This chapter focuses on the question: what is the state of the art in research on factors influencing the demand for microinsurance?

This chapter is structured as follows: in Section 2.1, expected utility theory will be taken as the starting point as it is typically used for understanding decision-making about insurance. There are several assumptions underlying application of expected utility theory. In real microinsurance markets these assumptions may not be valid, for example existence of perfect information and individual's ability to objectively assess probabilities of risk (Pauly, 1968; Kahneman and Tversky, 1979). These assumptions and their consequences for insurance demand in terms of expected utility will be discussed. The findings will be used to develop a coherent theoretical framework incorporating factors which can be used to analyze empirical studies on microinsurance demand. In Section 2.2 the methods for the analysis of the empirical papers are 
described and the papers are classified according to these factors. In Section 2.3 the empirical studies will be discussed in the light of the identified factors. Where the studies refer to theory or theoretical factors, these will also be discussed. Finally, in the conclusion the empirical findings will be related to the theories outlined in Section 2.2. Particular attention is paid to areas where there is no conclusive evidence and suggestions for future research will be addressed.

\subsection{General theoretical framework}

This section will start by providing a general overview of expected utility theory. Next, assumptions underlying the use of this theory will be discussed in terms of the reality of microinsurance markets. This section will be concluded with an overview of factors with which the empirical studies on microinsurance demand can be analyzed.

\subsubsection{Expected utility}

Many studies on the demand for microinsurance use economic theory (For example: Giné, Townsend and Vickery, 2008; Cole, Giné, Tobacman, Topalova, Towsend and Vickery, 2010; Ito and Kono, 2010; Clarke and Kalani, 2011; Dercon, Gunning and Zeitlin, 2011). Economic theory assumes that rational individuals try to maximize their expected utility of scarce resources. In this respect it looks at utility in economic or monetary terms. Demand or take up of insurance is often analyzed from the perspective of expected utility theory as it is typically used to study decision making behavior under uncertainty. It assumes that individuals have a utility function $u$ which for every wealth level $x$ provides the degree of utility $u(x)$ that an individual achieves by this wealth. The utility from a certain level of wealth varies from person to person and depends on his or her prior beliefs and preferences. One important element determining the shape of the utility function is an individuals' 'risk preferences' (Eeckhoudt, Gollier and Schlesinger, 2005). People are assumed to be risk averse, risk loving or risk neutral. People are risk averse if their utility function is concave. This implies that the utility of the expected outcome (or expected wealth) of a lottery exceeds the expected utility of the lottery (Figure 2-1A). The concave utility function implies decreasing marginal utility which means that a marginal loss of one unit leads to a higher decrease in utility compared to the increase in utility from a marginal gain of one unit. People are risk neutral if their utility function is linear. This implies that the utility of the expected outcome of a lottery

Figure 2-1 Shape of the utility function for different risk preferences

A. Concave - Risk averse

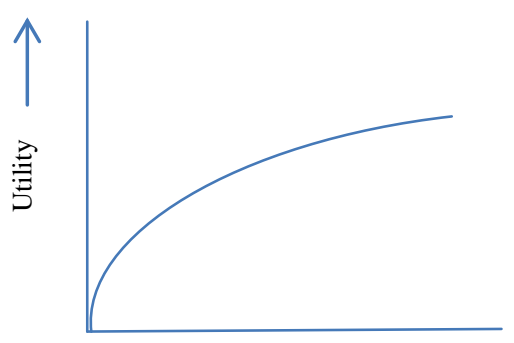

12
B. Linear - Risk neutral

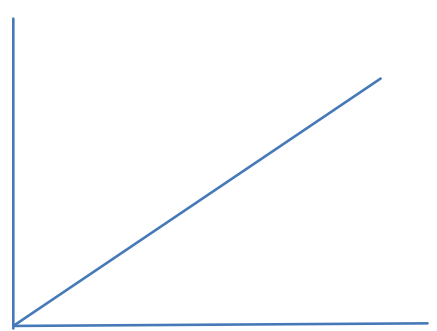

C. Convex - Risk loving

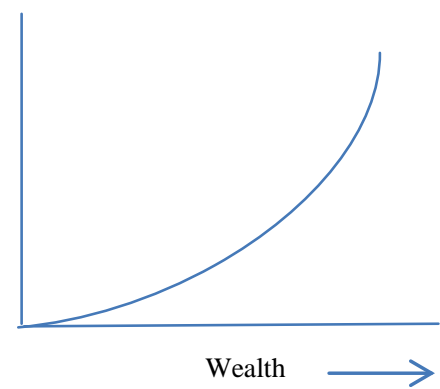


equals the expected utility (Figure 2-1B). People are risk loving if their utility function is convex. This implies that the utility of the expected outcome of a lottery is less than the expected utility of the lottery (Figure 2-1C).

Most people are assumed to be risk averse because most people are willing to buy insurance to avoid financial losses. Particular types of expected utility functions exist in which the expected utility criterion is restricted. The most common ones are: Decreasing Absolute Risk Aversion (DARA), Constant Absolute Risk Aversion (CARA) and Constant Relative Risk Aversion (CRRA), of which the last one is most often used (Eeckhoudt et al., 2005). These specific utility functions will not be discussed here since we are interested only in the role of the level of risk aversion of an individual and its influence on take up (yes or no) of the insurance. The effect of the utility function on insurance demand will be discussed below.

Expected utility theory is typically used to understand the demand for insurance. It is assumed that people will be confronted with shocks that have economic consequences (i.e. economic losses) at certain probabilities. Under the assumption that there is perfect information, if there was insurance of premium $m$ that would equal the expected utility and people were risk averse, then they would be willing to buy this insurance because it would maximize their utility. This insurance is called actuarially fair. In this way it is assumed that individuals would want to have insurance because it reduces the impact of shocks on overall consumption. Traditionally, under expected utility, it is assumed that demand for insurance is higher for more risk averse individuals who use insurance to avoid the risk of loss (e.g. Arrow, 1963, 1965; Pratt, 1964; Mossin, 1968; Feldstein, 1973; Schlesinger and Doherty, 1985). In the same way, risk neutral individuals would be indifferent about purchasing actuarially fair insurance or remaining uninsured and risk loving individuals would not want to purchase the actuarially fair insurance. Based on the expected utility theory the following factors can now be derived which may explain, under conditions of perfect information, the demand for microinsurance: the risk preference, the price of the insurance relative to expected pay outs, the probability of the risk.

\subsubsection{Actuarially fair insurance}

A first assumption, that of actuarially fair insurance, is not attainable in practice because insurance is not offered at actuarially fair rates. The administration cost and the risk premium for the shareholders have to be added to the actuarially fair rate. Administration costs are expenses made by the insurance company. The risk premium is a premium to the shareholders of the insurance company as payment for the risk they take in offering the insurance. In this way, the premium that has to be paid is higher than the actuarially fair premium. If all other factors are constant it is predicted that a higher price of the insurance will reduce the demand for the insurance (Mossin, 1968; Doherty and Schlesinger, 1990; Giné, Menand, Townsend and Vickery, 2010). Next to these costs there may be transaction costs as part of the insurance process, which create additional disutility. For example, when transportation costs and time for travel to a hospital have to be added to the premium for health insurance, or when, for premium payment, a person has to travel to a bank in a nearby town. 


\subsubsection{Credit-constraints}

Another factor related to the price of the insurance, which is especially relevant for insurance offered to low-income households in developing countries, is that of creditconstraints. There are two hypotheses about its potential influence on insurance demand that predict different directions of the effect. On the one hand it may be that creditconstrained individuals are more likely to purchase insurance because future creditconstraints due to economic losses may encourage them to sacrifice some current income to protect their future income (Morduch, 1995; Gollier, 2003). On the other hand there is evidence that households may be credit-constrained to the extent that, even if they would want to purchase insurance, they would not have the finances for it (Giné, Townsend and Vickery, 2008; Binswanger-Mkhize, 2011).

\subsubsection{Asymmetric information}

A second assumption underlying predictions about insurance demand is that the insurer and the insured have the same information about the probability and the level of the expected loss. In practice the insured may have more information about these factors than the insurer. This may lead to asymmetric information which typically leads to two problems with respect to the insurance market: adverse selection and moral hazard (Arrow, 1963, 1965; Pauly, 1974; Holmstrom, 1979; Arnott and Stiglitz, 1991). Adverse selection and moral hazard have important implications for long-term sustainability of the insurance market (for example: Arnott and Stiglitz, 1990).

Adverse selection refers to a situation where the insured has more information than the insurer about probability of the loss to which he or she is exposed. In practice this is often the case since the design of an insurance product is based on assessments of average losses and average probabilities of the risk of the targeted population. Assuming that households are risk averse and maximizing utility, the insurance would be especially interesting for individuals with higher than average probabilities of the risk. The outcome may be that, in a market where full coverage insurance policies are offered, premiums are high because they reflect take up of the insurance by high-risk households.

This suggests that, in understanding demand for a given insurance product, the insured risk and the risk situation of the specific household will influence the decision to take up insurance. It can be hypothesized that high risk households will be more likely to take up the insurance.

Moral hazard refers to a situation where the household can influence the probability of the risk or the level of the expected loss, such as by undertaking preventive activities or self-insurance. Preventive activities are for example people who stop smoking to reduce health risk, or households who tie the roof of a house with nails and ropes before a typhoon. Examples of self-insurance are households which rely on informal risk-sharing arrangements, savings or precautionary buildup of assets, such as in livestock in good years to anticipate potential shocks in bad years (Townsend, 1995). The use of such self-insurance may provide alternatives to low-income households when taking up insurance is not an option, for example if premiums are too high (Schneider, 2004). Schneider (2004) presents the role of formal insurance as complementary to informal 
risk-sharing. However, there is also evidence to suggest that these may substitute each other (Rosenzweig, 1988; Arnott and Stiglitz, 1991). Arnott and Stiglitz (1991) and Lin, Liu and Meng (2011) show that the extent to which formal insurance and informal risksharing may complement or substitute each other depends on the asymmetry of information about the probability and level of expected losses of the insured vis-à-vis the informal risk-sharing network and insurance company. Several studies on microinsurance recognize the potential effect of informal risk-sharing arrangements on demand. However, existence of informal risk-sharing is not easily observed. Jowett (2003) proposes to use data on previous borrowing from informal networks. He suggests two proxies for social capital under the assumption that increased social capital will lead to increased informal risk-sharing. These proxies are perceptions of social cohesion and an index for horizontal linkages. Clarke and Kalani (2011) include access to informal insurance networks in their analysis by referring to membership of mutual savings and funeral associations; and whether a household can obtain a certain amount of money in a short time period. It should be noted here that some of these proxies may not necessarily reflect informal risk-sharing. This topic will be further taken up under the section 2.4.3 Prevention, Self-insurance and informal risk-sharing.

\subsubsection{Behavioral explanations}

Another assumption underlying expected utility theory is that individuals' preferences remain unchanged when confronted with different situations. This assumption is challenged by Kahneman and Tversky (1979) who empirically tested, through choice experiments, predictions based on expected utility about decisions between alternatives. They found that people's choices in these experiments deviated and hypothesized that in practice individuals' preferences change relative to the situation. One of their conclusions was that individuals evaluate losses differently from the manner in which they evaluate gains and different individuals may evaluate a specific gain as a loss and vice versa (Kahneman and Tversky, 1979: 288). Furthermore, the perception of gain and loss depends on a predetermined point, called reference point, which is the point where the perception of gain changes into perception of loss (see Figure 2-2). The actual location of this point depends on the actual asset position of the individual (Kahneman and Tversky, 1979). Around this reference point the value function for losses is steeper than the value function for gains. The prediction is then that the value function for gains is concave while the value function for losses is convex. This implies that if individuals perceive insurance as covering losses, people who purchase insurance may behave as if they are risk loving and will only insure if the loss will occur with certainty, and not because they are risk averse as suggested by expected utility (Kahnemann and Tversky, 1979). The potential value of this theory in understanding insurance demand is that it postulates that the manner in which the message about the insurance is conveyed matters for the decision to take up the insurance. One of the implications of this is that through marketing messages about the insurance as gains or losses, the uptake of the insurance can be influenced (Cole et al., 2010). However, it was also established that the experience of gains and losses depends on a predetermined reference point of an individual. The reference point may be influenced by cognitive, emotional, social or contextual factors. 
Figure 2-2 Prospect Theory

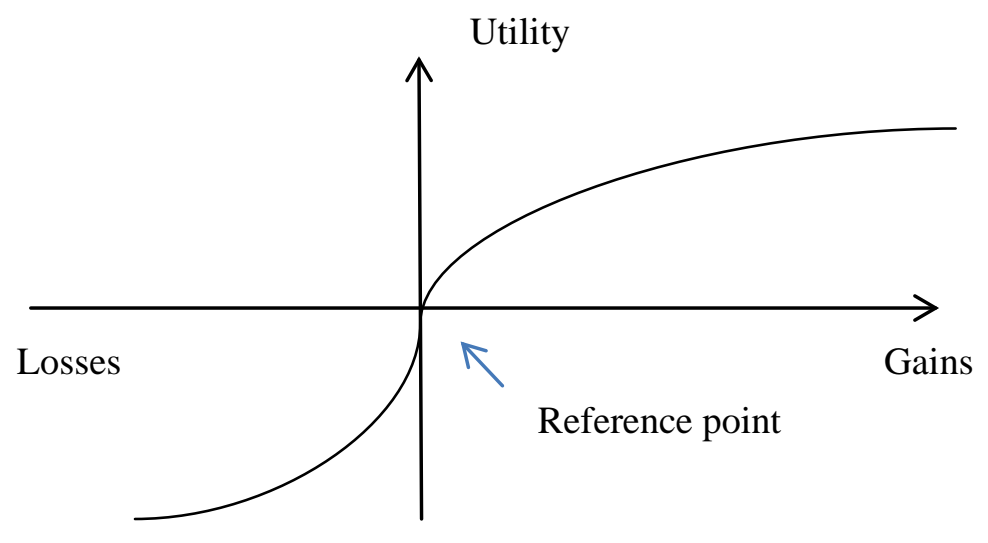

The empirical observations which demonstrate deviations from predictions based on expected utility theory were attributed by Kahneman and Tversky (1979) to characteristics of an individual's psychology. Other behavioral theories have also focused on so-called irrational behavior or cognitive biases (Kahneman and Tversky, 1972). For example, decisions under choice overload (Timmermans, 1993; Bertrand, Karlan, Mullainathan, Shafir and Zinman, 2010), ambiguity (Ellsberg, 1961; Hogarth and Kunreuther, 1985; Bryan, 2010), time inconsistencies, and intertemporal choice and self-control (Samuelson, 1937; Loewenstein and Prelec, 1992; Loewenstein, O’Donoghue and Rabin, 2002). To date there are few published articles which use these latter behavioral theories to explain microinsurance demand (Bryan, 2010; Ito and Kono, 2010; Hill, Hoddinott and Kumer, 2011). Ito and Kono (2010) investigate the self-control problem. The self-control problem refers to the fact that individuals will be tempted to consume and have difficulty to save. They refer to a study by Ashraf, Karlan and Yin (2006) who find that individuals who have a self-control problem are more likely to use commitment saving from which they can't withdraw. Ito and Kono (2010) hypothesize that this implies for insurance demand that individuals who are aware of their 'self-control' problem will recognize that they will consume at the current time and would therefore have a problem when economic losses occur. Hence it is suggested that individuals with self-control problems would be more inclined to take up insurance.

\subsubsection{Understanding of insurance}

In addition to these behavioural explanations, when confronted with a decision under uncertainty the outcome may also depend on the understanding of the decision problem. Previous experience with insurance, financial literacy and financial education may increase this understanding. This is especially relevant in the context of insurance in developing countries since many low-income households are illiterate or have not experienced insurance before. Hastings and Tejeda-Ashton (2008) show for example that demand elasticity for take up of investment funds increases by 25-50 per cent if the fees for the investment funds are presented in terms of a known currency instead of percentages suggesting that this increases an individual's understanding of the decision problem. Gaurav, Cole and Tobacman (2011) suggest that math skills, understanding of 
probabilities and debt literacy increase insurance understanding and may therefore influence insurance take up.

\subsubsection{Demand versus decision-making}

The factors discussed above are derived from a discussion of expected utility theory used to understand insurance demand. It should be realized that expected utility theory is concerned with decision-making under uncertainty. However, as was suggested in several studies insurance demand is also influenced by access to the insurance and knowledge about the insurance (Giné et al., 2008; Giesbert et al., 2011; Cai, 2012). When microinsurance take-up decisions are studied and households which have takenup the insurance are compared to households which have not taken-up the insurance, this is problematic when it is not certain if households are aware of the insurance or have started to make a decision. Rogers (2003: 162) recognizes two stages in the decision-process before the actual decision is made: the knowledge stage and the persuasion stage. The knowledge stage refers to the process when households become aware of the existence of an innovation and start understanding how it functions. Persuasion occurs when a household forms a favorable or unfavorable attitude towards the innovation. The existence of these different stages is especially relevant for the discussion about the effects of trust, social capital and networks below because they may have an effect on the different stages of the decision process.

This is especially relevant when studies investigate demand based on research designs in which the insurance is randomly assigned to different subjects and the introduction of the insurance occurs shortly before the take-up decision. There is evidence that even though a household is exposed to messages about an innovation, this has little effect on a potential decision unless an individual first experiences a need for the innovation (Hassinger, 1959). At the same time, even if the individual experiences a need and is exposed to awareness knowledge, he or she may need time to evaluate the opportunities before making a decision.

\subsubsection{Trust, social capital and network explanations}

Even though trust, social capital and networks are different factors, in this section they are jointly discussed. This is done because most studies do not separate these factors, the mechanisms through which they influence microinsurance demand and the stages of the decision process in which they play a role.

Social capital and networks are recognized as factors which influence the take up of insurance (Jowett, 2003; Giné et al., 2008). Clarke and Kalani (2011) refer to studies which find that households rely heavily on large information flows between members of social groups to decide whether on not to take up insurance. Most of the studies which include trust, social capital and networks do this by measuring characteristics of these factors, without further explaining which mechanisms influence their effects. For example, Jutting (2004) measures membership of ethnic groups. Giné et al. (2008) measure village membership, number of other groups that the household is a member of, number of well-known households and number of well-known households that bought insurance. Cole et al. (2010) measure membership groups and number of groups that the household belongs to. Zhang, Wang, Wang and Hsiao (2006) measure social 
capital by degrees of 'trust' and 'reciprocity'. The way they measure trust is through five questions about the generalized trust individuals have in other people. They do the same for reciprocity.

Often these variables are found to have an effect but none of these studies fully explains this effect. Since this chapter attempts to produce a theoretical framework the objective is to attempt to explain these effects.

As mentioned above, social factors may influence the reference point of individuals. In turn this reference point may determine if individuals view insurance as a gain or loss, and in this way it may determine their decision to take up microinsurance.

In addition, social capital and networks may influence the take up through the mechanism of creating informal risk-sharing opportunities for households. This was already discussed under the Section 2.2.4 Asymmetric Information where it was demonstrated that studies use proxies for informal risk-sharing based on access to social capital and networks. The presence of social capital and networks does not necessarily imply the existence of informal insurance (Dercon and Krishnan, 2002).

Furthermore, Jowett (2003: 1154-1155) explains that social capital and networks may also influence the uptake of insurance because more cohesive communities are more likely to engage in collective action and therefore participate in insurance.

Cai (2012) specifically focuses on two potential explanations for the effect of the social network: through mechanisms of insurance knowledge and purchase decisions.

Firstly, through the mechanism of insurance knowledge it is hypothesized that households' take up of the insurance is affected by their network because they learn about the insurance from peers in their network. The effect of understanding of the insurance on insurance uptake was described in Section 2.2.6 Understanding of insurance.

Secondly, households may be influenced by their friends' behavior in deciding whether to buy insurance. Next to the explanation of informal risk-sharing, Cai (2012) adds that this can occur because of scale effects and imitation. Scale effects are created when farmers have greater leverage over the insurance company if more of them purchase together. Imitation occurs when farmers want to act like each other (Cai, 2012: 19).

Another factor which may develop from social capital and networks and influence the take up decision of insurance is trust (Giné et al., 2008; Cole et al., 2010; Cai et al., 2010; Dercon et al., 2011). Trust is suggested to reduce uncertainty about the insurance product. Giné et al. (2008) hypothesize that low trust in the insurance vendor will lead to lower take up of insurance. Cole et al. (2010) suggest that trust in the local branch organization which provides the insurance is important, but they also hint that religious cues associated with the marketing of the insurance are related to trust. Cai et al. (2010) investigate the lack of trust in government-sponsored programs as an explanation for low take up of a government sponsored insurance program.

Through their work on non-contractual performance of insurance companies Doherty and Schlesinger (1990) show that uncertainty about the credibility of the insurer i.e. is the insurer going to payout?) adds an additional risk to the risk of the insured loss. In this way another state to the world is added: the insured pays the premium, experiences the insured loss and doesn't receive a payout. Dercon et al. (2011) hypothesize that trust can increase the perceived credibility of the insurer and so it is more likely that the 
insurance is taken up. In addition, they hypothesize that, controlling for trust, the probability of insurance purchase first increases and then decreases in risk aversion. However, as was explained above, uncertainty about the product may also be reduced by increasing the understanding about the insurance (Section 2.2.6 Understanding of insurance).

\subsubsection{Conclusion}

This section started with an introduction to expected utility theory and its underlying assumptions. It has discussed these in terms of their implications for the reality of microinsurance demand and it shows that the theoretical predictions for the effect of certain factors (for example credit-constraints) but also the explanations of their effects (social capital, networks and trust) are ambiguous. The following factors which are relevant for understanding microinsurance demand were advanced: price of the insurance, the insured risk and household risk situation, marketing of the product, (risk) preferences, credit-constraints, prevention and informal insurance and risk-sharing, understanding of insurance, and trust, social capital and social networks.

In addition to these factors, stages in the decision process were suggested: the awareness stage, when households are exposed to the existence of the insurance; the persuasion stage, when households develop a favorable or unfavorable attitude towards the insurance, and the actual decision.

Finally, different mechanisms were identified which may explain the effect of social capital, networks and trust. Factors may influence the demand for microinsurance through the mechanism of insurance knowledge but also by influencing the purchase decision.

After the description of the methods used in Section 2.2, these factors and mechanisms will be used to assess the empirical evidence from existing studies on microinsurance demand in Section 2.3.

\subsection{Method for analyzing empirical studies}

This chapter reviews empirical studies on determinants for microinsurance demand by considering the effect and significance of these factors. Other review methods such as meta-analysis were regarded as being less useful for the case of understanding microinsurance demand because firstly, the number of studies is still relatively low; secondly, the degree of comparability between the factors is low; and finally, the research designs vary. In addition, microinsurance is a term used for a wide variety of complex interventions in which insurance designs and products, supporting business processes and contexts vary substantially. The aim is to achieve an understanding of what works for whom, in what circumstances, in what respects and how it is likely to offer a more valuable contribution, especially for evidence-based policy making.

In this study, quantitative and qualitative empirical studies are included which focus on determinants of microinsurance demand, particularly because the objective is to understand which factors influence demand and why. In the selection of qualitative studies only peer-reviewed studies were included, in the selection of quantitative studies both peer-reviewed studies and also non-peer reviewed studies with adequate research 
designs. A statistical analysis of effects observed in the studies is not performed. The product designs and distribution processes happen in social systems and the results of studies are synthesized and contrasted accordingly (Pawson et al., 2005). For the quantitative studies, randomized experiments and quasi-experimental designs were enclosed. Studies focusing on insurance products in low-and middle-income countries were included. Previous literature reviews did not cover studies from before 2000 so only studies after that date are discussed here (Dercon et al., 2008).

\subsubsection{Criteria for inclusion and exclusion of studies.}

To narrow the scope of our study and to guarantee rigorous research designs we only include studies focusing on:

1. The demand for microinsurance. Many microinsurance impact studies control for selection issues by including variables which influence take up of microinsurance. Only studies are included which specifically analyze these factors and thus address a separate research question dealing with demand or uptake.

2. Insurance schemes which are run by institutions external to the local community.

3. Voluntary insurance, since this is a necessity for studying microinsurance demand and take up.

4. Insurance for the low-income population as this is inherent to the definition of microinsurance used here (explained in Chapter 1).

5. Demand. Demand consists of respondents who decide to take up, or not take up, microinsurance.

6. Demand at the micro-level (level of household).

The following search terms were used:

a. insurance, microinsurance, risk pooling, mutual health organizations (or 'MHO'), community based health insurance (or 'CBHI').

b. demand, take up, adoption, enrolment, decision-making.

Only 81 papers contained reference to the above six criteria. Out of the 81 papers another 50 are excluded, so in total 31 papers are included in the analysis. Of the 31 included papers, 24 are quantitative and seven are qualitative. Of the 24 quantitative papers, 11 are peer-reviewed and 13 are not peer reviewed, but considered to have sufficiently good quality research designs. The papers included in the analysis are listed in Table 2-1.

Out of the 50 excluded papers eight studies did not address insurance demand at all. Another seven studies addressed demand as part of impact without estimating a separate model for demand and were therefore excluded. Four were not peer reviewed and had an inadequate research design. Eight were previous versions of other papers, which are included. Fifteen papers reported evidence of willingness to pay studies for hypothetical insurance products, which were not found to contribute to our understanding of which factors influence insurance demand. Finally, another nine papers were excluded for other reasons. The list of the papers excluded is given in Appendix 2.1. 
Table 2-1 Overview of papers included in the study

\begin{tabular}{|c|c|}
\hline Quantitative N = 24 & Qualitative $N=8$ \\
\hline 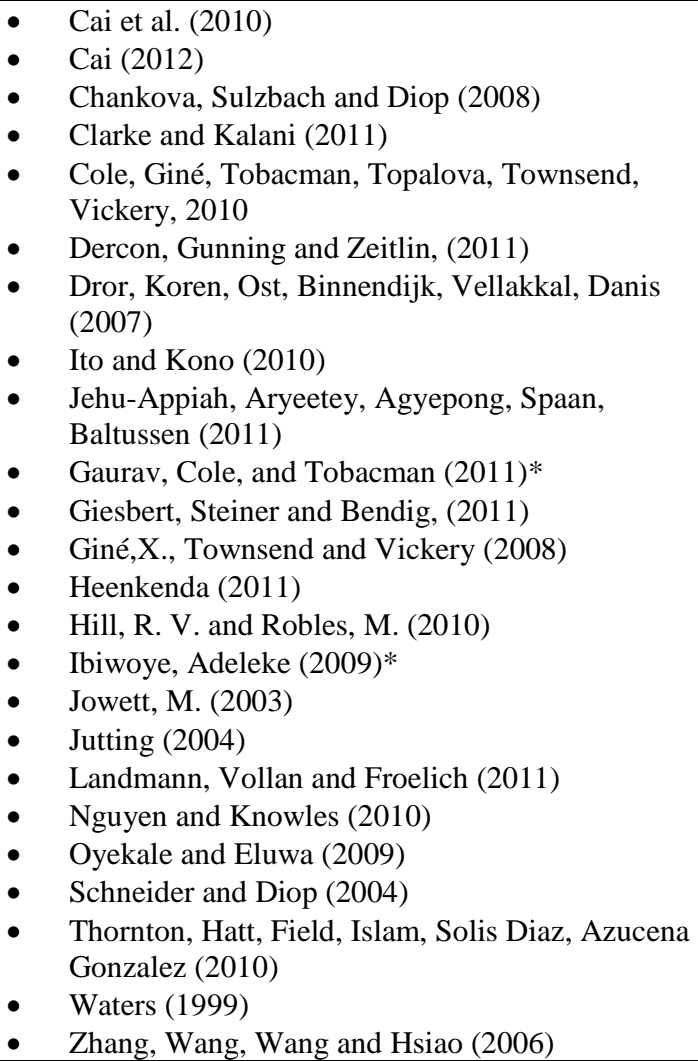 & $\begin{array}{ll}\text { - } & \text { Basaza, Criel, Van der Stuyft, (2008) } \\
\text { - } & \text { Criel and Waelkens (2003) } \\
\text { - } & \text { De Allegri, Sanon and Sauerborn, 2006, } \\
\text { - } & \text { De Allegri, Sanon, Bridges and Sauerborn (2006) } \\
\text { - } \quad \text { Mathauer, Schmidt, Wenyaa (2008) } \\
\text { - } \quad \text { Patt, Peterson, Carter, Velez, Hess and Suarez, } \\
\quad \text { 2009. } \\
\text { - Schneider (2005) }\end{array}$ \\
\hline
\end{tabular}

In Section 2.2 a number of factors were proposed which may affect insurance demand. These factors will be used to analyze the empirical studies on microinsurance demand. Table 2-2 provides an overview of the different studies organized by the factors that they address. In some studies the factors were used as controls and they were not analyzed. However, it was deemed important to include these in the discussions of the studies in Section 2.3 because they may hold interesting information. Some studies will be discussed more than once because they yield interesting information on several factors. Repetition of studies is kept at a minimum by referring to different sections. However, for purpose of clarity this was sometimes not maintained.

\subsection{Microinsurance demand determinants}

This section will discuss empirical evidence for the effect of each factor mentioned in Table 2-2 separately and will provide a conclusion at the end of each section. The overall conclusion and discussion will be provided in Section 2.6. 
Table 2-2 Studies classified by insured risk and demand factor category

\begin{tabular}{|c|c|c|c|}
\hline & Health & Agriculture & Other \\
\hline $\begin{array}{l}\text { Price, subsidies and } \\
\text { discounts }\end{array}$ & $\begin{array}{l}\text { Nguyen\& Knowles (2010) } \\
\text { Thornton et al. (2010) } \\
\text { Gaurav et al. (2011) } \\
\text { Dercon et al. (2011) }\end{array}$ & $\begin{array}{l}\text { Giné et al. (2008) } \\
\text { Cole et al. (2010) } \\
\text { Hill and Robles (2011) }\end{array}$ & \\
\hline $\begin{array}{l}\text { Insured risk and risk } \\
\text { situation of household }\end{array}$ & $\begin{array}{l}\text { Jowett (2003) } \\
\text { Chankova et al.( 2008) } \\
\text { Schneider \& Diop (2004) } \\
\text { Dror et al. (2007) } \\
\text { Dong et al. (2009) } \\
\text { Oyekale \& Eluwa (2009) } \\
\text { Ito and Kono (2010) } \\
\text { Nguyen \& Knowles (2010) } \\
\text { Thornton et al. (2010) } \\
\text { Jehu-Appiah et al. (2011) } \\
\text { Dercon et al. (2011) }\end{array}$ & Hill and Robles (2011) & \\
\hline $\begin{array}{l}\text { Prevention and informal } \\
\text { insurance }\end{array}$ & $\begin{array}{l}\text { Jowett (2003) } \\
\text { Cai (2012) } \\
\text { Clarke et al. (2011) } \\
\end{array}$ & & Landmann et al. (2011) \\
\hline $\begin{array}{l}\text { Marketing } \\
\text { characteristics }\end{array}$ & $\begin{array}{l}\text { Thornton et al. (2010) } \\
\text { Dercon et al. (2012) }\end{array}$ & $\begin{array}{l}\text { Gaurav et al. (2008) } \\
\text { Cole et al. (2008) }\end{array}$ & \\
\hline (Risk)preferences & $\begin{array}{l}\text { Ito \& Kono (2010) } \\
\text { Dercon et al. (2012) }\end{array}$ & $\begin{array}{l}\text { Giné et al. (2008) } \\
\text { Cai et al. (2010) } \\
\text { Cole et al. (2010) } \\
\text { Clarke \& Kalani (2011) } \\
\text { Cai (2012) }\end{array}$ & Giesbert et al. (2011) \\
\hline Credit-constraints & Ito \& Kono, (2010) & Giné et al. (2008) & \\
\hline $\begin{array}{l}\text { Understanding } \\
\text { insurance }\end{array}$ & Dercon et al. 2011 & $\begin{array}{l}\text { Giné et al. (2008) } \\
\text { Clarke \& Kalani (2011) } \\
\text { Cole et al.(2010) } \\
\text { Gaurav et al. (2011) } \\
\text { Heenkenda (2011) }\end{array}$ & \\
\hline $\begin{array}{l}\text { Social capital, networks } \\
\text { and trust }\end{array}$ & $\begin{array}{l}\text { Jowett (2003) } \\
\text { Jutting (2004) } \\
\text { Dror et al. (2007) } \\
\text { Zhang et al. (2006) }\end{array}$ & $\begin{array}{l}\text { Giné et al. (2008) } \\
\text { Cole et al. (2010) } \\
\text { Clarke \& Kalani (2011) } \\
\text { Cai et al. (2010) } \\
\text { Cai (2012) }\end{array}$ & $\begin{array}{l}\text { Landmann et al. (2011) } \\
\text { Giesbert et al. (2011) }\end{array}$ \\
\hline
\end{tabular}

\subsubsection{Price, subsidies and discounts}

Seven out of eight studies use an experimental design in which different treatments, or a combination thereof, are randomly assigned. Because the specific design of each treatment matters for the understanding of its effect on demand, the indicators will not be presented in a table but will be discussed in relation to the design of the treatments.

As mentioned above, if all factors are constant, it is expected that demand for insurance will decrease if the price of the insurance and additional transaction costs increases. Therefore discounts and subsidies are expected to have the opposite effect: if they increase, demand is expected to increase.

Nguyen and Knowles (2010) analyzed the demand for health insurance for school-age children and adolescent students making use of the Vietnam National Health Survey. They found that price of provincial hospital services, negatively and significantly influence participation in the health insurance scheme. Dercon, Gunning and Zeitlin (2011) conducted a field experiment consisting of different treatments ( $\mathrm{n}=30$ per 
treatment, 60 control) with variation in premium costs and marketing techniques. Two of the treatments are a voucher for 10 per cent premium discount, and a voucher for 20 per cent premium discount. Respondents with discount vouchers were more likely to take up the insurance with 20 per cent discount having a stronger effect.

Thornton, Hatt, Field, Islam, Solis Diaz, Azucena Gonzalez (2010) evaluated factors influencing health insurance enrollment by individuals randomly assigned to treatments with different prices and enrollment procedures. They performed an experimental evaluation $(\mathrm{N}=2215)$ with randomization at the individual level. They found that the brochure accompanied by a six-month insurance premium subsidy at a government institution for social security had a small, but significant, negative effect on enrollment. Gaurav, Cole and Tobacman (2011) tested the effect of a money-back guarantee. It offered clients who decided to take the insurance a full refund of the insurance premium if the policy did not payout. The money back guarantee had a robust and substantial positive effect on uptake.

Cole, Giné, Tobacman, Topalova, Townsend and Vickery (2010) conducted three experiments, one in Andra Pradesh and two in Gujarat. In the Andra Pradesh experiments some of the visited households received a low reward and some a high reward for participating in the experiment (low reward 25 Rs. and high reward 100 Rs.). The higher amount was sufficient to buy the product (i.e. to pay the premium for the insurance product). They found a significant positive effect of the high cash reward on take-up of the insurance, which was larger for poor households. In the Gujarat experiments a discount coupon was provided for the premium. The size of the discount was found to have a large effect on take-up of the insurance.

Next to subsidies and discounts, additional disutility may occur due to transaction costs such as costs for travelling and time spent on travelling. Schneider and Diop (2004) included the distance to the health facility and found that if the health facility is less than 30 minutes away this increases insurance take up. Zhang et al. (2006) found that the distance to a village health post negatively affected willingness to join a community health insurance. However, they also found that distance to the county hospital was positively related to willingness to join. They suggest that this may be explained by the fact that households who live far away from a county hospital rely more on the health services of the village health post and are therefore more likely to take up the insurance. Dong et al. (2009) investigated factors influencing the drop-out from a communitybased health insurance. They found that the further the distance to the health care facility the less likely households were to drop-out. Dong et al. (2009) explain that this may seem as a contradictory finding, but a qualitative study revealed that those living at distance from the facility appreciated the facility more.

To conclude, the studies discussed above confirm what might be expected, that increases in the premium levels lead to decreases in insurance take up. Additional utility from discounts and subsidies for a certain level of insurance premium lead to increased uptake of insurance. In all studies these effects were found to be significant. Disutility from travelling costs and time spent on travelling to health clinics was expected to negatively affect take up, but this result is not consistent because other factors such as reliance on local facilities and appreciation of health facilities may also influence this effect. Price elasticity of demand is not discussed here because products and contexts 
vary. However, as Cole et al. (2010) also suggest, even when the net policy price is below the actuarially fair premium of the insurance, the take up is found to be low. For example, more than 50 percent of households did not take up the insurance when the premium was below actuarially fair rates (Cole et al. 2010). The study by Gaurav et al. (2011) showed that with a full money-back guarantee there was only an increase in demand of 7 percentage points (the reference is not given). In the study by Thornton et al. (2010) the six months subsidy lead to an increase in demand from 28 to 50 per cent. These findings suggest that factors other than price are likely to play an important role in demand for insurance.

\subsubsection{The insured risk and household risk situation}

As was explained in the Section 2.2.4 on Asymmetric Information, design of the product and the coverage it provides, in combination with the risk situation of the insured, are expected to influence their decision to take up the insurance. Assuming that households are risk averse and attempt to maximize utility, the insurance would be especially interesting for individuals with higher than average probabilities of the risk. In the first part of this section, the household health risk situation will be discussed, in the second part the coverage of health insurance and agriculture insurance. Farmer risk situations were not separately included because these were not explicitly discussed as such in studies.

Out of the 12 studies addressing the insured risk and household risk situation, in one study drop-outs were analyzed (Dong et al. 2009) and one study had an experimental design. The outcomes from the drop-out analysis study will be separately discussed. The other ten studies were based on surveys. Out of the eleven studies looking at health insurance two studies look at enrollment in a Mutual Health Organization, four at community-based health insurance and five at public voluntary health insurance.

\section{Risk situation}

Table 2-3 presents the health status and characteristics that influence health insurance demand. It is evident from this table that the factors that were included in studies as potential determinants vary in their definition. 'Being sick' is a variable which was investigated in eight out of 11 studies and it had a positive significant effect in four studies (Jowett. 2003; Chankova et al. 2008; Ito and Kono, 2010; Thornton et al., 2010). The frequency of illness (Okeyale and Eluwa, 2009) and being handicapped (Chankova et al., 2008) were found to be positively significant while being vaccinated is negatively significant (Chankova et al. 2008). Chankova, Sulzbach and Diop (2008) found that households with a good and very good self-perceived health status were less likely to take up the insurance. Nguyen and Knowles (2010) also included indicators for the health status. There was no significant effect of overall bad or overall good health status. In Jowett's (2003) study the health status was measured based on the time since a health provider was contacted (good $>24$ months, fair 6-24 months). Jowett (2003) used illness during the last six months as reference category but also included this in the analysis. These variables show a mixed picture but generally they have a negative effect and are significant or strongly significant depending on the location. The long-standing limiting illness was also found to have a strongly negative and significant effect. 
Table 2-3 Health and agriculture characteristics $(\mathrm{N}=17)$.

\begin{tabular}{l|l|l|l}
\hline & $\begin{array}{l}\text { No. of studies } \\
\text { investigated }\end{array}$ & $\begin{array}{l}\text { No. of studies }+ \\
\text { effect }\end{array}$ & $\begin{array}{l}\text { No. of studies - } \\
\text { effect }\end{array}$ \\
\hline Health & 8 & 4 & - \\
Currently sick members & 2 & - & - \\
Previously sick members & 1 & - & - \\
Total time sick & 1 & 1 & - \\
Frequency ill & 1 & - & - \\
Frequency malaria treatment & 1 & 1 & - \\
Handicapped & 1 & - & 1 \\
Vaccination & 1 & - & - \\
No. of visits to provider & 1 & - & - \\
Any visit to provider & 1 & - & - \\
Recent pregnancy & 1 & - & - \\
Smokes & 1 & - & 1 \\
Cost of health care & 1 & - & 2 \\
Children overweight & 1 & - & - \\
Self-perceived H status ++ & 3 & - & - \\
Self-perceived H status + & 2 & - & - \\
Self-perceived H status - & 1 & - & \\
Family member in hospital & 1 & - & \\
Diarrhea & 1 & - & - \\
\hline
\end{tabular}

\section{Risk coverage}

A first element of health insurance product design is the coverage and benefits it provides. The experience of these benefits, especially with health insurance, also depends on the quality of health care provided. Dror, Koren, Ost, Binnendijk, Vellakkal, Danis (2007) found that both individuals and groups prefer health insurance packages which cover benefits that are directly related to vital care in case of illness and which cost the most: drugs, hospitalization, out-patient medicine and tests. Medical treatments with high aggregated costs were preferred over treatments with lower aggregated costs, independent of their probability of occurrence. They also found that respondents prefer a wide range of benefits at basic levels of coverage over a narrow choice of benefit types with high coverage levels. Oyekale and Eluwa (2009) studied willingness to pay for the National Health Insurance Scheme implemented by the Nigerian government $(\mathrm{N}=102)$ through a randomly selected sample survey. They found that the amount of family members covered by the product had a positive and significant effect on willingness to pay. Jehu-Appiah, Aryeetey, Spaan, Agyepong, and Baltussen (2011) studied the role of perceptions of a national health insurance product and the perceptions of the quality of health services on the enrollment into the national health insurance scheme in a survey of 3301 households in 30 communities in Ghana in 2009. They found that the positive perception of benefits significantly influenced insurance take up.

Nguyen and Knowles (2010) included quality of services provided and found it was positively related to enrollment in the scheme. Jehu-Appiah et al. (2011) also studied the quality of services provided, and considered convenience, facility adequacy and provider attitude in addition to quality of services. They found a positive and significant 
effect of perceptions of benefits and perception of convenience but not of the perceived quality of care, facility adequacy and provider attitude.

The preferences for different agricultural insurance products in relation to farmer characteristics were studied by Hill and Robles (2010). The research of Hill and Robles (2010) consisted of two series of experiments among farmers in Ethiopia. In these experiments weather securities (a specific type of index insurance product) were offered for different months of the rainy season and for different rainfall levels. A survey to assess farm specific characteristics was also conducted. Hill and Robles (2010) found that combinations of crop type, area planted, time planted, soil quality, type of fertilizer but also household/farmer specific characteristics, such as staple crop choice, influenced the purchase of insurance.

\section{Conclusion}

From the above studies the overall conclusion is that households which are more exposed to risk covered by the product are more likely to take up the insurance, which has its consequences for the sustainability of the insurance products because it implies that if more higher-risk households will take up the insurance, the premium will eventually increase.

The findings of Dror et al. (2007) suggest that the probabilities of health risks do not influence preferences for insurance options. This contradicts the predictions under both expected utility and prospect theory, because both include probabilities of the risk event. According to Dror et al. (2007) this pattern suggests that health insurance for lowprobability, high-cost health risks would not be attractive while products with highprobability, low-cost care would be taken up.

\subsubsection{Prevention, self-insurance and informal risk-sharing}

Jowett (2003) studied informal risk-sharing networks and their influence on individual demand for a voluntary health insurance in Vietnam. Data were collected through a household survey in three provinces $(\mathrm{n}=1568)$. The insured individuals were randomly selected from the health insurance organization data while non-insured were selected from residents' lists. The models were separately estimated for the different provinces. The variables of interest, as proxies for informal risk-sharing networks are the extent to which individuals rely on informal financial networks, index of general network density and social cohesion. Informal financial networks were measured through assessing the sources for borrowing money. Social cohesion was measured through a survey question about the perception of social cohesion. Index of general network density was measured through questions about economic heterogeneity, kin heterogeneity and perceived network functioning. Jowett (2003) found that strong informal financial networks have a consistent strong negative effect on purchase, which suggests that, where private transfers within families and friends are strong, individuals are less likely to purchase formal health insurance. The effect of density of heterogeneous networks was negative in one province, positive in the two others and significant in all. This evidence is thus inconclusive. The effect of social cohesion on demand was negative and significant, suggesting that the more cohesive a community, the less likely they were to buy the insurance. 
Clarke and Kalani (2011) included access to informal insurance networks in their analysis by referring to membership of mutual savings and funeral associations; and whether a household could obtain a certain amount of money in a short time-period. They estimated four models and found no consistent effect of these factors over these models, although in two models the ability to obtain a certain amount of money was found to be positively and significantly related to insurance take up.

Zhang et al. (2006) investigated the effect of reciprocity on insurance take up by asking respondents five questions: "Do you think villagers will provide help if someone really needs it", "Would you lend money to your neighbor if he/she needs it to see a doctor", "Would you say if your village were a large family, you would be a member in this family" and "Would you like to support a project that might not benefit you most, but benefit other villagers". They found that this indicator is not significant at the level of an individual, but when the average mean of respondents in a community is attributed to an individual, they found that this positively affected take up of insurance.

\section{Conclusion}

The results of the above studies are not consistent with respect to the effect of informal risk-sharing on insurance uptake. Jowett's (2003) results suggest that there is a negative effect while the results of the study of Clarke and Kalani (2011) and Zhang et al. (2006) suggest that there may be a positive effect. However, the only significant variable in the study by Clarke and Kalani (2011) was the ability to obtain a certain amount of money in a short time period. While they view this as an operationalization of informal risksharing, this may also be an indication of credit-constraints. If that is the case, then being credit-constrained would have a negative effect on insurance take up. The membership of mutual saving and funeral associations did not have a significant effect in their study. Zhang et al. (2006) found a positive effect of average community level reciprocity on insurance take up, but a non-significant effect of household-level reciprocity. This raises questions about the level of analysis of informal risk-sharing. The results from Zhang et al. (2006) suggest that the community-level is the correct unit of analysis. However, the positive effect of community-level reciprocity may also be an indication of a collective action hypothesis and not informal risk-sharing. As was mentioned in Sections 2.2.7 and 2.2.8 memberships of organizations and community characteristics do not necessarily reflect the informal risk-sharing hypothesis.

\subsubsection{Marketing treatments}

Thornton et al. (2010) tested three treatments: a brochure with information about the insurance (no details provided), a brochure accompanied by a 6-month insurance premium subsidy at a government institution for social security and finally, a brochure combined with a subsidy at an MFI. They found, in a model controlling for health insurance status and households characteristics, that the brochure had a small but significant negative effect on enrollment for all and for non-MFI clients; while the subsidy in both cases had a positive effect, which was stronger for the MFI subsidy.

Dercon et al. (2011) varied treatments based on variation in premium costs and marketing techniques. The different treatments were a voucher for 10 per cent premium discount, a voucher for 20 per cent premium discount, only marketing, an incentive to refer a peer, and education in financial literacy through study circles. The marketing 
was done through a meeting in which basic information about the product was provided by the marketing agents, accompanied by a member from the respondents' savings groups. These meetings lasted between one and two hours. Study circles and marketing had no measurable effect; peer referral had a negative significant effect on take up.

Gaurav et al. (2011) tested different treatments such as being invited to training, a money-back guarantee, and weather-forecasts. There were three different marketing messages. The money-back guarantee offered clients a full refund of the insurance premium if the policy did not payout. The second marketing message, millimeter demonstration, provided a demonstration of how the trigger works. The third message, weather forecast, provided the weather forecast for the next ten days. These messages were also offered in combination and a total of six different marketing messages were the treatments. Financial education had a significant and positive effect on the uptake, increasing it from 0.08 to 0.16 . Only the money-back guarantee had a robust and substantial positive effect on uptake.

In a policy research working paper Cole et al. (2010) reported results for three field experiments on uptake of a rainfall-index insurance, one in Andra Pradesh and two in Gujarat. In the first experiment there were four treatments: 1. A visit to the household by an insurance educator, 2. Endorsement of the educator by the branch organization of the insurance provider, 3. Presentation of the education module and 4. A reward for the household. Only being visited and the high reward for the interview showed a significant effect. The estimations with treatment interactions added less than 1 percent to the explained variance. However, interactions of the treatments with other factors were found to be significant. The first one was an interaction effect between knowing the local branch of the insurance provider which endorsed the insurance educator, with endorsement by the insurance provider. This increased take up by 10 percentage points. This endorsement had no effect if households did not know the insurance provider.

The treatments of the video-experiments in Gujarat consisted of three different discount levels with different framing messages in a video presented to the participants. In the model, interactions from the framings with the level of discount were included. The framing as a strong brand was significant and negatively influenced take up. Framing as safety instead of vulnerability was negatively and significantly related to take up. Positive framing and peer endorsement did not have a significant effect. Of the interactions, only discount with strong brand and vulnerability were significant.

In the final experiment the treatments consisted of flyers with different messages on values of insurance related to Muslim values, Hindu values or neutral group values. The Muslim and Hindu framing were not significant, whereas the group framing was. An interaction effect between the Muslim values and group values negatively and significantly influenced take up. In addition, if Muslims were presented with flyers with Hindu values or vice versa take up was significantly lower.

These studies on (combinations of) different marketing treatments lead to the suggestion that information and training activities (through brochures, meetings, visits, presentations, millimeter demonstrations of rainfall and weather forecasts) do not have a significant effect on the uptake of the insurance (Gaurav et al., 2011; Thornton et al., 2010; Cole et al., 2010; Dercon et al., 2011). Thornton et al. (2010) even found a small negative effect of a brochure with information about the insurance. The negative effects of the brochure, peer referral (Dercon et al., 2011 found a negative effect, Cole et al., 2010 no effect) and framing as a strong brand (Cole et al., 2010) even suggest that 
strong advertisement may have a negative effect. The Cole et al. (2010) study has addressed several framing options of which group framing had a significant positive effect and framing as vulnerable (versus 'safety') and as strong brand had a negative effect. Framing Hindu values to Muslims and vice versa also had a negative effect on take up. This was not analyzed further.

\section{Conclusion}

Most of the studies above do not present their results explicitly in terms of expected utility, prospect theory or another theoretical framework. Often the discussion of theory is limited to presentations of findings of previous studies on demand determinants. The overall conclusion is that there is a strong negative effect of increases in price on uptake and a strong positive effect of discounts and subsidies on uptake. The studies further suggest that marketing messages with the objective of increasing the understanding of the insurance by providing information do not influence uptake. This may imply that either the design of these information marketing messages is inadequate or that providing information through marketing messages does not increase take up.

\subsection{5 (Risk) preferences}

Table 2-4 provides an overview of preferences which were investigated in microinsurance demand studies. Giesbert et al. (2011) and Cai (2012) included risk preferences as controls. Six studies used an experimental design to elicit risk preferences and one study used a proxy (Giesbert et al., 2011). Out of the six experimental designs, four used a Binswanger (1980) lottery (Giné et al., 2008; Cole et al., 2010; Clarke and Kalani, 2011; Cai, 2012). Ito and Kono (2010) and Dercon et al. (2011) used a design in which they framed the experimental game in gain and loss frames. Giesbert et al. (2011) used a proxy for risk aversion based on the question: 'How do you see yourself?, Willing or unwilling to take risk?' Respondents were asked to rank this between 0-5. They found a significant effect, but the effect was positive. Since this is not further investigated and the authors explained that willingness to take risk may not be a good proxy for risk aversion, this will not be further discussed.

Table 2-4 Preferences $(\mathrm{N}=6)$

\begin{tabular}{l|l|l|l}
\hline Risk preferences & $\begin{array}{l}\text { No. of studies } \\
\text { investigated }\end{array}$ & $\begin{array}{l}\text { No. of studies } \\
\text { + effect }\end{array}$ & $\begin{array}{l}\text { No. of studies } \\
\text { - effect }\end{array}$ \\
\hline Risk aversion & 5 & - & 5 \\
Difference loss-gain frame & 1 & - & - \\
Risk averse for gains & 1 & - & 1 \\
Risk loving for losses & 1 & - & 1 \\
Risk perception & 1 & 1 & - \\
Hyperbolic discounting (HB) & 1 & 1 & - \\
Sophisticated HB* & 1 & - & - \\
\hline *Operationalization of sophistication is weak (see text)
\end{tabular}

\section{Risk aversion}

Giné et al. (2008) reported that risk-averse households in their study are less likely to purchase rainfall insurance. This result contradicts the prediction, based on expected 
utility theory, which expects risk averse households to demand more insurance. This is, to my knowledge, the first time a study has demonstrated these results. They suggested that risk-averse households are also averse to uncertainty about the insurance product and that this is related to their imperfect understanding of the product. They further investigated the interaction between risk aversion with familiarity with the insurer, the provider of the insurance and with previous insurance experiences. These interactions had a positive effect and the effect of familiarity to the insurer was significant. Based on this they concluded that the uncertainty explanation for the negative effect of risk aversion was to be supported. Cole et al. (2010) also found a negative effect of risk aversion on insurance purchase. Furthermore they found an interaction effect between familiarity to the insurer and its endorsement of an insurance educator on insurance purchase. This interaction increased take up by 10 percentage points. They suggested that they observed this effect because of the role of trust and hypothesize that the observed effect of Giné et al. (2008) of uncertainty may be either a lack of understanding or a lack of trust.

Clarke and Kalani (2011) investigated if the demand for index insurance was consistent with DARA EUT and also compared this to RDU. They did so by investigating demand for index- and indemnity-insurance in an experimental setting. They used wealth in livestock units to show that there is a hump-shaped relationship between take-up and wealth for the index insurance. However, this hump-shaped effect didn't exist for the indemnity insurance. According to Clarke and Kalani (2011) the negative effect of risk aversion on take up is therefore explained by rational choice based on DARA EUT rather than irrationality.

Dercon et al. (2011) conducted experiments to assess the role of risk preferences, trust and price on insurance demand. To assess risk preferences they conducted a Holt and Laury (2002) gamble choice-game framed both in the gain-frame and in the loss-frame. In another experiment they play a trust game through which they assessed the level of generalized trust of an individual through a Sender-Receiver setting (Barr, 2003). This will be further explained under the Section 2.4.8 Social capital, networks and trust. They found that demand was decreasing in measured risk aversion and increasing in measured trust. They concluded that a non-linear effect exists where, for risk-neutral individuals, the marginal effect of an increase in risk aversion is positive, while for the risk averse individuals an increase in risk aversion is negative. The provided this finding as an explanation of the observed inverse effect of risk aversion.

Cai (2012) conducted an experiment in which risk attitudes were elicited by confronting households to choose between increasing amounts of certain money and gambles with risk. The number of riskless gambles was used as an indication for risk aversion. Cai (2012) estimated several models for insurance uptake and finds that risk aversion had a positive and significant effect in all these estimations.

Risk preferences in gain frame and loss frame

Ito and Kono (2010) investigated if take up decisions of insurance were better explained by prospect theory or expected utility theory. They conducted risk preferences games in gain- and loss-frames and found that the value function for gains and losses differed significantly. They also included risk aversion for gains and different degrees of risk lovingness for losses as an explanation for insurance take up. Ito and Kono (2010) suggested that there is weak evidence (only significant for the highest degree of risk 
lovingness) that respondents behave risk loving for losses. They also concluded that this evidence is consistent with prospect theory. However, the results should be interpreted with care because the evidence is not very strong. Dercon et al. (2011), in their risk preferences game also included gain and loss frames. They did not find evidence to assume that respondents behave differently in the gain and loss frames. They also tested for robustness of their models by including first the parameter for risk aversion in the gain frame and replacing it with the parameter for risk aversion in the loss frame. No changes in the other estimates occurred suggesting no differences between framing as either gain or loss.

\section{Hyberbolic discounting}

Ito and Kono (2010) also investigated the effect of the self-control problem with a hyperbolic discounting model ${ }^{1}$ by conducting an experiment in which respondents were confronted with a series of choices between a lump sum now, or a future lump sum including interest in the future. The respondents were also provided with the option of receiving the amount as a lump sum or receiving it in periodic installments. According to them, the latter choice would be an indication of the respondents' awareness of their self-control problem because this would indicate temptation to overvalue consumption. These respondents were hypothesized to be more likely to use commitment devices such as insurance. Ito and Kono (2010) found a positive and significant effect of hyperbolic discounting on take up of insurance. They concluded that this is consistent with their hypothesis that individuals with hyperbolic discounting would be more likely to take up insurance because of its commitment effect. They also stated that this interpretation should be made with caution because there is large variation in the variable. Their sample did not allow for testing of the awareness of the self-control problem.

\section{Conclusion}

Increases in risk aversion were shown to have a positive and significant effect on the take up of microinsurance suggesting that the take up of microinsurance is considered as a risk itself. Dercon et al. (2011) attempted to explain this effect by involving trust in their model. They viewed trust as a factor which can reduce the perceived riskiness of an insurance purchase and found that demand was increasing in trust and decreasing in risk aversion. They suggested that for risk-neutral individuals the marginal effect of an increase in risk aversion is positive while for the risk averse individuals an increase in risk aversion is negative, suggesting a non-monotonic effect. This should be further investigated. The evidence for differences between the gain and loss frame is contradictory at this stage since Ito and Kono (2010) find evidence to support different value functions for gains and losses while Dercon et al. (2011) do not. This should also be further investigated especially because it may be that the inverse effect of increases in risk aversion is caused by framing of insurance as a loss, and may therefore be explained by Prospect Theory. The evidence for an effect of hyperbolic discounting on insurance take up is weak and comes from only one study and should thus be further investigated.

\footnotetext{
${ }^{1}$ Hyperbolic discounting models assume that individuals discount the value of future rewards by a factor that increases in the amount of delay. This is different from exponential discounting where the discount factor remains the same if the delay is increased. See for example Strotz (1956) and Laibson (1997).
} 


\subsubsection{Credit-constraints}

Giné et al. (2008) and Ito and Kono (2010) investigated the role of credit-constraints on insurance take up. Giné et al. (2008) used a proxy for credit-constraints by asking households why they do not have one more loan. If households gave a 'supply-side' reason ('bank will not give additional loan' or 'lack of collateral'), the proxy received value 1 . They found that credit-constraints have a negative significant effect on take up of insurance. Ito and Kono (2010) studied credit-constraints from banks by differentiating between receiving credit (yes or no) and the level of credit (as much as needed). In both cases, the effect of credit-constraints was found to be negative but not significant.

\section{Conclusion}

No definite conclusions can be drawn based on the above two studies. However, both show a negative effect of credit-constraints which may suggest that it is not anticipation of future credit-constraints that increases take up of insurance, but current creditconstraints which limit the ability to pay for the insurance premium.

\subsubsection{Understanding insurance}

Table 2-5 presents the indicators used for financial literacy, financial education and insurance experiences. Cole et al. (2010), Gaurav et al. (2011) and Dercon et al. (2011) combined survey questionnaires with experiments in which insurance education was randomly assigned to respondents. The other authors used survey questions.

Giné et al. (2008) included the effect of having 'another insurance' as an indication for experience with the insurance and did not find a significant effect. Clarke and Kalani (2011), in their questionnaire, included measures of understanding decision problems and measures for probability and mathematical skills and also did not find a significant effect. Heenkenda (2011) used questions about types of insurance products, attitude towards insurance and number of insurers known to the respondents. He found a small positive effect on take up of insurance.

Table 2-5 Financial literacy, education and insurance experiences $(\mathrm{N}=6)$

\begin{tabular}{l|l|l|l}
\hline Financial literacy and insurance experiences & $\begin{array}{l}\text { No. of studies } \\
\text { investigated }\end{array}$ & $\begin{array}{l}\text { No. of studies }+ \\
\text { effect }\end{array}$ & $\begin{array}{l}\text { No. of studies } \\
\text { - effect }\end{array}$ \\
\hline Understanding & 1 & - & - \\
Financial literacy & 3 & 2 & - \\
Math Skills & 1 & - & - \\
Probability skills & 1 & 1 & - \\
Insurance Skills & 1 & - & - \\
Financial education & 2 & - & - \\
Has other insurance & 2 & 1 & - \\
Has bought particular insurance in past & 2 & 1 & - \\
Average insurance payouts in village & 1 & 1 & \\
& & & \\
\hline
\end{tabular}


Gaurav, Cole and Tobacman (2011) tested the effect of financial literacy and financial education on take up of a rainfall-index insurance. They started by assessing financial literacy of 600 randomly selected small-scale farmers in India through questionnaires to assess the level of financial literacy. Following this, in the first part of the session, financial education was provided, focusing on personal financial management. In the second part of the training, participants played a set of interactive simulation games to learn about insurance. After this, different marketing treatments were provided which are described under the Section 2.4.4 Marketing Treatments above. Gaurav, Cole and Tobacman (2011) concluded that financial education had a positive and significant effect on the uptake of the insurance. However, the observed effect is small and the estimation is wrongfully done with OLS on a dichotomous dependent variable.

Cole et al. (2010) in their questionnaires, included questions about financial literacy and cognitive ability. They also administered tests of math, financial literacy and understanding of probabilities. They did not find a significant effect of math skills or financial literacy in any of the locations. They did find a positive and significant effect of probability skills in the different locations. There is a mixed picture with respect to insurance skills, which is positive and significant for one study site and negative and significant for the other study site although the same measurement instrument was used. Therefore this was reported as a non-significant effect in Table 2-5. As indicators for previous insurance experiences, Cole et al. (2010) included previous average insurance payouts in villages in the previous year, if the households bought the insurance in the previous year and if he/she had another insurance policy. These had a positive and significant effect on insurance take up. Finally Dercon et al. (2011), as one of their treatments, included study circles, which were existing literacy training modules already provided by one of the partners delivering the insurance. Study circles received education in financial literacy, with a focus on insurance. In these circles they trained someone in the community to lead regular study groups in which they discussed written materials together with a small group of peers. The training focused on indemnity insurance and health-related shocks and recurred on a weekly basis for a period of ten weeks. Dercon et al. (2011) did not find an effect of the study circles on uptake of the insurance.

\section{Conclusion}

None of the studies that conducted experiments to investigate the effect of financial education on uptake found a significant effect. Of the three studies which measured overall financial literacy through survey questions and tests, two found a small significant effect. This observed effect in one study (Gaurav et al., 2011) was found through using OLS estimation for a dichotomous choice variable. Even if this was a significant effect, it remains small. Therefore it should be further investigated. In another (non-peer reviewed) version of the paper this effect was also reported through OLS in a model with explained variance of $0.02 \mathrm{R}$ squared, without including controls (Gaurav, Cole and Tobacman, 2011). They report that the effect is small and holds only for the sub-sample. Based on the relatively small number of studies, no definite conclusion can be drawn about the effect of financial literacy and financial education. 


\subsubsection{Social capital, networks and trust}

First the different studies which have included indicators for social capital, networks and trust are discussed. The results of these studies are presented in Table 2-6. The indicators are separated into general measures, membership measures and insurance experiences.

\section{General measures}

Heenkenda (2011), Jowett (2003) and Zhang et al. (2006) measured the strength of general measures for social capital, networks and trust. Heenkenda (2011) created a social capital index based on 21 survey questions about trust, reciprocity and associations. These questions were then reduced to one index based on principal component analysis. Heenkenda (2011) found a strong, positive effect on the uptake of rainfall-index insurance. Jowett (2003) studied the effect of reliance on the informal financial networks, a community level index of general network density and social cohesion as proxies for informal risk-sharing. Informal financial networks were measured through assessing the sources for borrowing money. Social cohesion was measured through a survey question about the perception of social cohesion. Index of general network density was measured through questions about economic heterogeneity, kin heterogeneity and perceived network functioning. Jowett (2003) found that strong informal financial networks have a consistent strong negative effect on purchase. The effect of density of heterogeneous networks was negative in one province, positive in the two others and significant in all. This evidence is thus inconclusive. The effect of social cohesion on demand was negative and significant, suggesting that the more cohesive a community, the less likely they are to buy the insurance.

Zhang et al. (2006) studied the effect of trust and reciprocity at individual and aggregate community level on willingness-to-join. Each concept was measured by five questions. The index for trust and reciprocity were both included as indicators of individual levels of trust and reciprocity; and are aggregated as village-level indicators. High levels of reciprocity at the level of the community, positively and significantly influenced the willingness to join the community-based health insurance. For trust the individual-level variables influenced willingness to join. The higher the individual-level of trust, the higher was the willingness to join.

\section{Membership measures}

Giné et al. (2008), Hill and Robles (2010), Cole et al. (2010) and Clarke and Kalani (2011) studied membership of specific groups and its effect on insurance take up. The research of Hill and Robles (2010) included respondents who participated in informal insurance groups versus respondents who participated individually. The number of people in an informal insurance group positively affected the amount of insurance purchased, but not the type of insurance. Clarke and Kalani (2011) looked at membership of community insurance and mutual savings, which were not found to be significant. The number of groups a household is a member of, and membership to a local group, were both not significant in Cole et al. (2010) but they were in Giné et al. (2008). In Giné et al. (2008) the effect of membership of the local government was strongly positively significant. Cole et al. (2010) also investigated the effect of a Muslim emphasis, Hindu emphasis, a group emphasis and interactions between group and religious emphasis on take up by Muslims and Hindus. The group emphasis had a 
positive effect on uptake of insurance by Muslims, but not by Hindu's. Muslim emphasis interacted with group emphasis conveyed to Hindus and Hindu emphasis interacted with group emphasis conveyed to Muslims had a negative effect on take up. The effect is not further investigated.

\section{Insurance experiences}

Experience with the insurer, the insurance concept and the specific insurance product, may be indicators for trust but also for learning effects, as was discussed in the Section 2.4.7 Understanding insurance. Cole et al. (2010) found that not knowing the insurance provider had a significant negative effect on take up of the insurance. Being visited by an insurance educator, who is endorsed by the insurance provider, had a positive significant effect on take up. Giné et al (2008) found that membership and having a loan from the insurance provider had a positive significant effect. Having another insurance was not found to be significant in both the Giné et al (2008) and Cole et al. (2010) study. Previous experience with the particular insurance product had a positive and significant effect on uptake in the Giné et al. (2008) study.

A second category of variables is the role of experiences of peers with buying insurance and with receiving a claim. Cole et al. (2010) found that peer endorsement does not have a significant effect on take up, while Jehu-Appiah et al. (2011) found that lower peer pressure leads to higher take up rates. Knowing peers with insurance and knowing peers with claims had a positive effect on take up (Giné et al., 2008). This may suggest that peer experiences positively affect insurance uptake, but whenever they are deliberately included in marketing this seems to have a negative effect.

The following three studies will be discussed separately because they have experimentally explored the effect of social capital, networks and trust on insurance uptake. The design of their experiments is considered to be important for understanding the mechanisms underlying observed effects. The factors in these studies are therefore not included in Table 2-6.

Cai, Chen, Fang and Zhou (2010) tested a model which assessed the impact of a government subsidized sow insurance on farmers' production behavior in China. Different subsidized incentive schemes, varying the degree of subsidization, were randomized across villages. Cai et al. (2010) explained that local Chinese government has often shown not to be trustworthy. Therefore they used the effect of a snow storm and consequent payouts of the insurance company as proxy for increased trust. Controlling for the number of sows and the number of sow deaths they showed that the number of insured sows in the next season has increased. Another test for the effect of trust was done by using higher participation levels in government-sponsored insurance programs in the past as a proxy for trust. They showed that this indeed positively affected the take up of insurance. Cai et al. (2010) also suggested explanations other than trust, such as awareness and risk aversion, which they don't further investigate.

As described in Section 2.4.5 (Risk)preferences, Dercon et al. (2011) found that demand decreases in risk aversion and increases in trust. The experimental design for eliciting risk aversion was explained above. Here the experimental design for eliciting trust is 
explained. Players were assigned two roles, Sender or Receiver. Both received a similar endowment. The Sender could decide to send part of the endowment to the Receiver. In this case the amount was tripled. The Receiver could then decide to keep all of the endowment or return a certain amount to the Sender. The Receiver in their games was always the group leader of the group through which the health insurance was distributed. The Sender behavior of the respondents is used as proxy for their perceptions of the credibility of the insurer. They found that low trust (versus high) had a negative effect on take up of the insurance and this was especially strong when interacted with price. Different explanations for the behavior in the trust game may exist: altruism, risk preferences, expected trustworthiness of the Receiver, and preference for trusting behavior for which the authors attempted to control by including risk preferences and excluding centers with peer-referral incentives (Dercon et al., 2011: 19).

Table 2-6 Social capital, networks and trust $(\mathrm{N}=11)$

\begin{tabular}{|c|c|c|c|}
\hline Trust & $\begin{array}{l}\text { No. of studies } \\
\text { investigated }\end{array}$ & $\begin{array}{l}\text { No. of studies } \\
+ \text { effect }\end{array}$ & $\begin{array}{l}\text { No. of studies } \\
\text { - effect }\end{array}$ \\
\hline \multicolumn{4}{|l|}{ General measures } \\
\hline Network density & 1 & - & - \\
\hline Social cohesion & 1 & - & 1 \\
\hline Reciprocity (index) & 1 & - & - \\
\hline Trust (index) & 1 & - & - \\
\hline Social capital (index) & 1 & 1 & - \\
\hline Trust (index) & 1 & - & - \\
\hline Reciprocity (index) & 1 & - & - \\
\hline \multicolumn{4}{|l|}{ Membership measures } \\
\hline Member community network & 4 & 2 & - \\
\hline Informal financial networks & 1 & - & - \\
\hline No. of households known & 2 & - & - \\
\hline Schedules caste, schedules tribe & 1 & - & - \\
\hline Muslim (1=yes) & 1 & 1 & - \\
\hline \multicolumn{4}{|l|}{ Insurance experiences } \\
\hline Peer endorsement/pressure & 2 & - & 1 \\
\hline Knows peers with insurance & 1 & 1 & - \\
\hline Knowing peers with claims & 1 & 1 & - \\
\hline Does not know insurance provider & 1 & - & 1 \\
\hline Knows insurance provider & 2 & 1 & - \\
\hline Endorsement insurance provider & 1 & - & - \\
\hline Visit education* endorsement & 1 & - & 1 \\
\hline Pessimism about insurance & 2 & 2 & - \\
\hline Household has insurance & 1 & 1 & - \\
\hline Household bought insurance in past & 1 & - & 1 \\
\hline Other insurance payouts in village & 1 & - & - \\
\hline
\end{tabular}

Finally, Cai (2012) explored the role of social networks on the decision to insure through providing financial education about the insurance to a randomly selected treatment group of farmers. For the control group she found that the financial education 
provided to the treatment group influenced the decision of the control group to also take the insurance: a spillover effect. To explain the observed spill-over effect she tested different models focusing on different potential explanations for this effect: insurance knowledge and purchase decisions (scale, imitation or informal risk-sharing). She found a positive effect on insurance take up of strong (versus weak) ties for those who had received financial education. She continued to investigate the nature of the relationship and found a positive significant effect of government officials, friends and family on take up, with government officials having the strongest effect. She also tested the effect of the number of people who had received financial education in the respondents' social network and found that the higher the number of individuals in the social network which have received financial education, the higher the likelihood that the individual will take up the insurance. She continued by investigating the network density and found a positive effect of the density of the network on take up, while there is a negative effect associated with the number of households in the network. Cai also studied the centrality of an individual in a network in terms of how such a person can be influenced by others, or how a person can influence others. Those households which were named more often by others, who can be reached more easily and who have a more important network position, were less likely to be influenced by others. By comparing effects of financial education between two rounds and by testing insurance knowledge Cai (2012) concluded that there is an insurance knowledge effect and no purchase decision effect of financial education provided to ties in the network. She suggested that this may be caused by limited time for the purchase decision to occur, or because farmers don't want to reveal their decision. This was tested by looking at the effect of friends' take up decisions on the respondents take up decision and she found no effect. The last test which was conducted was that of having ties experience a claim; and she found a positive and significant effect. Explanations of changes in risk attitudes and changes in perceived probability were tested and not found to be significant. The conclusion of Cai was therefore that the effect of peers with claims is a learning effect.

\section{Conclusion}

The discussion above shows that while many studies confirm effects of social capital, networks and trust on insurance demand, the underlying mechanisms are not well understood.

The studies investigating the effect of general network indicators show mixed results. The explanations for the observed effects also vary. They may be indicators of potential collective action and therefore increase the likelihood of individuals in a community to enter into a community based health insurance (Jowett, 2003). Another explanation is that their effects are indications of the existence of informal risk-sharing and therefore have a negative effect on take up.

Cai (2012) analyzed some of these explanations by distinguishing between insurance knowledge and purchase decision effects. The effect of social capital and networks on an individual's insurance take up decision may be explained by learning effects caused by experiences of peers with the purchase of the insurance or the experience of a payout. As suggested by Cai (2012) it may be that these factors do not lead to a learning effect but to an imitation-, scale- or informal risk-sharing effect. Cai (2012) did not find a learning effect of purchase of others on an individual's purchase, while she did find an effect of payout experiences of peers on purchase decisions. However, she did not 
provide an explanation for the latter effect and it can still be a learning effect, an uncertainty reduction effect, an imitation effect or an informal risk-sharing effect.

In addition to the suggested effects above, another potential mechanism for explaining the observed effects of social capital and networks is trust. Dercon et al. (2011) found a positive effect of generalized trust on insurance take up. Cai et al. (2010) found a positive effect of trust in the government on a government-subsidized insurance product. Cole et al. (2010) suggested that messages conveyed about the insurance may also foster trust. The observed effect of knowing peers with claims (Cai, 2012) may also be an indication of uncertainty reduction through trust. However, as soon as peers are deliberately used in marketing there are negative effects of peer experiences (Cole et al., 2010; Dercon et al., 2011). Dercon et al. (2011) suggested that peer referral raised fears among people because of negative experiences with pyramid schemes in Kenya. They also found that this effect is only significant for households which exhibit high levels of trust. Another finding is that previous experiences matter for uptake; but for these studies it is however unclear if these are learning or trust effects. The fact that the interaction between education and endorsement by the insurance provider is significant may be an indication of the trust effect (Cole et al., 2010).

\subsection{Exploration of other explanations}

Qualitative studies are considered separately because they may expose, in addition to the common factors mentioned in quantitative studies, promising factors that may influence demand. Table 2-7 provides an overview of these studies and the topics they have investigated

Through a series of focus groups, Criel and Waelkens (2003) found that a lack of understanding or acceptance of insurance was not the reason for low subscription to a Mutual Health Organization (MHO). They state that the majority of participants had a complete understanding of the health insurance. They did find that respondents mentioned operational difficulties with the MHO) and lack of financial resources as a problem. However, most people reported that they refrained from joining because the quality of care in the health facilities was low.

Schneider (2005) conducted a series of 24 focus groups including micro-health insurance (MHI) members, non-members, Mutual Health Insurance (MHI) managers and health care providers as participants. Discussion points focused on trust built through assurance of the management of the health insurance scheme; providers' advocacy for patients and the legal and control mechanisms. She found that trust is relevant to all groups and influences insurance enrollment. Trust in the management of the insurance scheme, trust in the professional competence of health care providers and trust in legal and control mechanisms influenced enrollment. De Allegri, Sanon and Sauerborn (2006) found, through in-depth interviews with 32 households, that it is not the level of premium but the timing and manner in which the premium is collected that is the biggest problem. They also found that lack of adequate knowledge and understanding of the scheme played an important role in preventing uptake. Skepticism about the insurance product, low trust in the scheme management and previous bad 
experiences with similar collective arrangements were provided as explanations for households not to join the insurance. De Allegri et al. (2006) found that the respondents are likely to mistrust new initiatives because they doubt their institutional capacity to handle fraud and they are therefore reluctant to take up insurance unless they have proof of payouts. They also reported that respondents dislike the attitudes of personnel and the way the personnel treats patients. They also question the competencies of the personnel of the health provider.

Basaza, Criel and Van Der Stuyft (2008) performed a comparative case study evaluation of two community health insurances. They pointed to a series of explanations for low take up of these insurances both with respect to demand and supply issues. They found that potential explanations for low demand are the insurance scheme's design and operation, lack of understanding of the concept of community health insurance, lack of trust in local financial organizations, previous depressing experiences with similar institutions and problems with the ability to pay.

Mathauer, Schmidt and Wenyaa (2008) performed 19 focus group discussion with organized groups of informal sector workers to understand choices of potential clients to take up or reject the National Health Insurance Fund (NHIF) in Kenya. Availability of quality health care, ability to pay, knowledge and awareness of the insurance scheme and its enrollment procedures were considered as major barriers in the majority of focus groups. Knowledge of hospital costs, absence of risk management alternatives and credibility and trust in the management of the insurance scheme were mentioned as minor barriers in the majority of focus groups.

Table 2-7 Overview of qualitative studies investigating insurance demand

\begin{tabular}{l|l|l}
\hline & Health & Agriculture insurance \\
\hline Financial literacy & $\begin{array}{l}\text { Criel and Waelkens (2003) } \\
\text { De Allegri et al. (2006) } \\
\text { Basaza et al. (2008) } \\
\text { Mathauer et al. (2008) }\end{array}$ & \\
\hline Trust in management/insurer & $\begin{array}{l}\text { De Allegri et al. (2006) } \\
\text { Basaza et al. (2007) } \\
\text { Schneider (2005) }\end{array}$ & Patt et al. 2009 \\
\hline Trust in management of health care & Schneider (2005) & \\
\hline frility & $\begin{array}{l}\text { De Allegri et al. (2006) } \\
\text { Schneider (2005) }\end{array}$ & Patt et al. 2009 \\
\hline Previous bad experiences & $\begin{array}{l}\text { De Allegri et al. (2006) } \\
\text { Basaza et al. (2007) }\end{array}$ & \\
\hline Quality of care & $\begin{array}{l}\text { Criel and Waelkens (2003) } \\
\text { Schneider (2005) }\end{array}$ & \\
\hline Lack of finances & $\begin{array}{l}\text { Criel and Waelkens (2003) } \\
\text { Basaza et al. (2007) }\end{array}$ & \\
\hline Operational difficulties & $\begin{array}{l}\text { Criel and Waelkens (2003) } \\
\text { Basaza et al. (2007) }\end{array}$ & \\
\hline Timing of premium and pay out & $\begin{array}{l}\text { De Allegri et al. (2006) } \\
\text { Mathauer et al. (2007) }\end{array}$ & Patt et al. 2009 \\
\hline Way of collecting & De Allegri et al. (2006) & \\
\hline
\end{tabular}


Based on experiences of researchers with conducting games, workshops and surveys in India, Africa and South America, Patt, Peterson, Carter, Velez, Hess and Suarez (2009) concluded that the timing and cost of the premium, trust of people in the insurance product and the organizations involved in selling and managing are important for understanding potential clients' decision to participate in index-insurance. They explained the importance of trust in the product in terms of the understanding by farmers of the product. They also suggested that it is important to prevent events that reduce trust and that these factors may be more important than the socioeconomic ones in influencing demand.

\subsection{Conclusion and discussion}

Expected utility theory was taken as the starting point for this chapter as it is typically used for understanding decision-making about insurance. Critical assumptions underlying the application of expected utility theory were compared with the actual situation in microinsurance markets. This has led to the identification of the following factors potentially influencing insurance demand: price, subsidies and discounts, insured risk and the risk situation of the household, credit-constraints, prevention and informal insurance, marketing characteristics, (risk) preferences, understanding of insurance and social capital, networks and trust. A total of 31 empirical studies on microinsurance demand were compared by making use of the general theoretical framework. Even though Prospect theory and other behavioral explanations were considered, the amount of studies which have investigated their applicability to understanding microinsurance demand is not enough to draw any definite conclusions. This also implies that behavioral explanations should be further investigated.

Many studies investigating microinsurance demand compare adoption versus nonadoption. This makes sense when households have been properly informed and are thus aware of the costs and benefits of insurance; and when they have had time to make a decision. However, as soon as adopters are compared to non-adopters, while these nonadopters can be households without insurance awareness knowledge or households which are still in a persuasion stage, before they actually make their decision, it is difficult to attribute observed effects to the applicable predictors.

From the analysis of the studies it can be concluded that the higher the price, the lower the take up of insurance, with additional transaction costs such as transportation adding to this effect. Subsidies and discounts have a positive effect on take up. However even when the net policy price is below the actuarially fair premium of the insurance, the take up is low. These findings suggest that factors other than price are likely to play an important role in demand for insurance.

An additional finding is that higher risk households are more likely to take up microinsurance, which suggests that there is potential for adverse selection and moral hazard.

Another finding is that risk aversion leads to less, instead of more, take up of insurance, which contradicts predictions by expected utility theory. Despite several studies 
investigating this effect, few studies have investigated the framing of gains and losses as an explanation. If insured is evaluated in the loss frame, this may also explain the observed effects of risk aversion. This should be further investigated.

Uncertainty about the insurance is suggested as a confounding factor leading to the supposed inverse effect of risk aversion. Factors which are suggested to reduce uncertainty are financial literacy, education and trust. However, the evidence for their effects is not consistent. Some studies find a positive effect of both financial literacy and insurance education on take up, while others find no significant effect. Several explanations for this may exist. Firstly, it can be hypothesized that financial education, even though it may increase knowledge about insurance, does not influence the purchase decision. It may also imply that financial education provided is not adequate. Finally, it may be that, when experimentally investigated, the time lag between financial education and actual decision-making has been too short for households to come to a decision. The effect of financial literacy and education on insurance demand thus has to be further investigated.

Trust is another explanatory factor suggested to reduce uncertainty. Trust recurs in many qualitative studies as a factor determining microinsurance take up: trust in the insurance, trust in the insurer, trust in the management of the scheme, trust in legal and regulatory frameworks. Trust was investigated in two quantitative studies and both studies concluded that an increase in trust lead to an increase in microinsurance take up. However, both studies conceptualized trust in a different manner. The exact role of trust and its potential to reduce uncertainty and explain the inverse effect of risk aversion should be further investigated.

Social capital and network characteristics were observed to have a significant effect on insurance uptake but there is no clarity about the mechanisms through which these effects occur, especially because they may influence different stages in the decisionmaking process. It is suggested that social capital and networks may contribute to increasing understanding of insurance, and in this way reduce uncertainty. Social capital and networks may influence beliefs about microinsurance, leading to behavioral explanations for insurance demand. The effect of social capital and networks may also be an indication of issues of scale or collective action or of the prevalence of informal risk-sharing and therefore reduce the need for microinsurance. And finally, as was suggested above, social capital and networks may be an indication of trust which may play a role in reducing the uncertainty about the insurance transaction.

Many of the studies on the demand for microinsurance use expected utility theory for understanding microinsurance demand as it is a theory about decision-making under uncertainty. However, in these studies, many factors are included which may not (only) influence the decision-making but influence the stages preceding the decision where potential clients gain awareness knowledge or are in a persuasion phase. Other theories such as diffusion theory may be appropriate to try to understand these phases before the decision to take up or reject microinsurance. In particular, social capital and network variables may affect these different stages in different ways. In experimental studies that investigate the actual decision, this may be of less importance, but even here, when insurance is explained, the time lag between learning and decision making may be too short and thus also affect the decision. Untangling the different mechanisms in the 
different stages to get to the final take up or rejection decision is thus a recommendation for future research.

A better understanding of the mechanisms behind the effect of certain social or contextual factors is needed here. Is there an access effect, a learning effect, a trust effect, are reference points influenced? Answering these requires a much better understanding of not only factors but also the mechanisms through which insurance demand arises.

In the next chapter one of these suggestions for future research will be further investigated, namely that of trust in the insurance transaction, created through knowing peers in local networks which have experienced a claim payment. 


\section{Chapter 3}

\section{The trusted neighbour effect: Peer experience and demand for microinsurance ${ }^{1}$}

\subsection{Introduction}

Microinsurance is an innovation aimed at assisting vulnerable people in developing countries in managing risks, such as natural disasters. The correlated nature of natural disasters such as floods, typhoons and droughts, implies that risk management through traditional social security mechanisms and local risk pooling is often insufficient. This is further exacerbated by low capacity of many developing country states to provide widespread protection. This inability to deal with risks reduces a society's capacity to accumulate, innovate and develop (Fafchamps, 2003: 59). Structural failure in adequately managing risks may have enormous impacts and may lead to structural poverty that persists over generations (Hulme and Shepherd, 2003). Microinsurance has the potential to reduce the vulnerability of the poor to natural hazards in developing countries by offering an additional risk transfer mechanism, in the form of insurance, which is accessible to the poor (Linnerooth-Bayern and Mechler, 2006; Barnett, Barett and Skees, 2008; Warner, Ranger, Surminski, Arnold, Linnerooth-Bayer, MichelKerjan, Kovacs and Herweijer, 2007 and Suarez, Linnerooth-Bayer and Mechler, 2007).

However, even if microinsurance is supplied, the level of demand for microinsurance in developing countries is low in comparison to expected demand based on expected utility theory. Furthermore, an increasing number of empirical studies investigating microinsurance demand in developing countries find that risk aversion leads to less, instead of more, take up of microinsurance (Giné et. al., 2008; Cole et al., 2010; Ito and Kono, 2010; Clarke and Kalani, 2011; Dercon, Gunning and Zeitlin, 2011). This also contradicts predictions from expected utility theory, namely that demand for insurance is higher for risk averse individuals who use insurance to avoid the risk of loss (e.g. Arrow, 1963, 1965; Pratt, 1964; Mossin, 1968; Feldstein, 1973; Schlesinger and Doherty, 1985). Karlan and Morduch (2009) suggest that the most likely explanation for this inverse effect of risk aversion is that there is uncertainty about the microinsurance product itself. Trust is suggested in several studies as a mechanism to overcome this uncertainty (for example Giné et al., 2008 and Cole et al. 2010). Several qualitative studies also observe that trust has a positive effect on microinsurance take up and lack of trust has a negative effect (Schneider, 2005; De Allegri, Sanon, Bridges and Sauerborn, 2006; Basaza, Criel, Van der Stuyft, 2008; Patt, Peterson, Carter, Velez,

\footnotetext{
${ }^{1}$ This chapter is based on a paper which has been submitted.

I am grateful for comments from Glenn Harrison, Richard Philips, Daniel Clarke, Susan Steiner, Tobias Lechtenfeld and Francis Mulangu.
} 
Hess and Suarez, 2009). However, only a few studies (Cai, Chen, Fang, Zhou, 2010, Dercon, Gunning and Zeitlin, 2011) have empirically tested the role of trust; and as was explained in Chapter 2, the manner in which they have conceptualized and investigated trust is different.

In the light of the reported effects of inadequate risk management and the need for understanding the role of insurance as an additional risk management option, it is also necessary to understand why demand for microinsurance exists and how it may increase. The ultimate objective is to understand how policy and business can contribute to the uptake of microinsurance.

\subsection{Results from previous studies}

This section will start with an analysis of qualitative and quantitative studies which suggest that trust influences microinsurance demand (Schneider, 2005; De Allegri et al., 2006; Basaza et al., 2007; Giné et al., 2008; Patt, Peterson, Carter, Velez, Hess and Suarez, 2009; Cole et al., 2010; Bendig and Arun, 2011). This is followed by a discussion of findings from quantitative studies on trust as a determinant for microinsurance demand (Cai et al., 2010 and Dercon et al., 2011).

Schneider (2005) conducted a series of 24 focus groups with micro-health insurance (MHI) members, non-members, MHI managers and health care providers as participants. Discussion points focused on design and organisation, information campaigns and participation in MHI. She found that trust in the management of the insurance scheme, trust in the professional competence of health care providers and trust in legal and control mechanisms influence enrolment. De Allegri et al. (2006) found, through in-depth interviews and focus groups that scepticism about the insurance and previous bad experiences with similar collective arrangements are explanatory factors for demand. Basaza et al. (2008) performed a comparative case study evaluation of two community health insurances. They point to a series of not mutually exclusive explanations for low take up of these insurances both with respect to demand and supply issues. Their suggestion is that community involvement and lack of trust in the management of the scheme explain low insurance uptake. Giné et al. (2008) hypothesized that low trust in the insurance vendor will lead to lower take up of insurance. Based on discussions of experiences of researchers with conducting games, workshops and surveys in India, Africa and South America Patt et al. (2009) suggest that trust of people in the insurance product, and in the organizations involved in selling and managing it, is important for understanding the peoples' decision to participate in index insurance. Cole et al. (2010) suggest that trust in the local branch organization that provides the insurance is important, but they also hint that religious cues associated with the marketing of the insurance are related to trust. Bendig and Arun (2011) did not include trust in their regression analysis but suggest, after having observed large differences between communities studied, that demand is positively influenced if the insurance advisor responsible for sales and distribution of the insurance is from the same social background as potential clients. 
Cai, Chen, Fang and Zhou (2010) tested a model that assesses the impact of a government subsidized sow insurance on farmers' production behavior in China. Different subsidized incentive schemes, varying the degree of subsidization, are randomized across villages. Cai et al. (2010) explain that the local Chinese government has often shown not to be trustworthy. Therefore they used the effect of a snowstorm and consequent payouts of the insurance company as a proxy for increased trust. Controlling for the number of sows and the number of sow deaths they showed that the number of insured sows in the next season has increased. Another test for the effect of trust was done by using higher participation levels in government-sponsored insurance programs in the past as proxy for trust. They showed that this indeed positively affects the take up of insurance. Cai et al. (2010) also suggest other explanations for the significant effect of their proxies, such as awareness and risk aversion, which they don't further investigate.

Dercon et al. (2011) explored the effect of risk preferences and trust on the demand for health insurance and find that demand decreases in measured risk aversion and increases in measured trust. Trust was measured through an experimental design in which players were assigned two roles, Sender or Receiver. Both received a similar endowment. The Sender could decide to send part of the endowment to the Receiver. In this case the amount was tripled. The Receiver could then decide to keep all of the endowment or return a certain amount to the Sender. The Receiver in their games was always the group leader of the group through which the health insurance was distributed. The Sender behavior of the respondents was used as proxy for their perceptions of the credibility of the insurer. Dercon et al. (2011) found that low trust (versus high) had a negative effect on take up of the insurance and this was especially strong when interacted with the price.

The above studies suggest that increases in trust are positively related to microinsurance take up. They also show that many different types and interpretations of trust are studied, or that trust is operationalized in different manners. In the qualitative studies trust in the insurance, the insurance provider, trust in legal and control mechanisms, trust in the management of the scheme and trust created through social similarity are mentioned. The two quantitative empirical studies operationalize trust in a different way. Cai et al. (2010) used proxies for trust based on assumptions about mechanisms which increase trust. Dercon et al. (2011) experimentally assessed levels of trust through a game in which the 'potential' trusted party is the group leader of the group through which the insurance was distributed.

\subsection{The trusted neighbour effect in insurance transactions}

This section will start by defining, in terms of an insurance transaction, what trust actually does. It continues by exploring different mechanisms for building trust and will suggest, based on theory about trust-building, one mechanism which is likely to play an important role in building trust in microinsurance: knowing peers with claims.

Contrary to developed countries, experiences with insurance in developing countries are often lacking or are characterized by opportunistic behaviour of insurers, either because 
of lack of solvability or because of bad intentions. It was also suggested that the decision to take up insurance itself may be considered risky by low-income households because the insurance purchase implies a risk of loss if the claim is not paid (Doherty and Schlesinger, 1990; Karlan and Morduch, 2009; Clarke and Kalani, 2011 and Dercon et al., 2011). The purchase of insurance is an economic transaction between (at least) two individuals or entities (following Gambetta, 1988). In principle this economic transaction is uncertain because of fear of opportunistic behaviour on both sides. However, because the insurance premium is paid by the client to the insurer in advance to potential claims, the risk of opportunistic behaviour is balanced towards the side of the client. This makes an insurance transaction different from, for example, a credit transaction where the risk of opportunistic behaviour is more balanced toward the entity supplying a loan.

Doherty and Schlesinger (1990) present a model to understand insurance demand when there is a probability that the insurer will not give a pay-out when the insured experiences a loss. Doherty and Schlesinger (1990) call this contractual nonperformance. As was explained in Chapter 2 with indemnified insurance and certainty that the insurer is going to pay-out, there are two states of the world. One in which there is loss and one in which there is no loss. The loss for the insured is zero or L with probability of loss $p$ and (1-p). If there is a probability that the insurer will not pay-out there are in principle two states of the world added with probabilities (1-q) and $q$. Following Doherty and Schlesinger (1990), from the insured's perspective there are three states as it is assumed that only the situation where there is loss and no pay-out is of interest ${ }^{2}$. In addition it is assumed that the individual's initial wealth is $\mathrm{A}$, the insurance premium is $\mathrm{P}$ and pay out $\mathrm{T}$. As Clarke (2011) also explains the worst outcome for the insured is that he pays the premium but ends up with no pay-out because of the insurer's non-performance. The demand for the insurance will depend on the premiums $\mathrm{P}$, the loss probability $\mathrm{p}$ and information on the risk of contractual nonperformance (1-q). It is assumed that insurer and insured know $\mathrm{p}$.

The household will buy level of coverage $\alpha$ based on maximization of expected utility: $\mathrm{EU}=\mathrm{pqU}(\mathrm{A}-\alpha \mathrm{P}-\mathrm{L})+\mathrm{p}(1-\mathrm{q}) \mathrm{U}(\mathrm{A}-\alpha \mathrm{P}-\mathrm{L}+\alpha \mathrm{T})+(1-\mathrm{p}) \mathrm{U}(\mathrm{A}-\alpha \mathrm{P})$

As Dercon et al. (2011: 5) explain $q$ is a subjective probability. This subjective probability of contractual non-performance $q$ can be reduced by reducing the uncertainty about the new product or uncertainty about consequences of stakes involved (Shoemaker and Shoaf, 1975). The uncertainty can be reduced if there is enough trust in the insurer. So the definition of trust used in this study, following Gambetta (1988: 217), is: "The subjective probability $(1-q)$ that actor A will perform an action that is beneficial or at least not detrimental to actor B is high enough for actor B to consider engaging in some form of cooperation with him". In terms of a microinsurance purchase Dercon et al. (2011) define this as the credibility of the insurer, which is the potential policyholder's perceived likelihood that a claim would be paid in the event of a loss. Following Gambetta (1988), trust in the insurance transaction is now defined as: The

\footnotetext{
${ }^{2}$ As Clarke (2011) explains this is different for index insurance because there is a probability that there is no loss but the insured does receive a pay-out.
} 
subjective probability that the insurer will pay the claim if the low income household experiences the insured loss, is high enough for the low income household to engage in the insurance contract and pay the insurance premium.

Zucker (1986) proposes two different ways of trust-building related to uncertainty in transactions between actors: formal and informal trust building. Formal trust-building is tied to formal institutions such as professions, bureaucracies, government policies and financial intermediaries; and often plays a role at national or company levels. The role of this formal trust-building is also confirmed by Bauer (1961), and Altman and Taylor (1974) and specifically for microinsurance, it is suggested by Cole et al. (2010:19).

According to Zucker (1986) informal trust occurs through recurrent transactions or social similarity, often locally or through social networks. Formal and informal trust can substitute each other (Granovetter, 1974, Zucker, 1986, Shapiro, 1987, Coleman, 1990). Zucker (1986) also explains that informal trust is often disrupted in more modern societies and substituted by formal trust building institutions. Guiso, Sapienza and Zingales (2008) and Okonknow and Paulson (2008) also confirm the importance of these formal institutions in explaining participation in financial transactions by studying financial transactions of immigrants in the United States. They measure the strength of formal institutions by indicators such as quality of the bureaucracy, rule of law, ethnic harmony and 'protection from expropriation' which measures the extent to which individual property rights are protected. They find that individuals are more reluctant to participate in financial transactions if they have emigrated from countries where formal institutions are weaker.

Particularly for poor households in rural areas in developing countries, which often either don't have insurance experiences or have been exposed to bankruptcy of insurance companies in the past, these formal trust-building institutions are often not accessible, reliable or existent. This implies that those households have to rely on informal trust-building mechanisms such as previous experiences and trust built through social similarity of peers in social networks (Zucker, 1986, Rogers 2003). Recurrent transactions are not very frequent with microinsurance because claims are rare. Rogers (2003: 233) refers to innovations such as microinsurance as 'preventive innovations'. Preventive innovations are innovations which an individual adopts to lower the probability of some unwanted event in the future. The rate of adoption for such innovations is often low because the benefits are uncertain to the adopter. Rogers (2003) suggests that, because with such innovations individuals can not experience the innovation themselves, trials by peers can substitute these individual trials and reduce uncertainty about the innovation. As was discussed in Chapter 2, Cai (2012) has also found a positive and strong effect of peers with claims on the uptake of insurance. However, even though she explains it as a way to reduce uncertainty, the mechanism through which the uncertainty is reduced (understanding of the insurance versus increased trust in the insurance) is not further analysed.

Therefore this study investigates if knowing peers with claims is indeed the vehicle through which trust in the demand for microinsurance is expressed.

It is therefore hypothesized that: 
Trust, built through knowing peers with claims, positively affects the demand for microinsurance.

It is assumed that, especially because formal trust-building institutions are less accessible, reliable or existent in developing countries, informal trust-building through knowing peers with claims plays an important role in explaining microinsurance demand. Because formal trust-building institutions are often effective at the macro or national level and informal trust-building such as knowing peers with claims is localized, this may also explain the high relative importance of social capital and network variables and location dummies in comparison to other variables in the statistical models explaining demand (See also: Schneider and Diop, 2004; Chankova, Sulzback and Diop, 2008; Giné, Townsend and Vickery, 2008; Ito and Kono, 2010, Giesbert, Steiner and Bendig, 2011).

To scrutinize the role of knowing peers with claims in explaining demand, a model is tested in which informal trust-building factors are the key variables and previous experiences of risk, perceptions of risk, risk aversion, household characteristics and previous experiences with other insurances are also included.

\subsection{Domain, research design and measurement}

\subsubsection{Domain}

This paper is part of a broader study on demand and impact of natural calamity insurance in the Philippines. The product under study is PAID plan (Packaged Assistance in case of Disasters), which has a natural calamity re-housing insurance as a component of the product. The product is promoted as insurance for low-income households against the financial consequences of damage to residential houses because of typhoons. PAID plan is offered to low income households by the Centre for Agriculture and Rural Development Mutually Reinforcing Institutions (CARD MRI). CARD MRI consists of a variety of institutions such as an MFI, NGO and a training institute which all serve the purpose of financial inclusion of the Filipino population. They have 175 branches throughout the country and provincial offices in 44 out of 80 provinces. As of June 2011 they were providing microcredit to almost 1.5 million clients and insurance to more than 6.5 million people. This illustrates their outreach in a country of almost 100 million people. Their product PAID plan is a 3-in-1 non-life microinsurance product that provides natural calamity house reconstruction start-up capital, personal accident and funeral benefits to policy holders. PAID Plan costs Php 250 (USD 5.70 based on exchange rate of $1 \mathrm{Php}=0.0228$ USD, 7 January 2011) per year. The probability of a typhoon differs for different villages. For the sampled villages, typhoons which cause damage occur on average once in 12 years and the average pay-out received is $2129 \mathrm{Php}$. With this pay-out and the typhoon frequency this would imply that a premium of $177 \mathrm{Php}(2129 \mathrm{Php} / 12)$ per year would be an actuarially fair premium. In this case approximately 30 Per cent of the actual premium is used for loading costs and the risk premium for the insurer.

The product was introduced in 2007 and was developed bottom-up, based on an expressed need from CARD's clients for natural disaster insurance in the aftermath of 
the eruption of Mayon volcano and the simultaneous occurrence of typhoon Durian in November 2006. At the time of data collection, marketing of PAID plan was done through branch managers. In principle everybody is eligible for this insurance and the marketing is done both to non-CARD and CARD members. In practice CARD members receive more exposure to marketing messages during their meetings and all people with the insurance are CARD members. At the time of data collection, June to October 2009, PAID plan was the only natural calamity re-housing insurance that was supplied in the Philippines. In October 2009, CARD reported that there were around 58,000 households who had bought the insurance, and approximately 1500 claims had been paid. By mid2010 this had risen to some 130,000 households and approximately 3000 households had received a PAID plan pay-out.

PAID plan qualifies as a micro insurance product because it targets the poorest sections of the Philippine society (Category D, average family income 2979 USD per year and E, average family income 814 USD per year according to the Philippine National Statistics Office 2009). The yearly premium for PAID plan is less than 1 per cent of the average yearly family income of the poorest section of the Philippine society.

For license year 2009-2010 the insurance commission of the Philippines granted 120 insurance companies a license for conducting insurance business in the country. In total there were 1,138 informal complaints/claims filed with the Insurance Commission. A total of 2,434 hearings/conferences were held which resulted in the settlement/ termination of 859 claims as well as the resolution of 14 cases. During the pilot study it already became evident that news stories about bankruptcy of insurance companies or fraudulent insurance practices are known to most in the sample.

\subsubsection{Research design}

In order to study demand it is necessary to have a sufficient number of insured households in the sample. Because of the rare occurrence of insured households at the time of data collection the following procedure was executed. First, three typhoon-prone provinces in three culturally different regions were selected: Pangasinan, Bicol and Samar/Leyte. These different regions were chosen because key-informants supposed the influence of sociocultural factors on the uptake of the insurance. In practice, no differences between the culturally different regions were observed. Second, 11 villages were selected where the insurance had been introduced more than six months ago to make sure that households had had sufficient time in which they could have heard about the insurance and could have taken a decision to purchase the insurance. The product was introduced in a phased marketing strategy since the beginning of 2008. At the time only few villages met the above-mentioned conditions. In addition to that, villages were selected with high and low typhoon risk (sea-shore versus in-land locations) to understand the influence of previous experiences of risk and risk perceptions on the uptake of the insurance. In the third step, in each village, the selection of households was done through a disproportionally stratified random sample. All insured households $(n=64)$ and a random selection of non-insured households $(n=136)$ were personally interviewed. Among the group of households without the insurance there may be households which have decided not to take the insurance, households which have not 
made a decision yet (see also Coleman, Katz, Menzel, 1966 and Hassinger, 1959) and households which have not heard about the insurance. As was discussed in Chapter 2, to understand demand for microinsurance, it is important to distinguish between factors which influence access or having heard about the innovation and factors which directly influence the decision-making process (which assumes that people are aware of the innovation, Rogers, 2003). If knowing peers with claims represents trust, its effect has to be observed both on the total sample and on a sub-sample of households that definately have knowledge of the particular insurance. CARD members have knowledge about the particular insurance because they are informed during regular meetings organized by CARD. Therefore the effect of knowing peers with claims is tested on the total sample and the sub-sample of CARD-members. This provides a test for the effect of access and awareness knowledge especially because, in this study, it is not possible to include a variable which represents prior knowledge as it is impossible to distinguish between knowledge of the insurance which was present before take-up, and knowledge that was gained after the take-up. Checks for the effect of knowledge about the insurance are performed in Section 5.7.

The manner of selecting cases on the dependent variable, the so-called case-control design, is common in epidemiology where the occurrence of certain viruses is rare. In the sample all reachable insured households (approximately 30 per cent of the sample) and a random selection of uninsured households (approximately 70 per cent of the sample) in the 11 villages are represented. In the population the ratio is 5:95. The sample is not weighted to represent the population ratios for three reasons. First, the purpose of this study is to explain which factors influence demand and not to describe or predict demand in the population. This would be less relevant in the case of microinsurance since it is still in the initial stages of the product growth cycle. Second, the interest of this study is the population of uninsured, with the purpose of understanding which factors can contribute to them taking up the insurance. Finally, weighing leads to less power of the model and only leads to better results if the ratio of treated (insured) versus untreated (uninsured) in the population is extremely rare (1:400) (Scott and Wild, 2001). The only implication this has for the analysis is that location dummies cannot be included in the regression analysis. Because it is hypothesized that informal trust-building factors account for (part of) the observed effect of location dummies in other studies, a check for the effect of location dummies is performed in Section 5.7.

In advance of the personal interviews, focus groups were organized in the villages. Focus groups are group discussions to explore a specific set of issues in which the group interaction is central (Merton et al., 1956; Merton, 1987; Morgan, 1988; Kitzinger, 1994). The focus groups consisted of 6-20 participants and were held with the aim of making an event history of important community events such as floods, typhoons, pests, and major social trends such as housing, use of consumption smoothing activities, wealth and outmigration. Participants were selected to represent a sample of younger, older, wealthier and poorer households of the village. 


\subsubsection{Measurement}

In this section operationalization of the variables included in the model is described. The dependent variable in this study, having microinsurance, was measured by asking households if they were insured through PAID plan and if they could demonstrate the part of the sales slip which indicates this. Knowing peers with claims was measured by asking households if they knew people in their personal network who had experienced a claim; and who that was and how they knew that person. This name was doublechecked with a list of people in the region who had received a claim. This was done to distinguish people who knew peers with claims personally, from people who had heard about someone with a claim.

Measures for household characteristics, risk perception, risk aversion, previous experiences with risk and previous experiences with insurances are also included in the model to assess the importance of knowing peers with claims in relation to the other potential explanatory factors of demand.

Perceptions of risks were measured largely according to the participatory risk mapping method applied by Smith, Barrett and Box (2000: 1947) in East Africa. Their method is a two-stage system of ordinal rankings where respondents first identify risks and then rank the risks they identified. For the first step they rely on an open-ended question: "...so as not to influence the cited risks, how many risks were mentioned or in what order of importance." In the pilot phase of this study it was discovered that this actually had the opposite effect as some people were not willing to talk about certain risks and had no problem talking about others. However, this did not mean that the risks they didn't want to talk about were not worrying to them. This was especially found to be the case with risks relating to death or burial. In addition it was found that respondents were not, on the spot, able to recall all their worries. Therefore the following approach was taken. In the focus groups participants were asked about risks that households in the community are exposed to. These risks were written on cards in the local language. In the focus groups a variety of 21 risks was identified. The number and type of risks per village varied a little. In the second step, individual respondents of the community samples, not overlapping with the focus group participants, participated in a risk ranking exercise in the course of the interview. This risk ranking exercise consisted of three steps. In the first step respondents were asked to look at all the cards with risks that applied to their community, and were asked if they had any other worries, concerns or anxieties. This was never the case. In a second step they were asked to select all the cards with the risks that they felt were applicable to their situation. The number of risks that respondents selected varied from 1 to 14 (mean $=10$, sd $=2.5$ ). In only one occasion it was necessary to complement the written words with icons depicting the risk because of the respondent's insufficient command of reading. In the third step they were first asked to select the card with the risk that they worried about most. This card was put aside. Then they were asked to select, out of the remaining cards, the risk that they worried about most. This was repeated until a complete rank order was reached. For the purpose of this study only the perception of risk of typhoons and the perception of risk of accidents were included. For the purpose of analysing demand, the risk perception was made operational as 'worrying' when the risk was mentioned as the most or second 
most important in the rank order of risks. The accident risk is added here because the typhoon re-housing insurance also included an accident cover.

Previous experiences with typhoon risk and accident risk were therefore also included in the model. This was measured by asking respondents for all risks applicable to their community, if they personally or within their close social proximity, had experienced the risk. To test the robustness of this variable, they were also asked the number of years since they had experienced this risk and this was tested in the model as an alternative measurement of previous experience of risk.

As mentioned in Chapter 2, risk aversion appears to be negatively related to the take-up of microinsurance. Dercon et al. (2011), investigating both the impact of risk aversion and trust on microinsurance uptake, suggest that the credibility of the insurer is nonmonotonic in risk aversion, initially decreasing with risk aversion and then increasing, which may explain why those with either low or high risk aversion do not take-up microinsurance and those with medium risk aversion do.

Risk aversion was not directly measured in the interviews. Therefore a proxy for risk aversion is included based on wealth, under the assumption that risk aversion is inversely related to wealth (Gollier, 2001; Guiso and Paiella, 2001; Clarke, 2011). Further, it is assumed that the large majority of the population will behave as risk averse (Holt and Laury, 2002). To assess the relative wealth of the households in the community a wealth ranking was conducted. Wealth ranking provides an empirically valid technique to stratify households by socioeconomic status (Scoones, 1995 and Adams, Evans, Mohammed and Farnsworth, 1997). The wealth ranking technique was chosen because income and expenditure, as periodic income flows, do not adequately reflect vulnerability or poverty (Carter and May, 2001; Sahn and Stifel, 2003 and Barrett and McPeak, 2006). The nature of subsistence of the low-income households in this study further complicates the use of an income or expenditure measure. The wealth ranking was conducted in focus groups in which participants were asked to picture very poor households in their community and discuss the assets that they typically have and don't have. This was also done for poor and moderately poor households. After this they were asked to divide the households in their community into these three categories. Between the sampled communities hardly any differences were found in the assets owned by households in the different categories. To check for the potential nonmonotonic effect a dummy was constructed for both high and low risk aversion. In addition, interaction effects were tested with these dummies and knowing peers with claims, the indicator for trust.

Chapter 2 also addressed preventive activities, informal insurance and external government support as explanations for insurance demand. In the focus groups, building houses on poles and tying the roof, were advanced as preventive activities to reduce the damage caused by typhoons. Households were therefore asked if they undertake these activities as preparation for typhoons.

Access to informal insurance was discussed in the focus groups. Remittances and savings were advanced as forms of informal insurance used by households in the communities. In the survey access and reception of remittances were investigated by asking households if they had family members living abroad or in urban centres of the 
Philippines (Manila, Cebu) from which they received regular payments or relied on in case of large expenditures such as hospital visits, funerals or natural disasters. Government support in the form of distribution of galvanized iron after typhoons was also mentioned in the focus groups. Households were therefore asked if they had received government support after typhoons in the past.

Because the insurance is a re-housing insurance, controls for the structure of the house were also included. During the focus groups three types of house structures were distinguished: bad, medium and good house structures. Bad house structures are houses that are completely built from natural materials such as bamboo and wood. These houses require a relatively low investment, but are easily damaged. Medium house structures are house structures of which at least part of the house is built from concrete. Good house structures are those which are predominantly built from concrete and thus require a much larger investment, but are less easily damaged.

Understanding of insurance was cited in several studies as a method for reducing uncertainty about the insurance (Giné et al., 2008; Cole et al., 2010; Gaurav et al., 2011; Clarke and Kalani, 2011; Dercon et al., 2011 and Heenkenda, 2011). As previously discussed, this study was unable to test for the understanding of PAID plan because it was not possible to establish if households gained their knowledge about the insurance before or after the decision to take up the insurance. Therefore households were asked if they had another insurance, had had another insurance in the past, or had experienced a claim from an insurance in the past. These variables were combined into one variable: other insurance experiences.

The following other control variables were also included in the model: production and consumption assets, house structure, number of children, education and age in years.

To measure the uptake of the insurance the following regression equation is estimated:

$$
\text { Insurance }_{i=\alpha} \alpha+\beta_{1} \text { Knows peers with claims }_{i}+X^{\prime}{ }_{i} \mu+\varepsilon_{i}
$$

where 'Insurance ${ }_{i}$ ' is an indicator of if respondent ' $i$ ' has taken up the insurance. 'Knows peers with claims' is an indicator if respondent ' $i$ ' indicates that they knew a peer with a claim before the purchase of the insurance. The vector of control variables, $\mathrm{X}$, includes perception of typhoon and accident risk, experience of typhoon and accident in the past, risk aversion, other insurance experiences, wealth rank, bad and good house structure, a step interaction between house structure and wealth rank, receives remittances, number of children, education and age in years.

\subsection{Sample characteristics}

Table 3-1 presents the proportions, means and standard deviations of determinants of PAID plan insurance uptake tested on all households (second column, N=200), households with PAID plan (third column, $\mathrm{N}=64$ )) versus households without PAID plan and CARD members with PAID plan (fourth column, $\mathrm{N}=64$ ) versus CARD 
members without PAID plan. As was mentioned in Section 3.4.1, the sample size in the last two columns is both $\mathrm{N}=64$ because all households with PAID plan are CARD members.

From the focus group discussions it can be concluded that there is generally low trust in insurance and insurers. Either because of bankruptcy of insurers, or because of fraudulent practices in which premiums were collected but the insurer never existed or never paid claims. From the focus groups it can also be concluded that the households which had experiences with CARD generally had a high level of trust in CARD. None of the respondents in the survey reported distrust in CARD, or know of instances in which they were perceived, or others perceived, CARD to be unreliable.

Statistics on the characteristics of the sample are given in Table 3-1. The average respondent was 42 years old and had started or completed secondary education. In the total sample, 90 households had a medium house structure and 66 households had a bad house structure. The other 44 households had a house built of concrete. In the total sample the average number of children is three. The average is a bit higher for households with the insurance.

In the total sample 75 per cent of households had experienced a typhoon while only 18 per cent had experienced an accident in their household. More than 99 per cent of the households in the sample express some worry about typhoons (not represented in the table). 34 per cent of the households in the sample rank typhoons as the most worrying risk to which they are exposed. With an average of 10 risks reported per household, typhoon risk is overall ranked highest. This does indicate that the insurance covers a risk that is relevant to the population.

23 per cent of the households in the total sample build their house on poles and 33 per cent tie the roof of their house in advance of a typhoon. It should be noted that the percentage of households which tie their roof is significantly higher for households with PAID plan and for CARD members. This seems to contradict the prediction in Chapter 2 that households with a higher risk situation are more likely to take up microinsurance. However, this may be explained by the fact that CARD, in their awareness raising activities, addresses the importance of tying the roof.

29 per cent of households in the sample are highly risk averse. This percentage is slightly lower for CARD members with PAID plan. 22 Per cent of households exhibit low risk aversion of which this percentage is higher for households with PAID plan and households which are CARD members with PAID plan. This confirms the findings discussed in Chapter 2 that households which are less risk averse are more likely to take up microinsurance.

Out of the households with PAID plan 85 per cent owns consumption assets. This is significantly higher for households with PAID plan and CARD members with PAID plan. Also CARD members with PAID plan have significantly higher production assets. This may be explained by the fact that CARD members have a microcredit loan. 
With respect to insurance experiences in the past and with other insurances (insurance experience) there is no significant difference between insured and uninsured. 73 per cent of the households in the sample had, at the time of data collection, experience with insurance. Most commonly this was found to be Philhealth, a subsidized government health insurance, which is free for households below the poverty line. Households with previous or current formal jobs often participated in some other kind of social insurance program.

Table 3-1 Proportions, means and standard deviations of determinants of PAID plan insurance uptake, all households, households with PAID plan and CARD member households

\begin{tabular}{|c|c|c|c|}
\hline & $\begin{array}{l}\text { All } \\
\text { households } \\
(\mathrm{N}=200)\end{array}$ & $\begin{array}{l}\text { Households with PAID } \\
\text { plan }(\mathrm{N}=64) \#\end{array}$ & $\begin{array}{l}\text { CARD members } \\
\text { with PAID plan } \\
(\mathrm{N}=64) \# \#\end{array}$ \\
\hline PP (1=yes) & $.32(.47)$ & $.32(47)$ & .51 \\
\hline Previous government support (1=yes) & $.14(.35)$ & $.08(.27)^{* *}$ & $.13(.24)$ \\
\hline Experienced typhoon in past (1=yes) & $.75(.43)$ & $.77(.43)$ & $.79(.41)^{*}$ \\
\hline Experienced accident in past $(1=$ yes $)$ & $.18(.39)$ & $.14(.35)$ & $.18(.39)$ \\
\hline Perception of typhoon risk (high=1) & $.55(.50)$ & $.53(.50)$ & $.53(.50)$ \\
\hline Perception of accident risk (high=1) & $.23(.42)$ & $.22(.42)$ & $.21(.41)$ \\
\hline Savings ( 1 = yes $)$ & $.87(.34)$ & $.92(.27)^{*}$ & $.90(.30)^{*}$ \\
\hline Build house on poles $(1=$ yes $)$ & $.23(.42)$ & $.36(.48)^{* *}$ & $.25(.43)$ \\
\hline Tie roof of house $(1=$ yes $)$ & $.33(.47)$ & $.50(.50)^{* * *}$ & $.39(.49)^{* *}$ \\
\hline Receives remittance ( $1=y e s)$ & $.54(.50)$ & $.56(.50)$ & $.56(.50)$ \\
\hline Bad house structure (1=yes) & $.33(.47)$ & $.33(.47)$ & $.27(.45)^{* *}$ \\
\hline Good house structure (1=yes) & $.21(.40)$ & $.25(.44)$ & $.25(.43)^{*}$ \\
\hline Production assets ${ }^{\&}$ & $1.11(.87)$ & $1.16(.86)$ & $1.21(.43)^{* *}$ \\
\hline Has consumption assets $(1=$ yes $)$ & $.85(.36)$ & $.92(.27)^{* *}$ & $.88(.32)^{*}$ \\
\hline High risk aversion ${ }^{\text {\& }}$ & $.29(.45)$ & $.28(.45)$ & $.28(.45)^{*}$ \\
\hline Low risk aversion \&\& & $.22(.41)$ & $.34(.48)^{* * *}$ & $.24(.43)^{* *}$ \\
\hline Knows peers with claim (1=yes) & $.18(.39)$ & $.33(.47)^{* * *}$ & $.29(.45)^{* * *}$ \\
\hline Has experience with insurance (1=yes) & $.73(.45)$ & $.75(.44)$ & $.72(.45)$ \\
\hline Number of children & $3.02(1.83)$ & $3.37(2.26)^{* *}$ & $3.13(1.97)$ \\
\hline Education \&\&\& & $2.70(1.55)$ & $2.86(1.44)$ & $2.62(1.55)$ \\
\hline Age in years & $41.84(10.2)$ & $42.72(8.77)$ & $43.71(9.43)^{* * *}$ \\
\hline Understands product & $.31(.47)$ & $.68(.47)^{* * *}$ & $.50(.50)^{* * *}$ \\
\hline
\end{tabular}

\# Proportions and means compared of households with PAID-plan to households without PAID-plan, only significance level indicated.

\#\# Proportions and means compared of CARD members with PAID plan to CARD members without PAID plan, only significance level indicated

\& $0=$ no production assets $1=$ medium amount, $2=$ high amount

$\& \&$ Reference category is medium risk aversion

\&\&\& $0=$ primary level, $1=$ primary finished, $2=$ secondary level, $3=$ secondary finished, $4=$ bachelor level, $5=$ higher $* * *$ significant at the 0.01 level, ** Significant at the 0.05 level, * Significant at the 0.1 level 
18 per cent of the total sample knew a peer who had received a claim from PAID plan. In Table 3-1 it can be observed that there is a significant difference, at the 0.01 level, between households with and without PAID plan; and CARD members with and without PAID plan. Out of the households with PAID plan 33 per cent knew a peer who had experienced a claim and among CARD members with PAID plan this was 29 per cent.

Finally, of all the households in the sample 31 per cent understands the insurance while this percentage is 67 per cent for households with PAID plan and 50 per cent for CARD members with PAID plan. As was mentioned above, it is not possible to establish if this knowledge was present before the purchase decision or was actually created by the fact that households had purchased the insurance.

\subsection{Results: Knowing peers with claims and take up of PAID plan}

As explained above, two series of binary logit models are estimated: one on all households (Table 3-2) and one on CARD-members only (Table 3-3). The case control design leads us to apply a cut-off for take up versus no take up. The proportion insured is taken as the cut-off point, which is .32 in Table 3-2 and .4 in Table 3-3. The Hosmer and Lemenshow for both models is not significant which implies that the logit model is a valid model.

Model 1 in Table 3-2 shows the single effect of knowing peers with claims on the uptake. The small changes in the parameters in Models 2 to 6 show the robustness of the parameters. In Model 2 previous experiences with government support; and perceptions and experiences with risk are added. It should be noted that previous experiences with government assistance have a negative effect on take up although its effect is not significant. In Model 3, preventive activities and informal insurance are added. These variables cause an increase in the households correctly predicted to take up insurance from 53 to 67 per cent. Tying the roof and building the house on poles positively affect take up of the insurance; as does having consumption assets. This pattern does not change in Model 4-6. Model 4 adds risk aversion and knowing peers with claims. Knowing peers with claims has a positive and significant effect $(\mathrm{P}<0.01)$ on the uptake of PAID plan. Low risk aversion and high risk aversion (versus medium risk aversion) both have a positive effect on the take up of the insurance but the effect of low risk aversion is higher and significant while that of high risk aversion is not. A stepinteraction between low risk aversion and knowing peers with claims was also modelled and shows a negative sign. In total these variables cause an increase of households correctly predicted from 67 to 71 per cent. Model 5 shows that previous experiences with other insurance are not significant. In the final model, Model 6, the controls are added. The age and number of children positively and significantly affect the uptake of PAID plan. This final model also shows that low risk aversion (versus medium) and knowing peers with claims both have the strongest and positive effect on the take up of PAID plan in comparison to other variables in the model. It is also observed that for households with a relatively low risk aversion and households who know peers with claims 
Table 3-2 A logistic regression analysis of the determinants of PAID plan insurance uptake $(\mathrm{N}=\mathbf{2 0 0})$

\begin{tabular}{|c|c|c|c|c|c|c|}
\hline & Model 1 & Model 2 & Model 3 & Model 4 & Model 5 & Model 6 \\
\hline Constant & $\begin{array}{l}-1.04 \\
(.18)\end{array}$ & $\begin{array}{l}-.695 \\
(.371)\end{array}$ & $\begin{array}{l}-3.998 \\
(.980)\end{array}$ & $\begin{array}{l}-4.105 \\
(1.096)\end{array}$ & $\begin{array}{l}-4.081 \\
(1.169)\end{array}$ & $\begin{array}{l}-6.312 \\
(1.596)\end{array}$ \\
\hline Previous government support ( $1=$ yes) & & $\begin{array}{l}-.977 \\
(.530)^{*}\end{array}$ & $\begin{array}{l}-.582 \\
(.575)\end{array}$ & $\begin{array}{l}-.466 \\
(.659)\end{array}$ & $\begin{array}{l}-.462 \\
(.662)\end{array}$ & $\begin{array}{l}-.464 \\
(.716)\end{array}$ \\
\hline Experienced typhoon in past $(1=y e s)$ & & $\begin{array}{l}.271 \\
(.366)\end{array}$ & $\begin{array}{l}.271 \\
(.402)\end{array}$ & $\begin{array}{l}-.193 \\
(.436)\end{array}$ & $\begin{array}{l}-.195 \\
(.438)\end{array}$ & $\begin{array}{l}-.404 \\
(.470)\end{array}$ \\
\hline Experienced accident in past $(1=$ yes $)$ & & $\begin{array}{l}-.453 \\
(.422)\end{array}$ & $\begin{array}{l}-.419 \\
(.461)\end{array}$ & $\begin{array}{l}-.527 \\
(.495)\end{array}$ & $\begin{array}{l}-.528 \\
(.495)\end{array}$ & $\begin{array}{l}-.493 \\
(.520)\end{array}$ \\
\hline Perception of typhoon risk ( $1=$ high) & & $\begin{array}{l}-.083 \\
(.324)\end{array}$ & $\begin{array}{l}-.111 \\
(.363)\end{array}$ & $\begin{array}{c}-.047 \\
(.388)\end{array}$ & $\begin{array}{l}-.047 \\
(.388)\end{array}$ & $\begin{array}{l}-.144 \\
(.405)\end{array}$ \\
\hline Perception of accident risk ( $1=$ high) & & $\begin{array}{l}-.090 \\
(.384)\end{array}$ & $\begin{array}{l}-.022 \\
(.432)\end{array}$ & $\begin{array}{l}.083 \\
(.458)\end{array}$ & $\begin{array}{l}.081 \\
(.459)\end{array}$ & $\begin{array}{l}.117 \\
(.491)\end{array}$ \\
\hline Savings $(1=$ yes $)$ & & & $\begin{array}{l}.854 \\
(.571)\end{array}$ & $\begin{array}{l}.938 \\
(.663)\end{array}$ & $\begin{array}{l}.933 \\
(.667)\end{array}$ & $\begin{array}{l}.837 \\
(.676)\end{array}$ \\
\hline Build house on poles $(1=$ yes $)$ & & & $\begin{array}{l}1.088 \\
(.478)^{* *}\end{array}$ & $\begin{array}{l}1.014 \\
(.523)^{*}\end{array}$ & $\begin{array}{l}1.013 \\
(.523)^{*}\end{array}$ & $\begin{array}{l}1.172 \\
(.542)^{* *}\end{array}$ \\
\hline Tie roof of house $(1=$ yes $)$ & & & $\begin{array}{l}.947 \\
(.392)^{* *}\end{array}$ & $\begin{array}{l}1.004 \\
(.420)^{* *}\end{array}$ & $\begin{array}{l}1.006 \\
(.421)^{* *}\end{array}$ & $\begin{array}{l}1.077 \\
(.434)\end{array}$ \\
\hline Receives remittance (1=yes) & & & $\begin{array}{l}.194 \\
(.350)\end{array}$ & $\begin{array}{l}-.008 \\
(.387)\end{array}$ & $\begin{array}{l}-.006 \\
(.390)\end{array}$ & $\begin{array}{l}-.065 \\
(.416)\end{array}$ \\
\hline Bad house structure (1=yes) & & & $\begin{array}{l}.114 \\
(.451)\end{array}$ & $\begin{array}{l}-.279 \\
(.622)\end{array}$ & $\begin{array}{l}-.278 \\
(.622)\end{array}$ & $\begin{array}{l}-.137 \\
(.651)\end{array}$ \\
\hline Good house structure (1=yes) & & & $\begin{array}{l}.395 \\
(.439)\end{array}$ & $\begin{array}{l}-.528 \\
(.562)\end{array}$ & $\begin{array}{l}-.527 \\
(.563)\end{array}$ & $\begin{array}{l}-.828 \\
(.607)\end{array}$ \\
\hline Has production assets ${ }^{\&}$ & & & $\begin{array}{l}.170 \\
(.213)\end{array}$ & $\begin{array}{l}-.007 \\
(.245)\end{array}$ & $\begin{array}{l}-.010 \\
(.253)\end{array}$ & $\begin{array}{l}-.093 \\
(.266)\end{array}$ \\
\hline Has consumption assets ( 1 = yes $)$ & & & $\begin{array}{l}1.665 \\
(.610)^{* *}\end{array}$ & $\begin{array}{l}1.681 \\
(.664)^{* *}\end{array}$ & $\begin{array}{l}1.685 \\
(.667)^{* *}\end{array}$ & $\begin{array}{l}1.754 \\
(.696)^{* *}\end{array}$ \\
\hline High risk aversion ${ }^{\& \&}$ & & & & $\begin{array}{l}.516 \\
(.698)\end{array}$ & $\begin{array}{l}.510 \\
(.706)\end{array}$ & $\begin{array}{l}.394 \\
(.734)\end{array}$ \\
\hline Low risk aversion $^{\& \&}$ & & & & $\begin{array}{l}1.950 \\
(.596) * * *\end{array}$ & $\begin{array}{l}1.953 \\
(598)^{* * *}\end{array}$ & $\begin{array}{l}2.405 \\
(.688) * * *\end{array}$ \\
\hline Knows peers with claim (1=yes) & $\begin{array}{l}1.37 \\
(.38)^{* * *}\end{array}$ & & & 1.742 & $\begin{array}{l}1.742 \\
(.540)^{* * *}\end{array}$ & $\begin{array}{l}2.007 \\
(.572)^{* * *}\end{array}$ \\
\hline $\begin{array}{l}\text { Low risk aversion } * \text { knows peers with } \\
\text { claims }\end{array}$ & & & & $\begin{array}{l}(.540) * * * \\
-1.352 \\
(.982)\end{array}$ & $\begin{array}{l}-1.352 \\
(.982) \\
-.025\end{array}$ & $\begin{array}{l}-1.786 \\
(1.030)^{*} \\
-.089\end{array}$ \\
\hline Has experience with insurance (1=yes) & & & & & $(.440)$ & $\begin{array}{l}(.467) \\
.035\end{array}$ \\
\hline${\text { (Number of children })^{2}}^{2}$ & & & & & & $\begin{array}{l}.014)^{* *} \\
.004\end{array}$ \\
\hline$\left(\text { Education }^{\& \& \&}\right)^{2}$ & & & & & & $\begin{array}{l}(.026) \\
.046\end{array}$ \\
\hline Age in years & & & & & & $(.022)^{* *}$ \\
\hline & .09 & .04 & .22 & & .33 & .39 \\
\hline Nagelkerke Pseudo-R square & & & & .33 & & 11.642 \\
\hline Hosmer \&Lemenshow X-square. $\mathrm{df}=8$ & .32 & .53 & .67 & & .71 & .73 \\
\hline $\begin{array}{l}\text { Correctly predicted } \\
-2 \text { Log likelihood }\end{array}$ & 237.61 & 245.167 & $217 . .465$ & $\begin{array}{l}.71 \\
196.749\end{array}$ & 196.746 & 185.375 \\
\hline $\begin{array}{l}\text { The test for the hypothesis (knows peers wit } \\
\text { For correlation underlying this table see App } \\
\text { Cut-off used is } .32 \\
\& 0=\text { no production assets } 1=\text { medium amo } \\
\& \& \text { Reference category is medium risk ave } \\
\& \& \& 0=\text { primary level, } 1=\text { primary finishe } \\
* * * \text { Significant at the } 0.01 \text { level, } * * \text { Signific }\end{array}$ & $\begin{array}{l}\text { aim) is one-s } \\
\text { ix } 3-2 \\
2=\text { high an } \\
=\text { secondary }\end{array}$ & ed. The con & ls are tested & $=$ bachelor & el, $5=$ hig & \\
\hline
\end{tabular}


the combined effect is actually reduced, as shown by the interaction, almost to the effect of each parameter separately.

Experienced a typhoon in the past is positive in Model 2 and 3 and negative in Model 46 . This may be explained by the fact that knowing peers with claims is introduced in Model 4. Knowing peers with claims depends strongly on previous typhoon experiences and this is therefore suggested as an explanation. Having experienced an accident in the past has a consistent non-significant negative effect and perceptions of typhoons has a small, non-significant negative effect. In the final model 73 per cent of households are correctly predicted.

The Models presented in Table 3-3 show approximately the same picture. The effect of tying the roof is not significant when comparing CARD members with insurance to CARD members without the insurance, which suggests indeed that the effect of tying the roof in Table 3-2 can be explained by awareness raising activities by CARD. An interesting difference from the models in Table 3-2 is that high risk aversion (versus medium risk aversion) now has a consistent negative effect on take up while the effect of low risk aversion is stronger, significant and still positive. The interaction effect between low risk aversion and knowing peers with claims is, also here, negative and significant. In the final model 73 per cent of households are correctly predicted.

To check for multicollinearity the correlation matrices were inspected (see Appendix 32 and 3-3). None of the control variables show a strong correlation or is substantially higher than the correlation with the dependent variable. Robustness of the estimates was checked by systematically adding controls and checking for extreme values of standard errors.

\subsection{Discussion}

The trusted neighbour effect measured as knowing peers with claims is, apart from low risk aversion and a step-interaction between these, the most important explanatory factor for the uptake of microinsurance in this study, both for the test on all households as well as for the test on CARD-members. This supports the hypothesis that knowing peers with claims positively affects the demand for microinsurance.

The fact that the effect of knowing peers with claims holds when tested on both samples suggests that knowing peers with claims is not only an effect of access and awareness knowledge of PAID plan but also influences the decision-making process. It should be added here that out of the 64 households with the insurance, more than 50 per cent report that the main reason for adopting the insurance was the experience of a peer with a claim.

The positive correlation of high risk aversion with take up when estimated on the full sample and the negative correlation on the sample of CARD members may be caused by the fact that among the sample of all households there are people who do not have awareness knowledge about the insurance, or have not become members of CARD. As was mentioned, of the CARD sample it is certain that all households have been informed about the insurance. The observed negative effect of high risk aversion and the 
Table 3-3 A logistic regression analysis of the determinants of PAID plan insurance among CARD members $(\mathrm{N}=126)$

\begin{tabular}{|c|c|c|c|c|c|c|}
\hline & Model 1 & Model 2 & Model 3 & Model 4 & Model 5 & Model 6 \\
\hline Constant & $\begin{array}{l}-.089 \\
(.211)\end{array}$ & $\begin{array}{l}.352 \\
(.460)\end{array}$ & $\begin{array}{l}-3.245 \\
(1.220)\end{array}$ & $\begin{array}{l}-2.726 \\
(1.397)\end{array}$ & $\begin{array}{l}-2.757 \\
(1.486)\end{array}$ & $\begin{array}{l}-5.305 \\
(2.107)\end{array}$ \\
\hline Previous government support ( $1=y e s)$ & & $\begin{array}{l}-1.026 \\
(.589)^{*}\end{array}$ & $\begin{array}{l}-.420 \\
(.659)\end{array}$ & $\begin{array}{l}-1.426 \\
(.946)\end{array}$ & $\begin{array}{l}-1.437 \\
(.964)\end{array}$ & $\begin{array}{l}-1.445 \\
(1.015)\end{array}$ \\
\hline Experienced typhoon in past (1=yes) & & $\begin{array}{l}-.177 \\
(.459)\end{array}$ & $\begin{array}{l}-.312 \\
(.528)\end{array}$ & $\begin{array}{l}-.801 \\
(.602)\end{array}$ & $\begin{array}{l}-.795 \\
(.608)\end{array}$ & $\begin{array}{l}-1.036 \\
(.659)\end{array}$ \\
\hline Experienced accident in past $(1=$ yes $)$ & & $\begin{array}{l}-.578 \\
(.482)\end{array}$ & $\begin{array}{l}-.451 \\
(.525)\end{array}$ & $\begin{array}{l}-.581 \\
(.552)\end{array}$ & $\begin{array}{l}-.582 \\
(.552)\end{array}$ & $\begin{array}{c}-.543 \\
(.578)\end{array}$ \\
\hline Perception of typhoon risk(1=high) & & $\begin{array}{l}.083 \\
(.381)\end{array}$ & $\begin{array}{l}-.126 \\
(.427)\end{array}$ & $\begin{array}{l}-.075 \\
(.473)\end{array}$ & $\begin{array}{l}-.074 \\
(.473)\end{array}$ & $\begin{array}{l}-.200 \\
(.500)\end{array}$ \\
\hline Perception of accident risk( $1=$ high $)$ & & $\begin{array}{l}.060 \\
(.458)\end{array}$ & $\begin{array}{l}-.017 \\
(.526)\end{array}$ & $\begin{array}{l}-.017 \\
(.563)\end{array}$ & $\begin{array}{l}-.015 \\
(.564)\end{array}$ & $\begin{array}{l}.277 \\
(.599)\end{array}$ \\
\hline Savings $(1=$ yes $)$ & & & $\begin{array}{l}.793 \\
(.702)\end{array}$ & $\begin{array}{l}.653 \\
(.832)\end{array}$ & $\begin{array}{l}.659 \\
(.837)\end{array}$ & $\begin{array}{l}.588 \\
(.874)\end{array}$ \\
\hline Build house on poles $(1=$ yes $)$ & & & $\begin{array}{l}1.382 \\
(.640)^{* *}\end{array}$ & $\begin{array}{l}1.545 \\
(.690)^{* *}\end{array}$ & $\begin{array}{l}1.545 \\
(.690)^{* *}\end{array}$ & $\begin{array}{l}1.783 \\
(.735)^{* *}\end{array}$ \\
\hline Tie roof of house $(1=$ yes $)$ & & & $\begin{array}{l}.938 \\
(.497)^{*}\end{array}$ & $\begin{array}{l}.857 \\
(.525)\end{array}$ & $\begin{array}{l}.854 \\
(.528)\end{array}$ & $\begin{array}{l}.852 \\
(.543)\end{array}$ \\
\hline Receives remittance (1=yes) & & & $\begin{array}{l}.234 \\
(.435)\end{array}$ & $\begin{array}{l}-.015 \\
(.487)\end{array}$ & $\begin{array}{l}-.019 \\
(.493)\end{array}$ & $\begin{array}{l}-.042 \\
(.517)\end{array}$ \\
\hline Bad house structure (1=yes) & & & $\begin{array}{l}.765 \\
(.553)\end{array}$ & $\begin{array}{l}.737 \\
(.766)\end{array}$ & $\begin{array}{l}.726 \\
(.789)\end{array}$ & $\begin{array}{l}.874 \\
(.812)\end{array}$ \\
\hline Good house structure (1=yes) & & & $\begin{array}{l}.338 \\
(.504)\end{array}$ & $\begin{array}{l}-1.068 \\
(.742)\end{array}$ & $\begin{array}{l}-1.069 \\
(.742)\end{array}$ & $\begin{array}{l}-1.277 \\
(.806)\end{array}$ \\
\hline Has production assets ${ }^{\&}$ & & & $\begin{array}{l}.054 \\
(.265)\end{array}$ & $\begin{array}{l}-.388 \\
(.316)\end{array}$ & $\begin{array}{l}-.384 \\
(.323)\end{array}$ & $\begin{array}{l}-.491 \\
(.348)\end{array}$ \\
\hline Has consumption assets $(1=$ yes $)$ & & & $\begin{array}{l}2.132 \\
(.808) * * * *\end{array}$ & $\begin{array}{l}2.342 \\
(.917) * *\end{array}$ & $\begin{array}{l}2.339 \\
(.919) * *\end{array}$ & $\begin{array}{l}2.486 \\
(.978) * *\end{array}$ \\
\hline High risk aversion ${ }^{\& \&}$ & & & & $\begin{array}{l}-.112 \\
(.871)\end{array}$ & $\begin{array}{l}-.096 \\
(.914)\end{array}$ & $\begin{array}{l}-.059 \\
(.951)\end{array}$ \\
\hline Low risk aversion ${ }^{\& \&}$ & & & & $\begin{array}{l}3.391 \\
(.963)^{* * *}\end{array}$ & $\begin{array}{l}3.389 \\
(.964)^{* * *}\end{array}$ & $\begin{array}{l}3.774 \\
(1.092) * * *\end{array}$ \\
\hline Knows peers with claim (1=yes) & $\begin{array}{l}.425 \\
(.399)\end{array}$ & & & $\begin{array}{l}.783 \\
(.604)^{*}\end{array}$ & $\begin{array}{l}.782 \\
(.604)^{*}\end{array}$ & $\begin{array}{l}1.062 \\
(.647)^{* *}\end{array}$ \\
\hline Low risk aversion $*$ knows peers with claims & & & & $\begin{array}{l}-2.184 \\
(1.180)^{*}\end{array}$ & $\begin{array}{l}-2.185 \\
(1.181)^{* *}\end{array}$ & $\begin{array}{l}-2.692 \\
(1.259)^{* *}\end{array}$ \\
\hline Has experience with insurance ( $1=$ yes) & & & & & $\begin{array}{l}.033 \\
(.541)\end{array}$ & $\begin{array}{l}.014 \\
(.559)\end{array}$ \\
\hline$(\text { Number of children })^{2}$ & & & & & & $\begin{array}{l}.032 \\
(.016) *\end{array}$ \\
\hline$\left(\text { Education }{ }^{\& \& \&}\right)^{2}$ & & & & & & $\begin{array}{l}.033 \\
(.033)\end{array}$ \\
\hline Age in years & & & & & & $\begin{array}{l}.043 \\
(.029)\end{array}$ \\
\hline Nagelkerke Pseudo-R square & .01 & .06 & .24 & .38 & .38 & .43 \\
\hline Hosmer \&Lemenshow X-square. $\mathrm{df}=8$ & & & & & & 3.503 \\
\hline Correctly predicted & 54.0 & 59.5 & 69.0 & 72.2 & 72.2 & 77.8 \\
\hline -2 Log likelihood & 173.491 & 169.153 & 149.342 & 131.810 & 131.806 & 126.004 \\
\hline $\begin{array}{l}\text { The test for the hypothesis (knows peers with } \\
\text { For correlation underlying this table see App } \\
\text { Cut-off used is } . \\
\& 0=\text { no production assets } 1=\text { medium amou } \\
\& \& \text { Reference category is medium risk aver } \\
\& \& \& 0=\text { primary level, } 1=\text { primary finished } \\
* * * \text { Significant at the } 0.01 \text { level } * * \text { Significa }\end{array}$ & $\begin{array}{l}\text { ix } 3-3 \\
2=\text { high a } \\
n \\
=\text { seconda } \\
\text { th the } 0.05\end{array}$ & $\begin{array}{l}\text { ided. The } \\
\text { level, } 3=\end{array}$ & ntrols are tes & $\begin{array}{l}\text { two-sided. } \\
\text { d, } 4 \text { = bach }\end{array}$ & vel, $5=$ & \\
\hline
\end{tabular}


positive effect of low risk aversion (versus medium) fit with previous findings about a negative effect of increases in risk aversion of microinsurance take up. The interaction between risk aversion and knowing peers with claims, the indicator for trust, shows that especially for low risk averse households, the effect of knowing peers with claims is much lower than for households with higher risk aversion. The negative effect of this interaction versus the positive effect of both low risk aversion and knowing peers with claims suggest that trust can substitute for risk aversion.

The slightly smaller effect of knowing peers with claims on the CARD sample versus the sample with all households, suggests that knowing peers with claims is correlated to CARD-membership. This was mentioned above and is not surprising considering the weekly meetings of CARD and the manner in which these groups come about, which is through building on local institutions. This can either imply that households know peers with claims through their CARD network, or that they know peers with claims and this leads them to become members of CARD. Both effects may also occur at the same time. Households were asked about the self-reported reasons for taking up the insurance.

As was suggested, the strong effect of location dummies may be an indication of trust as it relies on informal networks, especially when knowing peers with claims is the mechanism through which it is built. To investigate this an ANOVA for the effect of location variables (11) on knowing peers with claims was performed and there is indeed a significant effect $(\mathrm{p}<0.01$; df 160,$10 ; \mathrm{F}$ 6.57). If knowing peers with claims is an indicator for trust in the insurance, and positively affects demand, then this implies that there should be a significant difference between villages which have experienced a typhoon in the years that the insurance was offered and villages which have not. This is especially so because the village typhoon experiences are location specific. The effect of recent typhoon experiences in villages on the prevalence of claims, prevalence of households which know peers with claims and on uptake of the insurance in the villages was checked. The effect of recent typhoon experiences on the prevalence of claims is significant (Somers' d 0.08; $\mathrm{p}<0.05$ ), on knowing peers with claims (Somers' d 0.34; $\mathrm{p}<0.01$ ), and on the uptake of the insurance (Somers' $\mathrm{d} 0.12 ; \mathrm{p}<0.1$, Note here that the objective is not to explain demand but an effect of recent typhoon experiences). In Table 3-2 and 3-3 it was already demonstrated that past experiences with typhoons do not significantly influence the uptake of the insurance by low income households, suggesting that the effect of recent typhoon experiences on take up of the insurance is not caused by increased fear of typhoons after their occurrence but more likely because of an increase in the likelihood of knowing peers with claims.

Another interpretation for the effect of knowing peers with claims is that it may not be an indicator for trust building, but rather an indicator for the marketing procedures in which peers with claims are used in marketing. Partly this interpretation was overcome by asking specifically if the 'peers with claims' were in the personal networks of households and if they did not only hear about them through CARD staff. Moreover, if the marketing effect would have caused knowing peers with claims than there should be an effect of branches on knowing peers with claims since the marketing is done at the branch level. The 11 locations in the sample represented five branches. For each branch there were two or more locations. In two branches there were typhoon experiences after 
the introduction of the insurance. In these branches the variation in knowing peers with claims between locations within branches is high $\left(X^{2} 0.08\right.$, df 2 and $X^{2} 0.01$, df 1 respectively). This supports the interpretation that knowing peers with claims is not an indication of marketing activities but an indication of informal trust-building.

As mentioned in the literature discussion, the observed effect of knowing peers with claims on demand may also be caused by its influence on access or 'having heard' about the insurance in addition to its effect on building trust in the insurance transaction. In this study it was impossible to measure at what stage of the take up process knowing peers with claims plays a role. It may be that because households experience a claim, other households become exposed to information about the insurance and consequently enter the process of making a decision to take up or reject the insurance. This was controlled for by testing both on the total sample as well as on the sub-sample of CARD members who had already heard about the insurance.

Another test to check that knowing peers with claims leads to increased understanding of the insurance was done by estimating a model in which knowledge of PAID plan is the dependent variable and knowing peers with claims is the explanatory variable. The Model is presented in Table 3-4 in Appendix 3-1. Model 1 shows that knowing peers with claims does not have a significant effect on understanding of the insurance.

\subsection{Conclusion}

This study provides evidence that knowing peers with claims has a strong positive effect on the take up of microinsurance. The extensive tests for alternative explanations confirm that knowing peers with claims builds trust and therefore reduces uncertainty about the insurance transaction. Alternative explanations investigated are marketing effects, effects of the prevalence of typhoons or increased fear of typhoons and understanding of the insurance. The interaction effect with risk aversion also strengthens the interpretation of knowing peers with claims as a trust-building mechanism.

It was suggested that informal trust-building can function as substitution of formal trustbuilding in insurance transactions. This is especially relevant in the case of microinsurance where formal trust-building institutions are often less accessible, reliable or non-existent. The fact that negative experiences, either through insolvency of insurers or fraudulent insurance practices, are common in the Philippines suggests that the reduction of uncertainty about the insurance is indeed a necessity. A problem for scaling up microinsurance is that formal trust-building institutions such as enacted legal and regulatory frameworks create trust ex-ante while in the case of knowing peers with claims the trust building occurs only after the risk and claim payments. This would imply that the demand for microinsurance is likely to increase at a slower rate in developing countries than would be expected in developed countries. The effect of knowing peers with claims can be expected to be strongest in insurance markets characterized by previous fraud or bankruptcy of insurers. The fact that microinsurance is a preventive innovation often with a long time lapse between take up and claim payments further complicates this. In the context of scaling up microinsurance in the 
light of a need for additional risk management, this study can teach us that communication about knowing peers with claims can be an effective marketing strategy. It should be noted here that other studies find that incentives for individuals through peer endorsement may not be a good strategy (Cole et al., 2010). Another way of doing this may be to make claim payments a public activity. In the longer term, creation of formal trust-building institutions which govern insurance transactions such as legal and regulatory frameworks and standard setting bodies are important for increasing demand. For future research it would be interesting to investigate the effect of formal and informal trust-building mechanisms. Chapter 6 proposes a design for a combined lab and framed field experiment.

It should be noted that the importance of knowing peers with claims may be strongest for products of which the take up is still relatively low. As Cole et al. (2010) also suggest, it can be hypothesized that over time the percentage of households knowing peers with claims will increase and therefore general trust in the insurance product will increase. If this is the case, factors other than trust, such as risk aversion, risk perceptions and household characteristics may become more important in later stages. In addition, as was mentioned above, this microinsurance product is affordable for even the lowest sections of the Philippine society. It might be expected that as soon as the product is less affordable, that price plays a bigger role and the effect of knowing peers with claims may become less strong. This study was unable to investigate this because it focused on one product

As suggested in Chapter 2, uncertainty about the insurance product may be reduced by trust in the general concept of insurance, trust in the insurer or trust in the specific insurance product. The effect of knowing peers with claims and the non-significance of having other insurances experiences suggests that, in particular, trust in the specific insurance product is more important than trust in the general concept of insurance. If this is the case then the effect of general financial or insurance literacy and education on increasing demand for a specific insurance product is less certain.

Another result of this study is that the role of trusted neighbours may provide an explanation for strong and significant effects of social capital and network variables and location dummies which are found in many demand studies. Local networks consist of local peers of a household. It is therefore hypothesized that a household's peers which have received a claim are also known to these households because of their local network. Other reasons for the effect of social capital and network variables, in which trust may also play a role, is through its effect on awareness knowledge and understanding the products (as suggested by Cai, 2012). For understanding the most important policy relevant factors it is important to include factors explaining uptake and factors leading to consideration of uptake.

This study was unable, because of general high trust in CARD and thus lack of variability in 'trust in the insurer', to separately include this variable in the model. Even though a strong effect of knowing peers with claims is observed in this study it can be hypothesized that, assuming that different trust-building mechanisms substitute each other, the effect of knowing peers with claims will only become stronger if trust in the 
insurer is lower than the trust in CARD in this study. If trust in the institution involved in a transaction is lacking or low, other types of trust such as those created by trusted neighbours, will play a more dominant role. 


\section{Chapter 4}

\section{Understanding and measuring the impact of microinsurance on poverty reduction ${ }^{1}$.}

\subsection{Introduction}

This Chapter will focus on the impact of microinsurance on poverty reduction. The first section will provide an overview of theories about the impact of microinsurance and the second section will focus on research designs for measuring microinsurance impact. Chapter 2 and 3 focused on understanding why low-income households demand microinsurance under the assumption that households which are risk averse and attempt to maximize their utility are willing to take up microinsurance to smooth consumption and protect themselves against the risk of loss. Empirical studies investigating the demand for microinsurance were analyzed to understand factors which lead to less than optimal demand, under the assumption that if these factors and the mechanisms through which they affect microinsurance demand are known then they can be corrected for to improve insurance demand. These individual maximization decisions are assumed to lead to an optimal distribution of welfare for a population (Arrow, 1964, Feldstein, 1973, Karlan and Morduch, 2009). This Chapter will start by discussing this consumption smoothing effect of microinsurance but will also discuss theories about ex-ante effects of microinsurance on changes in behavior and impacts outside of single period utility maximizing decisions. Furthermore, the distributional impact of microinsurance is considered in terms of poverty and inequality. In Section 4.3 current evidence for microinsurance impacts on poverty reduction will be discussed with a specific focus on the type of questions that these studies have addressed. Section 4.4 will start with a discussion about the role of Randomized Controlled Trials (RCTs) in the evaluation of development interventions, because this has implications for the evaluation of microinsurance impact. Following this, four validities: internal validity, external validity, construct validity and statistical conclusion validity and their implications for certain microinsurance impact questions are presented. Section 4.5 will then raise some suggestions for different research designs for studying microinsurance impact. Section 4.6 will present the conclusions.

\footnotetext{
${ }^{1}$ This chapter has been submitted for publication.
} 


\subsection{Theories about microinsurance impact}

This section will provide an overview of relevant questions to consider when evaluating the impact of microinsurance in terms of poverty reduction. It will consider ex-ante and ex-post effects and consequences for future productivity and economic growth. In addition it will consider distributional impacts of microinsurance.

Imagine risk. Risk is uncertainty about future states of the world. When the risk materializes with a negative consequence there is a shock. Shocks lead to fluctuations in consumption due to uncertain expenses. Insurance spreads the risk of loss over different states of the world. Uncertain expenses to which households are exposed prevent households from maximizing utility and therefore, if they are risk averse and rational decision makers, which attempt to maximize utility, they are assumed to be willing to insure in order to smooth consumption (Arrow, 1964, Mossin, 1968, Feldstein, 1973). In this way, and as was discussed in Chapter 2, microinsurance smooth consumption by providing a pay-out ex-post. However, uninsured risk has welfare implications which go well beyond consequences for short-term consumption; and is a cause of persistent poverty (Townsend, 1994, Dercon, 2004, Townsend, 2004, Carter, Little, Mogues, Negatu, 2007. To understand this, existing strategies that households use to cope with shocks are first discussed.

Poor households often rely on a diversity of strategies such as risk diversification, borrowing, using savings, depleting production assets and informal risk-sharing between households (informal insurance). Such activities, like insurance, also have the objective of smoothing income and smoothing consumption (Alderman and Paxson, 1994 and Morduch, 1995). Income smoothing or so-called ex-ante efforts to reduce risk exposure refer to activities that households undertake to protect themselves from adverse income shocks before they occur, such as combining farm and non-farm income activities or diversifying crops and production techniques (Alderman and Paxson, 1994). Consumption smoothing activities occur after shocks with the objective of protecting variability of the consumption pattern and consist of risk coping and informal risk-sharing arrangements. (Morduch, 1995, Barnett, Barrett and Skees, 2008).

These existing strategies used by households may also have negative consequences for future strategies (Morduch, 1995). First of all, the anticipation of becoming poorer after a shock leads households to take extreme income smoothing activities to reduce future risk such as investing in low-risk, low return activities (Alderman and Paxson, 1994, Morduch, 1995). These costs can be especially strong for low-income households which are risk averse because they are reluctant to invest in economic opportunities (Morduch, 1995). The result is that growth remains at a relatively low level (Dercon and Krishnan, 2003; Cai, Chen, Fang, and Zhou, 2009). Secondly, shocks can easily set people back because shocks may lead households to use consumption smoothing activities, which imply depletion of important assets, ranging from taking children out of school to save expenses for school fees and selling production assets such as cattle which is needed for future income. 
As was discussed in Chapter 2, microinsurance by providing a pay-out ex-post may smooth consumption. However, the impact of shocks may have welfare effects which go well-beyond consequences for a single current utility maximizing decision (Morduch, 1995, Dercon and Hoddinott, 2004). This implies that microinsurance as an alternative to costly consumption smoothing activities, may reduce the likelihood that households have to deplete important assets which are needed for future strategies. However, in the same way, microinsurance can crowd-out existing strategies which are not costly. Furthermore, microinsurance, by providing security ex-ante, may lead to a choice for higher-risk, higher-return strategies.

Research shows that the level of consumption smoothing which poor households achieve when dealing with idiosyncratic shocks by employing the consumption smoothing activities which are available to them are already no sufficient to allocate risk within communities or provide permanent income over time (Alderman and Paxson, 1994; Townsend, 1994; Fafchamps and Lund, 2003; Kazianga and Udry, 2006). Idiosyncratic shocks are shocks that are specific to a household and uncorrelated to shocks that other households experience such as breaking a leg or getting a heart attack. However, since natural hazards are correlated and households are assumed to be risk averse, this would imply that there is need for a complementary mechanism for coping with uncertain expenses because households are not fully insured. In this case microinsurance will lead to increases in welfare, if risk is better insured. However, as was mentioned above, microinsurance does not necessarily only have a complementary role to existing consumption smoothing activities, but these existing activities may also be substituted by microinsurance. If microinsurance was actuarially fair and would fully substitute existing consumption smoothing activities, there would not be a change in the level of insurance achieved; and there would not be changes in expected utility in terms of the single utility maximizing decision. However, there may be effects for future income or future productivity if important productive assets don't have to be depleted or if insurance creates a higher level of security ex-ante than the consumption smoothing activities do. These effects may be especially strong for low-income households. Dercon and Hoddinott (2004) show that especially the lowest income households may have to resort to the most harmful consumption smoothing activities in terms of persistent poverty such as taking children out of school or selling production assets, simply because they do not have access to less harmful strategies such as using savings or relying on informal risk-sharing networks.

\subsubsection{Demand and impact}

The above discussion focused on potential short- and long-term welfare impacts of microinsurance. It is assumed that, under certain conditions, if individuals completely insure this will lead to utility maximization. These maximization decisions will, in turn, lead to an optimal distribution of welfare for a population and thus have impact on welfare at the macro-economic level (Arrow, 1964; Feldstein, 1973; Karlan and Morduch, 2009. However, in terms of poverty and inequality the distributional impact of microinsurance should be considered. There is ample evidence that existing welfare distributions may have consequences for the impacts of financial services on certain (groups of) households. For example, Greenwood and 
Jovanovic (1990) show that high-income households are better positioned to take advantage of financial services than low-income households are; and that this initially leads to increases in inequality. However, Banerjee and Newman (1993) show, if insurance products are well-designed through for example deductibles and co-insurance to correct for relatively low demand for certain groups of households, that these distributional effects can be corrected for. Therefore, to understand the impact of microinsurance it is essential to investigate existing demand for microinsurance by (groups of) households and the impact it has on (groups of) households.

Chapter 2 has suggested potential factors which may lead to less than optimal insurance demand and it was investigated how they influence existing demand for microinsurance. These factors may also have consequences for the distributional impact of microinsurance. The following examples will suggest potential distributional impacts of microinsurance based on the factors identified in Chapter 2 and the theories about impact above. It is however important to realize that these are simply examples of potential impacts and do not provide a complete overview. The intention is to illustrate the importance, in terms of poverty reduction, of linking factors which may lead to less than optimal insurance demand, to potential impact of microinsurance on households with certain characteristics.

An example explained above is that the impact of low-risk and low-return income smoothing activities may be especially strong for risk averse households because they are also less likely to invest in economic opportunities. Microinsurance has the potential to stimulate investments in higher-risk, higher-return activities, which is especially needed for risk averse households. However, evidence suggests that especially risk averse households are also less likely to take up microinsurance (Giné et al, 2008; Cole et al., 2010; Clarke and Kalani, 2011). Even if potential impacts of microinsurance are high, expected demand for this particular group is especially low, which may imply relatively low impact of microinsurance on poverty reduction for this group.

Another factor that may lead to distributional effects of insurance demand is credit constraints. Credit constrained households are already less likely to invest in economic opportunities because of lack of credit for investment. If these credit constraints also lead to less take up of microinsurance, then the impacts of microinsurance may be relatively low for this group.

Trust may especially impact the ex-ante effect of insurance which is assumed to arise from an increased feeling of security (Dercon et al., 2008). Especially for households with low trust in the insurer, even if they have insurance, they may not feel secure that the insurance is going to pay-out. In this case the ex-ante effect of the insurance for households with low trust may be especially low.

Another reason to consider distributional impacts is because social capital and networks appear to have a strong effect on insurance uptake (Jowett, 2003; Cai, 2012). There is no conclusive evidence about the mechanisms leading to these observed effects. As mentioned in Chapter 2, they may affect access to the insurance, understanding of the insurance or they may influence subjective beliefs or lead to collective action or scale effects. Especially because social networks are also 
important for informal insurance it is important to understand why these effects arise and if they influence the impact of the insurance. For example, it can be imagined that a household with a strong social network is more likely to get access to microinsurance. If certain households are excluded from these networks the impact of microinsurance may be especially low for these particular households. These effects may be even stronger if the exclusion from these networks also prevents these households from accessing informal risk sharing opportunities. These households may then be left especially vulnerable to shocks.

\subsection{Current evidence of the impact of microinsurance}

Some studies on the impact of microinsurance have already been conducted and published and many others are underway ${ }^{2}$. This section will focus on the questions that the currently published studies have addressed; it will not attempt to provide an overview of available evidence on microinsurance impacts. Appendix 4-1 presents two tables, one for agriculture and one for health insurance, which list peer-reviewed published microinsurance impact studies according to the questions they have addressed. These tables have been adapted by combining the outcomes of two recent systematic reviews of microinsurance impact studies: Radermacher, McGowan and Dercon (2012) and Magnoni and Zimmerman (2011). From these tables it can be concluded that most studies on the impact of microinsurance have studied health microinsurance and few have focused on agriculture insurance. Impacts of other microinsurances have not been investigated in peer-reviewed studies. The impact indicators that were included in these reviews are:

- Increases in investment

- Protection of assets

- Consumption smoothing

- Reduced savings

- Utilization of health care

- Quality of health services

- Improved health outcomes

- Increased access to education

- $\quad$ Reduced borrowing

- $\quad$ Reduced out-of-pocket (OOP) expenditures

Studies on the impact of health microinsurance have mostly focused on utilization of health care and OOP payments for health care. Utilization of health care is commonly studied by comparing the use of out-patient and in-patient health care among insured and uninsured (for example Criel et al., 1999; Gnawali et al., 2009 Rao et al., 2009, Dror et al., 2009). The overall conclusion from these studies is that insured are more likely to use health care than uninsured. However, Radermacher et al. (2012) report that some of the studies show that low-income households are less often insured which raises questions about the impact of health insurance on these groups. In addition, many of these studies conduct an observational study without

\footnotetext{
${ }^{2}$ See for an overview of ongoing microinsurance impact evaluations: www.microinsurancenetwork.org/workinggroup/impact/stocktaking.php on 12 June 2012
} 
controlling for endogeneity and self-selection (for example Franco et al., 2008; Rao et al., 2009; Dror et al., 2009). Finally, the most commonly measured impacts of health insurance on OOP payments and utilization of health care have the potential to contribute to poverty reduction but on their own they are hardly evidence of a contribution to poverty reduction.

With respect to OOP payments, results are mixed. Wagstaff and Pradhan (2005) conclude that a Vietnamese health insurance reduces households' OOP expenditure for health. Chankova, Sulzbach and Diop (2008) found that health insurance reduces OOP expenditure for inpatient care. Jütting (2004) found reduced OOP expenditures for poor people who are members of community-based health insurance schemes. However, other studies did not find such results. Wagstaff (2007) and Wagstaff, Lindelow, Gao, Ling and Qian (2007) found no impact of insurance on OOP expenditures and Chankova et al. (2008) found that health insurance does not reduce OOP expenditure for outpatient care.

Wagstaff et al. (2007) and Chankova et al. (2008) may provide an explanation for these findings. Chankova et al. (2008) suggested that differences in impact of outpatient and in-patient care on OOP expenditures are caused by the benefit package and availability of co-payments. Wagstaff et al. (2007) suggested that OOP expenditures are not reduced because health care is sought more often by people who are insured, health care provided by the health care facility is more expensive since the insurance has been introduced and not all health care costs are always fully covered by the insurance pay-out.

Aggarwal (2010), and Hamid, Roberts and Mosley (2010b) have investigated the impact of health insurance on health outcomes. Aggarwal (2010), using propensity score matching techniques, investigated the effect of health insurance on posttreatment work ability, income lost during illness, days lost during illness, and the overall satisfaction level from treatment. While there are some positive effects observed for the higher income groups on indicators such as income loss, better postsurgery life, lower monetary loss, and fewer requirements for post-surgery, this is not consistent among all income groups. Hamid, Roberts and Mosley (2010b), through estimating a structural equation and reduced form equation, found that health insurance positively affects household income, stability of income, ownership of non-land assets and probability of being above or below the poverty line.

Protection of assets is investigated by Aggarwal (2010) and she found a positive effect of the insurance on reduced borrowing and sales of assets for the lowest income group which does not hold for the higher income groups.

Studies which have investigated ex-ante effects of microinsurance on investments are conducted by Cai et al. (2010), Giné and Yang (2009) and Karlan, Kusoati, McMillan and Udry (2011). Cai et al. (2010) found, through a randomized natural field experiment, that farmers with formal insurance have a higher tendency to raise sows than farmers without the insurance. Giné and Yang (2009), through a randomized field experiment, investigated the effect of insurance which was offered in combination with a loan on the take up of the loan. The loan was intended for financing of new crop technologies. They found that take up of the insured loan is significantly lower than take up of the uninsured loan. It is suggested that this is 
caused by the fact that the loan had already a limited liability clause in case of inability of farmers to repay. Karlan et al. (2011), through a randomized experiment, investigated the effect of a crop price indemnification which repays 50 per cent of the loan if crop prices fall below a certain threshold. They found a significant effect of the insurance on chemical use but not on other investments. In their discussion they suggested that either an existing loan forgiveness policy had been in place, or that crop price may not have been the most urgent risk to the farmers in the study. In a framed field experiment Hill and Viceiza (2010) also investigated the effect of a rainfall index insurance on fertilizer purchases and found a positive effect which is also strongly affected by previous realizations of weather in their field experiments.

This overview of some studies on microinsurance impact, although not a complete review, shows first of all that most studies have investigated health care utilization and OOP expenditure. These indicators do not provide a direct link to poverty reduction. Aggarwal (2010) in her study even showed that utilization does not imply improved health outcomes. OOP expenditure is a direct effect of the insurance payout and may be an indication of consumption smoothing but may also represent the frequency of usage of health care services (Wagstaff et al., 2007). Many of the health care utilization studies have considered the utilization by different groups of households. Few studies have been done on ex-ante impacts, consumption smoothing and economic impacts outside of the single period setting. The existing evidence on ex-ante impacts of agriculture microinsurance shows a mixed picture and ex-post impacts have hardly been investigated. Impacts of other insurances, such as natural disaster insurance, is still lacking. Another conclusion is that few studies have performed randomized evaluations of impacts. Some studies have used propensity score matching and reduced form equations but many have not controlled for selfselection and endogeneity (Radermacher et al., 2012). Finally, in the explanation of findings many studies refer to the particular context in which the insurance is introduced or specific design characteristics of the product as explanation of their findings. This stresses the importance of an understanding of factors which influence demand when studying impact.

\subsection{Valid research designs}

After relevant questions to understand microinsurance impact have been presented in Section 4.2 and current evidence has been presented in Section 4.3, this section will discuss research design for measuring the impact of interventions. It will start by a discussion of the advantages and disadvantages of the so-called 'gold standard' in rigorous research design: the RCT. This is done because its label 'gold standard' has implications for evaluations of microinsurance impact. This is followed by a discussion of four validities that should be considered in a research design: internal, external, construct and statistical conclusion validity.

The impact of interventions can be studied in a variety of ways. Plenty of literature exists about measuring the impact of interventions (Campbell, 1957; Campbell and Stanley, 1963; Rosenbaum and Rubin, 1983; Casley and Lury, 1982; Bemelmans- 
Videc et al., 1998; Baker, 2000, Shadisch, Cook and Campbell, 2002; Ravallion, 2009; Van der Knaap, Leeuw, Bogaerts and Nijssen, 2008). Designs, specifically those with randomized control trials (RCTs) in which subjects are randomly assigned to experimental and control groups, are viewed by large parts of the academic community as the 'gold standard' in rigorous research design. The random assignment in RCTs is applied because it is assumed that this has the effect that confounding factors will be randomly distributed over experimental and control groups. Therefore, in the estimated models, their effects will appear in the error terms and have no effect on the size of the estimated parameters, thus resulting in an average effect of the intervention. The attention for RCTs in impact evaluation in developing countries has significantly increased over the last years, in part because of increasing interest in the impact of microcredit (loans) on poverty reduction (Khander, 1998, 2005; Karlan, 2001; Goldberg, 2005; Duflo and Kremer, 2005; Hermes and Lensink, 2007; Banerjee and Duflo, 2009; Karlan and Zinman, 2010). The observed impact of microcredit on entrepreneurial success in certain studies was often mistakenly attributed to microcredit (Pitt and Khandker, 1998, versus Roodman and Morduch, 2009). Where initially entrepreneurial success was attributed to microcredit, randomized assignment of selected respondents led to the realization that this was not the case. Through further investigation it was established that the previously observed impact in observational studies could actually be partly attributed to the entrepreneurial attitude affecting positively both the uptake of microcredit and entrepreneurial success: a typical example of omitted variable bias. The recognition of RCTs as a technique of assignment which solves attribution problems has paved the way for their use in experiments evaluating microinsurance impact.

A potential advantage of randomized evaluation of development interventions is that it can prevent omitted-variable bias in assessing the average effect of an intervention on a specific impact indicator. Some academics claim that the practical evaluation of development interventions can also be motivated as a move away from theoretical and policy debates about the way out of poverty and practically evaluate development interventions (Banerjee and Duflo, 2011). Harrison (2011: 627) confirms that among some development economists, randomization is motivated by the fact that there is less need for theory: “...one of the claimed advantages of randomization is that the evaluation of policies can be 'hands off', in the sense that there is less need for maintained structural assumptions from economic theory or econometrics".

One of the potential negative consequences of practically evaluating poverty impacts of development interventions, without maintaining theory, is that it evaluates the impact of an intervention on certain indicators of poverty but not on the whole array of theoretically relevant factors. This may lead to the observation of positive and significant effects of treatments on certain poverty indicators while, if those on other indicators are ignored, the impact on poverty is still uncertain.

This discussion is relevant for the discussion of microinsurance impact because microinsurance is a new field and, as we saw in the preceding chapters, the effect of many factors on the demand for microinsurance is not well understood let alone the potential impacts. 
Another issue which is especially relevant because the demand for microinsurance is not well-understood is that RCTs provide information of average effects (see also Harrison, 2011: 637). As we saw in the discussion in Section 4.2 microinsurance may have distributional effects which influence the impact of microinsurance for households with certain characteristics. Understanding these distributional effects is especially important if interaction effects exist, as Dercon et al. (2011) suggest, because this may even change the direction of effects for certain sub-groups.

This discussion shows that the questions to be answered determine the appropriate research designs for assessing impact of an intervention, in this case microinsurance. RCTs offer value because they can assess if observed impacts can be attributed to the intervention and not to some omitted variable. It also shows the importance of theory development about the link between the intervention of microinsurance and poverty reduction. Furthermore, it shows that, especially because microinsurance demand is not well understood, impacts on households with certain characteristics should be further investigated. Therefore, in the following section the four validities which should be considered in a research design are discussed.

\subsubsection{Four validities in microinsurance impact research}

To provide rigorous evidence of the impact of microinsurance on clients, a study must have internal validity, external validity, construct validity and statistical conclusion validity. This section will present examples of these validities in terms of the impact of microinsurance on poverty reduction. Statistical conclusion validity will not be further discussed because it concerns the quantitative techniques to ensure the degree of confidence about the existence of a relationship between intervention and impact variable and the magnitude of change (de Leeuw and Vaessen, 2009: $\mathrm{XV}$ ). For example application of an ordinary least square (OLS) estimation, while the dependent variable is a dichotomy, which is often the case in impact studies, will lead to biased estimates (Harrison, 2011). It thus is specific to an analysis technique chosen and is less relevant in terms of the research design.

Internal validity is: 'The validity of inferences about whether observed covariation between A (the presumed treatment) and B (the presumed outcome) reflects a causal relationship from A to B as those variables were manipulated or measured (Shadish, Cook and Campbell, 2002: 38). Imagine the impact of microinsurance on risk prevention activities. Expected utility predicts that risk averse people are more likely to take up insurance to avoid the risk of loss. An individuals' level of risk aversion may also affect the extent to which they undertake risk prevention activities. It is assumed here that higher levels of risk aversion will lead to an increase in risk prevention activities undertaken. Imagine now a study investigating the impact of health microinsurance take up on OOP payments for health through an observational study. If risk aversion and preventive activities were not included as control variables, it may be concluded that people with microinsurance spend significantly less on OOP payments, which is not an internally valid conclusion. While in fact, part of the observed effect may be explained by the fact that people with microinsurance are more risk averse and, through the mechanisms of increased prevention activities leading to lower expenditure for health care, have lower OOP payments. 
However, as was discussed in Chapter 2, empirical evidence from developing countries is emerging which finds that risk averse people are less likely to take up microinsurance (Cai et al., 2010; Clarke and Kalani, 2011 and Dercon et al. 2011). If indeed risk averse people are less likely to take up insurance this implies that in the same observational study, the effect of microinsurance on reduction of OOP payments would be actually understated because people who are less risk averse take microinsurance and also take less preventive activities and have higher expenditure on health care and thus higher OOP payments. In the observational study this would not have led to problems with internal validity if risk aversion and prevention activities were included as control factors. If they would have been excluded, observed effects would have understated the effect. In a randomized evaluation of microinsurance, risk aversion and preventive activities would have been assumed to have been randomly distributed over the treatment and control group and their effects would have appeared in the error term thus automatically leading to an internally valid conclusion.

External validity is 'the validity of inferences about whether the cause effect relationship holds over variation in persons, settings, treatment variables and measurement variables.' (Shadish, Cook and Campbell, 2002: 38). The importance of external validity for microinsurance impact studies can be illustrated by referring to the distributional impacts of microinsurance. In Section 4.2 factors were identified which may prevent certain groups from getting access to or purchasing microinsurance. In a context of poverty reduction this is especially relevant because microinsurance attempts to reach out to households which are exposed to uninsured risk. Especially those households which are most vulnerable may also be the households that refrain from taking up microinsurance (more risk averse, lower income, leading to less take up of microinsurance). If statements are made about average effects of microinsurance, these may significantly overstate the effect of microinsurance on the intended target group. This may be even worse if interaction effects change the direction of the effect (Dercon et al., 2011).

Construct validity refers to 'Ensuring that the variables measured adequately represent the underlying realities of... ....interventions linked to processes of change' (de Leeuw and Vaessen, 2009: XV). Drawing an internally valid conclusion about the wrong concept will only blur our understanding of impact. For example, a common measure for ex-post welfare effects is 'out-of-pocket payments'. While the amount of OOP payment may be similar for two households, for one household it may come from their savings, another household may have sold a cow. In terms of poverty reduction impact the effect on these households may be different. Therefore, in relation to poverty reduction, OOP payment has low construct validity.

Another example is where measurement of direct welfare effects caused by microinsurance show a positive effect. However, if at the same time microinsurance crowds out other informal insurance mechanisms, then the overall welfare effect may be small or even zero if microinsurance fully substitutes informal insurance. A valid construct would not be direct microinsurance welfare effects but overall welfare effects for formal and informal insurance.

In the validity of a research design as a whole, all these four validities need to be optimized. However, in reality, focusing on one type of validity often implies 
relaxation of other validities; and the manner in which this is done should depend on the question the study attempts to address and the state-of-the-art of the existing theory that is used.

\subsection{Considerations when designing microinsurance impact studies}

This section will start out by describing some choices that have to be made when designing microinsurance impact studies. The second part will discuss advantages and disadvantages of some exemplary research designs for studying microinsurance impact. The first step in developing a research design for studying the impact of microinsurance on clients is to define the study's research questions. As was explained above health care utilization and OOP payments have been mostly investigated while ex-ante effects of microinsurance, ex-post effects outside of the single period setting and effects on different groups and of certain types of insurances are under-researched.

Effectiveness and efficiency of a research design must always be taken into account. In practice, research always requires tradeoffs between the four validities, methodological rigor, contributions to science, policy and practice and feasibility in terms of cost, logistical capability, and time.

An illustration of a difference in trade-off between methodological rigor and feasibility of the study are the ex-post effects of health insurance versus natural disaster insurance. The ex-post effects of insurance can only be observed after the occurrence of the insured event. For example in the case of health insurance, health risk may be experienced by all households, health care is needed on a relatively regular basis and is, most of the time, not a correlated risk, e.g. in one rural community in a developing country in a year it can be expected that health care is needed several times. If this is compared to natural disaster insurance, natural disasters are less frequent, geographically unequally distributed and often correlated to risks experienced by others in the same community. This implies that in one rural community in a developing country a natural disaster may occur only once in ten or 20 years and therefore measuring ex-post impacts through randomized experiments is difficult. In designing an empirical study, the objective of investigating impacts of health insurance on OOP payments allows for much more flexibility than the objective of investigating ex-post disaster impacts.

An example of a trade-off between internal validity and construct validity can be illustrated by referring to the example of crowding-out mentioned above. As was discussed, measuring direct ex-post welfare effects of microinsurance through OOP payments may not capture overall welfare effects because microinsurance may crowd out informal insurance. However, measuring overall welfare effects implies that the impact on informal insurance should be included in the analysis, which will be more complex to measure. While the first example has low construct validity, internal validity will be easier to achieve while for the latter example construct validity is higher but internal validity is lower.

An example of a trade-off between practical and scientific contributions can be illustrated by referring to impact studies on non-mature products. Products in the 
early stages of design and implementation can be expected to undergo many large and small changes that will alter their value to clients. This is especially relevant because, as was mentioned in Chapter 2, demand for microinsurance products is relatively low and not well-understood. For evaluations of such non-mature products, costly and time-intensive rigorous studies can be of scientific interest but are, from a policy and practical perspective, less effective. Products which do not offer value can be expected to have low impact. Time and money may be better spent on research attempting to understand demand, or research combining demand and impact.

\subsubsection{Research designs for studying microinsurance impact}

Experiments are studies in which interventions are deliberately introduced to observe their effects. In randomized control trials (RCTs) first a population is selected from which subjects are sampled. This is followed by a random assignment of the sampled subjects to either experimental or control group conditions. The choice of the population and the method of sampling from this population will play a role in the size of the effect that will be observed. The underlying assumption is that due to randomized assignment, confounding factors will be randomly distributed within the sample and therefore their effects will appear in the error term. Hence, internal validity is assumed to be high for RCTs. However, as was described above, especially because demand for microinsurance is not well understood, this claim of internal validity has to be handled carefully. There may be effects for certain groups which are opposite for other groups and hence demonstrate an effect that is an average effect. This also demonstrates the importance of including theoretically relevant factors as explanatory factors in the analysis, in addition to the intervention. Despite their potential for preventing omitted variable bias, research designs using RCTs are often costly (particularly where sample sizes must be very large) and microinsurance providers interested in studying the impact of their products may find randomization of the insurance treatment (which experiments require) in their potential client market unethical or in conflict with institutional objectives, especially as it may affect their trustworthiness in the field. Even when ethical considerations do not exclude the possibility of an RCT entirely, they limit the effectiveness of its design.

In the case of rare risk events, resource constraints or other limitations, quasiexperiments may be the most appropriate research design. Quasi-experiments are similar to experiments in that they also take a sample from the population and have treatment and control groups but are different because the treatment and control conditions are not randomly assigned. As a result, unknown, omitted factors being part of the control or treatment group may influence the effects of the treatment on the outcome, resulting in biased estimates. Relying on theory and careful sampling of control and treatment subjects is therefore extremely important. This is done through procedures of matching such as propensity score matching (PSM) on single or double differences or through stratified random sampling ${ }^{3}$. These designs suppose prior theoretical knowledge of specific factors leading to take up of the intervention, which can be used as instruments. As was discussed earlier in this Chapter the understanding of microinsurance demand is still low which makes the selection of

\footnotetext{
${ }^{3}$ For a discussion of propensity score matching: Khandker, Koolwal and Samad, 2010: 53 76
} 
instruments difficult. Stratified random sampling of respondents from the population can provide efficient use of the study subjects, and the results can be generalized to the general population by taking the ratios of sample versus population into account. Controls for self-selection and endogeneity are particularly important in quasiexperiments e.g. econometric techniques of Heckmann $(1978,1979)$ or Altonji, Elder and Taber (2000). When these problems are adequately addressed, the study's internal validity comes close to that of an RCT. Harrison (2011: 631) shows, based on Benson and Hartz (2000: 1878) and Concato et al. (2000: 1887) that estimates of treatment effects in well-designed observational studies do not overestimate the treatment effects in comparison to RCTs. An advantage of quasi-experiments is that they do not rely on artificial choice circumstances, which allows for inclusion of context factors from different levels through multi-level analysis (Snijders and Bosker, 1999) (e.g. showing effects through robust estimators of variables at district, community, and household levels on individual respondents) and for fewer threats to external validity (applicability in other contexts).

Qualitative methods such as focus group discussions and key-informant interviews are not well-suited to provide external validity and statistical conclusion validity. They are useful to obtain information about the scope, objectives, and potential impacts of an intervention and thus can contribute to internal and construct validity. They are valuable on their own or as a supplement to quantitative data (de Leeuw and Vaessen, 2009: xiv). For example, with respect to the impact of microinsurance it can contribute to understanding potential impact and mechanisms through which they arise. In addition, it allows for understanding the influence of product design and context on the generalizability of the impact findings. Focus groups, small scale surveys and key-informant interviews are to be considered. Contextual factors should also inform the research design and interpretation of results. Portfolios of the Poor (Collins et al., 2009) demonstrated the complexity of seemingly straightforward questions about the financial lives of the poor and the importance of gaining an indepth understanding of these questions. An alternative design, which also optimizes internal validity, is through qualitative, participatory research. Here construct validity is potentially high but external validity is lacking and a quantitative estimate of the impact of insurance is impossible.

\subsection{Conclusion}

The first section of this Chapter has discussed theories and evidence about the impact of microinsurance. Microinsurance may have consumption smoothing effects but may also lead to ex-ante effects of microinsurance on changes in behavior and impacts outside of single period utility maximizing decisions. Furthermore, less than optimal demand for microinsurance implies that certain (groups of) households may not have access or may not (be able to) take up the insurance. Therefore, in terms of poverty and inequality the distributional impact of microinsurance should be considered. Current evidence on microinsurance, except for evidence on health care utilization and OOP expenditure, is still rare and often contradictory. The particular context often provides an explanation for these findings. Indicators which address 
poverty and inequality through consumption smoothing, ex-ante behavior change and impacts outside of the single period setting are hardly addressed.

RCTs are often mentioned as the 'gold standard' for practically evaluating impacts of interventions. They can help prevent omitted variable bias and hence have the potential to lead to high internal validity. However, without maintaining theory, they may lead to overemphasis on researching certain impacts while others are underresearched. In addition, RCTs provide information on average effects, which may not be most valuable when evaluating impact of microinsurance, especially because demand is not well-understood. For valid research designs internal validity, but also construct validity, statistical conclusion validity and external validity should be addressed.

In practice, research always requires trade-offs between the four validities, methodological rigor, contributions to science, policy and practice and feasibility in terms of cost, logistical capability, and time. RCTs are adequate for addressing internal validity but are less adequate for achieving external validity. Even with respect to internal validity non-average effects have to be considered. To be valuable methods for evaluating policy interventions they should also include relevant theoretical factors or be combined with designs which can help understand mechanisms which lead to impacts. Their use for assessing ex-post effects of infrequent events is limited by financial and time considerations. Quasi-experiments are suitable in cases when randomized experiments are not feasible. The risk of omitted variable bias implies that theory about relevant factors is more important to achieve internal validity. Checks can be used to assess potential self-selection and endogeneity. Quasi-experiments also have the potential to provide external validity. Qualitative designs can be used to understand context and achieve construct validity. The overall conclusion is that the different research designs have their advantages and disadvantages in terms of the four validities and that good research designs should address all of these. Therefore combinations of research designs are best suited to make valid causal statements about unbiased constructs, to inform policy. 


\section{Chapter 5}

\section{Impact of microinsurance on consumption smoothing activities $^{1}$}

\subsection{Introduction}

Microinsurance has the potential to assist poor people in developing countries in coping with natural hazards (Linnerooth-Bayer and Mechler, 2006; Barnett, Barrett and Skees, 2008; Warner, Ranger, Surminski, Arnold, Linnerooth-Bayer, Michel-Kerjan, Kovacs and Herweijer, 2007 and Suarez and Linnerooth-Bayer, 2007). Poor people often lack the financial reserves to cope with natural hazard risks and the consequent shocks; and this has welfare implications which go well beyond the consequences for short term consumption, potentially leading to persistent poverty (Dercon, 2004; Carter, Little, Mogues, Negatu, 2007). The inability to deal with these shocks may reduce a society's capacity to accumulate, innovate and develop (Fafchamps, 2003: 146).

To cope with shocks, poor households often rely on a variety of existing strategies such as risk diversification, borrowing, using savings, depleting production assets and risk sharing between households. Such activities, like insurance, have the objective of smoothing income and smoothing consumption (Alderman and Paxson, 1994 and Morduch, 1995). Income smoothing, or so-called ex-ante efforts to reduce risk exposure, refers to activities which households undertake in order to protect themselves from adverse income shocks before they occur, such as combining farm and non-farm income activities, or diversifying crops and production techniques (Alderman and Paxson, 1994). Consumption smoothing activities occur after shocks with the objective of protecting variability of the consumption pattern. (Morduch, 1995; Barnett, Barrett and Skees, 2008). Traditionally, for some consumption smoothing activities, such as sharing risk with others, the poor rely on their social networks.

However, factors such as globalization, urbanization and increased mobility may change family and social structures and render social networks of security less powerful and less reliable. Furthermore, large-scale environmental variability rapidly increases the need for security. Changes in the strength and frequency of natural disasters, such as typhoons, is already a problem for many regions (Wisner, Blaikie, Cannon and Davis, 2004). Moreover, the nature of climate related risks, often being systematic and recurring, means that the poor cannot rely on traditional networks and small scale risk pooling alone to successfully cope with them. This is especially relevant with shocks like natural hazards, because these are covariant and thus result in households being

\footnotetext{
${ }^{1}$ This chapter is based on a paper which has been submitted for publication. I am grateful for comments from Robert Lensink, Wendy Janssens, Andreas Landmann, Daniel Clarke, Marleen Dekker, and three anonymous reviewers.
} 
impacted in the same direction at the same time. This is further exacerbated by the inability of governments of many developing countries to provide adequate risk management to their population.

The International Association of Insurance Supervisors (2007: 10-11) defines microinsurance as:

"....insurance that is accessed by low-income population, provided by a variety of different entities, but run in accordance with generally accepted insurance practices.......the risk insured under a microinsurance policy is managed based on insurance principles and funded by premiums.... Microinsurance therefore does not include government social welfare...Microinsurance is neutral in terms of the size of the risk carrier - it can be small and informal, while others are large mutual insurers or insurance companies.... Microinsurance covers a variety of different risks, including illnesses, accidental injuries, and death and property loss - basically any risk that is insurable, and is designed to be appropriate in terms of affordability and accessibility to low-income households."

Insurance against natural hazards, such as drought insurance, flood insurance, and typhoon insurance, receives a great deal of attention from international and national policy makers, civil society organizations, insurers and re-insurers. While there is substantial potential for microinsurance due to its ability to smooth risks, there is not yet sufficient evidence about the impact microinsurance has on poverty reduction. Even though some evidence exists about the impact of health insurance and agriculture insurance, often these studies look at direct welfare effects such as payouts to cope with ex-post economic losses or otherwise necessary out-of-pocket payments or ex-ante increases in investment. However, the consequences of these welfare effects in the context of poverty reduction are more complex. As was suggested in Chapter 4 the smoothing effects may have different consequences for different (groups of) households in the light of varying asset positions and other existing risk management activities. For example, microinsurance impact may be high for wealthier households because they can easily access the product, whilst policymakers want to target medium- and low-income households to help relieve the adverse effects of poverty. Another example is that microinsurance may crowd-out existing informal risk-sharing activities which households need for risks not covered by the insurance. In these cases it can be questioned what the utility of formal insurance is. Solutions for such challenges may lie in adequate product design, which combines the insurance with other preventive activities. Therefore, an understanding of the impacts of microinsurance is needed to ensure that microinsurance product design, development and investment keep pace with available evidence.

\subsection{Microinsurance and consumption smoothing activities}

Poor households make use of a variety of consumption smoothing and income smoothing activities. However, the covariant nature of natural disaster risk implies that 
existing strategies which combine ex-ante and ex-post strategies are still often insufficient and households therefore have to sacrifice assets to pay for the economic loss (Alderman and Paxson, 1994, Townsend, 1994, Fafchamps et al., 1998; Rosenzweig and Binswanger, 1993; Fafchamps and Lund, 2003, Kazianga and Udry, 2006).

As mentioned, a variety of smoothing activities exist such as using savings, selling production assets or taking a loan from a money-lender. However, some of these activities may have more severe costs in the light of economic growth paths (Morduch, 1995). Income smoothing production choices can be costly because lower-risk activities often yield lower returns. This effect is especially strong for the low-income households who are already risk averse by their nature (Alderman and Paxson, 1994). Consumption smoothing activities may also have significant costs for households if assets are depleted which they need for future income, such as production or human assets (Dercon and Hoddinott, 2004, Kazianga and Udry, 2006, Barnett, Barrett and Skees, 2008). This also implies that impacts of income and consumption smoothing may have consequences for future strategies and should not only be considered in terms of a single current utility maximizing decision (Morduch, 1995). For example, a commonly seen ex-post coping strategy is to take children out of school. In this case school fees and uniforms don't have to be paid and children can help in income-earning activities. The money made available in this manner can be used for the large expenditure. However, a child that is not in school can't accumulate knowledge (human asset) which it can use for future strategies.

There are several ways in which microinsurance can contribute to poverty reduction. With covariate risk and insufficient capacity of informal-risk sharing activities, microinsurance may complement existing smoothing activities. Moreover, microinsurance can also contribute to poverty reduction if it prevents households from having to resort to harmful consumption smoothing activities. In this way, it may not have a direct effect on the expected utility with respect to one specific decision about an uncertain expense, but rather it may have impact for future income through other mechanisms.

To study the impact of microinsurance on consumption smoothing activities, each activity should be considered in its own right because they come about through different mechanisms and their impact depends on the ex-ante situation of the particular household and local context in which they are used. One example of a consumption smoothing activity is the use of informal risk-sharing networks. Research about how formal insurance influences smoothing activities is not conclusive. Arnott and Stiglitz (1991) find that informal insurance crowds out formal insurance, or that they can coexist, depending on asymmetries in information. Attanasio and Rios-Rull (2000) suggest, and Mobarak and Rosenzweig (2012) find, that the nature of the insured risk, either idiosyncratic or aggregate, determines if informal insurance reduces demand for formal insurance or if both co-exist.

Another example is the effect of the sale of production assets. Empirical evidence shows mixed results with regards to the role of selling production assets as a consumption 
smoothing activity. Fafchamps, Udry and Czukas (1998) studied bullocks as production asset and found only a small effect of bullock sales on smoothing consumption. Kazianga and Udry (2006) also found no effect of bullock sales but instead discovered that households significantly reduce food consumption to reduce bullock sales. In contrast, Deaton (1991) found that households reduced half of the optimal bullock stock. In addition, Cain (1981) found a significant role of land sales in smoothing consumption. These examples show that the mechanisms behind understanding the use of each consumption smoothing activity are complex, context dependent and should be considered in their own right.

As was suggested above certain consumption smoothing activities can have a greater effect on poverty than others. However, consumption smoothing activities can also substitute for each other and in this respect the interchangeability of these activities needs to be recognized when analysing these activities (Townsend, 1994; Kazianga and Udry, 2006). Therefore this study will separately analyse the effect of microinsurance on specific consumption smoothing activities. In addition, it will attempt to combine the variety of consumption smoothing activities.

In the past, attempts have been made to categorize consumption smoothing activities based on their stressfulness. Watts (1983) categorized them based on the extent of commitment of household assets and their degree of reversibility. Ten strategies are identified, similar to the ones which were encountered in this study. Moreover, Watts (1983) categorizes them in ascending order of stressfulness. For example, savings are reversible or easily re-accumulated, while selling production assets is less reversible and leads to difficulties in accumulating of future income. Other contributors to the development of a categorization by stressfulness are Maxwell and Frankenberger (1992), Corbett (1988), Cutler (1984) and Cohen and Sebstad (2005). These authors identify three to four categories with the most negative being outmigration and sale of productive assets important for generating future income (Corbett, 1988:1106).

Therefore, the stressfulness of consumption smoothing activities will be considered here in terms of its effect on the future economic growth path. The use of consumption smoothing activities may have little or no effect on the future growth path (additional labour or using savings), in which case they are termed here 'low-stress'. Activities which have a larger effect on the future growth path by either restraining future income (taking up credit) or by affecting the future production function (selling production assets) are termed here 'high-stress'.

As discussed in Chapter 4, providing a pay-out may smooth consumption. Microinsurance may also affect future income and productivity by protecting the sale of certain assets. It is suggested here that microinsurance has value especially in terms of poverty reduction if it reduces the likelihood that a household has to use these highstress activities. The above discussion has already addressed the fact that it is difficult to derive a general order of more and less stressful consumption smoothing activities without considering how households use them in the specific context. Therefore an indepth analysis is necessary for all consumption smoothing activities to be identified, in their availability and application. 
Therefore it is hypothesized that (H1):

Households with microinsurance are relatively less likely to use higher-stress

consumption smoothing activities than households without micro insurance.

This hypothesis is tested by first estimating models of each consumption smoothing activity separately, with the other activities as controls. It is predicted that microinsurance will reduce the likelihood that households result to other consumption smoothing activities and more specifically high-stress activities.

In addition, and especially because it is suggested that households use more than one consumption smoothing activity which may be activities of different stress levels, it is attempted to construct an ordinal variable which categorizes consumption smoothing activities according to their stress levels. Here it is predicted that households are less likely to have to result to more stressful activities.

\subsection{Domain, research design and measurement}

In this section the characteristics of the insurance product are first described. Following this, under the heading Research design the selection of respondents and the method for dealing with endogeneity and self-selection is elaborated. Finally the measurement of variables is described.

\subsubsection{Domain}

As was discussed in Chapter 4, a requirement for studying the impact of microinsurance on consumption smoothing activities, is that respondents can be identified who have insurance and have experienced the insured risk event. As far as known, the Philippines are the first country where natural disaster microinsurance has been introduced which fulfils these conditions: PAID plan. PAID plan is a natural disaster insurance with its main objective being to insure against the financial consequences of typhoons. The insurance is a house asset insurance and, in the case of damage to residential houses due to typhoons, the insured receives a maximum of Php 10,000 (USD 228), dependent on the extent or per cent damage that the insured has incurred. In this respect the expected ex-post effect of this asset insurance is that it facilitates direct restocking of the asset from the indemnity payment and reduces the need to use assets to facilitate this restocking. Each household is permitted to purchase only one unit of the insurance and it costs 250 Php per year (USD 5,70 based on exchange rate of 1 Php $=0.0228$ USD, 7 January 2011). The payout is determined based on loss assessment by the staff of the organization who distribute the insurance (CARD). CARD pays out claims based on a 1-3-5 strategy which means that households will receive the pay-out within five days; and indeed households report that pay-outs are made within a week. At the time of data collection in October 2009 there were around 58,000 households which had bought the insurance and approximately 1500 claims had been paid out. By mid-2010 this had risen to some 130,000 households and approximately 3000 households had received a PAID plan pay-out. PAID plan qualifies as a microinsurance product because it targets the two poorest sections of the Philippine society. The yearly premium for PAID plan is less 
than one per cent of the average yearly family income of the poorest section of the Philippine society.

\subsubsection{Research design}

In order to sample insured and non-insured, with and without typhoon experience, a three-stage sampling procedure for the survey was applied. First, three typhoon-prone provinces in three culturally different regions were selected: Pangasinan, Bicol and Samar/Leyte. These different regions were chosen because key-informants supposed a potential impact of cultural differences on consumption smoothing activities. In practice, no differences were observed. Typhoon-prone provinces were chosen to have a sufficient number of respondents who have experienced a typhoon. Second, eleven villages were selected where insured and non-insured households, with and without typhoon experience were sufficiently represented. Only a limited number of villages where the insurance had been introduced had also recently experienced a typhoon (since the introduction of the insurance in 2008). In the third step, in each village, a disproportionally stratified random sample of households was taken. First all insured households in those villages were selected ( $n=64,39$ had typhoon experience: 25 had no typhoon experience). Secondly a random selection of non-insured households was taken ( $\mathrm{n}=134,95$ typhoon experience, 41 no typhoon experience).

To prepare the survey, all consumption smoothing activities identified in literature were listed (Watts, 1983; Maxwell and Frankenberger, 1992; Corbett, 1988; Cutler, 1984; Alderman and Paxson, 1994; Morduch, 1995; Cohen and Sebstad, 2005). These were used as input for focus groups. These focus groups were organized in 11 villages and consisted of six to 20 participants with the aim of getting an insight into living conditions and risk management. Important results are an inventory of possible consumption smoothing activities in the Filipino context, and the relevant ex-ante situation of households and communities. In addition, through event-histories in the focus groups, information was collected about occurrence and consequences of natural disasters. By making use of these focus groups it was possible to get precise information about the specific process belonging to each consumption smoothing activity (i.e. 'Did you eat less?' versus 'Did you eat less meat?' or if sold a pig: 'Did you own a piggery or did you have the pig for consumption?'). The following categories of consumption smoothing activities were advanced: reducing food intake (reduction of meat from diet), earning extra income through additional/casual labour (side line activities), using savings, risk-sharing with family, friends or neighbours, taking a loan from a moneylender, postpone debt repayment, pawn land or jewellery, sell consumption assets, sell production assets, take children out of school and outmigration. These were brought into the household survey questionnaires. Traditionally, a known strategy for coping with damage to houses is Bayanihan. It refers to a Filipino tradition in which houses after natural disasters would be shifted from the old location to a new location, where they would be repaired. The house, which was traditionally built on poles, would be carried by male village members on a bamboo frame to the new location where everybody would assist in the repair (see Figure 5-1). Bayanihan was not reported to still exist in any of the focus groups or household interviews. 
Figure 5-1 Mural by Carlos 'Botong' Francisco depicting Bayanihan

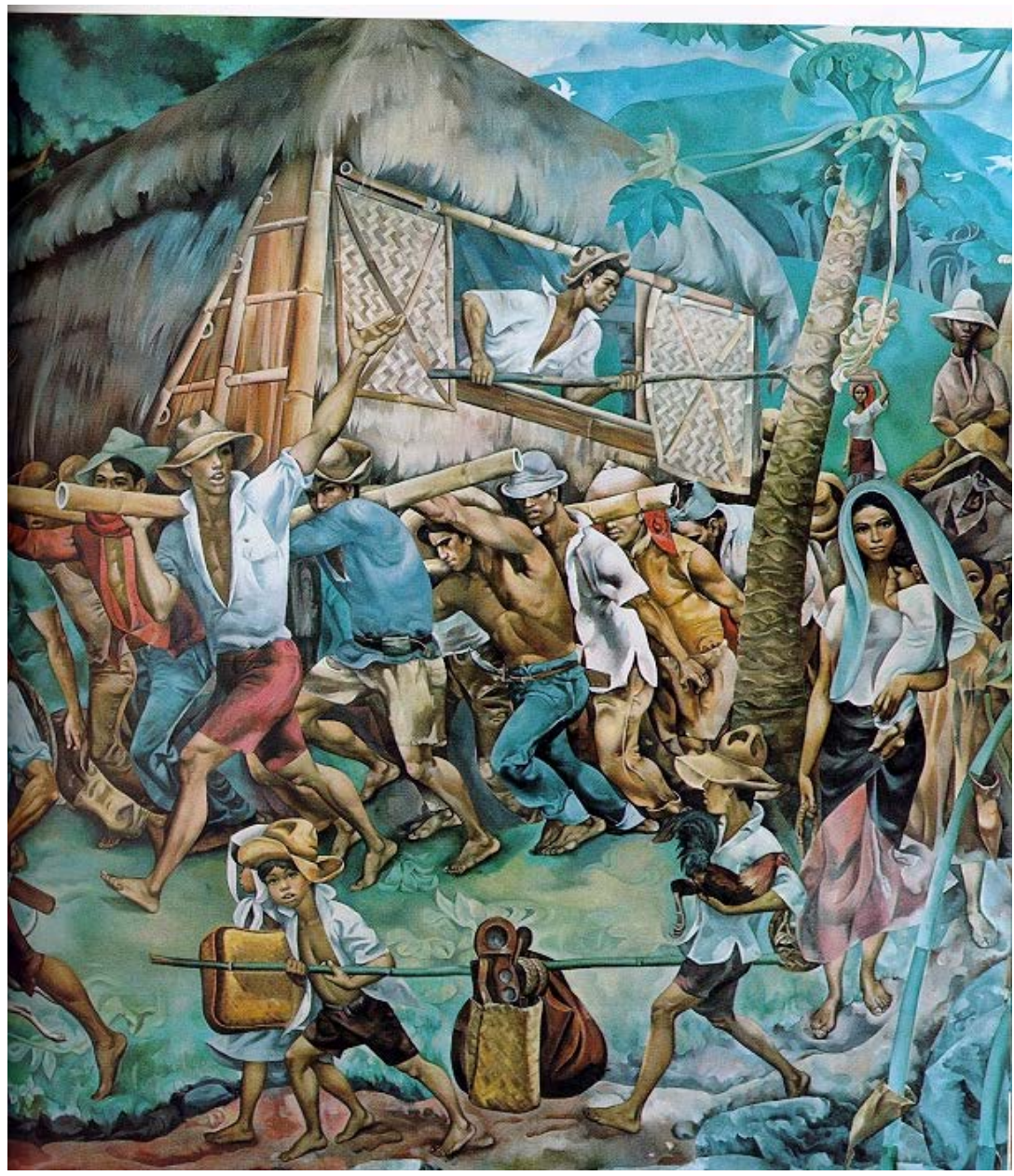

\section{Self-selection and endogeneity}

A general issue in impact assessment studies is the impossibility of comparing the effect of a treatment on one person with the status of the same person untreated. Therefore persons with the insurance are compared to persons without the insurance. As was explained in Chapter 4, this may however lead to uncertainties in the attribution of impacts to the insurance; while impacts may also be caused by differences in the ex-ante situation of people with and without insurance. A common way to overcome the risk of drawing internally invalid conclusions is to conduct experiments in which households are randomly assigned to the treatment and control condition because the effect of confounding factors will appear in the error term. However, in the case of measuring impact of insurance on consumption smoothing activities after typhoons, randomization of the insurance and waiting for the insured risk event is not feasible. It would either imply extremely high costs or a long waiting period (Black, 1996, Sanson-Fisher, Bonevski, Green and D’Este, 2007). Because it was deemed important to study the effect of insurance on consumption smoothing activities, focus groups and a household survey were applied, creating the risk of self-selection and endogeneity. Matching was considered, but there were no strong predictors of microinsurance impact observed in existing literature which could be used as matching criteria (Shadish, Cook and 
Campbell, 2002). Therefore, in this study, all theoretically relevant factors are included in the analyses and Heckman checks are conducted.

To observe consumption smoothing activities there are thus two treatments. Firstly there is the insurance treatment which is, since 2008, a choice variable and households decided to take up or not take up the insurance. This implies a risk of self-selection and endogeneity. Following the take up of insurance or no insurance, they either experience a typhoon or not, which in turn leads to the use of consumption smoothing activities. The treatments and their consequences are represented in Figure 5-2. Households either take up insurance I or no insurance nI. They experience a typhoon T or no typhoon nT. Following this they employ consumption smoothing $\mathrm{C}$ versus no consumption smoothing $\mathrm{nC}$. In theory this leads to eight situations. However, $\mathrm{T}$ and $\mathrm{C}$ are not independent and $\mathrm{C}$ is conditional (partly) on T. This means that situation 3 and 7 in Figure 5-2 will not occur; no damage caused by a typhoon will not lead to employment of consumption smoothing activities $(\mathrm{nT}=\mathrm{nC}, \mathrm{nT} \neq \mathrm{C}$ ) (there may be consumption smoothing activities but then they are not caused by the typhoon). It is possible that households do not employ consumption smoothing activities while they have experienced typhoon damage $(\mathrm{T}=\mathrm{C}, \mathrm{T}=\mathrm{nC})$. In theory the exclusion of situation 3 and 7 may lead to sample selection issues; however, these groups do not exist in the population and therefore there is no problem with self-selection in this respect.

Figure 5-2 Insurance, Typhoon and Consumption smoothing activities

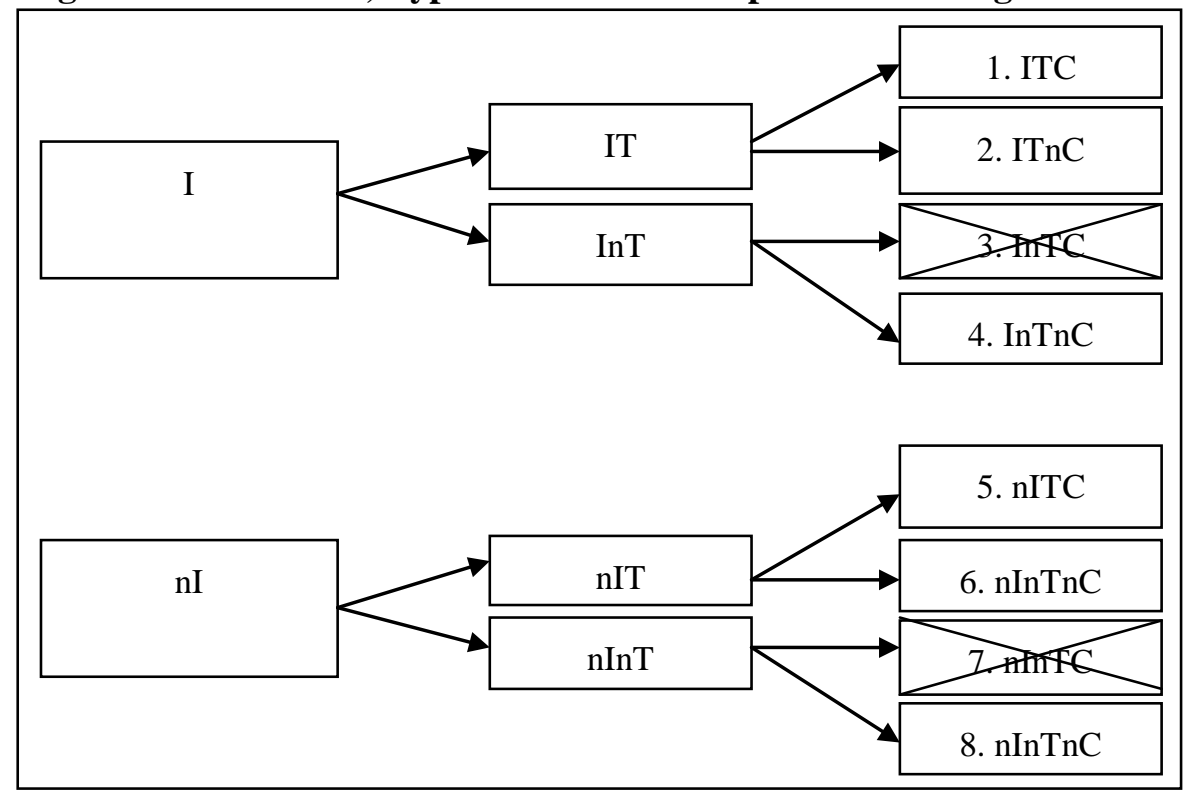

Insurance I, no Insurance nI, Typhoon T, no Typhoon nT, Coping C, no Coping nC

Bias due to confounding factors (self-selection and endogeneity) may occur due to the choice for I versus nI, due to the experience of $\mathrm{T}$ versus $\mathrm{nT}$ and due to $\mathrm{C}$ versus $\mathrm{nC}$. Self-selection bias may occur if the ex-ante situation of households influences take up of the insurance while simultaneously influencing the effect of the insurance on consumption smoothing activities. To control for self-selection into the insurance the 
ex-ante situation of households is included in the analysis. Endogeneity may occur if the take up of the insurance is a consequence of previous typhoon occurrences or previous coping with shocks. To control for this endogeneity controls for previous typhoon experiences and previous coping, such as previous government support in case of typhoons, use of savings and previous insurance and claim experiences were included. In Chapter 3 factors were identified which influence the demand for the insurance. These factors, if excluded from the analysis, have the potential to lead to omitted variable bias and are therefore included in the analysis.

The experience of a typhoon is considered to be an exogenous variable. It is assumed that households in villages cannot self-select a less typhoon-prone location because typhoons are rare and their impact depends on the direction from which it reaches a village. Typhoons can cause damage because of direct wind, rain or flooding but also, for example, because of uprooted trees which fall on houses and landslides due to rains or floods elsewhere. These are considered to be randomly distributed over the villages. However, one exception may be houses at sea-side locations. Higher risk of houses near the sea may influence household choice for the insurance and the consumption smoothing activities they employ. Therefore the effect of sea-side locations is controlled for.

In addition to the impact on individual households by destroying property and crops, its correlated nature may lead to local market failure and therefore lack of income, lack of food supply and increasing food prices. Finance is needed for repairing property and for compensating the lack of income. However, since this study concentrates on re-housing insurance, finances for repairing houses are the focus.

Other factors that potentially influence the extent of damage, and are therefore included, are the structure of houses and households' preventive activities. A house which is built from natural materials such as bamboo and wood is more likely to be damaged, ceteris paribus, than a concrete house. However, if there is damage, the economic loss (the amount of money required for repairing damage) is generally higher for a concrete house since resources used for this house are more costly. Materials used for building houses of natural resources are often recycled or taken from the forest. To check for endogeneity controls for previous typhoon experiences, previous coping and perceptions of typhoon risk were included.

Table 5-4 presents the Student's t-test for theoretically relevant factors which may lead to selection into the insurance and the F-test for factors leading to typhoon damage. Their potential effect on consumption smoothing activities is discussed under the section Descriptives. After having included all theoretically relevant variables in the analysis, the effect of potential unobserved variables is controlled for. Waters (1999), Jutting (2004) and Hamid, Roberts and Mosley (2010b) estimate a reduced-form equation of take up of the insurance. The predicted and actual take up are both included as regressors in a model for the prediction of the impact variable. However, the right application of this method is strongly dependent on the explanatory value of the model for take up and it is not clear if this is the case in Jutting (2004) and Hamid, Roberts and Mosley (2011a). Our model for the prediction for take up is considered to be sufficient since the Nagelkerke Pseudo R-square is 0.43 and 78 per cent of the observations are correctly predicted (see Table 3-3 in Chapter 3). 


\subsubsection{Measurement}

In this section the operationalization of the variables which were include in the model are described.

\section{Consumption smoothing activities}

The dependent variable in our study, consumption smoothing activities, was measured by the (self)reported consumption smoothing activities which households employed to manage the economic loss by the typhoon. The relevant consumption smoothing activities identified by the focus groups are combined into the following categories based on the explanation of underlying mechanisms and consequences for the economic growth path. Borrowing from and getting donations from family, friends and neighbours were considered to be similar informal risk-sharing mechanisms. Here Fafchamps and Gubert (2007a) are followed. They found that such informal loans are often with zerointerest or do not have to be repaid at all. Therefore borrowing and getting donations from family, friends and neighbours were considered to be one informal risk-sharing strategy. Reducing food intake was never found to imply a lack of food but removal of luxury food items from the diet. Selling and pawning consumption assets are again considered one strategy because both lead to disposal of the asset, whereas the cost for replacement is the same in the long run. The same reasoning was followed for selling and pawning production assets.

\section{Table 5-1 Consumption smoothing activities according to focus groups}

\begin{tabular}{l|l}
\hline $\begin{array}{l}\text { Consumption smoothing activity } \\
\text { (acronym) }\end{array}$ & Explanation \\
\hline Eatless & $\begin{array}{l}\text { Reduce food intake which implies removal of luxury food items } \\
\text { from the diet such as meat }\end{array}$ \\
\hline Ownsavings & Using own savings \\
\hline Sideline & $\begin{array}{l}\text { Earning extra income through additional/casual labour which is } \\
\text { not performed if there is not a shock. }\end{array}$ \\
\hline Informal & $\begin{array}{l}\text { Informal risk-sharing with family, friends or neighbours. This } \\
\text { implies receiving donations or borrowing money from family, } \\
\text { friends or neighbours }\end{array}$ \\
\hline Sellcons & $\begin{array}{l}\text { Selling or pawning of consumption assets such as radio, TV, } \\
\text { refrigerator, jewellery }\end{array}$ \\
\hline Moneylender & $\begin{array}{l}\text { Borrow from money lender or postpone the repayment of existing } \\
\text { debt. }\end{array}$ \\
\hline Stresschild & Taking children out of school or putting children to work \\
\hline Sellprod & $\begin{array}{l}\text { Selling or pawning of production assets such as cattle, land or } \\
\text { other investment goods (sewing machine, car) }\end{array}$ \\
\hline Moveout & $\begin{array}{l}\text { Outmigration: Abandon the house and move to another location } \\
\text { because the household sees no future in staying. }\end{array}$ \\
\hline
\end{tabular}

To study these nine observed consumption smoothing activities it has to be realized that all have a specific relation with the ex-ante asset situation. For example the selling of production assets (Sellprod) depends on previous ownership of production assets before the shock. Moreover, as was mentioned in the section Microinsurance and consumption smoothing activities all nine activities are applied from a different ex-ante situation and 
may have different ex-post consequences. For these reasons each activity is studied separately first.

However, as was mentioned above, because the activities may complement and substitute each other, the other consumption smoothing activities are included in the analyses as controls. In addition it is attempted to construct a simplified consumption smoothing variable combining the variety of consumption smoothing activities into high- and low-stress categories. To further do justice to this complex issue, four different categorizations of more and less stressful strategies are constructed to assess if the precise construction of the variable influences the overall results (see Table 5-2).

A principal component analysis was first executed to assess if categories of activities could be identified. This did not lead to any results. In the next step the number of categories of consumption smoothing activities were reduced into dichotomies ${ }^{2}$ and trichotomies assuming about equal stressfulness of some activities to the household (Table 5-2). The two dichotomies present high-stress versus low-stress activities, where it is assumed that high-stress activities are those which have consequences for future income or productivity. The two trichotomies are constructed based on the categories presented in literature above. An ordinal variable is constructed to test the hypothesis.

The assumption underlying this is that households will exhaust their options for using lower-stress consumption smoothing activities before they employ higher-stress consumption smoothing activities. In addition it is assumed that high-stress activities can be replaced by other high-stress activities or several lower-stress activities and it is more stressful to use one higher-stress activity then several lower-stress activities in terms of impact on future income and productivity. The maximum amount of mediumor high-stress consumption smoothing activities (Trichotomy 1) used in our sample is four. However, 90 per cent of households used a maximum of three of these consumption smoothing activities (three medium, one high and two medium, or two high and one medium, never three high). Tests for the validity of the construction of this variable are presented below.

For this variable applying no consumption smoothing activities is assigned zero; having used at least one low-stress coping strategy and no medium-or high-stress consumption smoothing activities is assigned one; having used at least one medium-stress coping strategy and no high-stress coping strategy is assigned two; having used at least one high-stress coping strategy is assigned three. This leads to the following prediction: Households with microinsurance are less likely to use high-stress coping strategies and less likely to use medium-stress coping strategies.

\footnotetext{
${ }^{2}$ Results of the estimations of the dichotomies will be presented in Appendix 5-2
} 
Table 5-2 Potential categorization of dependent variable 'consumption smoothing'

\begin{tabular}{|c|c|c|c|c|}
\hline & $\begin{array}{l}\text { Dichotomy } 1 \\
\text { (Stressdi1) }\end{array}$ & $\begin{array}{l}\text { Dichotomy } 2 \\
\text { (Stressdi2) }\end{array}$ & $\begin{array}{l}\text { Trichotomy } 1 \\
\text { (Stressord1) }\end{array}$ & $\begin{array}{l}\text { Trichotomy } 2 \\
(\text { Stressord2) }\end{array}$ \\
\hline $\begin{array}{l}\text { Low- } \\
\text { stress }\end{array}$ & $\begin{array}{ll}\text { - } & \text { Eatless } \\
\text { - } & \text { Ownsavings } \\
\text { - } & \text { Sideline } \\
\text { - } & \text { Informal } \\
\text { - } & \text { Sellcons }\end{array}$ & $\begin{array}{ll}\text { - } & \text { Eatless } \\
\text { - } & \text { Ownsavings } \\
\text { - } & \text { Sideline } \\
\text { - } & \text { Informal }\end{array}$ & $\begin{array}{ll}\text { - } & \text { Eatless } \\
\text { - } & \text { Ownsavings } \\
\text { - } & \text { Sideline }\end{array}$ & $\begin{array}{ll}\text { - } & \text { Eatless } \\
\text { - } & \text { Ownsavings } \\
\text { - } & \text { Sideline }\end{array}$ \\
\hline $\begin{array}{l}\text { Medium- } \\
\text { stress }\end{array}$ & & & $\begin{array}{ll}\text { - } & \text { Informal } \\
\text { - } & \text { Sellcons }\end{array}$ & $\begin{array}{ll}\text { - } & \text { Informal } \\
\text { - } & \text { Sellcons } \\
\text { - } & \text { Moneylender } \\
\end{array}$ \\
\hline $\begin{array}{l}\text { High- } \\
\text { stress }\end{array}$ & $\begin{array}{ll}\text { - } & \text { Moneylender } \\
\text { - } & \text { Stresschild } \\
\text { - } & \text { Sellprod } \\
\text { - } & \text { Moveout }\end{array}$ & $\begin{array}{ll}\text { - } & \text { Sellcons } \\
\text { - } & \text { Moneylender } \\
\text { - } & \text { Stresschild } \\
\text { - } & \text { Sellprod } \\
\text { - } & \text { Moveout }\end{array}$ & $\begin{array}{ll}\text { - } & \text { Moneylender } \\
\text { - } & \text { Stresschild } \\
\text { - } & \text { Sellprod } \\
\text { - } & \text { Moveout }\end{array}$ & $\begin{array}{ll}\text { - } & \text { Stresschild } \\
\text { - } & \text { Sellprod } \\
\text { - } & \text { Moveout }\end{array}$ \\
\hline
\end{tabular}

\section{Treatment and control variables}

The treatment variable in our study, having microinsurance, was measured by asking households if they were insured through PAID plan and if they could demonstrate the part of the slip which indicates this. However, since the pay out of the insurance is conditional both on the insurance and on the damage to a house by the typhoon, the damage to the house converted in the economic loss in Php and the payout in Php which is conditional on the damage is included. To check for robustness, different operationalizations were included: being insured or not, the damage in Php, the claim in Php and the damage minus the pay-out (net damage). The measurement of the control variables was described in Chapter 3, Section 4.3.3

\subsection{Descriptives}

In this section independent sample t-tests for insured versus uninsured are described for the consumption smoothing activities (Table 5-3). Two villages are excluded from further analyses because they had experienced an extreme shock in comparison to the other villages. In these villages the typhoon was accompanied by a volcanic eruption which implied that large parts of the villages were covered in lava and households had to leave the area permanently or completely rebuild. The seriousness of the shock resulted in large amounts of government aid and assistance of national and international NGOs. In Table 5-3 the consumption smoothing activities of the households in these two villages are compared to the activities by other households to demonstrate the differences. Table 5-4 presents the t-test for insured versus uninsured for theoretically relevant variables and the F-test for damage for the theoretically relevant variables. A separate control was executed for potential self-selection due to sea-side locations. No significant differences between insured and uninsured and damaged and undamaged households were observed. 
Most households were found to use a combination of consumption smoothing activities with an average amount of $2.7(\mathrm{SD}=1.74)$. In addition, eight per cent of the households did not use any of the consumption smoothing activities that were included. Those included in this study are financial consumption smoothing activities and therefore it is possible that households, for example, coped by praying or by refraining from repairing their house. An interesting result (Table 5-3) is that 77 per cent of households use their own savings, implying that they have savings. This percentage may seem high when dealing with low-income households but is in line with previous research on savings in the Philippines (Karlan et al. 2004). Also the percentages of households earning extra income and relying on informal risk-sharing ( 0.34 and 0.40 respectively) are high. It is probable that this is due to comparatively well-developed informal sectors in the Philippines and strong reliance on remittances (Charmes, 2000, Ang, Sugiyarto and Jha, 2009).

All insured typhoon victims have received a pay-out. Even though the damage is assessed based on indemnification, fraud could have occurred if houses were already damaged (due to other causes) before the occurrence of the typhoon. However, social control in villages and the acquaintanceship between local branch managers of the insurer and the insured made it virtually impossible to fake extent of the damage.

The independent sample t-test (Table 5-3, column 5) of the consumption smoothing activities comparing households with insurance pay-out with households without insurance pay-out, shows that there are differences for selling of production goods (Sellprod), informal gifts and loans (Informal), use of savings (Savings) and food consumption (Eatless). This suggests that there may be an effect of the insurance on these consumption smoothing activities which will be further studied in the next section.

Table 5-3 Proportion consumption smoothing activities for all households with and without payout and for households in heavy shock villages

\begin{tabular}{l|l|l|l|l|l|l}
\hline & $\begin{array}{l}\text { Sample } \\
(\mathrm{N}=134)\end{array}$ & $\begin{array}{l}\text { Households } \\
\text { with payout } \\
(\mathrm{N}=39)\end{array}$ & $\begin{array}{l}\text { Households } \\
\text { without } \\
\text { payout } \\
(\mathrm{N}=95)\end{array}$ & $\begin{array}{l}\text { t-test } \\
\text { with - } \\
\text { without } \\
\text { payout }\end{array}$ & $\begin{array}{l}\text { Extreme } \\
\text { shock } \\
\text { villages } \\
(\mathrm{N}=27)\end{array}$ & $\begin{array}{l}\text { t-test } \\
\text { Extreme } \\
\text { shock - } \\
\text { Sample }\end{array}$ \\
\hline Moveout & .01 & .00 & .02 & -1.42 & .63 & $6.45^{* * *}$ \\
\hline Sellprod & .11 & .00 & .16 & $-4.20^{* * *}$ & .07 & -.58 \\
\hline Stresschild & .07 & .13 & .05 & 1.28 & .00 & $-3.28^{* * *}$ \\
\hline Sellcons & .07 & .05 & .08 & -.65 & .07 & -.01 \\
\hline Moneylender & .13 & .15 & .12 & .60 & .41 & $2.79^{* *}$ \\
\hline Informal & .40 & .28 & .45 & $-1.91^{*}$ & .96 & $9.93^{* * *}$ \\
\hline Savings & .77 & .87 & .73 & $2.05^{* *}$ & .59 & $-1.71^{*}$ \\
\hline Eatless & .18 & .03 & .24 & $-4.24^{* * *}$ & .74 & $6.73^{* * *}$ \\
\hline Sideline & .34 & .28 & .37 & -.98 & .37 & .27 \\
\hline
\end{tabular}


The last two columns of Table 5-3 show that 63 per cent of the households in the two villages with extreme shocks have moved out of the village; 96 per cent of the households made use of informal insurance and 41 per cent borrowed money from a moneylender; 74 per cent significantly reduced food consumption. The sale of production assets is done less frequently by these households. A potential explanation may be that their production assets were also destroyed.

Table 5-4 shows that out of all households which have experienced a typhoon $(\mathrm{N}=134)$ there are 39 which were insured and 95 which were not insured. When damage is experienced the average damage is 4658 Php which is 7 per cent of average family income per year for the poorest section of the Philippine society. The average claim is 2129 Php. Table 5-4 shows that there is a significant difference between the damage experienced by insured and non-insured $(\mathrm{T}=-2.18)$. 32 per cent of households build houses on poles and 43 per cent of households tie the roof in advance to a typhoon. There is a significant difference between households which are insured and uninsured with respect to tying the roof $(\mathrm{T}=4.24)$. As was suggested in Chapter 3 this may be the result of training by the insurer (CARD) focusing on preventive activities.

Another observation is that 58 per cent of households receive government support after a typhoon which was mostly reported to be distribution of food and galvanized iron sheets for the roof.

Column 2 in Table 5-4 shows that 16 per cent of the households own a house with a good house structure and 39 per cent with a bad house structure. Insured households are less likely to have a house with a bad house structure $(\mathrm{T}=-2.60)$ and are more likely to have a good house structure $(\mathrm{T}=1.65)$ than households which are uninsured. There is no significant effect of house structure on the damage.

Households which are insured have significantly higher education $(\mathrm{T}=1.86)$ and uninsured are significantly more likely to have experienced damage from a typhoon in the past $(\mathrm{T}=-2.64)$. Finally, households with remittances have experienced significantly more damage $(\mathrm{F}=3.01)$.

\subsection{Consumption smoothing activities and their determinants}

Table 5-5 A, B and C present the results of the reduced form logit estimations for the effect of receiving a pay-out on the use of eight consumption smoothing activities separately. Sometimes the standard errors in these models are high and in some cases the models degenerate due to the large number of variables relative to the sample size. Move out is not included here because this was, with two exceptions, only done by households in the villages with extreme shocks and these were excluded from the analysis for reasons mentioned earlier. In each estimation the other consumption smoothing activities are included as controls. For each consumption smoothing activity two models are presented. Model 1 includes the payout, damage, government support and the other consumption smoothing activities. In model 2 all relevant theoretical factors are included. For all consumption smoothing activities a Heckman check is performed by adding the predicted value of being insured as an extra predictor in Model 2. In none of the estimations the effect of this predictor is significant. 
Table 5-4 Differences in characteristics between insured and non-insured (t-test) and differences in mean damage per characteristic (F-test)

\begin{tabular}{|c|c|c|c|c|c|}
\hline & Average & $\begin{array}{l}\text { Insured } \\
(\mathrm{N}=39)\end{array}$ & $\begin{array}{r}\text { Uninsured } \\
(\mathrm{N}=95)\end{array}$ & $\begin{array}{r}\text { t-test } \\
\text { Insured- } \\
\text { Uninsured }\end{array}$ & $\begin{array}{r}\text { F-test } \\
\text { damage\# }\end{array}$ \\
\hline Pay out (yes=1) & & & & & $-2.77 *$ \\
\hline Damage in Php & 4658 & 3539 (2704) & $5118(5654)$ & $-2.18^{* *}$ & \\
\hline Claim in Php (N=39) (1=yes) & 2129 & $2129(1040)$ & & & \\
\hline Previous government support (1=yes) & .58 & $.51(.08)$ & $.60(.05)$ & -.65 & .09 \\
\hline Savings (1 = yes) & .89 & $.90(.05)$ & $.88(.03)$ & .22 & 1.74 \\
\hline Build house on poles ( $1=$ yes) & .32 & $.36(.08)$ & $.31(.05)$ & .60 & -.26 \\
\hline Tie roof of house $(1=$ yes $)$ & .43 & $.69(.08)$ & $.32(.05)$ & $4.24 * * *$ & .01 \\
\hline Save food (1=yes) & .81 & $.74(.07)$ & $.82(.04)$ & -.96 & 1.50 \\
\hline Has production assets (1=yes) & .65 & $.64(.08)$ & $.65(.05)$ & -.13 & 1.90 \\
\hline Has consumption assets $(1=$ yes $)$ & .81 & $.87(.05)$ & $.78(.04)$ & 1.34 & -.65 \\
\hline Remittance, access to(1=yes) & .47 & $.46(.08)$ & $.47(.05)$ & -13 & $3.01 *$ \\
\hline Number of children & 3.1 & $3.46(.38)$ & $2,96(.17)$ & 1.15 & n.a \\
\hline Bad house structure (1=yes) $^{2}$ & .39 & $.23(.07)$ & $.45(.05)$ & $-2.60 * *$ & -1.80 \\
\hline Good house structure (1=yes) $)^{2}$ & .16 & $.26(.06)$ & $.13(.03)$ & $1.65 *$ & .01 \\
\hline Risk aversion high (1=yes) & .34 & $.26(.07)$ & $.37(.05)$ & -1.29 & -1.74 \\
\hline Risk aversion low (1=yes) & .19 & $.26(.07)$ & $.17(.04)$ & 1.09 & -.50 \\
\hline Education\# & 2.57 & $2.97(.24)$ & $2.41(.17)$ & $1.86 *$ & n.a \\
\hline Age in years & 42.6 & $43.3(1.24)$ & $42.32(1.04)$ & .61 & n.a \\
\hline Perception of typhoon risk ${ }^{\# \#}$ & .56 & $.51(.08)$ & $.58(.05)$ & -.70 & 2.24 \\
\hline Experienced typhoon in past (1=yes) & .90 & $.77(.07)$ & $.96(.02)$ & $-2.64 * * *$ & .22 \\
\hline Experienced accident in past $(1=$ yes $)$ & .17 & $.13(.05)$ & $.19(.04)$ & -.85 & .02 \\
\hline Has experience with insurance (1=yes) & .69 & $.72(.07)$ & $.67(.05)$ & .50 & .82 \\
\hline \multicolumn{6}{|c|}{$\begin{array}{l}\text { ( )=s.e.*** Significant at the } 0.01 \text { level, ** Significant at the } 0.05 \text { level, * Significant at the } 0.10 \text { level } \\
\text { \# A - sign was added to the F-value when the mean damage of the category } 0 \text { was higher than the mean } \\
\text { damage of category } 1 \text {. } \\
2=\text { reference category is medium house } \\
{ }^{*} 0=\text { primary level, } 1 \text { = primary finished, } 2=\text { secondary level, } 3=\text { secondary finished, } 4=\text { bachelor level, } \\
5=\text { higher } \\
\# \text { \# } 1 \text { = high rank, } 0=\text { low rank }\end{array}$} \\
\hline
\end{tabular}

The insurance pay-out shows a negative sign for all consumption smoothing activities, except for eating less and taking children out of school. The effect is significant for the likelihood that a household performs side line activities, relies on informal risk-sharing or uses their own savings and sells production assets. For the other consumption smoothing activities there is not a significant effect. Damage has a positive sign for the high-stress activities of selling production assets and taking children out of school. The damage is significant for the likelihood that a household has to resort to selling production assets. For all the other consumption smoothing activities the effect of damage is not significant. The fact that the variables added in Model 2 substantially 
increase the correctly predicted households suggests that the ex-ante situation of a household plays an important role in determining the use of consumption smoothing activities.

Having savings and previous typhoon experiences negatively affects the use of side line activities while tying the roof, having consumption assets and having a high-rank for the perception of typhoon risk are positively correlated with the use of side line activities. The pay-out negatively affects the likelihood that households have to use their own savings for coping with the risk. Households which built their house on poles, are highly risk averse and have a bad house structure, are less likely to use their own savings. This may suggest that those households which are worse off are particularly less likely to use savings to cope with the shock.

Households which are low in risk aversion (versus medium), have a higher probability of having a bad house structure and having experienced an accident in the past and are less likely to eat less. This may suggest that these particular households are already at a minimum and cannot remove anything from their diet in comparison to other households.

Households are less likely to use informal risk-sharing when they have production assets and are more likely to do so when they have access to remittance. Perception of typhoon risk and education negatively affect the use of informal risk-sharing. A potential explanation for the fact that the predicted value of informal risk-sharing based on our demand model in Chapter 3 is significant is that, even though remittances were included, no variable was included representing local social capital which may also play an important role in the use of informal risk-sharing. Households which have a larger number children are more likely to borrow from a money lender and households where the respondent is older are less likely to sell consumption assets.

From the different estimations some patterns emerge with respect to the consumption smoothing activities that households choose. Sellprod and Sideline are positively related and so are Moneylender, Stresschild and Sellcons. Sellprod and Stresschild, both assumed to be high-stress, are negatively related. Moneylender and Ownsavings and Moneylender and Eatless are also negatively related.

The last four columns of Table 5-6 show that the constructed dependent variables demonstrate robust effects for the parameters. In all these models the sign of the pay-out is negative and significant, suggesting that the insurance reduces the likelihood of using more stressful coping strategies. The effect of damage and net damage is positive and significant. Government assistance is also positive and significant. This is suggested to be caused by the fact that government assistance is more likely to be provided when the damage is higher. Having experienced an accident in the past increases the likelihood that a household uses more stressful activities. It is suggested that these households may be left more vulnerable after the accident. Models 1-3 show that the parameters are robust when variables are added. Heckman tests are not significant for any of the models. Parallel lines tests are conducted to validate the choice for the ordinal construction of the dependent variables. For three out of the suggested four constructions of the dependent variable the parallel lines test is not significant suggesting that indeed the ordinal construction is valid. The estimations for the two 
Table 5-5A Payout and Consumption smoothing activities (Sideline, Eatless and Savings)

\begin{tabular}{|c|c|c|c|c|c|c|}
\hline & \multicolumn{2}{|c|}{ Sideline } & \multicolumn{2}{|c|}{ Ownsavings } & \multicolumn{2}{|c|}{ Eatless } \\
\hline & Model 1 & Model 2 & Model 1 & Model 2 & Model 1 & Model 2 \\
\hline Constant & $\begin{array}{l}-1,785 \\
(.835) \\
\end{array}$ & $\begin{array}{r}-3.774 \\
(2.450) \\
\end{array}$ & $\begin{array}{r}-1.142 \\
(.878) \\
\end{array}$ & $\begin{array}{r}-.700 \\
(3.028) \\
\end{array}$ & $\begin{array}{r}.180 \\
(.728) \\
\end{array}$ & $\begin{array}{r}-1.063 \\
(2.766) \\
\end{array}$ \\
\hline Sideline & & & $\begin{array}{c}-.318 \\
(.556)\end{array}$ & $\begin{array}{r}-.503 \\
(.845) \\
\end{array}$ & $\begin{array}{r}.412 \\
(.501) \\
\end{array}$ & $\begin{array}{r}.762 \\
(.743) \\
\end{array}$ \\
\hline Eatless & $\begin{array}{r}-.234 \\
(.530) \\
\end{array}$ & $\begin{array}{r}.077 \\
(.650) \\
\end{array}$ & & & $\begin{array}{r}-.314 \\
(.542) \\
\end{array}$ & $\begin{array}{r}-.301 \\
(.636) \\
\end{array}$ \\
\hline Ownsavings & $\begin{array}{r}.459 \\
(.495) \\
\end{array}$ & $\begin{array}{r}.712 \\
(.644) \\
\end{array}$ & $\begin{array}{r}-.382 \\
(.553) \\
\end{array}$ & $\begin{array}{r}-.131 \\
(.744) \\
\end{array}$ & & \\
\hline Informal & $\begin{array}{r}.199 \\
(.403) \\
\end{array}$ & $\begin{array}{r}.691 \\
(.529) \\
\end{array}$ & $\begin{array}{r}.284 \\
(. .502) \\
\end{array}$ & $\begin{array}{r}-.131 \\
(.675) \\
\end{array}$ & $\begin{array}{r}-.450 \\
(.462) \\
\end{array}$ & $\begin{array}{r}-.232 \\
(.649) \\
\end{array}$ \\
\hline Moneylender & $\begin{array}{r}.197 \\
(.620) \\
\end{array}$ & $\begin{array}{r}.323 \\
(.768) \\
\end{array}$ & $\begin{array}{r}.203 \\
(.765) \\
\end{array}$ & $\begin{array}{r}.951 \\
(1.181) \\
\end{array}$ & $\begin{array}{r}-1.383^{* *} \\
(.684) \\
\end{array}$ & $\begin{array}{r}-1.971^{* *} \\
(.885) \\
\end{array}$ \\
\hline Sellcons & $\begin{array}{r}-.204 \\
(.770) \\
\end{array}$ & $\begin{array}{r}-.772 \\
(.961) \\
\end{array}$ & $\begin{array}{r}-.870 \\
(1.152) \\
\end{array}$ & $\begin{array}{r}-.175 \\
(1.390) \\
\end{array}$ & $\begin{array}{r}1.733 \\
(1.161) \\
\end{array}$ & $\begin{array}{r}1.444 \\
(1.397) \\
\end{array}$ \\
\hline Stresschild & $\begin{array}{r}.456 \\
(.785) \\
\end{array}$ & $\begin{array}{r}1.206 \\
(1.009) \\
\end{array}$ & $\begin{array}{r}1.277 \\
(.981) \\
\end{array}$ & $\begin{array}{r}1.402 \\
(1.329) \\
\end{array}$ & $\begin{array}{r}1.533 \\
(1.238) \\
\end{array}$ & $\begin{array}{r}1.261 \\
(1.400) \\
\end{array}$ \\
\hline Sellprod & $\begin{array}{r}1.332 * * \\
(.631) \\
\end{array}$ & $\begin{array}{r}1.729^{* *} \\
(.791) \\
\end{array}$ & $\begin{array}{r}.563 \\
(.694) \\
\end{array}$ & $\begin{array}{r}.943 \\
(.952) \\
\end{array}$ & $\begin{array}{r}-.135 \\
(.720) \\
\end{array}$ & $\begin{array}{r}-.021 \\
(.924) \\
\end{array}$ \\
\hline Pay out ${ }^{1}$ & $\begin{array}{r}-.279 \\
(.466) \\
\end{array}$ & $\begin{array}{r}-1.650 * * \\
(.741) \\
\end{array}$ & $\begin{array}{r}-2.576^{* * *} \\
(1.101) \\
\end{array}$ & $\begin{array}{r}-3.425^{* *} \\
(1.362) \\
\end{array}$ & $\begin{array}{r}.751 \\
(.582) \\
\end{array}$ & $\begin{array}{l}1.217 \\
(.809) \\
\end{array}$ \\
\hline Damage in Php & $\begin{array}{r}.150 \\
(.462) \\
\end{array}$ & $\begin{array}{r}.127 \\
(.527) \\
\end{array}$ & $\begin{array}{r}.303 \\
(.557) \\
\end{array}$ & $\begin{array}{r}.724 \\
(.670) \\
\end{array}$ & $\begin{array}{l}.899 * \\
(.506) \\
\end{array}$ & $\begin{array}{l}1.005 \\
(.631) \\
\end{array}$ \\
\hline Government support $^{1}$ & $\begin{array}{r}.635 \\
(.409) \\
\end{array}$ & $\begin{array}{r}.692 \\
(.499) \\
\end{array}$ & $\begin{array}{r}.795 \\
(.557) \\
\end{array}$ & $\begin{array}{r}.996 \\
(.675) \\
\end{array}$ & $\begin{array}{r}-.391 \\
(.471) \\
\end{array}$ & $\begin{array}{r}.559 \\
(.619) \\
\end{array}$ \\
\hline Savings $^{1}$ & & $\begin{array}{r}-1.394 * * \\
(.774) \\
\end{array}$ & & $\begin{array}{r}2.357 \\
(1.533) \\
\end{array}$ & & $\begin{array}{r}.806 \\
(.817) \\
\end{array}$ \\
\hline Build house on poles ${ }^{1}$ & & $\begin{array}{r}-.264 \\
(.755) \\
\end{array}$ & & $\begin{array}{r}-2.796^{* *} \\
(1.183) \\
\end{array}$ & & $\begin{array}{l}1.177 \\
(.787) \\
\end{array}$ \\
\hline Tie roof of house ${ }^{1}$ & & $\begin{array}{r}1.450^{* *} \\
(.641) \\
\end{array}$ & & $\begin{array}{r}1.010 \\
(.934) \\
\end{array}$ & & $\begin{array}{r}-.383 \\
(.717) \\
\end{array}$ \\
\hline Save food ${ }^{1}$ & & $\begin{array}{r}1.383^{*} \\
(.763)\end{array}$ & & $\begin{array}{r}.438 \\
(.863)\end{array}$ & & $\begin{array}{l}1.228 \\
(.659)\end{array}$ \\
\hline Has production assets ${ }^{2}$ & & $\begin{array}{r}.203 \\
(.569)\end{array}$ & & $\begin{array}{r}-.533 \\
(.714)\end{array}$ & & $\begin{array}{r}-.593 \\
(.660)\end{array}$ \\
\hline Has consumption assets ${ }^{1}$ & & $\begin{array}{r}1.764^{* *} \\
(.742) \\
\end{array}$ & & $\begin{array}{r}-1.081 \\
(.951) \\
\end{array}$ & & $\begin{array}{r}.287 \\
(.827) \\
\end{array}$ \\
\hline Remittance, access to ${ }^{1}$ & & $\begin{array}{r}.540 \\
(.538) \\
\end{array}$ & & $\begin{array}{r}.521 \\
(.692) \\
\end{array}$ & & $\begin{array}{r}-.757 \\
(.614) \\
\end{array}$ \\
\hline Number of children & & $\begin{array}{r}.025 \\
(.130) \\
\end{array}$ & & $\begin{array}{r}.209 \\
(.235) \\
\end{array}$ & & $\begin{array}{r}.210 \\
(.180) \\
\end{array}$ \\
\hline Risk aversion high & & $\begin{array}{r}.416 \\
(.962) \\
\end{array}$ & & $\begin{array}{r}2.158^{* *} \\
(1.025) \\
\end{array}$ & & $\begin{array}{r}.013 \\
(.853) \\
\end{array}$ \\
\hline Risk aversion low & & $\begin{array}{r}-.092 \\
(1.034) \\
\end{array}$ & & $\begin{array}{r}.847 \\
(1.251) \\
\end{array}$ & & $\begin{array}{c}-1.988^{*} \\
(1.147) \\
\end{array}$ \\
\hline Bad house structure $^{1}$ & & $\begin{array}{r}.437 \\
(.894) \\
\end{array}$ & & $\begin{array}{r}2.578 * * * \\
(.977) \\
\end{array}$ & & $\begin{array}{r}-1.833^{* *} \\
(.856) \\
\end{array}$ \\
\hline Good house structure $^{1}$ & & $\begin{array}{r}.736 \\
(1.082) \\
\end{array}$ & & $\begin{array}{r}-.252 \\
(1.200) \\
\end{array}$ & & $\begin{array}{r}1.537 \\
(1.166) \\
\end{array}$ \\
\hline Perception of typhoon risk ${ }^{1}$ & & $\begin{array}{r}1.068^{* *} \\
(.536) \\
\end{array}$ & & $\begin{array}{r}-.751 \\
(.688) \\
\end{array}$ & & $\begin{array}{r}.622 \\
(.585) \\
\end{array}$ \\
\hline Experienced typhoon in past ${ }^{1}$ & & $\begin{array}{r}-2.913^{* * *} \\
(1.046) \\
\end{array}$ & & $\#$ & & $\begin{array}{r}1.290 \\
(1.132) \\
\end{array}$ \\
\hline Experienced accident in past ${ }^{1}$ & & $\begin{array}{r}.133 \\
(.677) \\
\end{array}$ & & $\begin{aligned}-.525 \\
(.868) \\
\end{aligned}$ & & $\begin{array}{r}-1.791^{* *} \\
(.750) \\
\end{array}$ \\
\hline Education & & $\begin{aligned} .228 \\
(.190) \\
\end{aligned}$ & & $\begin{array}{r}-.021 \\
(.036) \\
\end{array}$ & & $\begin{aligned}-.139 \\
(.224) \\
\end{aligned}$ \\
\hline Age in years & & $\begin{array}{r}.009 \\
(.029)\end{array}$ & & $\begin{array}{r}-.019 \\
(.036)\end{array}$ & & $\begin{array}{l}-.016 \\
(.033)\end{array}$ \\
\hline Cut-off & .4 & .4 & .3 & .3 & .8 & .8 \\
\hline Nagelkerke R2 & .12 & .39 & .22 & .42 & .17 & .40 \\
\hline -2 Log Likelihood & 159.56 & 128.22 & 106.75 & 85.91 & 129.06 & 104.20 \\
\hline $\begin{array}{l}\text { Hosmer \& Lemeshow, } \mathrm{X}^{2}, \mathrm{df}=8 \text {, } \\
5 \% \text { significance }\end{array}$ & & 14.28, n.s & & 4.46, n.s & & 4.32, n.s. \\
\hline$\%$ Correctly predicted & 68 & 79 & 63 & 75 & 63 & 72 \\
\hline Heckmann test\#\# & & n.s. & & n.s & & n.s \\
\hline
\end{tabular}

The test for the hypothesis (Payout) is one-sided. The controls are tested two-sided.

*** Significant at the 0.01 level, ** Significant at the 0.05 level, * Significant at the 0.10 level

${ }^{1}$ Yes $=1,0=$ no

${ }^{2} 0=$ no production assets

\# 0 = primary level, 1 = primary finished, 2 = secondary level, 3 = secondary finished, 4 = bachelor level, 5 = higher,

\# = inclusion of this factor leads to a degenerated estimate, and therefore deleted.

\#\# = The predicted value of being insured, based on Table 3-2, Chapter 3, is added as an extra predictor. Non-significance of this predictor means that selection bias or endogeneity is highly unlikely, with significance there is a higher probability.For the correlations related to this table see Appendix 5-

1. 
Table 5-5B Payout and Consumption smoothing activities (Informal, Moneylender and Sellcons) (see 5-5A)

\begin{tabular}{|c|c|c|c|c|c|c|}
\hline & \multicolumn{2}{|c|}{ Informal } & \multicolumn{2}{|c|}{ Moneylender } & \multicolumn{2}{|c|}{ Sellcons } \\
\hline & Model 1 & Model 2 & Model 1 & Model 2 & Model 1 & Model 2 \\
\hline Constant & $\begin{array}{r}.938 \\
(.721)\end{array}$ & $\begin{array}{r}-.546 \\
(2.243)\end{array}$ & $\begin{array}{c}-1.664 \\
(1.075)\end{array}$ & $\begin{array}{r}-.439 \\
(3.371)\end{array}$ & $\begin{array}{r}-1.976 \\
(1.351)\end{array}$ & $\begin{array}{r}-2.825 \\
(5.186)\end{array}$ \\
\hline Sideline & $\begin{array}{r}.177 \\
(.407)\end{array}$ & $\begin{array}{r}.769 \\
(.558)\end{array}$ & $\begin{array}{r}.190 \\
(.656)\end{array}$ & $\begin{array}{r}.449 \\
(.828)\end{array}$ & $\begin{array}{r}.559 \\
(.816)\end{array}$ & $\begin{array}{r}-1.020 \\
(1.398)\end{array}$ \\
\hline Eatless & $\begin{array}{r}.263 \\
(.500)\end{array}$ & $\begin{array}{c}-.160 \\
(.617)\end{array}$ & $\begin{array}{r}.078 \\
(.787)\end{array}$ & $\begin{array}{r}.882 \\
(1.038)\end{array}$ & $\begin{array}{r}-.948 \\
(1.149)\end{array}$ & $\begin{array}{l}-1.286 \\
(1.962)\end{array}$ \\
\hline Ownsavings & $\begin{array}{r}.381 \\
(.453)\end{array}$ & $\begin{array}{r}-.344 \\
(.583)\end{array}$ & $\begin{array}{r}-1.301^{*} \\
(.685)\end{array}$ & $\begin{array}{r}-1.536^{*} \\
(.847)\end{array}$ & $\begin{array}{r}1.670 \\
(1.163)\end{array}$ & $\begin{array}{r}1.505 \\
(1.798)\end{array}$ \\
\hline Informal & & & $\begin{array}{c}. .105 \\
(.645)\end{array}$ & $\begin{array}{r}.174 \\
(.803)\end{array}$ & $\begin{array}{r}.309 \\
(.777)\end{array}$ & $\begin{array}{r}.656 \\
(1.357)\end{array}$ \\
\hline Moneylender & $\begin{array}{r}.010 \\
(.616)\end{array}$ & $\begin{array}{r}.407 \\
(.795)\end{array}$ & & & $\begin{array}{c}1.694^{*} \\
(.832)\end{array}$ & $\begin{array}{r}2.005 \\
(1.326)\end{array}$ \\
\hline Sellcons & $\begin{array}{r}-.329 \\
(.795)\end{array}$ & $\begin{array}{r}.582 \\
(.935)\end{array}$ & $\begin{array}{r}1.963^{* *} \\
(.861)\end{array}$ & $\begin{array}{r}2.360^{* *} \\
(1.126)\end{array}$ & & \\
\hline Stresschild & $\begin{array}{r}.787 \\
(.795)\end{array}$ & $\begin{array}{r}.620 \\
(1.031)\end{array}$ & $\begin{array}{r}2.812^{* * * *} \\
(.889)\end{array}$ & $\begin{array}{r}3.476^{* * * *} \\
(1.255)\end{array}$ & \# & \# \\
\hline Sellprod & $\begin{array}{r}.813 \\
(.633)\end{array}$ & $\begin{array}{l}1.071 \\
(.752)\end{array}$ & $\begin{array}{r}.867 \\
(.943)\end{array}$ & $\begin{array}{r}.530 \\
(1.255)\end{array}$ & $\begin{array}{r}.408 \\
(1.246)\end{array}$ & $\begin{array}{r}-.179 \\
(2.246)\end{array}$ \\
\hline Pay out ${ }^{1}$ & $\begin{array}{l}.593^{*} \\
(.460)\end{array}$ & $\begin{array}{l}.237^{*} \\
(.628)\end{array}$ & $\begin{array}{r}.521 \\
(.656)\end{array}$ & $\begin{array}{l}-.052 \\
(.886)\end{array}$ & $\begin{array}{c}.947 \\
(.903)\end{array}$ & $\begin{array}{l}-1.685 \\
(1.291)\end{array}$ \\
\hline Damage in Php & $\begin{array}{r}.313 \\
(.435)\end{array}$ & $\begin{array}{r}-.005 \\
(.504)\end{array}$ & $\begin{array}{c}. .202 \\
(.693)\end{array}$ & $\begin{array}{c}-.339 \\
(.822)\end{array}$ & $\begin{array}{l}-1.163 \\
(.776)\end{array}$ & $\begin{array}{r}-.649 \\
(1.116)\end{array}$ \\
\hline Previous government support ${ }^{1}$ & $\begin{array}{r}.514 \\
(.391)\end{array}$ & $\begin{array}{r}.411 \\
(.468)\end{array}$ & $\begin{array}{r}.010 \\
(.659)\end{array}$ & $\begin{array}{r}.241 \\
(.753)\end{array}$ & $\begin{array}{r}.190 \\
(.720)\end{array}$ & $\begin{array}{r}-.297 \\
(1.082)\end{array}$ \\
\hline Savings $^{1}$ & & $\begin{array}{r}.515 \\
(.781)\end{array}$ & & $\begin{array}{l}-1.516 \\
(.959)\end{array}$ & & $\begin{array}{r}.586 \\
(1.846)\end{array}$ \\
\hline Build house on poles ${ }^{1}$ & & $\begin{array}{r}-.770 \\
(.620)\end{array}$ & & $\begin{array}{r}-.701 \\
(1.096)\end{array}$ & & $\begin{array}{r}2.266 \\
(1.399)\end{array}$ \\
\hline Tie roof of house ${ }^{1}$ & & $\begin{array}{c}-.013 \\
(.550)\end{array}$ & & $\begin{array}{l}-.245 \\
(.943)\end{array}$ & & $\begin{array}{r}.848 \\
(1.288)\end{array}$ \\
\hline Save food ${ }^{1}$ & & $\begin{array}{r}.455 \\
(648)\end{array}$ & & $\begin{array}{r}-.100 \\
(.808)\end{array}$ & & $\begin{array}{r}-.746 \\
(1.277)\end{array}$ \\
\hline Has production assets ${ }^{2}$ & & $\begin{array}{r}-1.298^{* *} \\
(.551)\end{array}$ & & $\begin{array}{r}-.645 \\
(.779)\end{array}$ & & $\begin{array}{r}1.507 \\
(1.296)\end{array}$ \\
\hline Has consumption assets ${ }^{1}$ & & $\begin{array}{r}.802 \\
(.749)\end{array}$ & & $\begin{array}{r}.517 \\
(.1 .038)\end{array}$ & & $\begin{array}{r}.101 \\
(2.056)\end{array}$ \\
\hline Remittance, access to ${ }^{1}$ & & $\begin{array}{l}.868^{* *} \\
(.493)\end{array}$ & & $\begin{array}{r}.083 \\
(.797)\end{array}$ & & $\begin{array}{r}-1.171 \\
(1.176)\end{array}$ \\
\hline Number of children & & $\begin{array}{r}.171 \\
(.138)\end{array}$ & & $\begin{array}{l}.317^{*} \\
(.185)\end{array}$ & & $\begin{array}{r}.210 \\
(.279)\end{array}$ \\
\hline Risk aversion high & & $\begin{array}{l}-1.057 \\
(.818)\end{array}$ & & $\begin{array}{r}2.002 \\
(1.249) \\
\end{array}$ & & $\begin{array}{r}-1.008 \\
(1.998)\end{array}$ \\
\hline Risk aversion low & & $\begin{array}{r}.432 \\
(.994)\end{array}$ & & $\begin{array}{r}-2.237 \\
(1.663)\end{array}$ & & $\begin{array}{r}.235 \\
(1.940)\end{array}$ \\
\hline Bad house structure ${ }^{1}$ & & $\begin{array}{r}.328 \\
(.721) \\
\end{array}$ & & \begin{tabular}{r|}
-1.888 \\
$(1.204)$ \\
\end{tabular} & & $\begin{array}{r}-.527 \\
(1.933) \\
\end{array}$ \\
\hline Good house structure ${ }^{1}$ & & $\begin{array}{r}.089 \\
(1.023)\end{array}$ & & $\begin{array}{r}1.488 \\
(1.520)\end{array}$ & & $\begin{array}{r}1.242 \\
(1.964)\end{array}$ \\
\hline Perception of typhoon risk ${ }^{1}$ & & $\begin{array}{l}.850^{*} \\
(.517)\end{array}$ & & $\begin{array}{r}.326 \\
(.748)\end{array}$ & & $\begin{array}{r}.719 \\
(1.126)\end{array}$ \\
\hline Experienced typhoon in past ${ }^{1}$ & & $\begin{array}{r}1.917 \\
(1.088)\end{array}$ & & $\begin{array}{r}-.826 \\
(1.266)\end{array}$ & & $\begin{array}{r}.446 \\
(2.030)\end{array}$ \\
\hline Experienced accident in past ${ }^{1}$ & & $\begin{array}{r}.549 \\
(.592)\end{array}$ & & $\begin{array}{r}-.826 \\
(1.022)\end{array}$ & & $\begin{array}{r}.382 \\
(1.712)\end{array}$ \\
\hline Education & & $\begin{array}{r}-.407 * * \\
(.174)\end{array}$ & & $\begin{array}{r}.123 \\
(.276)\end{array}$ & & $\begin{array}{r}.406 \\
(.385)\end{array}$ \\
\hline Age in years & & $\begin{array}{r}.009 \\
(.026)\end{array}$ & & $\begin{array}{r}.005 \\
(.044)\end{array}$ & & $\begin{array}{l}-.117^{*} \\
(.069)\end{array}$ \\
\hline Cut-off & .4 & .4 & .13 & .13 & .1 & .1 \\
\hline Nagelkerke R2 & .13 & .37 & .24 & .37 & .16 & .44 \\
\hline -2 Log Likelihood & 167.03 & 138.35 & 83.85 & 72.45 & 62.05 & 44.17 \\
\hline $\begin{array}{l}\text { Hosmer \& Lemeshow } \\
\mathrm{X}^{2}, \mathrm{df}=8,5 \% \text { significance }\end{array}$ & & 5.79, n.s & & $9.02, \mathrm{n} . \mathrm{s}$ & & 7.75 , n.s \\
\hline$\%$ Correctly predicted & 64 & 68 & 74 & 78 & 77 & 84 \\
\hline Heckmann test\#\# & & n.s. & & n.s & & n.s \\
\hline
\end{tabular}


Table 5-5C Payout and Consumption smoothing activities (Child, Sellprod, Moveout)

\begin{tabular}{|c|c|c|c|c|}
\hline & Stresschild\#\#\# & & Sellprod $^{\mathrm{I}}$ & \\
\hline & Model 1 & Model 2 & Model 1 & Model 2 \\
\hline Constant & $\begin{array}{r}-15.093 \\
(4.085)\end{array}$ & $\begin{array}{l}-20.650 \\
(7.596)\end{array}$ & $\begin{array}{r}-7.536 \\
(2.331)\end{array}$ & $\begin{array}{l}-11.183 \\
(5.250)\end{array}$ \\
\hline Sideline & $\begin{array}{r}.778 \\
(.867)\end{array}$ & $\begin{array}{r}1.103 \\
(1.218)\end{array}$ & $\begin{array}{l}1.487 \\
(.646)\end{array}$ & $\begin{array}{r}2.824^{* * *} \\
(1.118)\end{array}$ \\
\hline Eatless & $\begin{array}{r}1.632 \\
(1.120)\end{array}$ & $\begin{array}{r}2.667 \\
(1.808)\end{array}$ & $\begin{array}{r}.844 \\
(.720)\end{array}$ & $\begin{array}{r}1.458 \\
(1.129)\end{array}$ \\
\hline Ownsavings & $\begin{array}{r}1.614 \\
(1.315)\end{array}$ & $\begin{array}{r}1.579 \\
(1.462)\end{array}$ & $\begin{array}{r}.718 \\
(.896)\end{array}$ & $\begin{array}{r}1.989 \\
(1.426)\end{array}$ \\
\hline Informal & $\begin{array}{r}.777 \\
(.827)\end{array}$ & $\begin{array}{r}1.161 \\
(1.156)\end{array}$ & $\begin{array}{l}1.064 \\
(.655)\end{array}$ & $\begin{array}{l}1.371 \\
(.940)\end{array}$ \\
\hline Moneylender & \# & \# & $\begin{array}{l}1.039 \\
(.938)\end{array}$ & $\begin{array}{r}1.570 \\
(1.411)\end{array}$ \\
\hline Sellcons & \# & \# & $\begin{array}{r}-.018 \\
(1.489)\end{array}$ & $\begin{array}{r}-3.338 \\
(2.990)\end{array}$ \\
\hline Stresschild & & & $\begin{array}{r}-2.206 \\
(1.397)\end{array}$ & $\begin{array}{r}-6.109 * * \\
(3.117)\end{array}$ \\
\hline Sellprod & $\begin{array}{r}-.543 \\
(1.369) \\
\end{array}$ & $\begin{array}{r}-.443 \\
(2.400) \\
\end{array}$ & & \\
\hline Pay out ${ }^{1}$ & $\begin{array}{r}2.178^{* * *} \\
(1.019) \\
\end{array}$ & $\begin{array}{r}2.541 \\
(1.703)\end{array}$ & \#,IV & \#, IV \\
\hline Damage in Php & $\begin{array}{r}4.879^{* * *} \\
(1.660)\end{array}$ & $\begin{array}{r}5.576 \\
(2.516)\end{array}$ & $\begin{array}{l}1.955 \\
(.948) \\
\end{array}$ & $\begin{array}{r}3.308^{* * *} \\
(1.524)\end{array}$ \\
\hline Previous government support ${ }^{1}$ & $\begin{array}{r}1.568 \\
(1.027)\end{array}$ & $\begin{array}{r}1.789 \\
(1.221)\end{array}$ & $\begin{array}{r}.583 \\
(.752)\end{array}$ & $\begin{array}{r}.539 \\
(1.184)\end{array}$ \\
\hline Savings ${ }^{1}$ & & \# & & $\begin{array}{r}.295 \\
(1.544) \\
\end{array}$ \\
\hline Build house on poles ${ }^{1}$ & & $\begin{array}{r}.445 \\
(2.045)\end{array}$ & & $\begin{array}{r}2.563^{* *} \\
(1.365)\end{array}$ \\
\hline Tie roof of house ${ }^{1}$ & & $\begin{array}{r}.888 \\
(1.255)\end{array}$ & & $\begin{array}{r}-4.513^{* * * *} \\
(1.689)\end{array}$ \\
\hline Save food ${ }^{1}$ & & $\begin{array}{r}.813 \\
(1.719)\end{array}$ & & $\begin{array}{r}-.509 \\
(1.671)\end{array}$ \\
\hline Has production assets ${ }^{2}$ & & $\begin{array}{r}2.334 \\
(1.779)\end{array}$ & & $\begin{array}{l}2.348^{*} \\
(1.275)\end{array}$ \\
\hline Has consumption assets ${ }^{1}$ & & $\begin{array}{r}-1.128 \\
(1.684)\end{array}$ & & $\begin{array}{r}1.164 \\
(1.502)\end{array}$ \\
\hline Remittance, access to ${ }^{1}$ & & $\begin{array}{r}.004 \\
(1.171)\end{array}$ & & $\begin{array}{r}1.686 \\
(1.132)\end{array}$ \\
\hline Number of children & & $\begin{array}{r}.474 \\
(.248)\end{array}$ & & $\begin{array}{r}-.256 \\
(.275)\end{array}$ \\
\hline Risk aversion high & & $\begin{array}{r}-.263 \\
(2.335)\end{array}$ & & $\begin{array}{r}1.501 \\
(1.623)\end{array}$ \\
\hline Risk aversion low & & $\begin{array}{r}-.254 \\
(1.966)\end{array}$ & & \#,IV \\
\hline Bad house structure $^{1}$ & & $\begin{array}{r}-1.325 \\
(2.182)\end{array}$ & & $\begin{array}{r}1.322 \\
(1.485)\end{array}$ \\
\hline Good house structure $^{1}$ & & $\begin{array}{r}-.296 \\
(1.839)\end{array}$ & & $\begin{array}{r}-.843 \\
(1.575)\end{array}$ \\
\hline Perception of typhoon risk ${ }^{1}$ & & \# & & $\begin{array}{r}-.549 \\
(1.077)\end{array}$ \\
\hline Experienced typhoon in past ${ }^{1}$ & & \# & & $\begin{array}{r}.509 \\
(2.272)\end{array}$ \\
\hline Experienced accident in past ${ }^{1}$ & & \# & & $\begin{array}{r}1.454 \\
(1.283)\end{array}$ \\
\hline Education & & \# & & $\begin{array}{r}.068 \\
(.309)\end{array}$ \\
\hline Age in years & & \# & & $\begin{array}{r}-.101 \\
(.064)\end{array}$ \\
\hline Cut-off & .1 & .1 & & .12 \\
\hline Nagelkerke R2 & .42 & .55 & .27 & .56 \\
\hline -2 Log Likelihood & 45.86 & 37.06 & 74.38 & 49.08 \\
\hline $\begin{array}{l}\text { Hosmer \& Lemeshow } \\
\mathrm{X}^{2}, \mathrm{df}=8,5 \% \text { significance }\end{array}$ & & $.86, \mathrm{cn} . \mathrm{s}$ & & $3.89, \mathrm{n} . \mathrm{s}$ \\
\hline$\%$ Correctly predicted & 81 & 84 & 73 & 85 \\
\hline Heckmann test\#\# & & n.s & & n.s \\
\hline
\end{tabular}

See Table 5-5A
$\# \#$ = only a few (10) observed in category 1 of the dependent.

$\mathrm{IV}=$ none of the insured applies this strategy. Only one household also takes children from school or is low risk averse and sell productions assets, therefore estimation issues arise(no variation). The interpretation of the results should consider this. 
Table 5-6 Combined consumption smoothing variable

\begin{tabular}{|c|c|c|c|c|c|c|c|}
\hline & $\begin{array}{r}\text { Model } 1 \\
\text { Stressord } 1 \\
\end{array}$ & $\begin{array}{r}\text { Model } 2 \\
\text { Stressord } 1 \\
\end{array}$ & $\begin{array}{r}\text { Model 2a } \\
\text { Stressord } 1 \\
\end{array}$ & $\begin{array}{r}\text { Stressord } 1 \\
\text { Payout } \\
\end{array}$ & $\begin{array}{r}\text { Stressord } 1 \\
\text { Net damage } \\
\end{array}$ & $\begin{array}{r}\text { Stressord } 2 \\
\text { Payout } \\
\end{array}$ & $\begin{array}{r}\text { Stressord } 2 \\
\text { Net damage } \\
\end{array}$ \\
\hline \multicolumn{8}{|l|}{$\begin{array}{l}\text { Threshold [low- } \\
\text { stress] }\end{array}$} \\
\hline $\begin{array}{l}\text { Threshold } \\
\text { [low- to medium- } \\
\text { stress] }\end{array}$ & $\begin{array}{l}1.743 \\
(.619)\end{array}$ & $\begin{array}{l}1.992 \\
(.813)\end{array}$ & $\begin{array}{r}2.387 \\
(1.122)\end{array}$ & $\begin{array}{r}.167 \\
(1.76)\end{array}$ & $\begin{array}{r}-.530 \\
(1.665)\end{array}$ & $\begin{array}{r}-.457 \\
(1.747)\end{array}$ & $\begin{array}{r}-.818 \\
(1.649)\end{array}$ \\
\hline $\begin{array}{l}\text { Threshold } \\
\text { [medium-to high- } \\
\text { stress] }\end{array}$ & $\begin{array}{l}3.711 \\
(.685)\end{array}$ & $\begin{array}{l}3.967 \\
(.871)\end{array}$ & $\begin{array}{r}4.396 \\
(1.172)\end{array}$ & $\begin{array}{l}2.305 \\
(1.77)\end{array}$ & $\begin{array}{r}1.575 \\
(1.672)\end{array}$ & $\begin{array}{r}1.101 \\
(1.749)\end{array}$ & $\begin{array}{r}.619 \\
(1.648)\end{array}$ \\
\hline $\begin{array}{l}\text { Payout } \\
\text { (1=yes) }\end{array}$ & $\begin{array}{r}-.824 * * * \\
(.379) \\
\end{array}$ & $\begin{array}{r}-.847 * * \\
(.409) \\
\end{array}$ & $\begin{array}{r}-.799 * * \\
(.423) \\
\end{array}$ & $\begin{array}{r}-.825^{* *} \\
(.463) \\
\end{array}$ & & $\begin{array}{r}-.912 * * \\
(.459) \\
\end{array}$ & \\
\hline Damage in Php & $\begin{array}{r}1.368 * * * \\
(.393)\end{array}$ & $\begin{array}{r}1.366^{* * *} \\
(.399) \\
\end{array}$ & $\begin{array}{r}1.336 * * * \\
(.405)\end{array}$ & $\begin{array}{r}1.455^{* * * *} \\
(.427)\end{array}$ & & $\begin{array}{r}1.199 * * * \\
(.414)\end{array}$ & \\
\hline Net damage & & & & & $\begin{array}{r}1.020^{* * *} \\
(297) \\
\end{array}$ & & $\begin{array}{r}.886^{* * * *} \\
(.290) \\
\end{array}$ \\
\hline $\begin{array}{l}\text { Previous } \\
\text { government } \\
\text { support }^{1} \\
\end{array}$ & $\begin{array}{l}.724 * * \\
(.346)\end{array}$ & $\begin{array}{l}.761^{* * *} \\
(.354)\end{array}$ & $\begin{array}{r}.723 * * \\
(.366)\end{array}$ & $\begin{array}{l}.698 * \\
(.379)\end{array}$ & $\begin{array}{l}.654^{*} \\
(.378)\end{array}$ & $\begin{array}{l}.647^{*} \\
(.373)\end{array}$ & $\begin{array}{l}.618^{*} \\
(.372)\end{array}$ \\
\hline Savings $^{1}$ & & $\begin{array}{r}.321 \\
(.552) \\
\end{array}$ & $\begin{array}{r}.391 \\
(.562) \\
\end{array}$ & $\begin{array}{r}.370 \\
(.596) \\
\end{array}$ & $\begin{array}{r}.498 \\
(.589)\end{array}$ & $\begin{array}{r}-.015 \\
(.575)\end{array}$ & $\begin{array}{r}.096 \\
(.570) \\
\end{array}$ \\
\hline $\begin{array}{l}\text { Build house on } \\
\text { poles }^{1}\end{array}$ & & $\begin{array}{r}.054 \\
(.403) \\
\end{array}$ & $\begin{array}{r}.080 \\
(.443) \\
\end{array}$ & $\begin{array}{r}.029 \\
(.483) \\
\end{array}$ & $\begin{array}{r}-.017 \\
(.481) \\
\end{array}$ & $\begin{array}{r}-.086 \\
(.480) \\
\end{array}$ & $\begin{array}{r}-.082 \\
(.476) \\
\end{array}$ \\
\hline $\begin{array}{l}\text { Tie roof of house } \\
1\end{array}$ & & $\begin{array}{r}-.010 \\
(.403) \\
\end{array}$ & $\begin{array}{r}-.049 \\
(.410) \\
\end{array}$ & $\begin{array}{r}-.077 \\
(.423) \\
\end{array}$ & $\begin{array}{r}-.071 \\
(.408) \\
\end{array}$ & $\begin{array}{r}-.036 \\
(.418) \\
\end{array}$ & $\begin{array}{r}-.095 \\
(.403) \\
\end{array}$ \\
\hline Save food ${ }^{1}$ & & $\begin{array}{r}-.080 \\
(.439) \\
\end{array}$ & $\begin{array}{r}-.072 \\
(.447) \\
\end{array}$ & $\begin{array}{r}-.026 \\
(.474) \\
\end{array}$ & $\begin{array}{r}.025 \\
(.470) \\
\end{array}$ & $\begin{array}{r}-.078 \\
(.468) \\
\end{array}$ & $\begin{array}{r}-.045 \\
(.463) \\
\end{array}$ \\
\hline $\begin{array}{l}\text { Has production } \\
\text { assets }^{2}\end{array}$ & & & $\begin{array}{r}.418 \\
(.401) \\
\end{array}$ & $\begin{array}{r}.499 \\
(.417) \\
\end{array}$ & $\begin{array}{r}.469 \\
(.416) \\
\end{array}$ & $\begin{array}{r}.416 \\
(.410) \\
\end{array}$ & $\begin{array}{r}.415 \\
(.409) \\
\end{array}$ \\
\hline $\begin{array}{l}\text { Has consumption } \\
\text { assets }{ }^{1}\end{array}$ & & & $\begin{array}{r}-.024 \\
(.526)\end{array}$ & $\begin{array}{r}-.111 \\
(.539) \\
\end{array}$ & $\begin{array}{r}-.213 \\
(.529)\end{array}$ & $\begin{array}{r}.087 \\
(.468)\end{array}$ & $\begin{array}{r}-.021 \\
(.523)\end{array}$ \\
\hline $\begin{array}{l}\text { Remittance, } \\
\text { access to }^{1}\end{array}$ & & & $\begin{array}{r}.353 \\
(.365) \\
\end{array}$ & $\begin{array}{r}.446 \\
(.394) \\
\end{array}$ & $\begin{array}{r}.402 \\
(.391) \\
\end{array}$ & $\begin{array}{r}.322 \\
(.389) \\
\end{array}$ & $\begin{array}{r}.284 \\
(.387) \\
\end{array}$ \\
\hline $\begin{array}{l}\text { Number of } \\
\text { children }\end{array}$ & & & $\begin{array}{r}.002 \\
(.093) \\
\end{array}$ & $\begin{array}{r}-.012 \\
(.096) \\
\end{array}$ & $\begin{array}{r}-.019 \\
(.095) \\
\end{array}$ & $\begin{array}{r}.013 \\
(.095) \\
\end{array}$ & $\begin{array}{r}-.001 \\
(.094) \\
\end{array}$ \\
\hline $\begin{array}{l}\text { Risk aversion } \\
\text { high }\end{array}$ & & & $\begin{array}{r}.086 \\
(.486)\end{array}$ & $\begin{array}{r}-.001 \\
(.634)\end{array}$ & $\begin{array}{r}-.059 \\
(.629)\end{array}$ & $\begin{array}{r}.154 \\
(.623)\end{array}$ & $\begin{array}{r}.090 \\
(.619) \\
\end{array}$ \\
\hline Risk aversion low & & & $\begin{array}{r}-.257 \\
(.483) \\
\end{array}$ & $\begin{array}{r}-.454 \\
(.764) \\
\end{array}$ & $\begin{array}{r}-.574 \\
(.371) \\
\end{array}$ & $\begin{array}{r}-.544 \\
(.770) \\
\end{array}$ & $\begin{array}{r}-.600 \\
(.760) \\
\end{array}$ \\
\hline $\begin{array}{l}\text { Bad house } \\
\text { structure }^{1}\end{array}$ & & & & $\begin{array}{r}.045 \\
(.566) \\
\end{array}$ & $\begin{array}{r}-.002 \\
(.555) \\
\end{array}$ & $\begin{array}{r}-.062 \\
(.560) \\
\end{array}$ & $\begin{array}{r}-.067 \\
(.548) \\
\end{array}$ \\
\hline $\begin{array}{l}\text { Good house } \\
\text { structure }^{1}\end{array}$ & & & & $\begin{array}{r}.188 \\
(.821) \\
\end{array}$ & $\begin{array}{r}.318 \\
(.808) \\
\end{array}$ & $\begin{array}{r}.214 \\
(.828) \\
\end{array}$ & $\begin{array}{r}.244 \\
(.810) \\
\end{array}$ \\
\hline $\begin{array}{l}\text { Perception of } \\
\text { typhoon risk }^{1}\end{array}$ & & & & $\begin{array}{r}-.531 \\
(.369) \\
\end{array}$ & $\begin{array}{r}-.591 \\
(.371) \\
\end{array}$ & $\begin{array}{r}-.441 \\
(.364) \\
\end{array}$ & $\begin{array}{r}-.504 \\
(.366) \\
\end{array}$ \\
\hline $\begin{array}{l}\text { Experienced } \\
\text { typhoon in past }^{1}\end{array}$ & & & & $\begin{array}{r}-.445 \\
(.660) \\
\end{array}$ & $\begin{array}{r}-.350 \\
(.627) \\
\end{array}$ & $\begin{array}{r}.847 \\
(.657) \\
\end{array}$ & $\begin{array}{r}.662 \\
(.618) \\
\end{array}$ \\
\hline $\begin{array}{l}\text { Experienced } \\
\text { accident in past }^{1}\end{array}$ & & & & $\begin{array}{l}.910^{*} \\
(.497)\end{array}$ & $\begin{array}{r}.780 \\
(.491)\end{array}$ & $\begin{array}{r}.910 \\
(.494) \\
\end{array}$ & $\begin{array}{l}.806 * \\
(.488)\end{array}$ \\
\hline Education & & & & $\begin{array}{r}-.114 \\
(.131) \\
\end{array}$ & $\begin{array}{r}-.131 \\
(.130) \\
\end{array}$ & $\begin{array}{r}-.102 \\
(.129) \\
\end{array}$ & $\begin{array}{r}-.128 \\
(.128) \\
\end{array}$ \\
\hline Age in years & & & & $\begin{array}{r}-.034 \\
(.022)\end{array}$ & $\begin{array}{r}-.034 \\
(.022)\end{array}$ & $\begin{array}{l}-.027 \\
(.022)\end{array}$ & $\begin{array}{r}-.028 \\
(.021)\end{array}$ \\
\hline Nagelkerke R2 & .18 & .18 & .20 & .27 & .25 & .23 & .21 \\
\hline $\begin{array}{l}\text {-2 Log Likelihood } \\
\text { - Intercept only }\end{array}$ & 157.384 & 236.728 & 279.860 & 281.354 & 281.246 & 289.187 & 289.187 \\
\hline $\begin{array}{l}\text {-2 log likelihood } \\
\text { model }\end{array}$ & 134.343 & 213.334 & 254.030 & 244.710 & 247.500 & 259.337 & 262.125 \\
\hline Heckmann test\#\# & & & n.s. & n.s. & n.s. & n.s. & n.s. \\
\hline $\begin{array}{l}\text { Parallel lines test } \\
\mathrm{X}^{2}\end{array}$ & & & & $\begin{array}{r}\mathrm{df}=20 \\
24.593 \\
\mathrm{n} . \mathrm{s}\end{array}$ & $\begin{array}{l}\mathrm{Df}=19 \\
30.834\end{array}$ & $\begin{array}{r}\mathrm{df}=20, \\
18.935 \\
\mathrm{n} . \mathrm{s}\end{array}$ & $\begin{array}{r}\mathrm{Df}=19, \\
21.732 \text { n.s }\end{array}$ \\
\hline
\end{tabular}

See Table 5-5A 


\subsection{Discussion}

Analysis of the effect of the microinsurance pay-out on the separate consumption smoothing activities shows that the pay-out has a negative effect on most activities and this effect is significant for the side line activities: use of own savings, use of informal risk-sharing and sale of production assets. For eat less and taking children out of school there is a positive effect of the pay-out which is not significant. The inclusion of theoretically relevant factors and the Heckman check suggest that it is unlikely that there is omitted variable bias.

It may be that the positive effect on eat less can be explained by the fact that less higherstress consumption smoothing activities are used and these are substituted by the insurance and other low-stress activities. This is however not certain. It should be noted that households which take children out of school are all insured. In addition, the positive effect may be caused by the fact that the insured are more likely to have children in school. CARD has a school-fee program which may lead insured households to have more children in school and therefore could make them more likely to take children out of school in case of shocks. This should be further investigated.

The significant effect of the pay-out on the combined consumption smoothing variable, suggests that indeed the insurance reduces the use of higher-stress consumption smoothing activities. Several assumptions were made to construct this variable. The non-significance of the parallel lines test suggests that the ordinal character is a valid approach. The robustness of the models over the different constructions of the dependent variables further strengthens this.

The finding that selling production assets is negatively related with taking children out of school and borrowing from a money lender (the activities which were advanced as high-stress) supports the assumption that if a household uses one high-stress activity, they are less likely to use another high-stress activity, especially because the average amount of consumption smoothing activities used is 2.7.

It is also interesting to note that the preventive activities and ex-ante situation of households in all estimations account for a substantial proportion of the explained variance. This suggests that households don't pick consumption smoothing activities at random but that a choice is made specific to the household's situation. The significant effect of other consumption smoothing activities on a particular activity further supports this. Most notable is the relation between production assets and side line activities which may be an indication of the fact that these households are entrepreneurial.

The sample size used in this study and the necessity of including many factors as controls sometimes causes standard errors to be high and leads some models to degenerate, which implies that especially the non-significance of certain factors in Table 5-5 may not hold if the sample size was larger.

The categorization of the various consumption smoothing activities into low, mediumand high-stress activities was based on theories about coping strategies and were 
verified in the focus groups and interviews. To further support the validity of our findings different constructions of the dependent variable were also tested (Table 5-6 and Appendix 5-2). In addition, the robustness of our findings was further investigated by constructing a variable reflecting the amount of consumption smoothing activities that a household used. For this construction the significant and negative effect of the pay-out remains; and so does the positive and significant effect of damage and government support.

\subsection{Conclusion}

Micro insurance does indeed have the expected effect that it reduces the likelihood that households have to employ more stressful consumption smoothing activities after a shock, with the exception of Stresschild. Even though it is a robust effect, the effect is not very strong. This is likely to be caused by this particular insurance product, which does not attempt to fully cover the damage but intends to provide start-up capital after a typhoon. The economic loss of damage to houses caused by typhoons in typhoon-prone regions in the Philippines is on average Php 4658 per affected household and the average claim payment Php 2129. For the poorest section of the Philippine society this is 7 per cent of the average family income per year. 28 Per cent of the insured typhoon victims have received a pay-out at least equalling the economic loss. Therefore they do not necessarily have to resort to use of a coping strategy. The other 72 per cent of insured typhoon victims received a pay-out which covered part of the total economic loss and therefore still had to resort to other consumption smoothing activities.

This also suggests that the strength of observed effects in this study are likely to be different when other insurance products are considered. The implication is that the effect of the insurance will become stronger when the insurance is intended to cover shocks with higher losses. However, the designs and business process of the insurance will determine the effect. As mentioned, PAID-plan pays out based on the 1-3-5 strategy and indeed households report that pay-outs are made within a week. As soon as the time lapse between the shock and the pay-out increases households may be forced to use stressful consumption smoothing activities, even though the pay-out comes later. In this case the effect of the insurance may be significantly reduced. Another characteristic of PAID plan is that the insurance is meant to provide initial start-up capital for rebuilding the house. This reduces the likelihood of crowding-out of ex-ante prevention activities such as tying a house following a typhoon warning. This assumption is supported by the fact that 72 per cent of the insured typhoon victims in our sample still use consumption smoothing activities in addition to the PAID plan pay-out. It can be hypothesized that if the insurance fully covers the losses, over time, households will take fewer preventive measures and this may also reduce the effect of the insurance.

There are some factors which have the potential to lead to distributional effects of the insurance identified in Table 5-4. Households with a bad house structure and households with previous typhoon experiences are less likely to have insurance; while households with a good house structure and higher education are more likely to have insurance. This may be an indication that well-off households are more likely to take up 
the insurance, even though this was not confirmed in Chapter 3 when demand was analyzed. In Chapter 3 the effect of lower levels of risk aversion was observed to influence insurance demand. These factors are not identified as significant in the estimations of the high-stress activities in Table 5-5 and the combined variables in Table 5-6. This result should be taken carefully because, as was previously mentioned, for some consumption smoothing activities the sample size in this study is relatively small, which may imply that some factors for some consumption smoothing activities do not appear as significant in the models.

The pattern of consumption smoothing activities of households in villages with extreme shocks shows that in these cases the consumption smoothing activities which are employed significantly change. 63 per cent of households in these villages moved out and were relocated. The sale of production assets is significantly less, which may suggest that these were also destroyed, while informal risk-sharing, eating less and borrowing from a moneylender significantly increase, to an average 93 per cent reliance on informal risk-sharing. The pay-out of the insurance in this study is not intended to deal with such extreme shocks.

The pattern of use of consumption smoothing activities also appears to change in different contexts. As mentioned the smoothing activities are specific to a particular context (for example: large percentage of households with savings in The Philippines leads to frequent use of savings as a smoothing activity) and therefore the frequency with which they are used and their importance to overall coping, is assumed to be different in different contexts. Therefore the generic categorization of consumption smoothing activities that is proposed by Watts (1983), Maxwell and Frankenberger (1992), Corbett, (1988) and Cutler (1984) and Cohen and Sebstad (2005) is not considered to be of value. This is also supported by the information from our focus groups in which the use of certain activities was found not to fit with categorizations suggested by above authors.

However, the contribution of this study is that it shows that the choice for consumption smoothing activities is highly dependent on the ex-ante situation of households and that this is often more important than the extent of the damage. This is different in the extreme shock villages, which may be explained by the fact that the extreme shock did not leave households a choice. This study also found the existence of patterns of combinations of consumption smoothing activities. A final contribution of this study is that it recognizes that microinsurance may also impact persistent poverty which is often caused by the fact that, due to shocks, households have to employ costly consumption smoothing activities in the light of future income and productivity (Dercon, 2004; Carter, Little, Mogues, Negatu, 2007; Fafchamps, 2003). The parallel lines test and check for alternative constructions of the dependent variable show that the ordinal construction is valid. This confirms that households will exhaust their options for using lower-stress consumption smoothing activities before they employ higher-stress consumption smoothing activities. In addition it confirms that high-stress activities can be replaced by other high-stress activities or several lower-stress activities and it is more stressful to use one higher-stress activity then several lower-stress activities in terms of impact on future income and productivity. 


\section{Chapter 6}

\section{Conclusions and discussion}

\subsection{Introduction}

Microinsurance has the potential to assist poor people in developing countries to cope with natural disasters. Poor people often lack the financial reserves to deal with these risks and the consequent shocks. Uninsured risk has welfare implications which go well beyond the consequences for short-term consumption and is a cause of persistent poverty (Townsend, 1994, Dercon, 2004, Carter, Little, Mogues, Negatu, 2007). The inability to deal with shocks may reduce a society's capacity to accumulate, innovate and develop (Fafchamps, 2003: 146).

In recent years microinsurance has been introduced as a mechanism with the potential to assist the poor in dealing with risk. Under the assumption that there is perfect information, if there was insurance of premium $m$ that would equal the expected outcome (economic loss multiplied by probability of the loss) and individuals were risk averse, then they would be willing to buy full insurance because it would maximize their utility.

To cope with shocks, poor households often already rely on existing strategies such as risk diversification, borrowing, using savings, depleting production assets and informal risk-sharing between households. Such activities, like insurance, have the objective of smoothing income and smoothing consumption (Alderman and Paxson, 1994 and Morduch, 1995). Research shows that the level of consumption smoothing which poor households confronted with idiosyncratic shocks achieve through existing activities is not sufficient. Furthermore, natural hazards tend to be correlated and because households are assumed to be risk averse, this implies that there is opportunity for complementary mechanisms for coping with uncertain expenses, such as microinsurance.

However, even if microinsurance is supplied, the demand for microinsurance in developing countries is low in comparison to expected demand based on expected utility theory. An increasing number of empirical studies investigating microinsurance demand in developing countries conclude that risk aversion leads to less, instead of more, take up (Gine et. al., 2008, Cole et al., 2010, Ito and Kono, 2010, Clarke and Kalani, 2011, Dercon, Gunning and Zeitlin, 2011). This also contradicts predictions by expected utility theory, namely that demand for insurance is higher for risk-averse individuals who use insurance to avoid the risk of loss (e.g. Arrow, 1963, 1965, Pratt, 1964, Mossin, 1968; Feldstein, 1973; Schlesinger and Doherty, 1985). How can the relatively low demand and the inverse effect of risk aversion be explained? 
Insurance does not necessarily only have a complementary role to existing consumption smoothing activities, but these existing activities and microinsurance may also substitute each other (Arnott and Stiglitz, 1991). If microinsurance was actuarially fair and would fully substitute existing consumption smoothing activities, there would be no change in the level of insurance achieved; and there would not be changes in expected utility for a single period utility maximizing decision. However, the question remains, are there effects of microinsurance outside of this single period decision?

\subsection{Research question}

Despite the potential of microinsurance to lead to welfare improvements caused by increasing consumption, demand is relatively low. This may result in suboptimal levels of welfare and have distributional effects for households with certain characteristics. In addition, households already rely on existing income- and consumption smoothing activities. In this way, microinsurance can complement or substitute existing mechanisms which may have consequences beyond immediate impact on current levels of consumption. Therefore the following dual research question was asked:

Why do low income households demand microinsurance and does it impact poverty reduction?

To answer this question this thesis was divided in two parts: The first part focused on understanding demand and the second part on assessing microinsurance impact.

\subsection{Conclusions from chapters}

In Chapter 2 an analysis of theory and a literature review was done to understand why low-income households demand microinsurance. A total of 31 empirical studies on microinsurance demand were compared by making use of a general theoretical framework. Expected utility theory was taken as the starting point, as it is typically used for understanding decision making about insurance. Critical assumptions based on application of expected utility theory were compared with the actual situation in microinsurance markets. This led to identification of the following factors potentially influencing insurance demand: price, subsidies and discounts, insured risk and the risk situation of the household, credit constraints, prevention and informal insurance, marketing characteristics, (risk) preferences, understanding of insurance and social capital, networks and trust.

The first conclusion is that many studies compared adoption versus non-adoption. This makes sense if households are aware of the existence of the insurance and have been properly informed. However, as soon as adopters are compared to non-adopters, while these non-adopters can be households without insurance awareness knowledge or households which are still in a persuasion stage before they actually make their decision, it is difficult to attribute observed effects to the correct mechanisms. 
The literature study also showed that there is consistent evidence that a higher price of the insurance leads to lower take up of insurance, with additional transaction costs such as transportation adding to this effect. Subsidies and discounts were found to have a positive effect on take up. However, it was also found that, even when the net policy price was below the actuarially fair premium of the insurance, the take up was low. These findings suggest that factors other than price are likely to play an important role in demand for insurance.

Households with a high-risk exposure compared to the average were more likely to take up microinsurance. This implies that there is potential for adverse selection and moral hazard if the insurance product designs are not corrected for this.

Another finding is that it appears that risk aversion leads to less, instead of more, take up of insurance, which contradicts general predictions by theories used to understand insurance demand. Even though this effect was observed in several studies, most of these studies did not consider the possibility that low-income households may view insurance as a loss and did not attempt to assess risk preferences in gain and loss frames, as suggested by Prospect Theory. This option should be further investigated.

Another explanation which was provided in these studies for the unexpected effect of risk aversion was uncertainty about the insurance itself. Factors investigated, because of their potential for reducing uncertainty, are: financial literacy and education and trust. The evidence for the effect of financial literacy and education on insurance uptake is not consistent. Some studies find a positive effect while others find no significant effect.

Trust recurs in many qualitative studies as an important factor for microinsurance take up: trust in the insurance, trust in the insurer, trust in the management of the scheme, trust in legal and regulatory frameworks. Only two quantitative studies have investigated trust but operationalized and investigated it in a different manner. This implies that further research is needed to understand how and to what extent uncertainty influences microinsurance demand and how this uncertainty can be reduced. .

Social capital and network characteristics were observed to have a significant effect on insurance uptake, but also here no consistent evidence was provided about the mechanisms through which these effects occur. It is suggested that social capital and networks may contribute to increasing understanding of insurance and in this way reduce uncertainty. Social capital and networks may influence beliefs about microinsurance, leading to behavioral explanations for insurance demand. There may be issues of scale or collective action, or they may be an indication of the prevalence of informal risk-sharing and therefore the need for microinsurance may be reduced. Finally, it was suggested in Chapter 2 that social capital and networks may reduce uncertainty about the insurance by increasing the level of trust in the insurance transaction.

The need for a better understanding of the mechanisms behind the effect of social capital, networks and trust led to a focus in Chapter 3 on trust built through insurance experiences of neighbors. 
The concept of trust may be especially relevant to understanding demand for insurance in developing countries because experiences with insurance are often lacking, or are characterized by opportunistic behavior of insurers, either because of lack of solvability or because of bad intentions. It is also known that an individual's decision to take up insurance itself is considered to be risky because the insurance purchase implies a risk of loss if the claim is not paid. Following Gambetta (1988), trust in the insurance transaction is defined as: the perceived probability that the insurer will pay the claim if the low income household experiences the insured loss is high enough for the low income household to engage in the insurance contract and pay the insurance premium. Therefore in this study a key question addressed was: how, and to what extent, does trust influence the demand for microinsurance? This question is especially important for poor households in rural areas in developing countries, which often either don't have insurance experiences, or have been exposed to bankruptcy of insurance companies in the past; so these formal trust-building institutions are often not accessible, reliable or existent. In addition, recurrent transactions are not very frequent with microinsurance because claims are rare. Rogers (2003:177) explains that in this case of 'preventive innovations' knowing positive experiences with microinsurance of trusted neighbors in local peer networks can play a strong role in building trust in the insurance transaction. Therefore in this chapter it was investigated if knowing peers with claims is indeed the vehicle through which trust in the microinsurance transaction occurs.

Therefore in Chapter 3 it was hypothesized that:

Trust, built through knowing peers with claims, positively affects the demand for microinsurance.

To scrutinize the role of trust in explaining demand, a model was tested in which knowing peers with claims was the key variable and the factors identified in Chapter 2 were used as controls. The data used were collected through a combination of eleven focus groups and interviews with 200 low-income households in the Philippines with and without insurance. Knowing peers with claims was found to be, apart from risk aversion and ownership of consumption assets, the most important factor explaining the uptake of microinsurance in the study. Another interesting finding was that, especially for low risk averse households, the effect of knowing peers with claims is significantly lower than for households with higher risk aversion. For households with higher risk aversion, knowing peers with claims had a positive effect on insurance demand. This suggests that indeed trust can reduce uncertainty in the insurance transaction. Other potential explanations for the observed effect of knowing peers with claims in our study such as access to awareness knowledge about the insurance, learning about the insurance, imitation, occurrence of the risk and marketing effects, were tested for but not found to have an effect. The extensive tests for alternative explanations make it highly likely that the effect of knowing peers with claims is indeed an indication of informal trust-building.

Chapter 2 and 3 focused on understanding why low-income households demand microinsurance under the assumption that households which are risk averse and attempt to maximize their utility are willing to take up microinsurance to smooth consumption and protect themselves against the risk of loss. Empirical studies investigating the 
demand for microinsurance were analyzed to understand factors which lead to less than optimal demand under the assumption that if these factors, and the mechanisms through which they affect microinsurance demand, are known then they can be corrected for to improve insurance demand. In Chapter 4 and 5 this approach is extended to include the component of the central research question that concerns microinsurance impact.

Chapter 4 started with a discussion of theories for understanding microinsurance impact. These theories explain that consumption smoothing effects of insurance, as also described in Chapter 2, occur because insurance provides a payout after a shock. However, microinsurance also has the potential to have impacts outside the single period utility maximizing decision, by preventing households from depleting important assets that are needed for future strategies. Furthermore, by providing security ex-ante, microinsurance may change behavior and lead to choices that enable higher-risk, higher-return strategies.

In addition to the identification of these potential short- and long-term welfare impacts of microinsurance, the distributional impact of microinsurance was also considered. Factors influencing demand for microinsurance which were indentified in Chapter 2, and further investigated in Chapter 3, may have consequences for the impact of microinsurance on households with certain characteristics such as risk aversion, low trust in the insurance transaction and credit constraints.

The review of theories in Chapter 4 was followed by a discussion of research designs that can be used for evaluating microinsurance impact. Randomized Control Trials (RCTs) were analyzed first because they are viewed by large parts of the academic community as the gold standard for impact evaluation. While RCTs can have enormous value because they may prevent omitted variables bias, they provide information about average effects, and so do not provide information about the distributional impact of microinsurance on households with different characteristics. In addition, they are wellsuited to provide internal validity, but they do not specifically address external validity, construct validity and statistical conclusion validity. In addition, as was explained in Chapter 2, microinsurance demand (and thus its effects) depends on mechanisms influencing access to the insurance, knowledge about the insurance, persuasion about the insurance and finally the actual decision. Because these mechanisms are not well understood, randomly assigning insurance to certain groups without properly understanding why low income households take up microinsurance, may not provide the required information about the impact of microinsurance. Practical considerations, such as finances or the fact that many insured risks do often not occur regularly, make the application of RCTs for measuring some impacts difficult.

In current literature on the impacts of microinsurance, the impact on out-of-pocket payments and health care utilization is often studied, while ex-post impact of natural disaster insurance, are not. Therefore in the remainder of Chapter 4, different research designs and their advantages and limitations for studying different microinsurance impacts were discussed. It was concluded that well-thought through theories about microinsurance impact, reflecting an understanding of both access to the particular insurance as well as decision-making about the particular insurance, are important for understanding impact of microinsurance on different groups of people. Observational studies with more focus on external and construct validity should be 
supported by (randomized) experimental research designs, when possible, to make valid causal statements about unbiased constructs, to inform policy.

Chapter 4 showed that ex-post effects of microinsurance, especially for low-frequency events were not studied in existing microinsurance impact literature. It was also discussed that microinsurance could function as a complement and as a substitute for existing consumption smoothing activities. If microinsurance substitutes existing smoothing activities then it is suggested that it matters for welfare outside of the single period setting what types of consumption smoothing activities, out of the full range, they substitute, especially because some consumption smoothing activities can be more stressful for future growth than others.

Therefore in Chapter 5 it was hypothesized that:

Households with microinsurance are relatively less likely to use higher-stress consumption smoothing activities than households without micro insurance.

In Chapter 5 this hypothesis is tested on the same data as were used for the analysis in Chapter 3. The nature of the insurance product studied made it impossible to randomize the insurance and wait for a natural hazard such as a typhoon to occur. In addition, because the theoretically relevant factors determining insurance uptake are also uncertain, as shown in Chapter 2, it was decided that matching would also not be an option. Therefore an observational study was performed relying heavily on the demand model estimated in Chapter 3 together with other theoretically relevant factors, such as previous experiences with aid after typhoons and other income smoothing and consumption smoothing activities, to control for self-selection and endogeneity.

The objective of this study was to understand the use of ex-post consumption smoothing activities after typhoons and assess the impact of microinsurance on these activities. Models for each consumption smoothing activity were estimated separately, controlling for the use of other consumption smoothing activities. In addition, it was attempted, based on existing theory about coping strategies and the specific context drawn from focus groups, to construct a variable that ranked consumption smoothing activities as more and less stressful. Chapter 5 revealed that the general pattern is that insurance reduces the likelihood that households use other consumption smoothing activities. This effect is significant for selling production assets, performing side-line activities and using a household's own savings for coping with risk. It is also concluded that the household's ex-ante situation plays an important role in determining the consumption smoothing activities that households use. For the combined consumption smoothing variable it can be concluded that the pay-out significantly reduces the stressfulness of consumption smoothing activities. Even for alternative constructions of the dependent variable this effect is robust. This implies that the insurance reduces the likelihood that households have to result to the use of costly consumption smoothing activities in terms of future income and productivity. 


\subsection{Discussion and recommendations for future research}

One of the main objectives of this thesis was to understand why low-income households demand microinsurance. Previous studies had found that demand for microinsurance in developing countries is low in comparison to expected demand based on expected utility theory. Furthermore, an increasing number of empirical studies investigating microinsurance demand in developing countries revealed that risk aversion leads to less, instead of more, take up of microinsurance. This contradicts predictions from expected utility theory, in particular that demand for insurance is higher for risk-averse individuals who use insurance to avoid the risk of loss.

\section{Different stages of the decision-making process}

One of the findings of this thesis is that many observational studies use expected utility theory as a starting point for their analysis; some of these studies compare households with insurance to households without the insurance. Households without the insurance may be households which have not heard about insurance, or households which have heard about the insurance but have not yet made a decision to either take up or reject the insurance. These different stages can be described, following diffusion literature, as the awareness knowledge stage, persuasion stage and the decision stage. Generalized expected utility theories are decision-making theories, and should thus be used for the decision-making stage. Literature about the diffusion of innovations (Tarde, 1903, Ryan and Gross, 1943, Katz, 1961, Coleman, 1966, Rogers, 2003, Banerjee, Chandrasekhar, Duflo and Jackson, 2012) may yield interesting information about the other stages. For example, Hassinger (1959) finds that individuals are not open to messages about an innovation if they do not experience a need and that, even if they are exposed, that it does not influence their decision unless the innovation fits with the individual's attitudes and beliefs. Rogers (2003) provides a framework of perceptions of an innovation and how they influence adoption of innovations. Status, compatibility with values and beliefs, and previous ideas are among these perceptions. For experimental studies investigating the demand for microinsurance, where the insurance is randomly assigned, this may seem less of a problem but in many cases (for example Cole et al., 2010, Clarke and Kalani, 2011) households are exposed to knowledge and education about the insurance and immediately afterwards confronted with a take up or rejection decision. In this case the persuasion stage may be left out and the time lag between learning and decision-making may be too short and thus affect the actual decision. Untangling the different mechanisms in the different stages to get to the final take up or rejection decision is thus a recommendation for future research.

To understand demand it is suggested that it is important to distinguish the different stages of the decision-making process. In Chapter 2 the awareness knowledge stage; the persuasion stage and decision-making stage were identified. An interesting suggestion for future research would be to analyze the types of factors that influence insurance demand in which stage. For example, it can be envisaged that households first evaluate the characteristics of the insurance such as the price and the coverage. Consequently they make up their mind if this product is potentially interesting for them. However, they will only enter the insurance transaction if the necessary level of trust in the insurer also exists. By understanding these decision-processes more thoroughly it will be possible to expose clients to different types of information at different stages. 


\section{Mechanisms leading to demand}

Another finding with respect to insurance demand is that traditional factors, which are part of expected utility theories, are often found to have a significant effect in research studies, but still leave a large part of variance in insurance demand unexplained. At the same time the marginal effects of location dummies, social capital, networks and trust is high. However, the mechanisms through which these factors influence insurance demand are not well understood. Cai (2012) suggests that these variables may influence insurance demand through mechanisms of learning; or through mechanisms affecting the purchase decision through imitation, scale effects or the existence of informal risksharing activities. This study has added trust as a potential mechanism which can affect both the learning process and the purchase decision.

\section{The trusted neighbor effect}

This study demonstrated that the trusted neighbor effect of knowing peers with claims influenced take up of microinsurance through the mechanism of trust. For households these experiences of peers can act as a trial for their own experiences with the insurance, and reduce uncertainty in the insurance transaction. Another important finding is that the effect of trust is especially strong for households with high levels of risk aversion. The fact that knowing peers with claims builds trust also implies that the observed effects of location dummies, social capital and networks may be partially explained by trust. Peers that households are acquainted to, are, by their very nature, part of the social capital and network of these households. This thus implies that the effect of social capital and networks, as it is found in several studies, may be (partly) explained by their effect on building trust through peer experiences.

To further investigate trust a better understanding of the mechanisms leading to insurance demand may be helpful here. For example, uncertainty about future pay-outs because of fear of contractual non-performance may be conceptualized as an added state of the world as suggested by Doherty and Schlesinger (1990). Uncertainty about future pay-outs may also occur because of the nature of the insurance product design (basis risk for index insurance) as is suggested by Clarke (2011). Uncertainty may also refer to the credibility of the insurer as Dercon et al. (2011) suggest. In these examples, trust can increase the perceived probability that there will be a pay-out. However, Cole et al. (2010) suggest that identification with certain religious values and groups may also increase trust. Do the credibility of the insurer and identification with religious values and groups both lead to an increase in the perceived probability that the insurer is going to provide a pay-out?

\section{The role of trust in the PAID plan case study}

This study has investigated trust in a context with a given legal and regulatory framework (Philippines), product (PAID plan) and insurance delivery organization (CARD). Many of the potential trust-building factors such as legal and regulatory frameworks and the insurance delivery organization are a given within the specific institutional matrix of the case study. In the Philippines, insurance is relatively wellknown to low-income households because they have been exposed to other insurance products such as a government-sponsored health insurance. This could imply that their understanding of microinsurance is relatively high and therefore uncertainty is low. On 
the other hand, during the last few years there have been several cases of lack of solvency and fraud by insurers, which have been broadcast on the radio. This may imply low levels of trust in insurance. It can be imagined that in insurance markets where there are no negative experiences or even positive experiences with insurance, there is less need for trust-building to reduce uncertainty caused by previous fraudulent practices or insolvency. In this case the effect of knowing peers with claims may be lower. However, at the same time, if there are no experiences with insurance at all, as is the case with many low-income households in developing countries, trust in the concept of insurance may be especially low and uncertainty higher.

Another consideration with respect to the case study is that CARD is generally welltrusted and has a permanent presence in rural villages. Because of CARD's established microcredit activities, many households already have experience with them. Despite this, the effect of knowing peers with claims is strong. It is hypothesized that if the insurance delivery organization is less well-trusted then the effect of knowing peers with claims will even become stronger.

\section{Formal and informal trust}

In this study the approach of Gambetta (1988) was followed, he distinguishes different formal and informal trust-building mechanisms and suggests these can function as substitutes. This is especially relevant in the case of microinsurance where formal trustbuilding institutions are often less accessible, reliable or non-existent, suggesting that households have to rely on informal trust-building factors. However, in this study only informal trust-building mechanisms could be studied because the legal and regulatory framework (Philippines), the product (PAID plan) and the organization delivering the insurance (CARD) were a given.

To further understand the effect of different mechanisms for building trust it would be interesting to study these components further. A potential research design would be to combine laboratory experiments with information from focus groups and field experiments. The laboratory experiments would allow for careful testing of the mechanisms underlying the effect of risk preferences, perceived probabilities of payouts, trust and understanding on insurance demand. The advantage of the experimental design (versus observational studies) is that it allows for the manipulation of only one factor while holding the other factors constant. This implies that it is possible to understand how and to what extent only one particular factor influences the dependent variable, in this case insurance demand. After these mechanisms are well-understood, by making use of focus-groups, field experiments can be designed in such a way that they include the actual trust-building factors in the way they are known and natural to the respondents in the study. The extent to which they influence mechanisms and insurance demand can then be further investigated in the field.

\section{Trust and understanding the insurance}

The findings from Chapter 3 suggest that indeed trust can reduce uncertainty in the insurance transaction. However, financial literacy and financial education are also mechanisms important for reducing uncertainty because they increase understanding of the insurance. Evidence for the effect of insurance understanding is mixed. Some studies find that it increases insurance demand while other studies do not find a significant effect. Several explanations for this may exist. Firstly, it can be hypothesized 
that financial education, even though it may increase knowledge about insurance, does not influence the purchase decision if there is still uncertainty about the insurance transaction. It may also imply that the financial education provided is not adequate. Finally, as was suggested above, it may be that, when experimentally investigated, the time lag between financial education and actual decision-making has been too short for households to come to a decision. Cole et al. (2010) find that insurance education is only significant if it is provided by a trusted source. Since both trust and understanding insurance may reduce uncertainty in the insurance transaction, a suggestion for future research would be to experimentally investigate these mechanisms and untangle their effects as was explained above.

\section{Impact outside of single period decisions}

Another objective of this study was to assess the impact of microinsurance on poverty reduction. Commonly the impact of microinsurance is considered in terms of its potential to smooth consumption and lead to utility maximization. However, there may be ex-ante behavioral changes which lead households to invest in higher-risk, higherreturn strategies. Furthermore, by reducing the likelihood that households use costly consumption smoothing activities, such as selling production assets, microinsurance has the potential to impact the consequences of shocks, which are especially relevant in terms of long-term and persistent poverty (Townsend, 1994, Dercon, 2004, Carter, Little, Mogues, Negatu, 2007). Only considering welfare impacts in terms of a single period decision may not help in understanding both positive and negative impacts in the context of poverty reduction.

Even though microinsurance is assumed to contribute to smoothing of consumption when it is taken up, another element of understanding microinsurance's impact on poverty reduction, which is closely related to factors influencing microinsurance demand, is to understand its distributional impact, especially because microinsurance is intended to target low-income populations which have been excluded from access to insurance so far.

The method should follow the question

This thesis has also addressed a concern about the practical evaluation of development initiatives as proposed by, amongst others, Banerjee and Duflo (2009). The lack of using theory structurally for analyzing all potential impacts from microinsurance may lead to a focus on analysis of socially and practically desirable or scientifically interesting impacts while other impacts are understudied. Potentially, there is great harm in this if some crucial impacts are missed.

A similar reasoning holds for the strong focus on randomization of interventions in which the methodology (RCTs) has become the standard, while in robust research design, the method should follow the theory and the question. One consequence of this, in the field of microinsurance, may be that ex-post natural disaster impacts have not been studied since they are difficult to investigate through an RCT. This raises the question: should the choice for the research question in evaluations be motivated by the possibility of using an RCT; or should we start by using theory to derive relevant questions and then consider which research design, given the particular intervention, is optimal? 
Even though randomization can contribute to internally valid conclusions, the focus is on average effects, and RCTs are not the best way to establish external validity and construct validity (of which the latter is strongly related to adequate theory building). These latter two are especially important for policy-making because external validity is concerned with the impacts of an intervention on different (groups of) people while construct validity in terms of poverty reduction would ask if the right kind of indicators for poverty reduction are used. The above 'essay' does not intend to say that randomization should not be done; rather it intends to show that it should be complemented by designs that pay attention to the other validities, that it should be based on a strong theoretical framework and that it should be feasible in terms of relevant research questions. This is especially important for ex-post impacts of microinsurance in case of infrequent events and distributional impacts.

\section{Impact on consumption smoothing activities}

This thesis has investigated the impact of microinsurance on the use of consumption smoothing activities, controlling for theoretically relevant factors and factors which, if excluded, can lead to issues with self-selection and endogeneity. A variable was constructed which categorizes the activities based on their stressfulness to the household. A combined analysis of more and less stressful consumption smoothing activities is a challenge because several different mechanisms exist, through which households choose different consumption smoothing activities and for some activities it is difficult to assess their level of stressfulness. However, the combined variable does justice to the fact that households use a variety of strategies, with different costs in terms of future income and productivity. Therefore, the idea of considering the impact of microinsurance by assessing its impact on the total set of more, and less stressful, consumption smoothing activities can provide a good measure of ex-post impact of microinsurance with respect to long-term consequences and persistent poverty.

The ordering of more and less stressful strategies was done based on focus groups; and several alternatives were tested still showing robust results. However, especially because the constructed variable is contextualized it should only be used in the specific Filipino context. It would be interesting to investigate the applicability of a similar construction of more and less stressful strategies in different contexts and for different products. The sample size was not large and many factors had to be included in the analysis to prevent self-selection and endogeneity issues, so it would be interesting to repeat this study on a larger sample and test the effect of a randomly assigned insurance, for example a health insurance, on the stressfulness of coping strategies used.

\subsection{Contributions to policy and practice}

Even though traditional factors, such as price and probability of risk, are important in determining insurance demand, factors such as social capital, networks and trust also significantly influence insurance demand and often have a strong effect. They thus have potential as factors which can be influenced, either by policy makers or practitioners. However, the mechanisms through which they have an effect are not well-understood, they are local and context specific; and trust is something which requires time to build up. Therefore, collaboration with trusted local partners can be an advantage. 
For policy-making it is also important to understand the factors and mechanisms behind the effect of these factors. Since it is assumed that many low-income households are underinsured it is, for normative policy, of great importance to understand why there is relatively low demand and to recognize factors which have a strong effect and can be manipulated.

In the early stages of the product life cycle of microinsurance, where many households are not yet well informed about it, a specific focus in research should be on creating an understanding of how low income households learn about microinsurance, how they collect information about it and which factors finally influence their decision. Currently many donors, governments and practitioners are investing in impact evaluations of microinsurance. Since it is not yet well-understood how microinsurance products can deliver value to low-income households, investments in research to understand demand may be more effective than efforts to evaluate the impact of microinsurance products which are not taken up and hence may be low in value to low-income households.

The role of trust and insurance education to reduce uncertainty about the insurance transaction are an example where further research is needed. However, at the same time quite a lot of money is invested in insurance education. Even though this may be valuable for other reasons, there is no conclusive evidence that it will actually increase insurance take up. It may even be that insurance education without trust building is not effective, but when combined, they have a strong effect on take up. This may imply that some of the investment in insurance education to stimulate insurance uptake is better spent on trust-building, or a combination of both.

Another important outcome of the study is that trust is built through the informal trustbuilding mechanism of 'knowing peers with claims', which occurs ex-post a shock. This implies that demand can be expected to increase slowly. The informal trustbuilding mechanisms were hypothesized to be especially important in developing countries where formal trust-building mechanisms are less reliable, accessible or nonexistent. Since these formal and informal trust-building activities are suggested to substitute each other, it can be hypothesized that investment in formal trust, such as that built through reliable legal and regulatory frameworks, is important because it builds trust ex-ante. If these mechanisms become stronger, reliance on ex-post trust building through informal mechanisms may become less important. This implies that investment in legal and regulatory frameworks is important to increase insurance demand.

In practice, research always requires tradeoffs between methodological rigor, contributions to science, policy and practice and feasibility in terms of cost, logistical capability, and time. RCTs are adequate for measuring the causal effect of a treatment on an outcome (internal validity) but are less adequate for generalizations (external validity), understanding uptake, distributional effects and are not guaranteed to measure the right outcome (construct validity). The 'practical' evaluation of development interventions should therefore rely on careful theory building especially because good research designs should address the four validities. In addition, combinations of methods are advised in order to come to optimally valid designs. For example, this study has demonstrated that, for microinsurance, not all relevant research questions have been adequately addressed. In addition, and especially because of the 
characteristics of microinsurance, ex-post effects cannot be answered through an RCT and require quasi-experimental designs with adequate theory building to control for confounding factors.

Finally, this study has found that microinsurance indeed reduces the likelihood that households have to use harmful coping strategies after shocks which have long-term consequences for future income and productivity. For policy-making this is important evidence, especially because the impact of shocks on such activities is an important cause of persistent poverty. Future research should focus on impact assessments of different types of (well-designed) insurances specifically looking at consumption smoothing activities which have long-term consequences. 


\section{Dissemination of the research}

The motivation for this thesis has been a desire to contribute to the reduction of vulnerability of low-income people in developing countries. Even though several theoretical problems were addressed in this thesis, they stem from practical challenges in the implementation of microinsurance, faced by practitioners and policy makers. Working on such a practical topic has brought with it the felt obligation to be part of the continuous dialogue with different stakeholders working in the microinsurance field. Firstly to understand practical and policy-relevant challenges and then translate them into relevant research. Secondly to translate and disseminate scientific findings for this audience. Therefore, during my four years as a $\mathrm{PhD}$ candidate I have undertaken numerous activities which have met either or both of these objectives. Naturally, I have presented my research at academic conferences such as:

- April 2012, 2012 Research Conference on Microinsurance, University of Twente, Presentation of 'Changes in credit uptake and on-farm risk management preferences due to agriculture input insurance', and earlier versions of Chapter 3 and Chapter 4.

- March 2012, 2012 CSAE Conference, Centre for the Study of African Economies (CSAE), Oxford, UK. Presentation of an earlier version of Chapter 3.

- November 2011, 7th Annual International Microinsurance Conference, Rio de Janeiro, Brasil. Presentation 'Value for farmers from meso-level index insurance!?’and an earlier version of Chapter 3.

- September 2011, Conference Contemporary Microfinance: Institutions, Policies, and Performance Conference, Cairo, Egypt. Presentation of a earlier version of Chapter 5.

- June 2011, Summer School CERES/EADI 2011, Utrecht, The Netherlands. Presentation of earlier version Chapter 5.

- June 2011, Second European Research Conference on Microfinance, Groningen, The Netherlands. Presentation of an earlier version of Chapter 2 and Chapter 5.

Next to these presentations to academic audiences I have presented outcomes from my research to non-academic audiences through presentations at organizations (such as PharmAccess, Netherlands; Center for Agriculture and Rural Development (CARD), The Philippines; Micro Insurance Association the Netherlands) and at professional conferences such as the First and Second Conference on Adaptation to Climate Change in Developing Countries.

Together with representatives from Dutch insurance industry and development organizations I participate, as an academic, in the Dutch Ministry of Foreign Affairs Working Group on Agricultural Insurance. The objective of the working group is to strengthen the capacity of small-scale farmers, pastoralists and fisher folk to deal with risk by contributing to scaling up and sustainability of agricultural insurances in Africa, in a broader risk management structure. This has led to the organization of two seminars. One on agriculture insurance held in 2009 where policy makers, industry representatives and people from an Indian development organization spoke about the potential of 
scaling up agriculture insurance and challenges faced to achieve this in existing projects. An output of the seminar was a discussion paper on issues with achieving scale in agriculture insurance. Many of the issues with respect to demand for microinsurance, which are addressed in Chapter 2, were part of this paper. In 2011, a seminar on the use of satellite data for index-insurance was held where Dr. Daniel Clarke and myself gave a presentation to a mixed audience about the (lack of) value from current indexinsurance products which also resonated with Chapter 2. My activities for the Dutch Ministry have evolved into a formal assignment as 'Advisor on insurance' to the Dutch Ministry of Foreign Affairs. The objective of this assignment is to advice on a solution to support food security in Africa in which agriculture insurance plays a central role.

Since 2009 I have also been a member of the Microinsurance Network (MIN) which is a network promoting the development and delivery of effective insurance services for low-income people by encouraging shared learning, facilitating knowledge generation and dissemination, and providing a multi-stakeholder platform. I have been a member of the agriculture insurance and impact working group of this network. The Agriculture Insurance Working Group seeks to promote the wider use of agricultural insurance, particularly crop and livestock insurance, as a modern financial risk management instrument in developing countries. At the Annual International Microinsurance Conference 2011 I presented, in the name of the working group, a paper on meso-level index insurance to an audience of academics, policy-makers and practitioners. The Impact Working Group of the MIN seeks to enhance knowledge about the impact of microinsurance by increasing the quality and quantity of available evidence, and to assist in its dissemination. One of the main activities has been the "Practical Guide for Impact Assessment in Micro-insurance" which is geared towards explaining, to a nonacademic audience, the importance of rigorous impact evaluation. One chapter in this practical guide is based on Chapter 4 of this thesis. One of my main objectives has been to stress the importance of thorough theory development and the use of mixed methodologies for different questions. After a felt need by the network for having a group to accommodate researchers I have become the facilitator of the Research Discussion Group. The Research Discussion Group aims to provide a platform for researchers from different disciplines and regions to discuss and share information, among themselves and with policy-makers and practitioners. Their first activities are a report reflecting the research presented at the 2012 Research Conference on Microinsurance and the organization of PhD-seminars on research on microinsurance.

On 11,12 and 13 April 2012, together with academic and non-academic partners, I organized The 2012 Research Conference on Microinsurance at the University of Twente. Contributing organizations were The African Studies Centre (ASC), The Micro Insurance Network (MIN), The Center for Economic Analysis of Risk (CEAR), Munich Re Foundation, German Institute for Economic Research (DIW Berlin), The University of Mannheim, ILO Microinsurance Innovation Facility (ILO MIF), Appui au Développement Autonome (ADA) and the Dutch Ministry of Foreign Affairs. The aim of this conference was two-fold. First of all its objective was to assess the state of the art in microinsurance research and to provide a platform for further in-depth academic discussions. In addition, the conference aimed to create a dialogue between researchers and with policy-makers and practitioners from different geographical regions and the 
variety of research disciplines. The conference hosted three plenary key notes, three plenary panel discussions, 19 parallel session, more than 50 presentations of microinsurance papers and $5 \mathrm{PhD}$ research proposal presentations. Unsurprisingly, the topics of demand and impact were central topics in the conference programme (see Appendix 6A). United Nations Secretary General's Special Advocate for Inclusive Finance for Development H.R.H. Princess Máxima of the Netherlands gave an opening speech (see Appendix 6B). Topics addressed in this thesis, for example trust as determinant of demand, understanding demand to understand impact and exploring theory from different disciplines are specifically mentioned in this speech. I directed a short movie about the topic of microinsurance which was published on the University of Twente website ${ }^{1}$.

Recently I started working as Financial Inclusion Expert and Research Consultant to the United Nations Secretary General's Special Advocate (UNSGSA) for Inclusive Finance for Development H.R.H. Princess Máxima of the Netherlands, preparing the UNSGSA for advocacy on microinsurance. For this assignment I have contributed to two speeches. One speech given at a conference of the European Insurance and Reinsurance federation and one for the 'Access to health insurance' conference held on 5 June 2012, organized by the UNSGSA, Erasmus University, Pharmaccess and the Dutch Ministry of Foreign Affairs. The speeches are provided in Appendix 6B. For this latter conference I was also a member of the Steering Group of the seminar and contributed to the development of the content of the seminar. One of the six parallel sessions addressed the topic of trust in insurance and resonates with Chapter 2 and 3.

${ }^{1}$ http://vimeo.com/40222099/ on 20 August 2012 


\section{References}

Adams, A.M., Evans, T.G., Mohammed, R. and Farnsworth, J. (1997). Socioeconomic stratification by wealth ranking: Is it valid? World Development, 25(7): 11651172.

Aggarwal, A. (2010). Impact evaluation of India's 'Yeshasvini' community-based health insurance programme. Health Economics, 19: 5-35.

Ahuja, R. and Jutting, J. (2004). Are the Poor Too Poor to Demand Health Insurance? Journal of Microfinance / ESR Review, 6(1): 1-20.

Alderman, H., Paxson, C.H. (1992). Do the poor insure? A synthesis of the literature on risk and consumption in developing countries. In: Bacha, E.L. (Ed.), Development, Trade and the Environment, Economic in a Changing World. London: Macmillan.

Allegri, M. de, Sanon, M., Bridges, J., Sauerborn, R. (2006). Understanding consumers' preferences and decision to enroll in community-based health insurance in rural West Africa. Health Policy, 76: 58-71.

Allegri, M. de, Sanon, M., Sauerborn, R. (2006). “To enrol or not to enrol?’': A qualitative investigation of demand for health insurance in rural West Africa. Social Science \& Medicine 62: 1520-1527.

Altman, I.; Taylor, D. A. (1974). Social penetration: the development of marketing interpersonal relationships. New York: Holt Rinehart \& Winston.

Altonji, J.G., Elder, T.E. and Taber, C.R. (2000). Selection on Observed and Unobserved Variables: Assessing the Effectiveness of Catholic Schools. Paper presented at the Winter meetings of the American Economic Association.

Ang, P.A., Sugiyarto, G., Jha, S. (2009). Remittances and Household Behavior in the Philippines. ADB Economics Working Paper Series 188. Asian Development Bank.

Arnott, R. and Stiglitz, J. (1991). The Welfare Economics of Moral Hazard. NBER Working Papers 3316. National Bureau of Economic Research, Inc.

Arrow, K.J. (1965). Aspects of a Theory of Risk Bearing. Helsinki: Yrjo Jahnsson Lectures.

Arrow, K.J. (1964). The Role of Securities in the Optimal Allocation of Risk Bearing. Review of Economic Studies; 31: 91-96.

Arrow, K.J. (1963). Uncertainty and the welfare economics of medical care. American Economic Review, 53: 941-973.

Ashraf, N., Karlan, D. and Yin, W. (2010). Female empowerment: Impact of a commitment savings product in the Philippines. World Development, 38: 333344.

Atim, C. (1999). Social movements and health insurance: a critical evaluation of voluntary, non-profit insurance schemes with case studies from Ghana and Cameroon. Social Science and Medicine, 48: 881-886.

Attanasio, O., Rios-Rull, J.-V. (2000). Consumption smoothing in island economies: Can public insurance reduce welfare? European Economic Review, 44: 12251258. 
Azariadis, C. and Stachurski, J. (2005). Poverty traps. In: P. Aghion and S. Durlauf (Eds.) Handbook of economic growth (Vol. 1A) Amsterdam, London, San Diego: Elsevier Press.

Baker, J. (2000). Evaluating the impact of development projects on poverty: a handbook for practitioners. Washington D.C.: World Bank.

Bähre, E. (2007). Money and Violence: Financial Self-help Groups in a South African Township. Leiden: Brill.

Banerjee, A. and Duflo, E. (2009). Poor Economics: A radical Rethinking of the Way to Fight Global Poverty. New York: Public Affairs.

Banerjee, A., Duflo, E. (2005). Growth Theory through the Lens of Development Economics. In: P. Aghion, S. Durlauf (Eds.), Handbook of Economic Growth. Amsterdam, London, San Diego: Elsevier Press.

Banerjee, A., Newman, A. (1993). Occupational Choice and the Process of Development. Journal of Political Economy, 101: 274-298.

Banerjee, A., Chandrasekhar, G., Duflo, E., Jackson, M.O. (2012). The Diffusion of Microfinance. NBER Working Paper No. 17743.

Barnett, B.J., Barrett, C.B. and Skees, J.R. (2008). Poverty Traps and Index-Based Risk Transfer Products. World Development, 36: 1766-1785.

Barr, A., (2003) Trust and expected trustworthiness: Experimental evidence from Zimbabwean villages, The Economic Journal, 113: 614-630.

Barrett, C.B. and McPeak, J.G. (2006). Poverty Traps and Safety Nets. Poverty, inequality and development, 1: 131-154.

Barrett, C.B. and Swallow, B.M. (2006). Fractal poverty traps. World Development, 24: 1-15.

Basaza, R., Criel, B. and Van der Stuyft, P. (2008). Community health insurance in Uganda: Why does enrolment remain low? A view from beneath. Health Policy 87: 172-184.

Battalio, R., Kagel, J., Winkler, J., Fisher, R., Basmann, R., Krasner, L. (1973). A Test of Consumer Demand Theory Using Observations of Individuals Consumer Purchases. Economic Inquiry, 11(4): 411-428.

Bauer, R.A. (1961). Risk handling in drug adoption: the role of company preference. Public Opin Q, 25(4): 546-559.

Bauchet, J., Dalal, A., Mayasudhakar, P., Morduch, J.and Radermacher, R. (2010). Can insurers improve healthcare quality? Evidence from a community microinsurance scheme in India. New York: Financial Access Initiative.

Beegle, K., De Weerdt, J. and Dercon, S. (2008). Adult mortality and consumption growth in the age of HIV/AIDS. Economic Development and Cultural Change, 56(2): 299-326.

Bellows, J. and Miguel, E. (2009). War and local collective action in Sierra Leone. Journal of Public Economics, 93: 1144-1157.

Bemelmans-Videc, M.-L., Rist, R. and Vedung. E. (1998). Carrots, Sticks, and Sermons: Policy Instruments and their Evaluation. Brunswick, NJ: Transaction.

Bendig, M. and Arun, T.G. (2011). Enrolment in Micro Life and Health Insurance: Evidences from Sri Lanka. IZA Discussion Paper No. 5427. Available at SSRN: http://ssrn.com/abstract=1741615. 
Bendig, M., Giesbert, L. and Steiner, S. (2009). Savings, credit and insurance: Household demand for formal financial services in rural Ghana. GIGA Working Paper No. 94.

Benson, K. and Hartz, A.J. (2000). A Comparison of Observational Studies and Randomized, Controlled Trials. New England Journal of Medicine, 342(25):1878-86.

Bertrand, M., Karlan, D., Mullainathan, S., Shafir, E., Zinman, J. (2010). What's Advertising Content Worth? Evidence from a Consumer Credit Marketing Field Experiment. The Quarterly Journal of Economics. 125 (1): 263-305

Bhat, R., and Jain, N. (2006). Factoring affecting the demand for health insurance in a micro insurance scheme. Indian Institute of Management. Working Paper no. 2006-07-02.

Binswanger-Mkhize, H.P. (2011). “Is there too much hype about index-based agricultural insurance?,” mimeo 2011. Journal of Development Studies, 48 (2):187-200.

Binswanger, H.P., (1980). Attitudes toward risk: Experimental measurement in rural India. American Journal of Agricultural Economics, 62 (3): 395-407.

Black, N. (1996). Why we need observational studies to evaluate the effectiveness of health care. British Medical Journal, 312 (7040): 1215-8.

Bogg, L., Hengjin, D., Keli, W., Wenwei, C. and Diwan, V. (1996). The cost of coverage: Rural health insurance in China. Health Policy and Planning, 11: 238-252.

Bowles, S., Durlauf, S.N. and Hoff, K. (Eds.) (2006). Poverty traps. Princeton: Princeton University Press.

Boucher, S., Carter, M. R. and Guirkinger, C. (2008). Risk rationing and wealth effects in credit markets: Implications for agricultural development. American Journal of Agricultural Economics, 90: 409-423.

Bryan, G. (2010). Ambiguity and Insurance. Yale working paper.

Breustedt, G., Bokusheva, R., and Heidelbach, O. (2008). Evaluating the potential of index insurance schemes to reduce crop yield risk in an arid region. Journal of Agricultural Economics, 59: 312-328.

Cai, H. (2012) Social Networks and the Decision to Insure: Evidence from Randomized Experiments in China. Job Market Paper University of California, Berkeley http://ecnr.berkeley.edu/vfs/PPs/Cai-Jin/web/JMP_JingCai_012812.pdf

Cai, H., Chen, Y, Fang, H. and Zhou, L. (2010). Microinsurance, Trust and Economic Development: Evidence from a Randomized Natural Field Experiment. BREAD Working paper No. 279.

Cai, H., Chen, H., Fang, H., Zhou, L.A. (2009) Microinsurance, Trust and Economic Development: Evidence from a Randomized Natural Field Experiment. Cambridge, MS: The National Bureau of Economic Research, Working Paper No. 15396.

Cain, M. (1981) Risk and Insurance: perspectives on Fertility and Agrarian Change in India and Bangladesh. Population and Development Review, 7(3):435-474

Campbell, D. (1957). Factors relevant to the validity of experiments in social settings. Psychological Bulletin, 54(4): 297-312. 
Campbell, D. T. and Stanley, J.C. (1963). Experimental and quasi-experimental designs for research on teaching. In: N. L. Gage (Ed.) Handbook of Re- search on Teaching. Chicago: Rand McNally.

Carter, M. R. and May, J. (2001). One kind of freedom: the dynamics of poverty in post-apartheid South Africa. World Development, 29: 1987-2006.

Carter, M.R. and Barrett, C.B. (2006). The economics of poverty traps and persistent poverty: An asset-based approach. Journal of Development Studies, 42(2): 178199.

Carter, M.R., Little, P.D., Mogues, T. and Negatu, W.(2007). Poverty traps and Natural Disasters in Ethiopia and Honduras. World Development, 35(5): 835-856.

Carter, M.R. and May, J. (1999). Poverty, Livelihood and Class in Rural South Africa. World Development, 27(1): 1-20.

Casley, D.J. and Lury, D.A. (198). Monitoring and evaluation of agricultural and rural development projects. Ottawa: Johns Hopkins University Press.

Chankova, S., Sulzbach, S. and Diop, F. (2008). Impact of mutual health organizations: evidence from West Africa. Health Policy and Planning, 23(4): 264-276.

Chambers, R.G. (1989). Insurability and moral hazard in agricultural insurance markets. American Journal of Agricultural Economics, 71: 604-616.

Chambers, R. and Conway, G. (1992). Sustainable rural livelihoods: practical concepts for the 21st century. IDS Discussion Paper 296. Brighton, UK: IDS, University of Sussex.

Charmes, J. (2000). The Contribution of Informal Sector to GDP in Developing Countries: Assessment, Estimates, Methods, Orientations for the Future. Paper presented at the Fourth Meeting of the Expert Group on Informal Sector Statistics (Delhi Group).

Chen, M.A. and Dunn, E. (1996). Household Economic Portfolio's. Report for Microenterprise Impact Project (PCE-0406-C-00-5036-00) of USAID’s Office of Microenterprise Development.

Cheng, S.-H., Chiang, T.-L. (1997). The effect of universal health insurance on healthcare utilization in Taiwan: Results from a natural experiment. Journal of American Medical Association, 278: 89-93.

Churchill, C. (2006). What is insurance for the poor? In: C. Churchill (Ed.) Protecting the Poor. Geneva: ILO.

Churchill, C. and McCord, M.J. (2012) Current trends in microinsurance. In: C. Churchill and M. Matul (Eds.) Protecting the poor, A microinsurance compendium, Volume 11. Geneva:International Labour Organization.

Chou, S.-Y., Liu, J.-T. and Hammitt, J. K. (2003). National Health Insurance and precautionary saving: Evidence from Taiwan. Journal of Public Economics, 87: 1873-94.

Clarke, D. (2011). A Theory of Rational Demand for Index Insurance. Discussion paper series. Oxford, UK: Department of Economics University of Oxford, ISSN 1471-0498.

Clarke, D. and Kalani, G. (2011). Microinsurance Decisions: Evidence from Ethiopia. Mimeo. Oxford, UK: University of Oxford.

Cohen, M. and Sebstad, J. (2005). Reducing vulnerability: the demand for microinsurance. Journal of International Development, 17(3): 397-474 
Cohen, M. and Sebstad, J. (2001). Microfinance, Risk Management and Poverty. Washington, D.C.: Office of Microenterprise Development, USAID, http://microfinanceopportunities.org/docs/Microfinance_Risk_Management_an d_Poverty.pdf.

Cole, S.A., Giné, X., Tobacman, J., Topalova, P., Townsend, R. and Vickery, J. (2010). Barriers to Household Risk Management: Evidence from India. Working Paper No. 09-116. Boston, MA: Harvard Business School.

Coleman, J.S. (1990). Foundations of Social Theory. Boston, MA: The Belknap Press of Harvard University Press.

Coleman, J.S., Katz, E. and Menzel, H. (1966). Medical Innovation: A diffusion Study. New York: Bobbs-Merrill.

Collins, D., Morduch, J., Rutherford, S. and Ruthven, O. (2009). Portfolios of the poor: How the world's poor live on two dollars a day. Princeton, NJ: Princeton University Press.

Concato, J., Shah, N. and Horowitz, R.I. (2000). Randomized, Controlled Trials, Observational Studies, and the Hierarchy of Research Designs. New England Journal of Medicine, 342 (25): 1887-92.

Cook, P.J. and Graham, D.A. (1977). The Demand for Insurance and Protection: The Case of Irreplaceable Commodities. The Quarterly Journal of Economics, 91(1): 143-156.

Corbett, J. (1988). Famine and Household Consumption smoothing activities. World Development, 16(9): 1009.

Criel, B. and Waelkens, M.P. (2003). Declining subscriptions to the Maliando Mutual Health Organisation in Guinea-Conakry (West-Africa). Social Science and Medicine, 57 (2003): 1205-1219.

Criel, B., Van der Stufyt, P. and Van Lerberghe, W. (1999). The Bwamanda hospital insurance scheme: Effective for whom? A study of its impact on hospital utilization patterns. Social Science and Medicine, 48: 897-911.

Criel, B. and Kegels, G. (1997). A health insurance scheme for hospital care in Bwamanda district, Zaire: Lessons and questions after 10 years of functioning. Tropical Medicine and International Health, 2: 654-672.

Cutler, P. (1984). Food crisis detection; going beyond the balance sheet. Food Policy, 9(3): 189-192.

Dalal, A. and Morduch, J. (2010). The Psychology of Microinsurance, Small Changes can make a surprising difference. Microinsurance paper; no.5. Geneva: International Labour Office

Dalal, A., Bouchet, J. and Morduch, J. (2011). Evaluation fundamentals. Chapter prepared for the ILO Microinsurance Impact Evaluation Practical Guide. Financial Access Initiative Research Framing Note.

Davies, S. (1996). Adaptable Livelihoods: Coping with Food Insecurity in the Malian Sahel. London: Macmillan.

Deaton, A. (1992). Household savings in LDCs: Credit markets, insurance, and welfare. Scandinavian Journal of Economics, 94: 253-73.

Deaton, A. (1991). Saving and liquidity constraints.. Growth and shocks: evidence from rural Ethiopia. Econometrica, 59(5), 1221-1248.

Dercon, S., Gunning, J.W. and Zeitlin, A. (2011). The demand for insurance under limited credibility: Evidence from Kenya. International Development 
Conference. DIAL, Paris.

http://www.aae.wisc.edu/mwiedc/papers/2011/Zeitlin_Andrew.pdf

Dercon, S., Gunning, J.W. and Zeitlin, A. (2010). A. Friends, Fear and Finance Buying health Insurance in Rural Kenya. Paper presented at the academic track of the Sixth Annual International Microinsurance Conference, Philippines, Manila.

Dercon, S., Kirchenberger, M., Gunning, J. W. and Platteau, J.-P. (2008). Literature review on microinsurance. Microinsurance paper no. 1. Geneva: International Labour Organisation Microinsurance Innovation Facility.

Dercon, S. and Christiaensen, L. (2007). Consumption risk, technology adoption and poverty traps: Evidence from Ethiopia. Policy Research Working Paper 4257. Washington DC: World Bank.

Dercon, S., Hoddinott, J. (2004). Health, shocks, and poverty persistence. In: S. Dercon (Ed.) Insurance Against Poverty. Oxford, UK: Oxford University Press.

Dercon, S. (2005). Risk, Insurance and Poverty: A Review. In: S. Dercon (Ed.) Insurance Against Poverty. Oxford, UK: Oxford University Press.

Dercon, S. (2004). Growth and shocks: evidence from rural Ethiopia. Journal of Development Economics, 74(2): 309-329.

Dercon, S. and Krishnan, P. (2003). Risk sharing and public transfers. The Economic Journal, 113: C86-C94.

Dercon, S. and Krishnan, P. (2000). In sickness and in health: Risk-sharing within households in rural Ethiopia. Journal of Political Economy, 108: 688-727.

Dercon, S. (2000). Income risk, consumption smoothing activities and safety nets.

Oxford: Centre for the Study of African Economics, Department of Economics, Oxford University. WPS/2000.26.

Devadasan, N., Manoharan, S., Menon, N., Menon, S., Thekaekara, M. and Thekaekara, S. (2007). Indian community health insurance schemes provide partial protection against catastrophic health expenditure. BMC Health Services Research, 7: 43.

Devereux, Stephen (1993). Collection of Production and Income Data: A Commentary. In: Joachim von Braun and Detlev Puetz (Eds.) Data Needs for Food Policy in Developing Countries: New Directions for Household Surveys. Washington, DC: International Food Policy Research Institute.

Diop, F. P., Sulzbach, S. and Chankova, S. (2006). The impact of mutual health organizations on social inclusion, access to health care and household income protection: Evidence from Ghana, Senegal and Mali. Bethesda, MD: Partners for Health Reformplus.

Dirks, R. (1980). Social responses during severe food shortages and famines. Current Anthropology, 21(1): 21-44.

Doherty, N.A. and Schlesinger, H. (1990). Rational insurance purchasing: consideration of contract nonperformance. The Quarterly Journal of Economics, 105(1): 243253.

Dong, H., De Allegri, M., Gnawali, D., Souares, A., Sauerborn, R. (2009) Drop-out analysis of community-based health insurance membership at Nouna, Burkina Faso. Health Policy 92: 174-179.

Dror, D. M., Radermacher, R., Khadilkar, S. B., Schout, P., Hay, F. X., Singh, A. and Koren, R. (2009). Microinsurance in India: Three approaches; Microinsurance efforts targeted at resource-poor populations provided no less, and perhaps 
more, protection against financial catastrophe than commercial insurance. Health Affairs, 28: 1788-1798.

Dror, D.M., Koren, R., Ost, A., Binnendijk, E., Vellakkale, S. and Danis, M, (2007). Health insurance benefit packages prioritized by low-income clients in India: Three criteria to estimate effectiveness of choice. Social Science \& Medicine, 64: 884-896.

Dror, D.M., Soriano, E.S., Lorenzo, M.E., Sarol, J.N., Azcuna, R.S. and Koren, R. (2006). Field based evidence of enhanced healthcare utilization among persons insured by micro health insurance units in Philippines. Health Policy, 73 (3): 263-271.

Dror, D.M., Koren, R., Steinberg, D.M. (2005). The impact of Filipino micro healthinsurance units on income-related equality of access to health care. Health Policy, 77(3): 304-317.

Dror, David M., Christian Jacquier (1999). Micro-insurance: Extending Health Insurance to the Excluded. International Social Security Review, 52(1): 71-97.

Duflo, E., Glennerster, R., Kremer, M. (2006). Using randomization in development economics research: a toolkit. Working Paper No. 06-36.Cambridge, MA: MIT Department of Economics.

Duflo, E. and Kremer, M. (2005). Use of randomization in the evaluation of development effectiveness. In: G. Pitman, O. Feinstein and G. Ingram (Eds.), Evaluating Development Effectiveness. New Brunswick, NJ: Transaction Publishers.

Eeckhoudt, L., Gollier, C., Schlesinger, H. (2005). Economic and Financial Decisions Under Risk. Princeton, NJ: Princeton University Press.

Ekman, B. (2007). Catastrophic health payments and health insurance: Some counterintuitive evidence from one low-income country. Health Policy, 83, 304313.

Ekman, B. (2004). Community-based health insurance in low-income countries: a systematic review of the evidence. Health Policy and Planning, 19: 249-270.

Ellsberg, D. (1961). Risk, Ambiguity and the Savage Axioms. Quarterly Journal of Economics, 75: 643-669.

Fafchamps, M., Gubert, F. (2007a). The formation of risk sharing networks. Journal of Development Economics, 83: 326-350.

Fafchamps, M. (2003). Rural poverty, risk and development. Cheltenham, UK: Edward Elgar.

Fafchamps, M. and Lund, S. (2003). Risk sharing networks in rural Philippines. Journal of Development Economics, 71: 261-287.

Fafchamps, M., Udry, C., Czukas, K. (1998). Drought and saving in west Africa: are livestock a buffer stock? Journal of Development Economics, 55(2): 273-305.

Feinstein, Osvaldo (1993). Surveys at Household Level for Monitoring and Evaluation. In: Joachim von Braun and Detlev Puetz (Eds.) Data Needs for Food Policy in Developing Countries: New Directions for Household Surveys. Washington, DC: International Food Policy Research Institute.

Feldstein, M. and Friedman, B. (1977). Tax subsidies, the rational demand for health insurance, and the health care crisis. Journal of Public Economics, 7: 155-178.

Feldstein, M. (1973). The welfare loss of excess health insurance. Journal of Political Economics, 81: 251-280. 
Feldman, R. and Dowd, B. (1991). A New Estimate of the Welfare Loss of Excess Health Insurance. The American Economic Review, 81(1):. 297-301.

Filmer, D. and Pritchett, L.H. (2001). Estimating wealth effects without expenditure data-or tears: an application to educational enrolments in states of India. Demography, 38(1): 115-32.

Franco, L. M., Diop, F. P., Burgert, C. R., Kelley, A. G., Makinen, M.and Simpara, C. H. T. (2008). Effects of mutual health organizations on use of priority health care services in urban and rural Mali: A case-control study. Bulletin of the World Health Organization, 86: 830-838.

Gambetta, D. (1988). Can we trust? In: D. Gambetta (Ed.), Trust: Making and breaking cooperative relations. New York: Blackwell.

Gaurav, S., Cole, S. and Tobacman, J. (2011). The Randomized Evaluation of Financial Literacy on Rainfall Insurance Take-up in Gujarat. ILO Microinsurance Innovation Facility Research Paper no. 1.

Giesbert, L., Steiner, S. and Bendig, M. (2011). Participation in Micro Life Insurance and the Use of Other Financial Services in Ghana. The Journal of Risk and Insurance, 78(1): 7-35.

Giné, X. and Yang, D. (2009). Insurance, credit, and technology adoption: Field experimental evidence from Malawi. Journal of Development Economics, 89: $1-11$.

Giné, X., Menand, L., Townsend, R. and Vickery, J. (2010). Microinsurance: A case study of the Indian rainfall index insurance market. World Bank Policy Research Working Paper No. 5459. Washington, DC: World Bank.

Giné, X., Townsend, R. and Vickery, J. (2008). Patterns of rainfall insurance participation in rural India. World Bank Economic Review, 22 (3): 593-566.

Giné, X., Townsend, R. and Vickery, J. (2007). Statistical Analysis of Rainfall Insurance Payouts in Southern India. American Journal of Agricultural Economics, 89(5): 1248-54.

Gnawali, D. P., Pokhrel, S., Sie, A., Sanon, M., De Allegri, M., Souares, A., Dong, H. and Sauerborn, R. (2009). The effect of community-based health insurance on the utilization of modern health care services: Evidence from Burkina-Faso. Health Policy, 90: 214-222.

Goldberg, N. (2005). Measuring the impact of microfinance: taking stock of what we know. Washington D.C.: Grameen Foundation USA

Gollier, C. (2001). Wealth Inequality and Asset Pricing. Review of Economic Studies, 68(1): 181-203.

Gollier, C. (2003). To Insure or Not to Insure? An Insurance Puzzle. Geneva Papers on Risk and Insurance Theory, 28(1): 5-24.

Guiso, L. and Paiella, M. (2001). Risk Aversion, Wealth and Background Risk. CEPR Discussion Paper 2728.

Guiso, L. and Jappelli, T. (1998). Background Uncertainty and the Demand for Insurance Against Insurable Risks. The GENEVA Papers on Risk and Insurance - Theory, 23(1).

Guiso, L., Sapienza, P. and Zingales, L. (2008). Trusting the Stock Market. Journal of Finance, 63(6): 2557-2600. 
Gumber, A. (2001). Hedging the health of the poor: The case for community financing in India. Health, Nutrition and Population Discussion Paper. Washington, DC: World Bank.

Granovetter, M. (1974). Getting a Job: A Study of Contacts and Careers. Cambridge, MA.: Harvard University Press.

Granovetter, M.S. (1973). The Strength of Weak Ties. American Journal of Sociology 78: $1360-1380$.

Greenwood, J., Jovanovic, B. (1990). Financial development, growth, and the distribution of income. Journal of Political Economy 98: 1070-1107.

Hamid, S. A., Roberts, J. and Mosley, P. (2010b). Evaluating the health effects of micro health insurance placement: Evidence from Bangladesh. Sheffield Economic Research Paper Series No. 2010009.

Hamid, S. A., Roberts, J. and Mosley, P. (2010a). Can micro health insurance reduce poverty? Evidence from Bangladesh. Sheffield Economic Research Paper Series No. 2010001.

Harrison, G.W. (2011). Randomisation and its discontents. Journal of African Economies, 20(4): 626-652.

Harrison, G.W., List, J.A. and Towe, C. (2007). Naturally Occurring Preferences and Exogenous Laboratory Experiments: A Case Study of Risk Aversion. Econometrica, 75(2): 433-458.

Hassinger, E. (1959). Stages in the Adoption Process. Rural Sociology, 24: 52-53.

Hastings, J.S. and Tejeda-Ashton, L. (2008). Financial Literacy, Information and Demand Elasticity: Survey and Experimental Evidence from Mexico. NBER Working Paper 14538, National Bureau of Economic Research.

Hazell, Peter, Pomareda, Carlos and Valdes, Alberto (Eds.) (1986). Crop Insurance for Agricultural Development: Issues and Experience. Baltimore: Johns Hopkins Press.

Heenkenda, S. (2011). Index-Based Microinsurance for Paddy Sector in Sri Lanka: An Evaluation of Demand Behavior. Graduate School of International Development (GSID), Nagoya University, Japan.

Heckman, J. (1978). Dummy endogenous variables in a simultaneous equations system. Econometrica, 46: 931-961.

Heckman, J. (1979). Sample selection bias as a specification error. Econometrica 47: 153-161.

Hermes, N. and Lensink, R. (2007). The empirics of microfinance: what do we know? The Economic Journal, 117(517): F1-F10.

Hess, U. (2003). Innovative financial services for rural India: Monsoon-Index lending and insurance for small-holders. ARD Working Paper 9. Washington, DC: World Bank.

Hill, R.V., Hoddinott, J. and Kumar, N. (2011). Adoption of Weather Index Insurance, Learning from Willingness to Pay among a Panel of Households in Rural Ethiopia. IFPRI Discussion Paper 01088.

Hill, R.V. and Robles, M. (2010) Flexible insurance for heterogenous farmers: results from a Small scale pilot in Ethiopia. mimeo 2010.

Hill, R.V. and Viceisza, A. (2010) An experiment on the impact of weather shocks and insurance on risky investment, IFPRI discussion papers 974, International Food Policy Research Institute (IFPRI). 
Hill, R.V., Viceisza, A. and Deustua-Rossel, J. (2009). The welfare and behavioral impact of insurance provision in rural Ethiopia. Report submitted to USAID.

Hintz, M. (2010). Understanding the context is understanding the impact: Evidence from a qualitative microinsurance impact survey in Indonesia, in: Emanuela Morelli, Giorgio Amsicora Onnis, Walter J. Ammann, Corina Sutter (Eds.) Microinsurance: An Innovative Tool for Risk and Disaster Management. Davos: Global Risk Forum GRF.

Hogarth, R.M. and Kunreuther, H. (1985). Ambiguity and insurance decisions. American Economic Association Papers and Proceedings, 75: 386-390.

Holt, C.A. and Laury, S.K. (2002). Risk Aversion and Incentive Effects. The American Economic Review, 92(5): 1644-1655.

Holmstrom, B. (1979). Moral Hazard and Observability. Bell Journal of Economics, 10(1): 74-91.

Horowitz, J. K. and Lichtenberg, E. (1993). Insurance, moral hazard, and chemical use in agriculture. American Journal of Agricultural Economics, 75: 926-935.

Hulme, D. and Shepherd, A. (2003). Conceptualizing Chronic poverty. World Development, 31(3): 403-423.

Ibiwoye, A. and Adeleke, I.A. (2009). A Log-Lineair Analysis of Factors Affecting the Usage of Nigeria's National Health Insurance Scheme, The Social Sciences 4 (6): 587-592

Ito, S. and Kono, H. (2010). Why Is the Take-up of Microinsurance So Low? Evidence From a Health Insurance Scheme in India. Developing Economies, 48(1): 74101.

Jalan, J. and Ravallion, M. (1997). Are the poor less well insured? Evidence on vulnerability to income risk in rural China. Development Research Group Policy Research Working Paper No.1863, Washington D.C.:World Bank.

Jehu-Appiah,C., Aryeetey, G., Agyepong, I., Spaan, E. and Baltussen, R. (2011). Household perceptions and their implications for enrolment in the National Health Insurance Scheme in Ghana. Health Policy and Planning, 2012 May;27(3):222-33. Epub 2011 Apr 18.

Jowett, M., Deolalikar, A. and Martinsson, P. (2004). Health insurance and treatment seeking behaviour: Evidence from a low-income country. Health Economics, 13: 845-857.

Jowett, M. (2003). Do informal risk sharing networks crowd out public voluntary health insurance? Evidence from Vietnam. Applied Economics, 35: 1153-1161.

Jutting, J.P. (2004). Do community-based health insurance schemes improve poor people's access to health care? Evidence from rural Senegal. World Development, 32(2): 273-288.

Kagubare, M. (2005). The impact of CBHI on health care utilization and financial sustainability: The example of Rwanda. Doctoral dissertation. Baltimore, MD: John Hopkins University.

Kahneman, D. and Tversky, A. (1979). Prospect theory: an analysis of decision under risk. Econometrica, 47: 263-291.

Karlan, D., Kutsoati, E., McMillan, M. and Udry, C. (2011). Crop price indemnified loans for farmers: A pilot experiment in rural Ghana. The Journal of Risk and Insurance, 78(1): 37-55. 
Karlan, D. and Zinman, J. (2010). Expanding credit access: using randomized supply decisions to estimate the impacts. Review of Financial Studies, 23(1): 433-464

Karlan, D. and Morduch, J. (2009). Access to Finance: Credit Markets, Insurance, and Saving. In: Dani Rodrik and Mark Rosenzweig (eds), Handbook of Development Economics, 5, ch. 71. Amsterdam: North Holland.

Karlan, D.S., Ahraf, N. and Wesley, Y. (2004). Market survey report. Universities of Princeton and Harvard. Mimeo.

Karlan, D.S. (2001). Microfinance Impact Assessments: The Perils of Using New Members as a Control Group. Journal of Microfinance, 3(2): 76-85.

Katz, Elihu. (1961) The Social Itinerary of Technical Change: Two Studies on the Diffusion of Innovation. Human Organization, 20 (Summer): 70-82.

Kazianga, H., Udry, C. (2006) Consumption smoothing? Livestock, insurance and drought in rural Burkina Faso. Journal of Development Economics, 79: 413446.

Khandker, S. R., Koolwal, G. and Samad, H. (2009) Handbook on impact evaluation: Quantitative methods and practices. Washington, DC: World Bank.

Khandker, S. R. (2005). Micro-finance and Poverty: Evidence Using Panel Data from Bangladesh. World Bank Economic Review, 19: 263-286.

Khandker, Shahidur (1998). Fighting Poverty with Microcredit: Experience in Bangladesh. New York: Oxford University, Press for the World Bank.

Kitzinger, J. (1994). The methodology of Focus Groups: the importance of interaction between research participants. Sociology of Health \& Illness, 16: 103-121.

Kruk, M. E., Goldman, E. and Galea, S. (2009). Borrowing and selling to pay for health care in low- and middle-income countries. Health Affairs, 28: 1056-1066.

Laffont, J.J. and Matoussi, M.S. (1995). Moral Hazard, Financial Constraints and Sharecropping in El Oulja. The Review of Economic Studies, 62(3): 381-399.

Laibson, D. (1997). Golden eggs and hyperbolic discounting. Quarterly Journal of Economics, 62:443-477.

Landmann, A., Vollan, B., Frölich, M. (2011). Saving, Microinsurance: Why You Should Do Both or Nothing. A Behavioral Experiment on the Philippines. Paper provided by Verein für Socialpolitik, Research Committee Development Economics in its series Proceedings of the German Development Economics Conference, Berlin 2011 with number 51.

Leeuw, F. and Vaessen, J. (2009). Impact Evaluations and Development. NONIE guidance on impact evaluation. Washington, D.C.: World Bank

Lei, X. and Lin, W. (2009). The New Cooperative Medical Scheme in rural China: Does more coverage mean more service and better health? Health Economics, 18: S25-S46.

Lekprichakul, T. (2009). Ex Ante and Ex Post Risk Consumption smoothing activities: How do subsistence farmers in Southern and Eastern Province of Zambia Cope? In: Vulnerability and Resilience of Social-Ecological Systems FY 2008 Project Report. Kyoto, Japan: Research Institute for Humanity and Nature.

Limwattananon, S., Tangcharoensathien, V. and Prakongsai, P. (2007). Catastrophic and poverty impacts of health payments: Results from national household surveys in Thailand. Bulletin of the World Health Organization, 85: 600-606.

Lin, Wanchuan, Liu, Yiming and Meng, Juanjuan (2011) The Crowding-Out Effect of Formal Insurance on Informal Risk Sharing Arrangements: An Experimental 
Study. (October 3, 2011). Available at SSRN: http://ssrn.com/abstract=1937514 or http://dx.doi.org/10.2139/ssrn.1937514

Linnerooth-Bayer, J. and Mechler, R. (2006). Insurance for assisting adaptation to climate change in developing countries; a proposed strategy. Climate policy, 6

Loewenstein, G. O'Donoghue, T. and Rabin, M. (2002) Projection Bias in Predicting Future Utility. Working Papers 02-11, Cornell University, Center for Analytic Economics.

Loewenstein, George and Drazen Prelec. (1991). "Negative Time Preference," American Economic Review, 81: 347-52.

Magnoni B., E. Zimmerman (2011) Do clients get value from microinsurance. A systematic review of recent and current research. Appleton, WI: The MicroInsurance Centre, LLC.

Manning, W.G. and Marquis, M.S. (1996). Health Insurance: The Tradeoff between Risk Pooling and Moral Hazard. Journal of Health Economics, 15(5): 609-640.

Mathauer I, Schmidt J.O., Wenyaa M (2008) Extending social health insurance to the informal sector in Kenya. An assessment of factors affecting demand. International Journal of Health Planning Management, 23:51-68.

Maxwell, M. and Frankenberger (eds) (1992). Household Food Security: Concepts, Indicators, Measurements. Rome/New York: IFAD and UNICEF.

Mayers, D. and Smith, C.W. (1983). The Interdependence of Individual Portfolio Decisions and the Demand for Insurance. Journal of Political Economy, 91(2): 304-311.

McCord, M.J. and Churchill, C. (2005). Delta Life Bangladesh. CGAP Working Group on Microinsurance, Good and Bad Practices Case Study No. 7.

McCord, M. (2001) Microinsurance: A case study of an example of the provider model of microinsurance provision: Cambodia: GRET; Nairobi:MicroSave.

Merton, R.K., Fiske, M. and Kendall, P.L. (1956/1990). The Focused Interview. New York: Free Press. 2nd ed.

Merton, R.K. (1987). The focused interview and focus groups: continuities and discontinuities. Public Opinion, Q.51: 550-66.

Mobarak, M. And Rosenzweig, M. (2012) Selling Formal Insurance to the Informally Insured. Working Papers id:4777, eSocialSciences.

Moench, M and Dixit, A. (2004). Adaptive capacity and Livelihood Resilience: Adaptive Strategies for Responding to Floods and Droughts in South Asia. ISET (Institute for Social and Environmental Transition). Nepal, India/Boulder, Colorado.

Morduch, J. (2006) Micro-insurance - The next revolution? In: A. Banerjee, R. Benabou and D. Mookherjee, What have we Learned About Poverty? Oxford, UK: Oxford University Press.

Morduch, Jonathan (1995). Income Smoothing and Consumption Smoothing. The Journal of Economic Perspectives, 9(3): 103-114.

Morgan, D.L. (1988). Focus Groups as Qualitative Research. Thousand Oaks, CA: Sage.

Moser, C. (1998). The asset vulnerability framework: Reassessing urban poverty reduction strategies. World Development 26(1): 1-19.

Mossin, J. (1968). Aspects of Rational Insurance Purchasing. Journal of Political Economy, 76(4), Part (1): 553-568. 
Msuya, J. M., Jutting, J. P. and Asfaw, A. (2007). The impact of community health funds on the access to health care: Empirical evidence from rural Tanzania. International Journal of Public Administration, 30: 813-833.

Mullainathan, Sendhil and Eldar, Shafir (2009). Savings Policy and Decision-Making in Low-Income Households. In: Michael Barr and Rebecca Blank (Eds.) Insufficient Funds: Savings, Assets, Credit and Banking Among Low-Income Households. Russell Sage Foundation Press, pp. 121-145.

Neumann, J. von and Morgenstern, O. (1944). Theory of Games and Economic Behavior. Princeton: Princeton University Press.

Nguyen, H. and Knowles, J. (2010). Demand for voluntary health insurance in developing countries: The case of Vietnam's school-age children and adolescent student health insurance program. Social Science and Medicine, 71: 2074-2082.

Noterman, J.-P., Criel, B., Kegels, G. and Isu, K. (1995). A prepayment scheme for hospital care in the Masisi district in Zaire: A critical evaluation. Social Science and Medicine, 40: 919-930.

Okonkwo, U. and Paulson, A. (2008). What Can We Learn about Financial Access from U.S. Immigrants? The Role of Country of Origin Institutions and Immigrant Beliefs. World Bank Economic Review, 22(3): 431-455.

Onwujekwe O., Hanson, K. and Fox-Rushby, J. (2006). Some indicators of socioeconomic status may not be reliable and use of indices with these data could worsen equity. Health Economics, 15(6): 639-44.

Oyekale, A.S. and Eluwa, C.G. (2009). Utilization of Health-Care and Health Insurance among Rural Households in Irewole Local Government, Osun State, Nigeria. International Journal of Tropical Medicine, 2(2): 70-75.

Patt, A., Peterson, N., Carter, M., Velez, M., Hess, U. and Suarez, P. (2009). Making index insurance attractive to farmers. Mitigation and Adaptation Strategies for Global Change, 14(8): 737-753.

Pauly, M. (1974) Overinsurance and Public Provision of Insurance: The Roles of Moral Hazard and Adverse Selection. The Quarterly Journal of Economics, 88(1): 4462. doi: $10.2307 / 1881793$.

Pauly, M. (1968). The economics of moral hazard: Comment. American Economic Review, 58: 531-537.

Pawson, R., Greenhalgh, T., Harvey, G., Walshe, K. (2005). Realist review-A new method of systematic review designed for complex policy interventions. Journal of Health Services Research and Policy, 10: (Suppl 1)21-34.

Pitt, M. M. and Khandker, S. (1998) The Impact of Group-Based Credit Programs on Poor Households in Bangladesh: Does the Gender of Participants Matter? Journal of Political Economy, 958-996.

Polonsky, J., Balabanova, D., McPake, B., Poletti, T., Vyas, S., Ghazaryan, O. and Yanni, M. K. (2009). Equity in community health insurance schemes: Evidence and lessons from Armenia. Health Policy and Planning, 24: 209-216.

Prahalad, C.K. (2004). Fortune at the Bottom of the Pyramid: Eradicating Poverty through Profits. Wharton School Publishing.

Pratt, J.W. (1964). Risk Aversion in the Small and in the Large. Econometrica: Journal of the Econometric Society, 32(1): 122-136. 
Quimbo, S., Florentino, J., Peabody, J. W., Shimkhada, R., Panelo C. and Solon, O. (2008). Underutilization of social insurance among the poor: Evidence from the Philippines. PLoS ONE, 3, e3379. doi:10.1371/journal.pone.0003379

Radermacher, R., McGowan, H. and Dercon, S. (2012) What is the impact of microinsurance? In: C. Churchill and M. Matul (Eds.) Protecting the poor, A microinsurance compendium, Volume 2. Geneva: International Labour Organization.

Radermacher, R., Ashok, S., Zabel, K. and Dror, I. (2010). What do we know about the impact of microinsurance? Paper submitted for discussion for the Annual International Microinsurance Conference 2009 in Dakar.

Rahmato, D. (1987). Famine and survival strategies: A case study from Northeast Ethiopia. Food and Famine Monograph Series No. 1. Addis Ababa: Addis Ababa University, Institute of Development Research.

Rao, K. D., Waters, H., Steinhardt, L., Alam, S., Hansen, P. and Naeem, A.J. (2009). An experiment with community health funds in Afghanistan. Health Policy and Planning, 24: 301-311.

Ranson, M. K., Sinha, T., Chatterjee, M., Gandhi, F., Jayswal, R., Patel, F, Mills, A. J. (2007). Equitable utilization of Indian community-based health insurance scheme among its rural membership: Cluster randomised controlled trial. British Medical Journal 334: 1309. doi:10.1136/bmj.39192.719583.AE.

Ranson, M.K., Sinha, T., Chatterjee, M., Acharya, A., Bhavsar, A., Morris, S. S.and Mills, A. J. (2006). Making health insurance work for the poor: Learning from the Self-Employed Women's Association's (SEWA) community-based health insurance scheme in India. Social Science \& Medicine, 62: 707-720.

Ranson, M. K. (2002). Reduction of catastrophic health care expenditures by a community-based health insurance scheme in Gujarat, India: Current experiences and challenges. Bulletin of the World Health Organisation, 80: 613-621.

Ranson, M. K. (2001). The impact of SEWA's Medical Insurance Fund on hospital utilization and expenditure: A household survey. Health, Nutrition and Population Discussion Paper. Washington, DC: World Bank.

Ravallion, M. (2009), Should the Randomistas Rule? Economists Voice, February, www.bepress.com/ev.

Rogers, Everett M. (1973). Communication Strategies for Family Planning. New York: Free Press.

Rogers, E.M. (2003). Diffusion of innovations. Fifth edition. New York: The Free Press.

Roodman, D., Morduch, J. (2009). The impact of microcredit on the poor in Bangladesh: Revisiting the evidence. Center for Global Development Working Paper 174. Washington, D.C.: Center for Global Development

Rosenbaum, P.R. and Rubin. D.B. (1983) The central role of the propensity score in observational studies for causal effects. Biometrika, 70(1): 41-55.

Rosenzweig, M. R. and Wolpin, K. I. (1993). Credit market constraints, consumption smoothing, and the accumulation of durable production assets in low-income countries: Investments in bullocks in India. Journal of Political Economy, 101: 223-244. 
Rosenzweig, M. and Binswanger, H. (1993). Wealth, Weather Risk and the Composition and Profitability of Agricultural Investments, Economic Journal, 103: 56-78.

Rosenzweig, M. R. (1988). Risk, implicit contracts, and the family in rural areas of low income countries. Economic Journal 98: 1148-1170.

Rutherford, S. (1999). The Poor and Their Money: An Essay About Financial Services for Poor People. New Delhi: Department for International Development (DFID).

Rutstein, S.O., Johnson, K. (2004). DHS Comparative Reports 6: The DHS Wealth Index. ORC Macro MEASURE DHS, Calverton, Maryland, USA 2004.

Ryan, B. and Gross, N.C. (1943) The Diffusion of Hybrid Seed Corn in Two Iowa Communities. Rural Sociology, 13: 15-24.

Sahn, D.E. and Stifel, D.C. (2003). Progress toward the Millennium Development Goals in Africa. World Development, 31(1): 23-52.

Samuelson, P. A. (1937), Some aspects of the pure theory of capital. Quarterly Journal of Economics, 51: 469-496.

Sanson-Fisher, R.W., Bonevski, B., Green, L.W. and D’Este, C. (2007). Limitations of the randomized controlled trial in evaluating population-based health interventions Am J Prev Med, 33(2): 155-61.

Schlesinger, H. and Doherty, N.A. (1985). Incomplete Markets for Insurance: An Overview. The Journal of Risk and Insurance, 52(3): 402-423.

Schneider, P. (2005). Trust in micro-health insurance: an exploratory study in Rwanda. Social Science \& Medicine, 61(7): 1430-1438.

Schneider, P. (2004). The contribution of micro-health insurance to equity and sustainability in Rwanda. PhD thesis, London School of Hygiene and Tropical Medicine. London: University of London.

Schneider, P. and Hanson, K. (2006). Horizontal equity in utilization of care and fairness of health financing: A comparison of micro-health insurance and user fees in Rwanda. Health Economics, 15: 19-31.

Schneider, P. (2005). Trust in micro-health insurance: an exploratory study in Rwanda. Social Science and Medicine, 61:1430-38.

Schneider, P. and Diop, F. (2004). Community-based health insurance in Rwanda. In: A.S. Preker, G. Carrin (Eds.) Health financing for poor people-resource mobilization and risk sharing. Washington D.C.: The World Bank.

Shoemaker, R.W. and Shoaf, F.R. (1975). Behavioral Changes in the Trial of New Products. Journal of Consumer Research, 2, 2, September, 47-53.

Scoones, I. (1998). Sustainable Rural Livelihoods: A framework for analysis. IDS Working Paper 72. Brighton: Institute of Development Studies.

Scoones, I. (1995). Investigating Difference: Applications of Wealth Ranking and Household Survey Approaches among Farming Households in Southern Zimbabwe. Development and Change, 26: 67-88.

Scott, A. J. and Wild, C. J. (2001). Maximum likelihood for generalised case-control studies. Statistical design of medical experiments. II. J. Statist. Plann. Inference, 96: 3-27.

Scott, A. and Wild, C. (2002). On the robustness of weighted methods for fitting models to case-control data. Journal of the Royal Statistical Society: Series B (Statistical Methodology), 64: 207-219. 
Selvaraju, R., Subbiah, A.R., Baas, S. and Juergens, I. (2006). Livelihood adaptation to climate variability and change in drought-prone areas of Bangladesh. Rome: Food and Agriculture Organization (FAO) (ftp://ftp.fao.org/docrep/fao/009/a0820e/a0820e01.pdf)

Sen, A. (1981). Poverty and Famines: an Essay on Entitlement and Deprivation. Oxford, U.K.: Clarendon Press.

Shadish, W.R., Cook, T.D., Campbell, D.T. (2002). Experimental and quasiexperimental designs for generalized causal inference. Boston: HoughtonMifflin.

Shapiro, S.P. (1987). The Social Control of Impersonal Trust. American Journal of Sociology, 93(3): 623-658.

Shepard, D. S., Vian, T. and Kleinau, E. F. (1996). Performance and impact of four health insurance programs in rural and urban areas of Zaire. In R. P. Shaw and M. Ainsworth (Eds.) Financing health services through user fees and insurance: case studies from sub-Saharan Africa. World Bank discussion paper No. 294. Washington, DC: World Bank.

Sinha, T., Kent Ranson, M. and Mills, A.J. (2007). Protecting the Poor? The distributional Impact of a Bundled Insurance Scheme. World Development, 35(8):1404-1421.

Slovic, P. (1987). Perception of Risk. Science, 236: 280-290.

Slovic, P., Fischhoff, B., Lichtenstein, S., Corrigan, B. and Coombs, B. (1977). Preference for Insuring Against Probable Small Losses: Insurance Implications. Journal of Risk and Insurance, 44: 237-258.

Smith, K. V. and Sulzbach, S. (2008). Community-based health insurance and access to maternal health services: Evidence from three West African countries. Social Science and Medicine, 66: 2460-2473.

Smith, K., Barrett, C.B. and Box, P.W. (2000). Participatory Risk Mapping for Targeting Research and Assistance: With an Example from East African Pastoralists. World Development, 28(11): 1945-1959.

Smith, Vernon L., (1976) Experimental Economics: Induced Value Theory, American Economic Review, 1976, vol. 66, issue 2, pages 274-79

Snijders, T.A.B., and Bosker R.J (1999). Multilevel analysis: An introduction to basic and advanced multilevel modeling. London : Sage Publishers, 1999.

Sparrow, R. A., Suryahadi, A. and Widyanti, W. (2008). Public Health Insurance for the Poor in Indonesia: Targeting and Impact of Indonesia's Askeskin Programme. Paper presented during the conference on Seminar on Health Equity and Financing the Poor organized by The SMERU Research Institute Jakarta, Indonesia on 18 November 2008.

Stiglitz, J. (1973). Incentives and Risk-Sharing in Sharecropping. Cowles Foundation Discussion Papers 353, Cowles Foundation for Research in Economics, Yale University.

Strotz, R. (1956). Myopia and inconsistency in dynamic utility maximization. Review of Economic Studies, 23(3): 165-180.

Suarez, P., Linnerooth-Bayer, J., Mechler, R. (2007). The Feasibility of Risk Financing Schemes for Climate Adaptation: The case of Malawi. Washington DC: DECResearch Group, Infrastructure and Environment Unit, The World Bank. 
Sutter, and C. Sutter (2011). Microinsurance: An Innovative Tool for Dis-aster and Risk Reduction. Davos: GRF Forum.

Sun, X., Jackson, S., Carmichael, G. and Sleigh, A. (2009). Catastrophic medical payment and financial protection in rural China: Evidence from the New Cooperative Medical Scheme in Shandong Province. Health Economics, 18: 103-119.

Tarde, Gabriel (1903). The Laws of Imitation.Trans. Elsie Clews Parsons. 1st French ed., 1880; 2nd ed., 1885. New York: Henry Holt.

Thornton, R.L., Hatt, L.E., Field, E.M, Islam, M., Solis Diaz, F. Azucena Gonzalez, M.A. (2010). Social security Health Insurance for the informal Sector in Nicaragua: A randomized evaluation. Health Economics, 9(1): 181-206.

Timmermans, D. (1993). The Impact of Task Complexity on Information Use in Multiattribute Decision Making. Journal of Behavioral Decision Making, 6(2): 95111.

Townsend, R.M. (1994). Risk and Insurance in Village India. Econometrica, 62(3): 539-591.

Townsend, R. M. (1995). Financial systems in Northern Thai villages. Quarterly Journal of Economics, 110: 1011-1046.

Trujillo, A., Portillo, J. and Vernon, J. (2005). The impact of subsidized health insurance for the poor: Evaluating the Colombian experience using propensity score matching. International Journal of Health Care Finance and Economics, 5: 211-239.

Udry, C. (1994). Risk and Insurance in a Rural Credit Market: An Empirical Investigation in Northern Nigeria. Rev. Econ. Stud., 61(3): 495-526, July 1994.

Van der Knaap, L.M., Leeuw, F.L., Bogaerts, S. and Nijssen, L.T.J. (2008). Combining Campbell standards and the realist evaluation approach - the best of two worlds? American Journal of Evaluation, 29(1): 48-57.

Wagstaff, A., Lindelow, M., Jun, G., Ling, X. and Juncheng, Q. (2009). Extending health insurance to the rural population: An impact evaluation of China's New Cooperative Medical Scheme. Journal of Health Economics, 28: 1-19.

Wagstaff, A. (2007). Health Insurance for the Poor: Initial Impacts of Vietnam's Health Care Fund for the Poor. Impact Evaluation Series No. 11. Washington DC: the World Bank.

Wagstaff, A., Lindelow, M. (2008). Can insurance increase financial risk? The curious case of health insurance in China. Journal of Health Economics, 27: 990-1005.

Wagstaff, A., Lindelow, M., Gao, J., Ling, X. and Qian, J. (2007). Extending health insurance to the rural population : an impact evaluation of China's new cooperative medical scheme. Journal of Health Economics, 28(1): 1-19.

Wagstaff, A. and Pradhan, M. (2005). Health Insurance Impacts on Health and Nonmedical Consumption in a Developing Country World Bank Policy Research Working Paper 3563, April 2005.

Wang, H., Yip, W., Zhang, L. and Hsiao, W. C. (2009). The impact of rural mutual health care on health status: Evaluation of a social experiment in rural China. Health Economics, 18, S65-S82. doi: 10.1002/hec.1465

Warner, K., Ranger, N. ,Surminski, S., Arnold, M., Linnerooth-Bayer, J., MichelKerjan, E., Kovacs, P. and Herweijer, C. (2007). Adaptation to Climate Change: Linking Disaster Risk Reduction and Insurance. Geneva: UNISDR. 
(http://opim.wharton.upenn.edu/risk/library/2009UNISDR_Adaptation-toCC.pdf)

Waters, H. R. (1999). Measuring the impact of health insurance with a correction for selection bias - A case study of Ecuador. Health Economics, 8: 473-483.

Watts, M. (1983). Silent Violence: Food, Famine and Peasantry in Northern Nigeria. Berkeley, CA, USA: University of California Press.

White, R. (2004). Managing and interpreting uncertainty for climate change risk. Building Research and Information, 32: 438-448.

Wisner, B., Blaikie, P., Cannon, T., Davis, I. (2004). At risk: natural hazards, people's vulnerability and disasters. London: Routledge.

Xu, K., Evans, D. B., Kadama, P., Nabyonga, J., Ogwal, P. O., Nabukhonzo, P. and Aguilara, A. M. (2006). Understanding the impact of eliminating user fees: Utilization and catastrophic health expenditures in Uganda. Social Science \& Medicine, 62: 866-876.

Yip, W. and Berman, P. (2001). Targeted health insurance in a low income country and its impact on access and equity in access: Egypt's school health insurance. Health Economics, 10: 207- 220.

Yunus, M. (2008). Creating a World Without Poverty: Social Business and the Future of Capitalism. New York: Public Affairs.

Zhang, L., Wang, H., Wang, L., Hsiao, W. (2006) Social capital and farmer’s willingness-to-join a newly established community-based health insurance in rural China. Health Policy, 76: 233-242.

Zucker, L.G. (1986). Institutional Theories of Organization. Annual Review of

Sociology, 13: 443-464.

\section{Other sources}

International Association of Insurance Supervisors and CGAP working group on Microinsurance. (2007) Issues in regulation and supervision of microinsurance, Issues paper 7. http://www.iaisweb.org/view/element_href.cfm?src=1/2495.pdf on 21 August 2012

Lloyd's (2009) Report 260 degrees Risk Insight, Insurance in Developing Countries: Exploring Opportunities in Microinsurance, http://www.lloyds.com/ /media/Lloyds/Reports/360\%20Other/InsuranceInDeve lopingCountries.pdf on 15 June 2012

Swiss Re (2011) Insurance in emerging markets: growth drivers and profitability Sigma 5/2011 http://media.swissre.com/documents/sigma5_2011_en.pdf on 15 June 2012

Swiss Re (2011) News release 10 June 2011 Swiss Re partners with Oxfam America and the World Food Programme to insure poor rural communities against climate risks http://www.swissre.com/media/news_releases/pr_20110610_oxfam.html on 15 June 2012 


\section{Appendix 2-1 Excluded studies ( $\mathrm{N}=50)$}

\begin{tabular}{|c|c|}
\hline 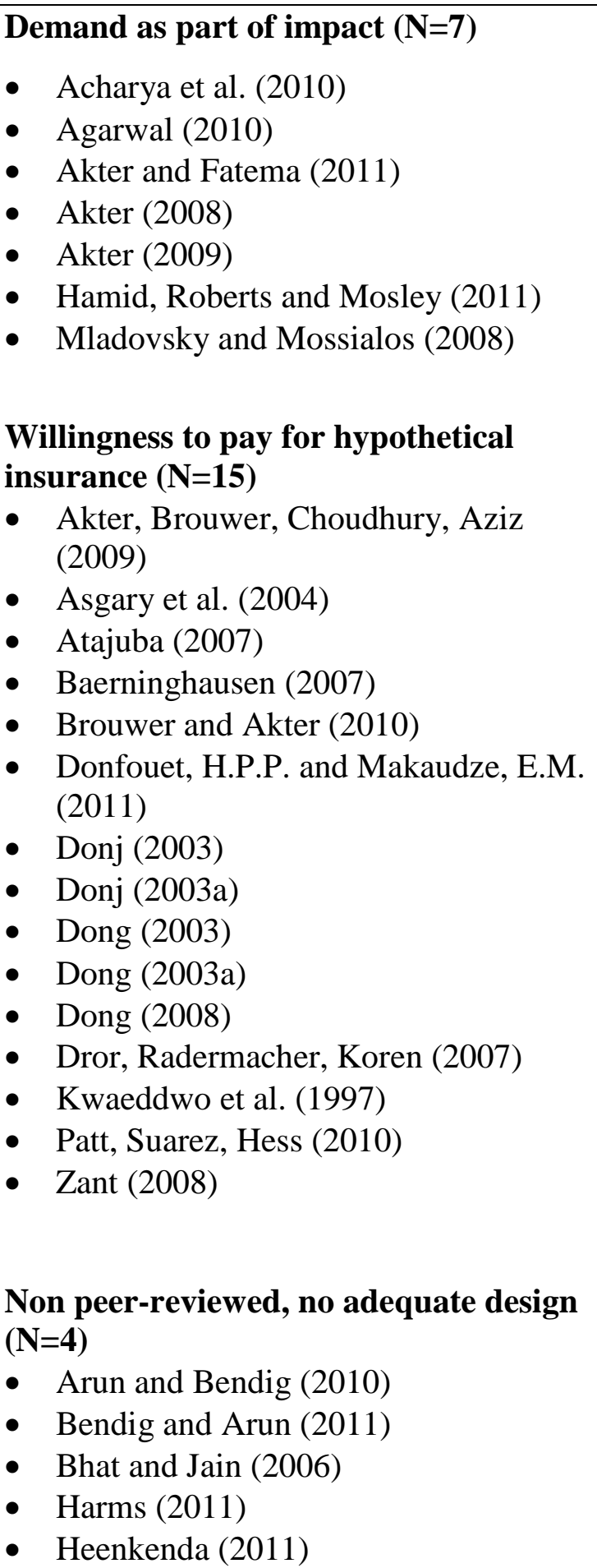 & 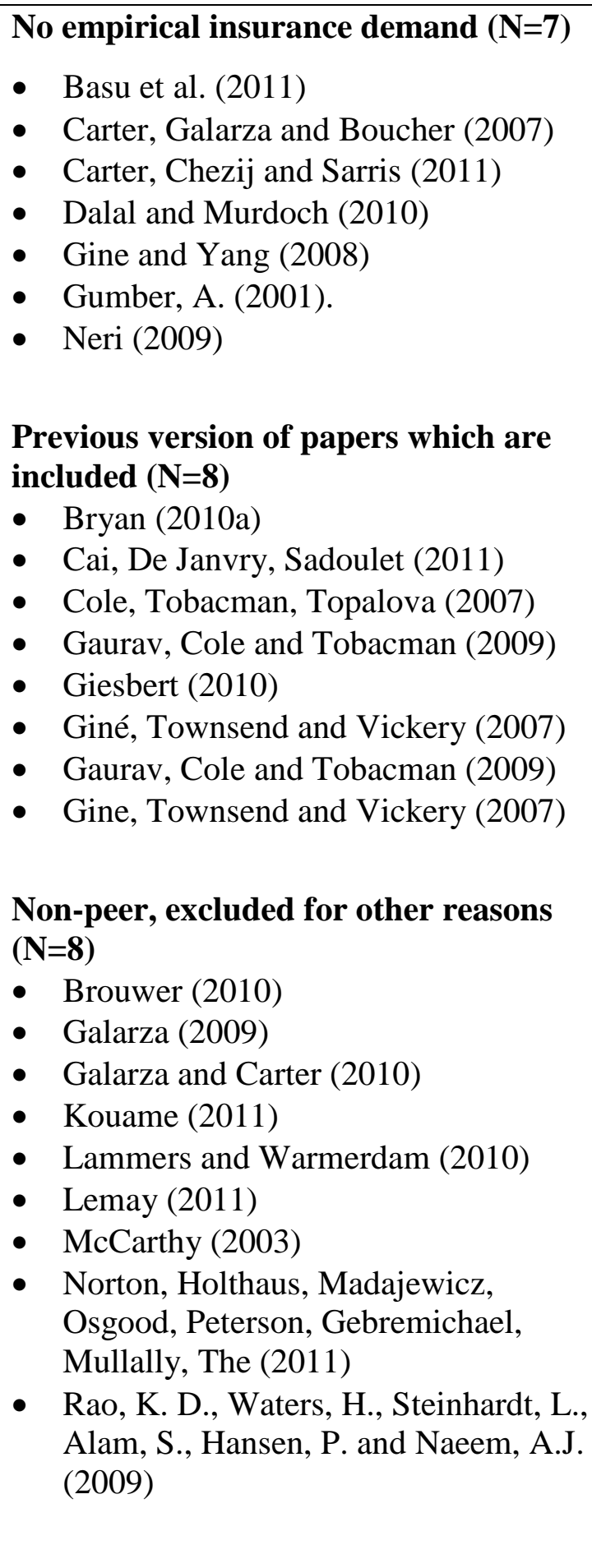 \\
\hline
\end{tabular}




\section{Appendix 3-1 Determinants of Understanding PAID plan}

Table 3-4 A logistic regression analysis of the determinants of understanding PAID plan among CARD members $(\mathrm{N}=126)$

Model 1

\section{Constant}

Previous government support (1=yes)

Experienced typhoon in past (1=yes)

Experienced accident in past $(1=$ yes $)$

Perception of typhoon risk (1=high)

Perception of accident risk ( $1=$ high $)$

Receives remittance (1=yes)

Bad house structure (1=yes)

Good house structure (1=yes)

High risk aversion ${ }^{\& \&}$

Low risk aversion ${ }^{\text {\& }}$

Knows peers with claim (1=yes)

Low risk aversion $*$ knows peers with

claims

Has experience with insurance (1=yes)

(Number of children)2

$\left(\right.$ Education $\left.^{\& \& \&}\right) 2$

Age in years
$-2.046(1.619)$

$2.075(.540)^{* * *}$

$3.138(.771)^{* * *}$

$.641(.625)$

$.778(.521)$

$-.247(.659)$

$.906(.514)^{*}$

$-.184(.834)$

$.750(.724)$

$-.086(.870)$

$-.764(.853)$

$-.786(.642)$

$-.491(1.179)$

$.026(.542)$

$.002(.015)$

$.042(.035)$

$-.055(.031)^{*}$

Nagelkerke Pseudo-R square $\quad .46$

Correctly predicted $\quad 74$

-2 Log likelihood 121.395

The test for the hypothesis (knows peers with claim) is one-sided. The controls are tested two-sided.

Cut-off used is .5

$\& \&$ Reference category is medium risk aversion

$\& \& \& 0=$ primary level, $1=$ primary finished, $2=$ secondary level, $3=$ secondary finished, $4=$ bachelor level, $5=$ higher

*** Significant at the 0.01 level, ** Significant at the 0.05 level, 0.01 Significant at the 0.01 level 
Appendix 3-2 Correlations underlying Table 3-2

\begin{tabular}{|c|c|c|c|c|c|c|c|c|c|c|c|c|c|c|c|c|c|c|c|c|c|c|c|}
\hline \multicolumn{2}{|r|}{ Having Paid Plan } & 1 & 2 & 3 & 4 & 5 & 6 & 7 & 8 & 9 & 10 & 11 & 12 & 13 & 14 & 15 & 16 & 17 & 18 & 19 & 20 & 21 & 22 \\
\hline & Having Paid Plan & . 130 إ & & & & & & & & & & & & & & & & & & & & & \\
\hline & Experienced typhoon in past ( $1=$ yes) & . & .205 & & & & & & & & & & & & & & & & & & & & \\
\hline 4. & Experienced accident in past $(1=$ yes $)$ & -.078 & .023 & .007 & & & & & & & & & & & & & & & & & & & \\
\hline 5 . & Perception of typhoon risk\#\# & -.026 & .173 & .174 & -.035 & & & & & & & & & & & & & & & & & & \\
\hline 6. & Perception of accident risk\#\# & -.010 & -.086 & -.131 & .052 & -.283 & & & & & & & & & & & & & & & & & \\
\hline 7. & Savings $(1=$ yes $)$ & .106 & .033 & .086 & .031 & .099 & -.077 & & & & & & & & & & & & & & & & \\
\hline 8. & Build house on poles $(1=$ yes $)$ & .211 & -.225 & -.014 & -.138 & .088 & .047 & $-.071]$ & & & & & & & & & & & & & & & \\
\hline 9. & Tie roof of house $(1=$ yes $)$ & .248 & -.289 & -.012 & -.088 & -.006 & -.022 & -.013 & .450 & & & & & & & & & & & & & & \\
\hline 10 & Receives remittance ( $1=$ yes) & .038 & .128 & -.029 & .057 & -.057 & -.098 & -.003 & -.086 & -.071 & 1 & & & & & & & & & & & & \\
\hline 1 & Bad house structure (1=yes) & -.003 & -.047 & .061 & -.197 & .122 & .131 & -.108 & .374 & .118 & -.198 & & & & & & & & & & & & \\
\hline & Good house structure (1=yes) & .076 & .072 & -.021 & .013 & -.138 & -.155 & .086 & -.189 & -.093 & .200 & -.356 & & & & & & & & & & & \\
\hline & Has production assets \#\#\# & .037 & .095 & -.073 & .059 & -.141 & .070 & -.037 & -.221 & -.200 & .142 & -360 & .265 & 1 & & & & & & & & & \\
\hline 1 & Has consumption assets $(1=$ yes $)$ & .146 & .098 & .008 & .097 & -.054 & -.001 & .081 & -.291 & -.170 & .127 & -.375 & .217 & .262 & & & & & & & & & \\
\hline & High risk aversion\& & -.006 & -.071 & .006 & -.187 & .059 & .005 & -.118 & .418 & .216 & -.166 & .711 & -.266 & -.465 & -.495 & & & & & & & & \\
\hline 1 & Low risk aversion\& & .205 & .124 & .056 & .058 & -.053 & -.113 & .062 & -.176 & -.116 & .277 & -.321 & .567 & .351 & .227 & -.335 & & & & & & & \\
\hline 17 & Knows peers with claim ( $1=y e s)$ & 264 & -.193 & .150 & .045 & -.047 & -.003 & -.051 & .084 & .114 & .019 & .059 & .052 & .106 & .057 & -.036 & .065 & & & & & & \\
\hline $1 \varepsilon$ & Has experience with insurance ( $1=y e s)$ & .031 & .059 & -.065 & .029 & -.029 & -.050 & -.034 & -.096 & -.004 & 201 & -.220 & .169 & -.040 & .175 & -.240 & .187 & -.008 & & & & & \\
\hline 19 & Number of children & .188 & -.085 & -.034 & .050 & .039 & .043 & -.018 & .107 & .105 & -.103 & .042 & -.041 & -.096 & .002 & .111 & -.061 & -.015 & -.011 & 1 & & & \\
\hline 26 & Education & .048 & .108 & .082 & -.055 & -.062 & -.032 & .005 & -.179 & -.095 & .169 & -.236 & .175 & .177 & .228 & -.303 & .390 & .049 & .256 & -.124 & & & \\
\hline 2 & Age in years & .059 & .051 & .158 & -.050 & .006 & -.082 & . 051 & -.187 & -.082 & .163 & -.171 & .187 & .169 & .095 & -.167 & 097 & -.014 & .041 & -.080 & -.129 & 1 & \\
\hline & Understands product & .527 & -.065 & .292 & .037 & .051 & -.056 & .070 & .064 & .142 & .114 & -.110 & .056 & .088 & .171 & -.118 & .134 & 215 & .000 & 106 & . 098 & .056 & \\
\hline
\end{tabular}




\section{Appendix 3-3 Correlations underlying Table 3-3}

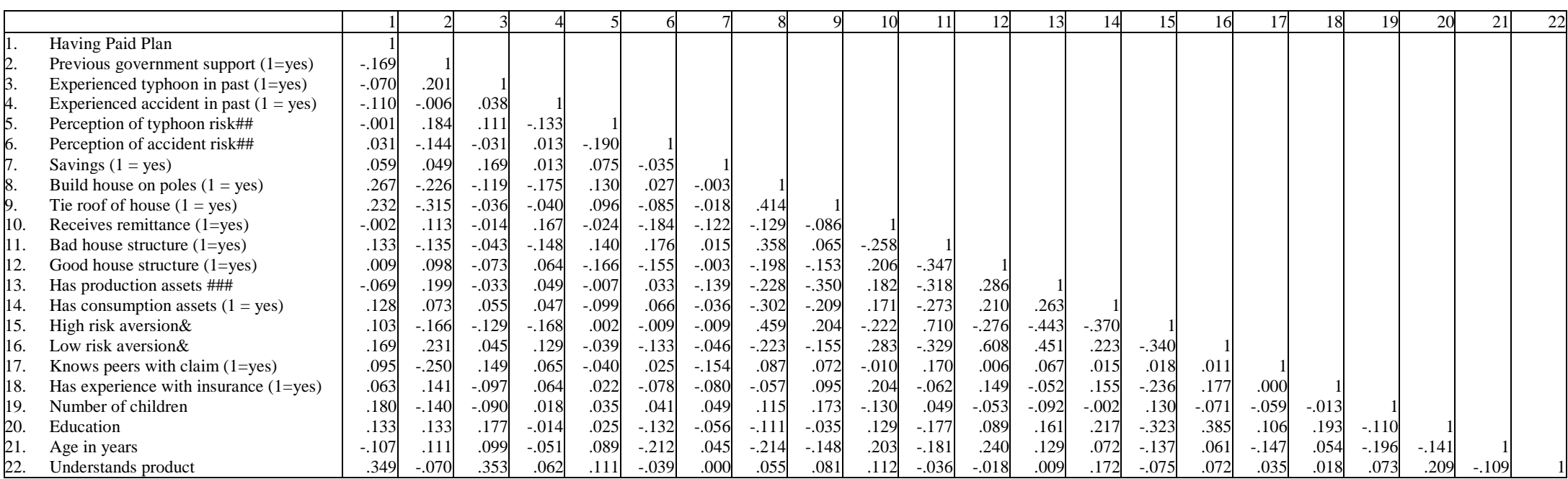




\section{Appendix 4-1 Peer-reviewed studies on microinsurance impact}

Table 4-1 Studies investigating the impact of agriculture microinsurance

\begin{tabular}{|l|l|l|l|}
\hline & Question addressed & Randomized experiment & Quantitative \\
\hline $\begin{array}{l}\text { Ex-ante welfare } \\
\text { impacts }\end{array}$ & $\begin{array}{l}\text { Increased business } \\
\text { investment or riskier } \\
\text { business decision } \\
\text { Cai et al. (2010) } \\
\text { Giné and Yang (2009) } \\
\text { Hill and Viceisza (2010) } \\
\text { Karlan et al. (2010) }\end{array}$ & \\
\hline $\begin{array}{l}\text { Ex-post welfare } \\
\text { impacts }\end{array}$ & Protection of assets & & Chanterat et al. (2009) \\
\cline { 2 - 4 } & Lower expenses & Giné et al. (2007) & $\begin{array}{l}\text { Breustedt et al. (2008) } \\
\text { Hess (2003) }\end{array}$ \\
\cline { 2 - 4 } & $\begin{array}{l}\text { Consumption } \\
\text { smoothing }\end{array}$ & & \\
\hline
\end{tabular}

Extracted and compiled from Radermacher et al. (2012) and Magnoni and Zimmerman (2011) 
Table 4-2 Studies investigating the impact of health microinsurance

\begin{tabular}{|c|c|c|c|}
\hline & Question addressed & Randomized experiment & Quantitative \\
\hline \multirow{2}{*}{$\begin{array}{l}\text { Ex-ante welfare } \\
\text { impacts }\end{array}$} & Reduced savings & & Chou et al. (2003) \\
\hline & $\begin{array}{l}\text { Increased } \\
\text { consumption or } \\
\text { household investment }\end{array}$ & & $\begin{array}{l}\text { Hamid et al. (2010) } \\
\text { Wagstaff and Pradhan (2005) }\end{array}$ \\
\hline \multirow[t]{4}{*}{ Service quality } & $\begin{array}{l}\text { Utilization of health } \\
\text { care }\end{array}$ & Thornton et al. (2009) & $\begin{array}{l}\text { Aggarwal (2010) } \\
\text { Chankova et al. (2008) } \\
\text { Cheng and Chiang (1997) } \\
\text { Devadasan et al. (2007) } \\
\text { Diop et al. (2006) } \\
\text { Dror et al. (2005) } \\
\text { Dror et al. (2006) } \\
\text { Dror et al. (2009) } \\
\text { Franco et al. (2008) } \\
\text { Gnawali et al. (2009) } \\
\text { Hamid et al. (2010) } \\
\text { Jowett (2004) } \\
\text { Jutting (2004) } \\
\text { Kagubare (2005) } \\
\text { Lei and Lin (2009) } \\
\text { Msuya et al. (2004) } \\
\text { Noterman et al. (1995) } \\
\text { Polonsky et al. (2009) } \\
\text { Rao et al. (2009) } \\
\text { Schneider and Diop (2001) } \\
\text { Schneider and Hanson (2006) } \\
\text { Smith and Sulzbach (2008) } \\
\text { Sparrow et al. (2010) } \\
\text { Trujilo et al. (2005) } \\
\text { Wagstaff (2007) } \\
\text { Wagstaff and Pradhan (2005) } \\
\text { Wagstaff et al. (2009) } \\
\text { Waters (1999) } \\
\text { Xu et al. (2006) } \\
\text { Yip and Berman (2001) }\end{array}$ \\
\hline & $\begin{array}{l}\text { Quality of health } \\
\text { services }\end{array}$ & & $\begin{array}{l}\text { Bauchet et al. (2010) } \\
\text { Cheng and Chiang (1997) }\end{array}$ \\
\hline & $\begin{array}{l}\text { Does insurance } \\
\text { improve health } \\
\text { outcomes }\end{array}$ & & $\begin{array}{l}\text { Aggarwal (2010) } \\
\text { Dror et al. (2005) } \\
\text { Hamid et al. (2010) } \\
\text { Wang et al. (2009) }\end{array}$ \\
\hline & $\begin{array}{l}\text { Does insurance lead } \\
\text { to education or access } \\
\text { to other services }\end{array}$ & & $\begin{array}{l}\text { Bauchet et al. (2010) } \\
\text { Hamid et al. (2010) }\end{array}$ \\
\hline \multirow[t]{2}{*}{$\begin{array}{l}\text { Ex-post welfare } \\
\text { impacts }\end{array}$} & Protect assets & & $\begin{array}{l}\text { Aggarwal. (2010) } \\
\text { Kruk et al. (2009) }\end{array}$ \\
\hline & Borrow less & & $\begin{array}{l}\text { Aggarwal. (2010) } \\
\text { Kruk et al. (2009) }\end{array}$ \\
\hline
\end{tabular}




\begin{tabular}{|c|c|c|}
\hline $\begin{array}{l}\text { Reduction in out-of- } \\
\text { pocket expenditure }\end{array}$ & Thornton et al 2009 & $\begin{array}{l}\text { Aggarwal (2010) } \\
\text { Bogg et al. (1996) } \\
\text { Chankova et al. (2008) } \\
\text { Devadasan et al. (2007) } \\
\text { Diop et al. (2006) } \\
\text { Dror et al. (2009) } \\
\text { Ekman (2007) } \\
\text { Franco et al. (2008) } \\
\text { Gumber (2001) } \\
\text { Jutting (2004) } \\
\text { Lei and Lin (2009) } \\
\text { Limwattananon et al. (2007) } \\
\text { Msuya (2004) } \\
\text { Ranson (2002) } \\
\text { Rao et al. (2009) } \\
\text { Schneider and Diop (2001) } \\
\text { Schneider and Hanson (2006) } \\
\text { Sepehri et al. (2006) } \\
\text { Sparrow et al. (2010) } \\
\text { Sun et al. (2009) } \\
\text { Wagstaff et al. (2009) } \\
\text { Wagstaff and Lindelow } \\
\text { (2008) } \\
\text { Wagstaff (2007) } \\
\text { Wagstaff and Pradhan (2005) } \\
\text { Xu et al. (2006) } \\
\text { Yip and Berman (2001) }\end{array}$ \\
\hline Cash flow smoothing & & $\begin{array}{l}\text { Aggarwal (2010) } \\
\text { Franco et al. (2008) } \\
\text { Hamid et al. (2010) }\end{array}$ \\
\hline
\end{tabular}

Extracted and compiled from Radermacher et al. (2012) and Magnoni and Zimmerman (2011) 


\section{Appendix 5.1 Correlation Matrix belonging to Table 5-5 and 5-6}

Table 5-7 Correlation matrix belonging to Table 5-5 and Table 5-6

\begin{tabular}{|c|c|c|c|c|c|c|c|c|c|c|c|c|c|c|}
\hline Part 1-2 & 11 & 2 & 3 & 4 & 5 & 6 & 77 & 8 & 9 & 10 & 11 & 12 & 13 & 14 \\
\hline 1. Sellprod & 1 & & & & & & & & & & & & & \\
\hline 2. Stresschild & -.011 & 1 & & & & & & & & & & & & \\
\hline 3. Sellcons & -.011 & -.081 & 1 & & & & & & & & & & & \\
\hline 4. Moneylender & .078 & .318 & .148 & 1 & & & & & & & & & & \\
\hline 5. Informal & .191 & .114 & -.060 & .053 & 1 & & & & & & & & & \\
\hline 6. Ownsavings & -.030 & .088 & .088 & -.110 & -.090 & 1 & & & & & & & & \\
\hline 7. Eatless & .143 & .090 & -.059 & .056 & .132 & -.113 & 1 & & & & & & & \\
\hline 8. Sideline & .242 & .094 & -.026 & .055 & .111 & .061 & .031 & 1 & & & & & & \\
\hline 9. Claim in Php & -.222 & .163 & -.048 & .048 & -.139 & .161 & -.269 & -.099 & 1 & & & & & \\
\hline 10. Damage in Php & .186 & .266 & -.115 & .050 & .114 & .161 & -.007 & .110 & .105 & 1 & & & & \\
\hline 11. Previous government support (1=yes) & .109 & .125 & -.047 & .050 & .172 & -.070 & .159 & .166 & -.058 & .090 & 1 & & & \\
\hline 12. High risk aversion & -.002 & -.082 & -.022 & .014 & -.069 & -.060 & -.044 & .018 & -.141 & -.046 & .058 & 1 & & \\
\hline 13. Low risk aversion & -.114 & .004 & .076 & -.074 & .020 & -.044 & .017 & .003 & .094 & .063 & -.120 & -349 & 1 & \\
\hline 14. Savings $(1=$ yes $)$ & -.024 & .101 & .011 & -.078 & .050 & .142 & .104 & -.042 & .011 & .083 & -109 & .098 & .114 & 1 \\
\hline 15. Build house on poles $(1=$ yes $)$ & -.041 & -.013 & .170 & -.022 & -.174 & .112 & -.196 & .075 & .048 & -100 & -.066 & .425 & -176 & .060 \\
\hline 16. Tie roof of house $(1=$ yes $)$ & -.210 & .100 & .100 & .035 & -.091 & .114 & -166 & 141 & 378 & -.015 & .056 & 187 & .117 & .030 \\
\hline 17. Save food & .060 & .072 & -.070 & -.088 & .147 & .166 & .089 & .206 & .061 & .119 & .102 & .037 & .105 & .176 \\
\hline 18. Has production assets & .112 & .090 & .090 & -.002 & -.066 & -.069 & .017 & .037 & .004 & -.017 & -.052 &. .371 & .282 & .063 \\
\hline 19. Has consumption assets & -.005 & -.004 & .068 & .017 & -.020 & .044 & -.066 & .077 & .105 & -.117 & -186 & .530 & .241 & .125 \\
\hline 20. Receives remittance ( $1=y e s)$ & .092 & .074 & -.040 & .000 & .232 & -.121 & .028 & .138 & -.008 & .081 & .131 & -.195 & .218 & .050 \\
\hline 21. Number of children & -.146 & .196 & .060 & .170 & -.127 & .115 & -.088 & -.023 & .152 & -.033 & -106 & .011 & .037 & .020 \\
\hline 22. Bad house structure (1=yes) & .057 & -.110 & -.051 & -.073 & -.061 & -.108 & .107 & .069 & -.255 & -.094 & -.008 & .731 &. .352 & .106 \\
\hline 21. Good house structure (1=yes) & .034 & .027 & .104 & .013 & .047 & .004 & .003 & .019 & .161 & .040 & .074 & .315 & .750 & 157 \\
\hline 24. Perception of typhoon risk & -.067 & -.206 & .023 & -.114 & -.099 & .155 & -.095 & .103 & -.072 & -.001 & -.050 & .058 & .097 & 114 \\
\hline 25. Experienced typhoon in past & .036 & -.003 & -.003 & -.027 & .166 & .000 & .153 & -135 & -.265 & -.111 & .131 & -141 & .033 & .116 \\
\hline 26. Experienced accident in past & .152 & .097 & .021 & .064 & .231 & -.173 & .045 & .004 & .036 & .019 & .105 & .156 & .077 & .036 \\
\hline 27. Education & .035 & -.031 & .129 & .045 & -.172 & -.002 & -.010 & .035 & .141 & -.133 & .049 & .285 & 355 & .035 \\
\hline 28. Age in years & -.055 & -.096 & -.210 & -.110 & .113 & -.008 & -.053 & .006 & .053 & 187 & -.011 & .183 & .058 & .007 \\
\hline
\end{tabular}


Table 5-7 Correlation matrix belonging to Table 5-5 and Table 5-6

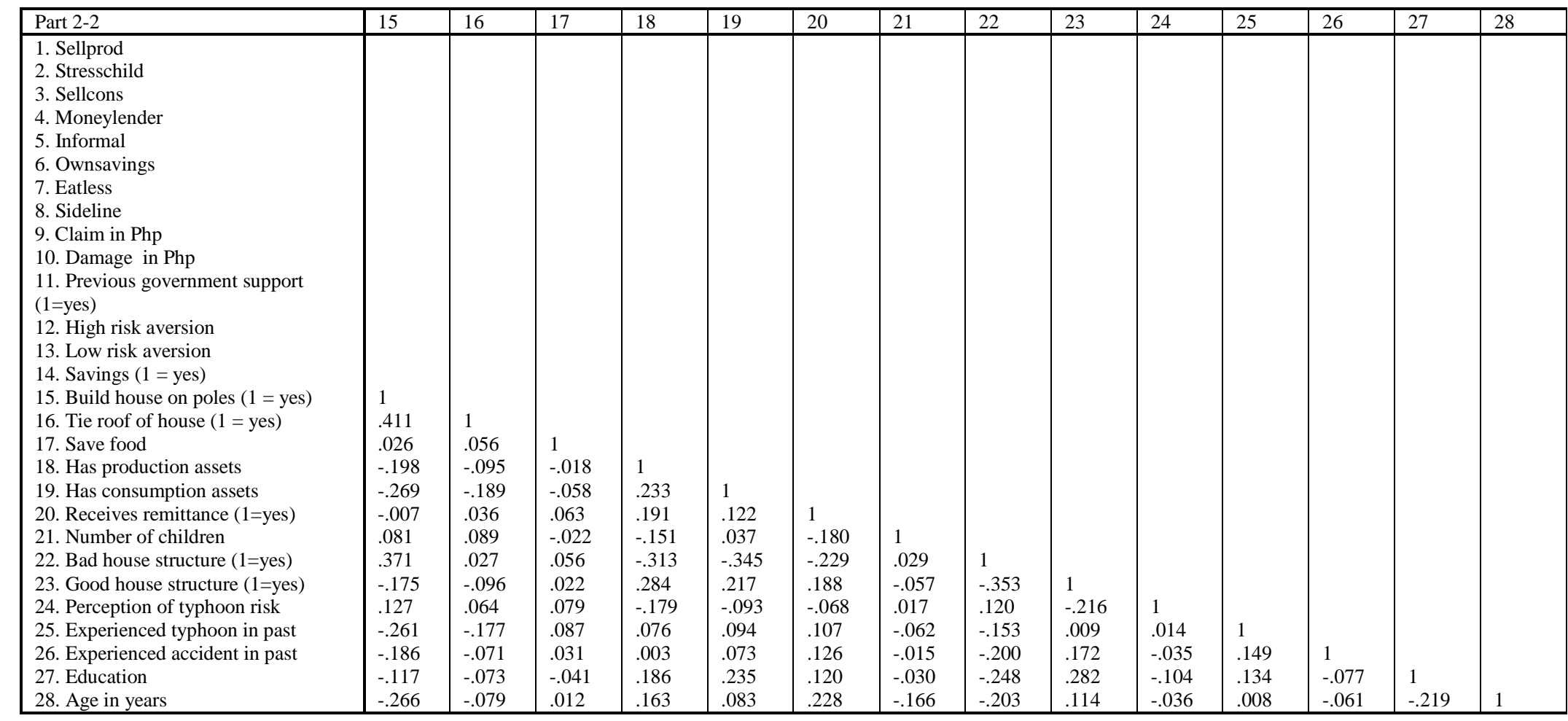




\section{Appendix 5-2 Dichotomous combined consumption smoothing variable}

Table 5-8 Dichotomous combined consumption smoothing variable Stressdi1 and Stressdi2

\begin{tabular}{|c|c|c|}
\hline & Model Stressdi1\# & Model Stressdi2\#\# \\
\hline Constant & $-2.988(2.341)$ & $-1.896(2.168)$ \\
\hline Payout (1=yes) & $-.628(.608)^{* * *}$ & $-1.047(.569)^{* * *}$ \\
\hline Damage in Php & $1.964(.653)$ & $1.421(.536)$ \\
\hline Previous government support $^{1}$ & $.418(.489)$ & $.480(.459)$ \\
\hline Savings ${ }^{1}$ & $-.350(.722)$ & $.034(.706)$ \\
\hline Build house on poles $^{1}$ & $.021(.638)$ & $.678(.592)$ \\
\hline Tie roof of house ${ }^{1}$ & $-.084(.543)$ & $-.043(.511)$ \\
\hline Save food ${ }^{1}$ & $-.238(.622)$ & $-.450(.577)$ \\
\hline Has production assets $^{2}$ & $1.106(.561)^{* * *}$ & $1.277(.536)^{* *}$ \\
\hline Has consumption assets $^{1}$ & $.362(.704)$ & $.250(.655)$ \\
\hline Remittance, access to $^{1}$ & $-.170(.502)$ & $-.011(.472)$ \\
\hline Number of children & $.055(.121)$ & $.106(.115)$ \\
\hline Risk aversion high & $.270(.746)$ & $-.045(.724)$ \\
\hline Risk aversion low & $-.022(1.209)$ & $.746(1.102)$ \\
\hline Bad house structure $^{1}$ & $-.618(.465)$ & $-.311(.447)$ \\
\hline Good house structure $^{1}$ & $-1.027(.822)$ & $-1.010(.791)$ \\
\hline Perception of typhoon risk $^{1}$ & $.956(.631)$ & $.756(.595)$ \\
\hline Experienced typhoon in past ${ }^{1}$ & $.334(.844)$ & $.255(.804)$ \\
\hline Experienced accident in past $^{1}$ & $-1.100(1.136)$ & $-.886(1.044)$ \\
\hline Education\& & $.051(.167)$ & $.029(.157)$ \\
\hline Age in years & $-.018(.028)$ & $-.033(.028)$ \\
\hline
\end{tabular}

\# stressdi 1 is dichotomous, low stress: Eatless, Ownsavings, Sideline, Informal, Sellcons, high stress: Moneylender, Stresschild, Sellprod, Moveout

\#\# stressdi2 is dichotomous, low stress: Eatless, Ownsavings, Sideline, Informal, high stress: Sellcons, Moneylender, Stresschild, Sellprod, Moveout

The test for the hypothesis (Payout) is one-sided. The controls are tested two-sided.

$* * *$ Significant at the 0.01 level, ** Significant at the 0.05 level, * Significant at the 0.10 level

1 Yes $=1,0=$ no

${ }^{2} 0=$ no production assets,

$\& 0=$ primary level, $1=$ primary finished, $2=$ secondary level, $3=$ secondary finished, $4=$ bachelor level, 5 = higher, 


\section{Appendix 5-3 Combined consumption smoothing variable, number of activities}

Table 5-9 Combined consumption smoothing variable, number of activities

\begin{tabular}{|c|c|}
\hline & $\begin{array}{l}\text { Number of consumption } \\
\text { smoothing activities }\end{array}$ \\
\hline Constant & $1.284(1.063)$ \\
\hline Payout (1=yes) & $-.519(.273) * *$ \\
\hline Damage in Php & $.608(.242)^{* *}$ \\
\hline Previous government support $^{1}$ & $.405(.226)^{*}$ \\
\hline Savings $^{1}$ & $.148(.355)$ \\
\hline Build house on poles $^{1}$ & $-.099(.287)$ \\
\hline Tie roof of house ${ }^{1}$ & $.186(.254)$ \\
\hline Save food ${ }^{1}$ & $.471(.277) *$ \\
\hline Has production assets $^{2}$ & $.119(.247)$ \\
\hline Has consumption assets $^{1}$ & $.220(.326)$ \\
\hline Remittance, access to $^{1}$ & $.265(.233)$ \\
\hline Number of children & $.031(.058)$ \\
\hline Risk aversion high & $-.146(.379)$ \\
\hline Risk aversion low & $-.614(.430)$ \\
\hline Bad house structure $^{1}$ & $.089(.343)$ \\
\hline Good house structure $^{1}$ & $.649(.456)$ \\
\hline Perception of typhoon risk $^{1}$ & $-.119(.221)$ \\
\hline Experienced typhoon in past $^{\top}$ & $-.113(.399)$ \\
\hline Experienced accident in past $^{\top}$ & $.109(.301)$ \\
\hline Education\& & $-.019(.079)$ \\
\hline Age in years & $-.022(.013) *$ \\
\hline & \\
\hline
\end{tabular}

The test for the hypothesis (Payout) is one-sided. The controls are tested two-sided.

$* * *$ Significant at the 0.01 level, ** Significant at the 0.05 level, * Significant at the 0.10 level

1 Yes $=1,0=$ no

${ }^{2} 0=$ no production assets,

$\& 0=$ primary level, $1=$ primary finished, $2=$ secondary level, $3=$ secondary finished, $4=$ bachelor level, 5 = higher, 


\section{Appendix 6-1 Programme 2012 Research Conference on Microinsurance}

\begin{tabular}{|c|c|c|}
\hline \multicolumn{3}{|c|}{ Wednesday 11 April, First day } \\
\hline $\begin{array}{l}11.00-12.30 \\
\text { Waaier Foyer }\end{array}$ & \multicolumn{2}{|l|}{ Arrival, coffee and registration } \\
\hline $12.30-12.40$ & \multicolumn{2}{|c|}{ All participants have to be in Waaier 4 before 12.40} \\
\hline $\begin{array}{l}13.00-13.05 \\
\text { Waaier } 4\end{array}$ & \multicolumn{2}{|c|}{ Welcome, Chair of Board of University, Anne Flierman } \\
\hline $\begin{array}{l}13.05-13.20 \\
\text { Waaier } 4\end{array}$ & \multicolumn{2}{|c|}{$\begin{array}{l}\text { Opening key-note: } \\
\text { H.R.H. Princess Máxima of The Netherlands, United Nations Secretary- } \\
\text { General's Special Advocate for Inclusive Finance for Development. }\end{array}$} \\
\hline $\begin{array}{l}13.20-13.35 \\
\text { Waaier } 4\end{array}$ & \multicolumn{2}{|c|}{$\begin{array}{l}\text { Plenary key note: } \\
\text { Craig Churchill, Team Leader of ILO's Microinsurance Innovation Facility, } \\
\text { Chair of the Microinsurance Network }\end{array}$} \\
\hline $\begin{array}{l}13.35-13.50 \\
\text { Waaier } 4\end{array}$ & \multicolumn{2}{|c|}{$\begin{array}{l}\text { Plenary key note: } \\
\text { Xavier Giné, Senior Economist Research Department World Bank }\end{array}$} \\
\hline $\begin{array}{l}13.50-14.30 \\
\text { Waaier Foyer }\end{array}$ & \multicolumn{2}{|l|}{ Lunch } \\
\hline $\begin{array}{l}14.45-15.45 \\
\text { Waaier } 4\end{array}$ & \multicolumn{2}{|c|}{$\begin{array}{l}\text { Panel discussion: } \\
\text { 'What are the implications of impact studies of microinsurance products on } \\
\text { science and society?' } \\
\text { Moderator: Véronique Faber, Microinsurance Network } \\
\text { Panelists: } \\
\text { Xavier Giné, World Bank } \\
\text { Craig Churchill, ILO Microinsurance Innovation Facility } \\
\text { Glenn Harrison, Center for Economic Analysis of Risk (CEAR) } \\
\text { Brandon Mathews, Microinsurance Network }\end{array}$} \\
\hline \multirow{2}{*}{$\begin{array}{l}15.45-17.45 \\
\text { Ravelijn }\end{array}$} & \multicolumn{2}{|l|}{ 1. Parallel sessions } \\
\hline & $\begin{array}{l}\text { 1A. Comparing health insurance } \\
\text { demand } \\
\text { Facilitator: } \\
\text { Aaltje de Roos, Dutch Ministry of } \\
\text { Foreign Affairs } \\
\text { Discussant: } \\
\text { André Leliveld, African Studies } \\
\text { Centre } \\
\text { Rapporteur: } \\
\text { Jesse D'Anjou }\end{array}$ & $\begin{array}{l}\text { Quimbo, University of The } \\
\text { Philippines, Diliman, Patterns of } \\
\text { voluntary enrolment in private versus } \\
\text { social health insurance in the } \\
\text { Philippines: Is adverse selection or } \\
\text { moral hazard a concern? } \\
\text { Chatterjee, Centre for Insurance and } \\
\text { Risk Management- Institute of } \\
\text { Financial Management and Research } \\
\text { (CIRM-IFMR), India, Addressing the } \\
\text { low demand for preventive health care } \\
\text { through the provision of free medical } \\
\text { check-ups in Kolkata slums? } \\
\\
\text { Degens and May, University of } \\
\text { Cologne, Analysing Membership in the }\end{array}$ \\
\hline
\end{tabular}




\begin{tabular}{|c|c|c|}
\hline & & $\begin{array}{l}\text { National Health Insurance Scheme in } \\
\text { Ghana. Applying qualitative } \\
\text { comparative analysis. }\end{array}$ \\
\hline & $\begin{array}{l}\text { 1B. Social structures and social } \\
\text { relations and insurance demand } \\
\text { and impact. } \\
\text { Facilitator and discussant: } \\
\text { Andreas Landmann, University of } \\
\text { Mannheim } \\
\text { Rapporteurs: } \\
\text { Friederike Lenel and Karla } \\
\text { Henning } \\
\text { Ravelijn } 2502\end{array}$ & $\begin{array}{l}\text { Henning and Lechtenfeld, University } \\
\text { of Goettingen, Remittances and } \\
\text { weather insurance: Evidence from } \\
\text { rainfall shocks in Indonesia. } \\
\text { Grimm, International Institute of } \\
\text { Social Studies (ISS) of Erasmus } \\
\text { University, The impact of informal risk } \\
\text { sharing systems on investment } \\
\text { decisions of small entrepreneurs. } \\
\text { Janssens, Kramer, VU University and } \\
\text { Tinbergen Institute, The social } \\
\text { dilemma of microinsurance. A framed } \\
\text { field experiment with microcredit } \\
\text { groups in Tanzania. }\end{array}$ \\
\hline & $\begin{array}{l}\text { 1C. Design and demand for } \\
\text { insurance for farmers } \\
\text { Facilitator and discussant: Jerry } \\
\text { Skees, University of Kentucky } \\
\text { Rapporteurs: } \\
\text { Lisa Chassin and Amrei Lahno }\end{array}$ & $\begin{array}{l}\text { de Nicola, International Food Policy } \\
\text { Research Institute, (IFPRI), The value } \\
\text { of (customized) insurance for farmers } \\
\text { in rural Bangladesh. } \\
\text { Clarke, World Bank and University of } \\
\text { Oxford, Improving farmers' access to } \\
\text { agricultural insurance in India. } \\
\text { Guush Berhane Tesfay, International } \\
\text { Food Policy Research Institute, } \\
\text { (IFPRI), Do informal risk-sharing } \\
\text { groups reduce the challenges of } \\
\text { providing weather indexed insurance } \\
\text { products? Evidence from a } \\
\text { randomized field experiment in } \\
\text { Ethiopia. }\end{array}$ \\
\hline $\begin{array}{l}17.45-19.30 \\
\text { Ravelijn Foyer }\end{array}$ & \multicolumn{2}{|l|}{ Drinks } \\
\hline \multicolumn{3}{|c|}{ Thursday 12 April, Second day } \\
\hline $\begin{array}{l}08.30-9.00 \\
\text { Ravelijn Foyer }\end{array}$ & \multicolumn{2}{|l|}{ Coffee and Tea } \\
\hline $\begin{array}{l}09.00-09.30 \\
\text { Waaier } 4\end{array}$ & \multicolumn{2}{|c|}{$\begin{array}{l}\text { Plenary key-note: Agriculture and natural disaster insurance } \\
\text { Jerry Skees, University of Kentucky }\end{array}$} \\
\hline $\begin{array}{l}\text { 09.30-10.30 } \\
\text { Waaier } 4\end{array}$ & \multicolumn{2}{|c|}{ Follow-up panel: Can weather-index products be good products? } \\
\hline
\end{tabular}




\begin{tabular}{|c|c|c|}
\hline & \multicolumn{2}{|l|}{ Xavier Giné, World Bank } \\
\hline $\begin{array}{l}10.30-11.00 \\
\text { Ravelijn Foyer }\end{array}$ & \multicolumn{2}{|l|}{ Coffee and Tea } \\
\hline \multirow{5}{*}{$\begin{array}{l}11.00-12.30 \\
\text { Ravelijn }\end{array}$} & 2. Parallel sessions RA & \\
\hline & $\begin{array}{l}\text { 2A. Insurance awareness, insurance } \\
\text { literacy and marketing } \\
\text { Facilitator: } \\
\text { Michal Matul, ILO Microinsurance } \\
\text { Innovation Facility } \\
\text { Discussant: } \\
\text { Markus Olapade, University of } \\
\text { Mannheim } \\
\text { Rapporteur: } \\
\text { Lisa Chassin } \\
\text { Ravelijn } 2501\end{array}$ & $\begin{array}{l}\text { LeMay-Boucher, Heriot-Watt } \\
\text { University, Is it all about } \\
\text { money? A randomized } \\
\text { evaluation of the impact of } \\
\text { insurance literacy and } \\
\text { marketing treatments on the } \\
\text { demand for health insurance in } \\
\text { Senegal. } \\
\text { Owusu and Ackah, University } \\
\text { of Ghana, Legon, Insurance } \\
\text { awareness study in Ghana. }\end{array}$ \\
\hline & $\begin{array}{l}\text { 2B. Insurance choice decisions } \\
\text { Facilitator and discussant: Glenn } \\
\text { Harrison, Center for Economic Analysis } \\
\text { of Risk } \\
\text { Rapporteur: } \\
\text { Karla Henning } \\
\text { Ravelijn } 2502\end{array}$ & $\begin{array}{l}\text { Kouamé, University of Cocody- } \\
\text { Abidjan. Risk preferences and } \\
\text { demand for insurance under } \\
\text { price uncertainty: an } \\
\text { experimental approach for } \\
\text { cocoa farmers in Côte d'Ivoire. } \\
\\
\text { Ikegami, International Livestock } \\
\text { Research Institute (ILRI). } \\
\text { Dynamic effects of index based } \\
\text { livestock insurance on } \\
\text { household intertemporal } \\
\text { behavior and welfare. }\end{array}$ \\
\hline & $\begin{array}{l}\text { 2C. Access to and adoption of } \\
\text { agricultural insurance } \\
\text { Facilitator and discussant: Xavier Giné } \\
\text { Rapporteur: } \\
\text { Amrei Lahno }\end{array}$ & $\begin{array}{l}\text { Robles and Shekhar, } \\
\text { International Food Policy } \\
\text { Research Institute and, Centre } \\
\text { for Insurance and Risk } \\
\text { Management (CIRM) } \\
\text { respectively. Smallholder access } \\
\text { to weather securities: demand } \\
\text { and impact on consumption and } \\
\text { production decisions. } \\
\text { Ramasubramanian, University } \\
\text { of Sussex. Willingness to pay for } \\
\text { index based crop insurance in } \\
\text { India. } \\
\text { Clarke, World Bank and } \\
\text { University of Oxford, Weather- } \\
\text { based crop insurance in India. }\end{array}$ \\
\hline & 2D. Insurance in combination with other & De Nicola, International Food \\
\hline
\end{tabular}




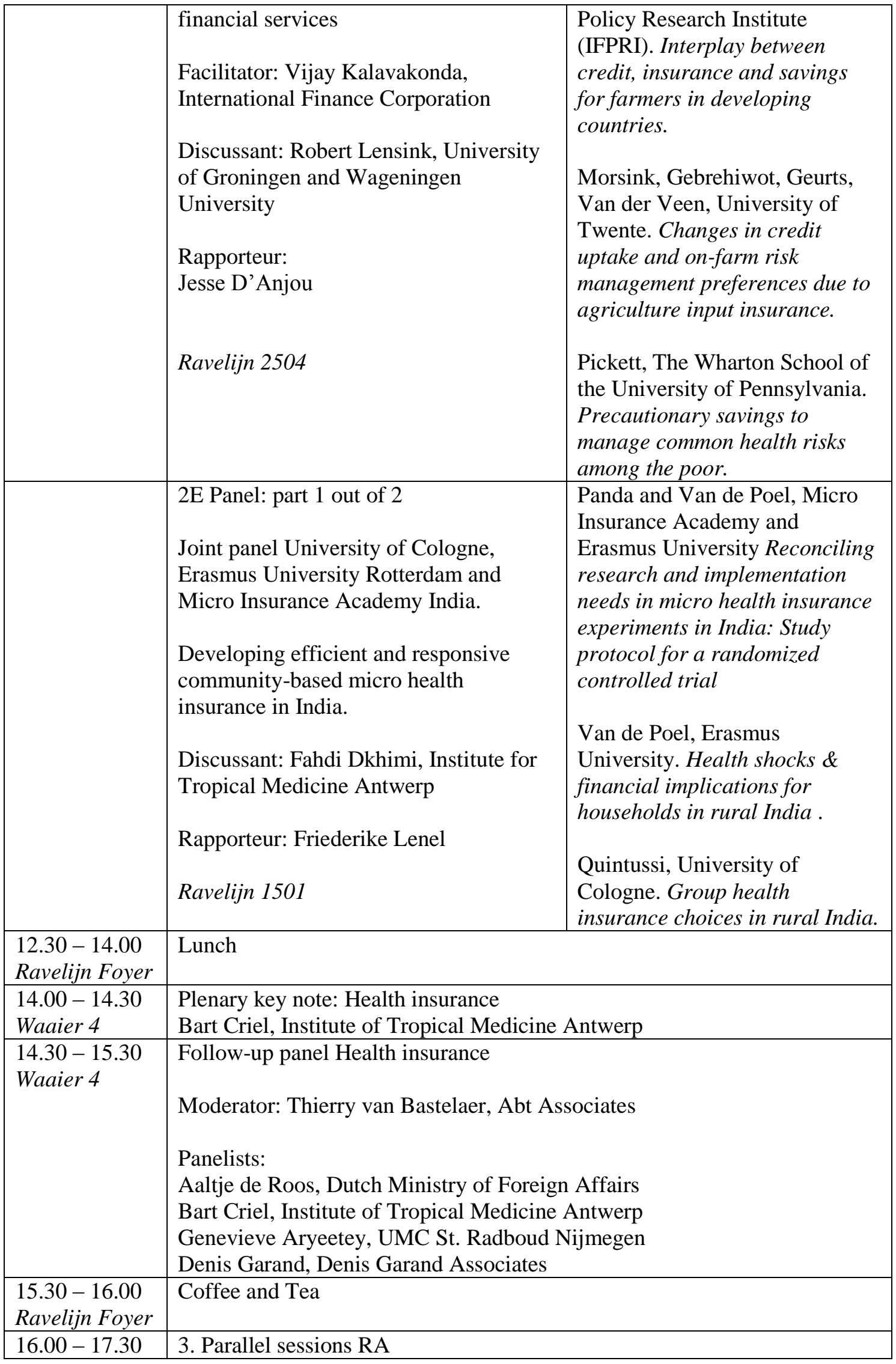




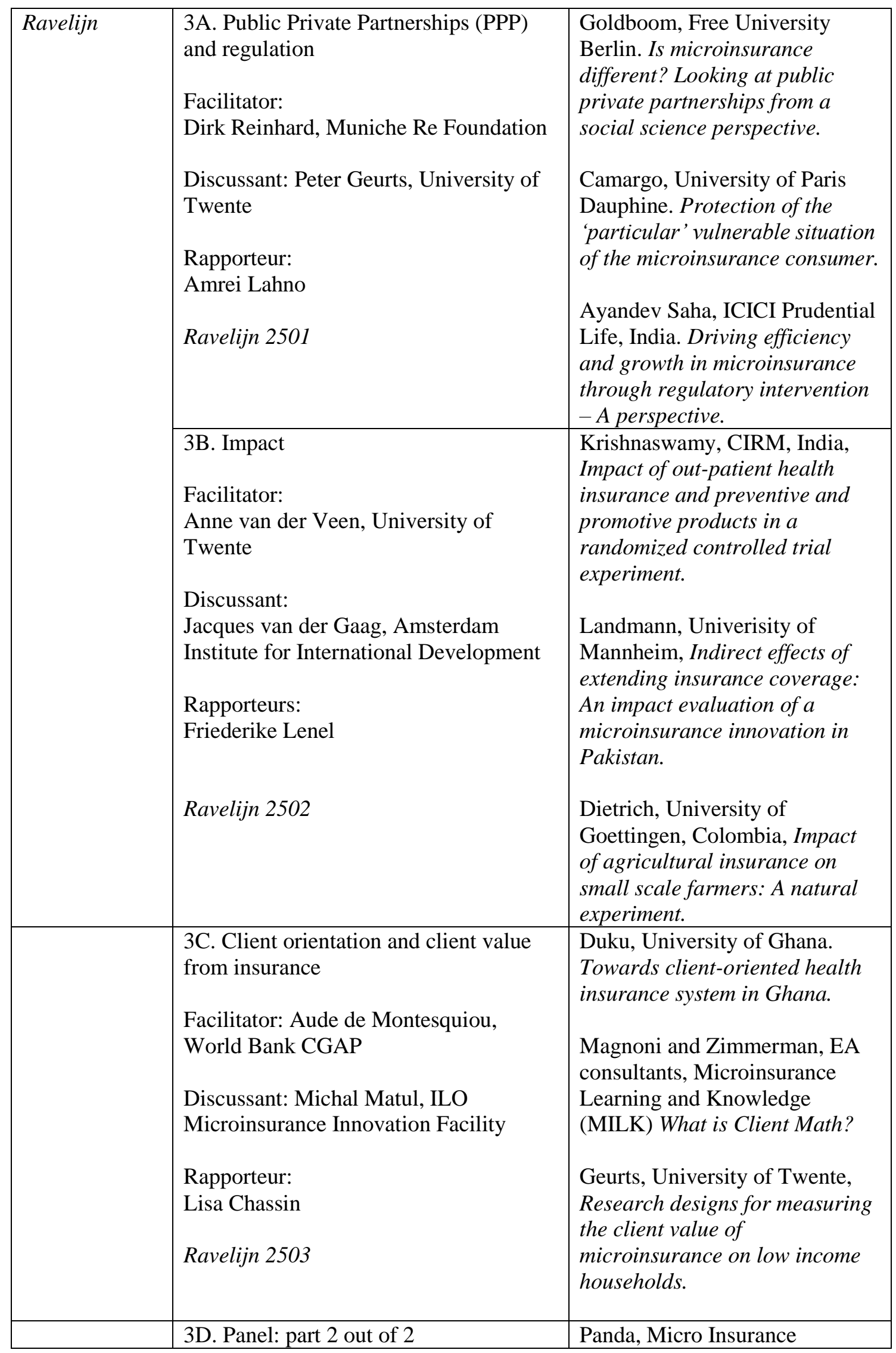




\begin{tabular}{|c|c|c|}
\hline & $\begin{array}{l}\text { Joint panel University of Cologne, } \\
\text { Erasmus University Rotterdam and } \\
\text { Micro Insurance Academy India. } \\
\text { Developing efficient and responsive } \\
\text { community-based micro health } \\
\text { insurance in India } \\
\text { Discussant: Fahdi Dkhimi, Institute for } \\
\text { Tropical Medicine Antwerp } \\
\text { Rapporteur: Jesse D'Anjou } \\
\text { Ravelijn } 2504\end{array}$ & $\begin{array}{l}\text { Academy. Factors Influencing } \\
\text { Uptake of Micro Health } \\
\text { Insurance Products in Rural } \\
\text { India. } \\
\text { May, University of Cologne. } \\
\text { Understanding Uptake } \\
\text { Decisions in a Micro Health } \\
\text { Insurance Programme in } \\
\text { Northern India-Qualitative } \\
\text { Evidence. }\end{array}$ \\
\hline & $\begin{array}{l}\text { 3E Agriculture insurance and risk } \\
\text { management } \\
\text { Facilitator and discussant: } \\
\text { Kees de Bie, University of Twente } \\
\text { Rapporteur: Karla Henning } \\
\text { Ravelijn } 1501\end{array}$ & $\begin{array}{l}\text { Meijerink, Wageningen } \\
\text { University. Mapping weather } \\
\text { index-based insurance in Mali } \\
\text { using spatial data analysis } \\
\text { Mueller, Helmholtz Centre for } \\
\text { Environmental Research (UFZ) } \\
\text { Pitfalls and potential of } \\
\text { institutional change: Rain-index } \\
\text { insurance and the } \\
\text { sustainability of rangeland } \\
\text { management }\end{array}$ \\
\hline $\begin{array}{l}19.00 \\
\text { De Twee } \\
\text { Wezen, } \\
\text { Hengelo }\end{array}$ & Conference dinner & \\
\hline \multicolumn{3}{|c|}{ Friday 13 April, Third day } \\
\hline $\begin{array}{l}08.30-9.00 \\
\text { Ravelijn Foyer }\end{array}$ & \multicolumn{2}{|l|}{ Coffee and Tea } \\
\hline \multirow{3}{*}{$\begin{array}{l}9.00-10.30 \\
\text { Ravelijn }\end{array}$} & 4. Parallel sessions & \\
\hline & $\begin{array}{l}\text { 4A. Comparing health seeking behavior } \\
\text { of insured versus uninsured } \\
\text { Facilitator: } \\
\text { Sophie Wiesner, Appui au } \\
\text { Développement Autonome } \\
\text { Discussant: } \\
\text { André Leliveld, African Studies Centre } \\
\text { Rapporteur: } \\
\text { Amrei Lahno } \\
\text { Ravelijn } 2501\end{array}$ & $\begin{array}{l}\text { Bonfrer, Erasmus University, } \\
\text { Health shocks and foregone } \\
\text { care in rural Kenya. } \\
\text { Owoeye, University of Ibadan, } \\
\text { Nigeria. Effect of Health } \\
\text { Insurance on the Demand for } \\
\text { Health Care in Oyo State, } \\
\text { Nigeria. } \\
\text { Sinha, Vimo SEWA, India, } \\
\text { Understanding Hospitalization } \\
\text { among Insured Women. }\end{array}$ \\
\hline & 4B. Panel: Giesbert, & Morsink, Geurts, University of \\
\hline
\end{tabular}




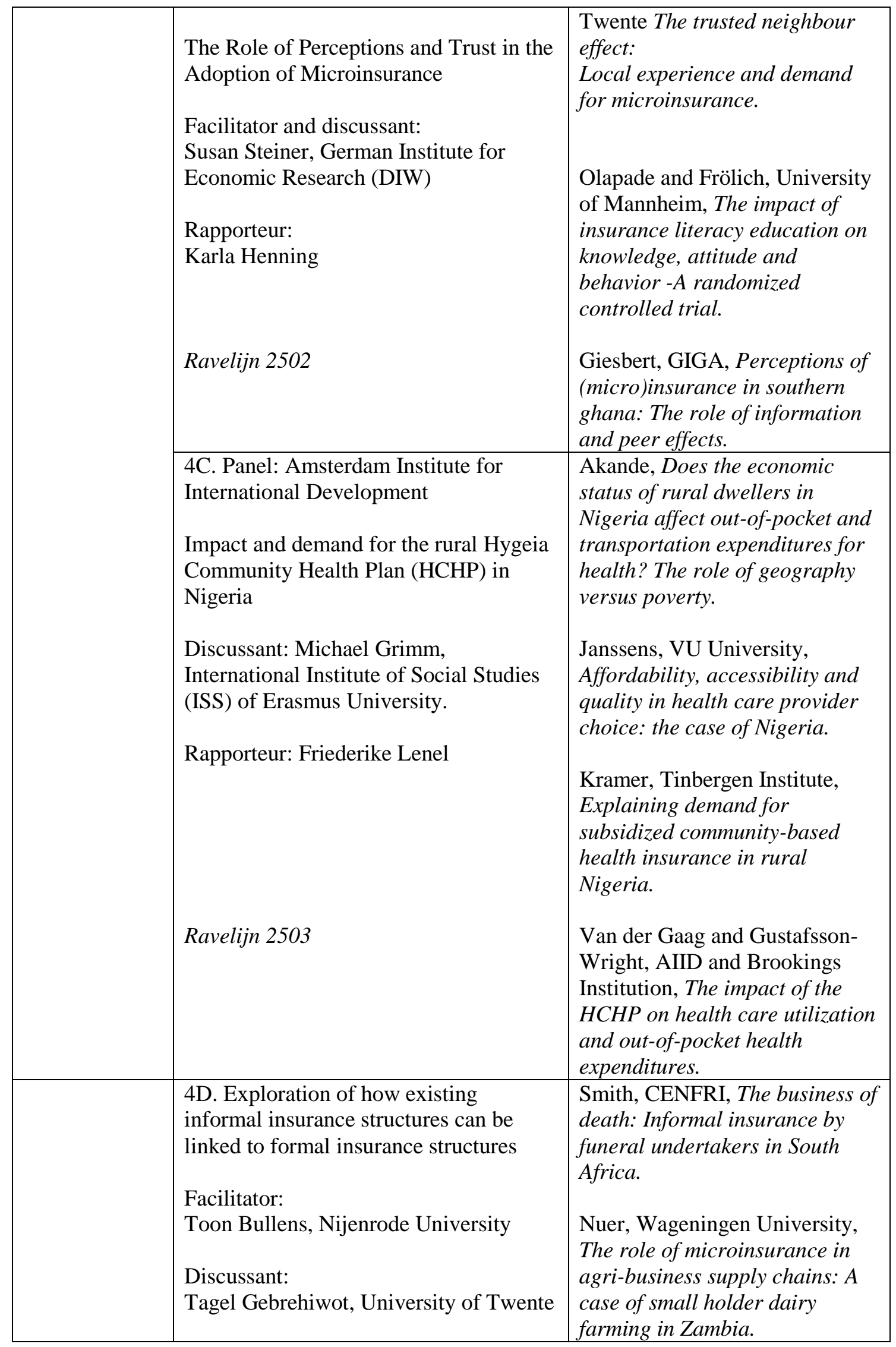




\begin{tabular}{|c|c|c|}
\hline & $\begin{array}{l}\text { Rapporteur: } \\
\text { Lisa Chassin } \\
\text { Ravelijn } 2504\end{array}$ & \\
\hline & $\begin{array}{l}\text { 4E Session proposal: World Bank and } \\
\text { University of Oxford } \\
\text { Actuarial principles for microinsurance: } \\
\text { what you should know and what we } \\
\text { have yet to learn? } \\
\text { Facilitator: } \\
\text { Jerry Skees, University of Kentucky } \\
\text { Rapporteur: Jesse D'Anjou } \\
\text { Ravelijn } 2503\end{array}$ & $\begin{array}{l}\text { Clarke, World Bank and } \\
\text { University of Oxford, Index } \\
\text { based crop insurance product } \\
\text { design and ratemaking: The } \\
\text { case of the modified NAIS in } \\
\text { India. } \\
\text { Garand, } \\
\text { Biener, University of St. Gallen, } \\
\text { Pricing in Microinsurance } \\
\text { Markets. }\end{array}$ \\
\hline $\begin{array}{l}10.30-11.00 \\
\text { Ravelijn Foyer }\end{array}$ & Coffee and Tea & \\
\hline $11.00-12.30$ & 5. Parallel sessions & \\
\hline Ravelijn & 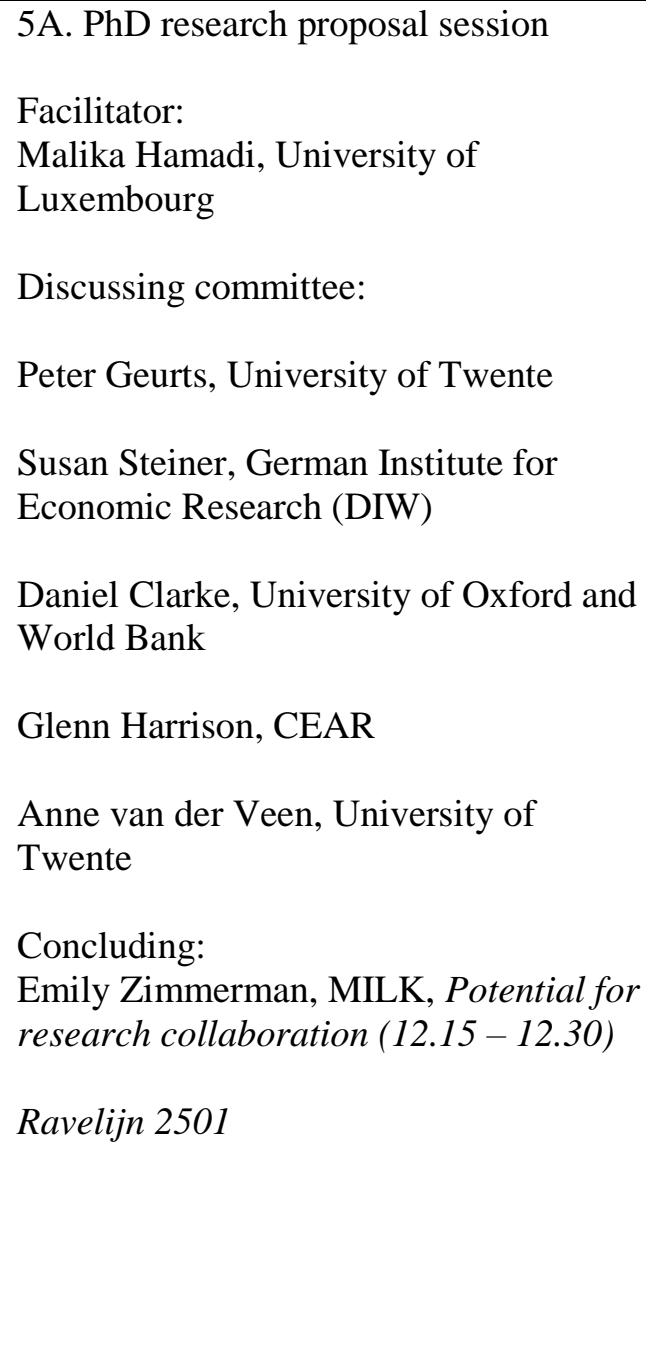 & $\begin{array}{l}\text { Lenel, German Institute for } \\
\text { Economic Research (DIW) } \\
\text { Access to Microinsurance and } \\
\text { Social Networks. } \\
\text { Henning, PhD student Planet } \\
\text { Guarantee, The effect of } \\
\text { microinsurance on informal risk } \\
\text { management in solidarity } \\
\text { networks. } \\
\text { Lahno, University of Munich, } \\
\text { Peer effects and the demand for } \\
\text { microinsurance. } \\
\text { D'Anjou, Université Libre de } \\
\text { Bruxelles, Essays on } \\
\text { microinsurance in fragile states; } \\
\text { A micro-level quantitative } \\
\text { understanding of the } \\
\text { mechanisms behind } \\
\text { microinsurance challenges in an } \\
\text { empirical setting. } \\
\text { Jozwick, University of Oxford, } \\
\text { The impact of different index } \\
\text { insurance schemes on continued } \\
\text { adoption of yield-improving } \\
\text { technologies: evidence from a } \\
\text { framed field experiment in }\end{array}$ \\
\hline
\end{tabular}




\begin{tabular}{|c|c|c|}
\hline & & Ghana. \\
\hline & $\begin{array}{l}\text { 5B. 'Health insurance demand' } \\
\text { Research presented during the } \\
\text { conference about health insurance } \\
\text { demand is discussed and concluded. } \\
\text { Facilitators: } \\
\text { Grimm, International Institute of Social } \\
\text { Studies (ISS) of Erasmus University. } \\
\text { Morsink, University of Twente } \\
\text { Discussants: } \\
\text { Thierry van Bastelaer, Abt Associates } \\
\text { Jacques van der Gaag, AIID and } \\
\text { Brookings Institute, TBC } \\
\text { Fahdi Dkhimi, Institute for Tropical } \\
\text { Medicine Antwerp, TBC } \\
\text { Ravelijn } 2502\end{array}$ & $\begin{array}{l}\text { Presenters: } \\
\text { Stella Quimbo, International } \\
\text { Institute of Social Studies (ISS) } \\
\text { Berber Kramer, Tinbergen } \\
\text { Institute and VU University } \\
\text { Wendy Janssens, VU } \\
\text { University } \\
\text { Christina May, University of } \\
\text { Cologne } \\
\text { Pradeep Panda, Micro Insurance } \\
\text { Academy }\end{array}$ \\
\hline & $\begin{array}{l}\text { 4E Achmea session } \\
\text { Facilitator: Annette Houtekamer, } \\
\text { Achmea } \\
\text { Discussant: Tagel Gebrehiwot, } \\
\text { University of Twente TBC } \\
\text { Rapporteur: Jesse D'Anjou } \\
\text { Ravelijn } 1501\end{array}$ & $\begin{array}{l}\text { Heesmans, Wageningen } \\
\text { University } \\
\text { Umarani, Tata Dhan Academy, } \\
\text { Health Insurance } \\
\text { Karthikeyan, Dhan Foundation, } \\
\text { Crop Insurance }\end{array}$ \\
\hline $\begin{array}{l}12.30-13.15 \\
\text { Ravelijn Foyer }\end{array}$ & \multicolumn{2}{|c|}{ Next Steps Workshop Microinsurance Network } \\
\hline $\begin{array}{l}13.15-13.45 \\
\text { Ravelijn Foyer }\end{array}$ & \multicolumn{2}{|l|}{ Closing and take away lunch } \\
\hline
\end{tabular}




\title{
Appendix 6-2 Speeches UNSGSA
}

\author{
Her Royal Highness Princess Máxima of the Netherlands \\ UN Secretary General's Special Advocate for Inclusive Finance for Development \\ and \\ Honorary Chair of the G20 Global Partnership for Financial Inclusion \\ Speech at the 2012 Research Conference on Microinsurance \\ Enschede, 11 April 2012
}

"Good afternoon distinguished speakers, ladies and gentlemen. I am pleased to be here today for this timely conference.

In my work as the UN Secretary General's Special Advocate, I have seen the impact of unexpected shocks on people.

Events like illness and injury are the number one reason why a family that is progressing can fall back into poverty. Microinsurance has so much potential to help prevent that. Weather-indexed insurance cannot prevent drought or floods that destroy crops. But it can mitigate the impact in future seasons by replacing seeds and fertilizer. So, we are all gathered here because we understand the importance of helping people to protect themselves from unforeseen risks and its devastating consequences.

The good news is that more insurance reaches lower-income populations every day. There are many promising products and so much interest. But some efforts have been less successful, costly or slow to take off. And there is so much we do not know about this new field. How should a microinsurance product look like? How can we make the business model sustainable?

How do we encourage enrollment? What creates impact?

Research, ladies and gentlemen, is therefore more important than ever.

But what should be the focus of research? In my work in the field of financial inclusion, I have realized that two issues are very important: client demand and impact. So the first priority for research is client demand. Only when we understand demand will we design products that have the right features, the right prices and the proper delivery mechanisms. And when products are valued by clients, they will be used. And product use leads to expansion, scale and sustainability.

One important question is why poor clients take up an insurance product. And at this early stage, are we sure that usage equals value? For example, credit-life insurance subscriptions are increasingly popular. We know that credit providers promote this because it protects their loans and cash flows. Sometimes they promote it as a benefit to the loan and factor the cost into the interest rates. Other times, they bundle the two products. But then fees and benefits may not be clear to the client. Used in the right way, packaging can be a positive opportunity to meet demand and promote uptake. But I think we need research to distinguish product value from good uptake because of good packaging. 
What is also important to consider is the trust clients have in the system. And that is of course related to the way the benefits have been paid out. When looking at product design, research should also consider the shape of institutions and marketing.

And of course, also policies such as transparency and consumer protection regulations could be considered.

The second priority for research is what is it that creates impact?

I always remind myself that demand and impact are not the same thing. Some things that are not in demand can have big impact. Such as preventative health care. We know that this is one of the best ways to avoid extended illness and big expenses, and increase productive lives. It is one reason why countries like Brazil and Mexico are making cash transfers to poor households conditional on visiting health clinics. Conversely, there are insurance products that are in demand, but have little social-welfare impact. For example, some mobile phone companies in South Africa are providing insurance plans with pre-paid minutes to cover loss of the lost phone.

I therefore think that we must broaden the scope of research to understand behavior that does create impact on community welfare as well as households and individuals. This is a great opportunity to maybe partner with experts in other fields, including anthropologists and sociologists.

Like us, most poor people use several or even a dozen financial products to meet their needs. I am happy to see that there are studies on the interaction of microinsurance with other products. Payments are particularly important. We know from research that small, regular payments are more convenient to poor people.

But can they actually make them in an easy and convenient way?

Research could also look at what combinations of financial products are best for meeting people's goals. Savings is of course the simplest form of insurance. Yet, some findings reflect that poor people do not like to use savings for unexpected events. They would rather borrow from friends or take a loan. Does this preference affect willingness to pay for insurance? Or will uptake of insurance depend more on availability and learning over time?

To illustrate what I want to say, I will give you two examples. One company in Indonesia is piloting a product that encourages families to save for their children's education. It also provides life insurance and hospital cash coverage as a benefit to protect these weekly contributions. Insurance also seems to have an impact on access to other needed services. In Sri Lanka, the International Finance Corporation is assessing whether having insurance makes SMEs more able to get formal loans and credit. So the interaction with other financial services seems to be important.

And, one of my favorite subjects is more and comparable data on all aspects of microinsurance and its impact. Insurance providers need more data so that they can price risks and develop the right products and make good investments. And, better and more complete data will help authorities develop effective policies and programs. I would like to emphasize that local context, culture and habits matter so much to 
understanding and using data properly.

We will probably need to rely on different sources of data. National databases and surveys. On-going product monitoring by insurance providers. But also mobile phone, farm supply and other private companies. We will also have independent evaluations of pilots as well as randomized control trials. But this will mean a strong degree of cooperation. A cooperation that could be helped by donors and aid programs around the world.

In my roles with the $\mathrm{UN}$ and the $\mathrm{G} 20$, I have been promoting national coordination platforms for financial inclusion, backed by strategic action plans and good data. This process, where it is happening, gives policy makers an opportunity to include microinsurance data collection in the target setting and planning. I hope you can help that to occur.

The International Association of Insurance Supervisors, and other international bodies and organizations can also have great influence on data too-and are on their way. The Access to Insurance Initiative and MicroInsurance Network can encourage and aid various agencies on the ground to collect better data. I hope you can build upon these efforts.

Research on microinsurance is still relatively new and just beginning to yield results. So we need to do more. And that is why a gathering like this is so important and welcome.

In trying to follow up on this, on the 5th of June, we will be hosting here in the Netherlands a conference on micro-health insurance. We are happy to do this together with Professor Stella Quimbo, the holder of the Prince Claus Chair 2011/2013. In November, the MicroInsurance Network will have its global meeting. Both provide timely opportunity to build from this conference's findings.

So ladies and gentlemen, enough for us to realize still. But I would like to hereby express my support to all your work and I hope that I can be of help in the future. Knowledge will be the basis through which we can really make a difference.

My last words go to the ILO and the Munich Re Foundation. I would like to congratulate them on the completion of the second volume of the Microinsurance Compendium. The first volume, published in 2006, was very important for the microinsurance community. Undoubtedly the second volume will be important too.

Thank you." 


\section{Her Royal Highness Princess Máxima of the Netherlands UN Secretary General's Special Advocate for Inclusive Finance for Development and Honorary Chair of 'Wiser in Money Matters' Speech at the International Insurance Conference Amsterdam, 1 June 2012}

"Good morning, Mr. Barnier, Mr. Balbinot, Excellencies, Ladies and Gentlemen. When I received the invitation to speak at this gathering, I gladly accepted because insurance plays an extremely important role in building inclusive financial systems for development. And inclusiveness is not only about development, but also stability. It has a strong relationship with stability, an issue that Mr. Balbinot touched upon.

When talking about financial inclusion, I find it helpful to share a definition. Financial inclusion is universal access, at a reasonable cost, to a wide range of financial services, provided by a diversity of sound and sustainable institutions. This is for individuals and small and medium-sized enterprises. What is important is what financial services help us to achieve - savings for education, an investment to grow a company, insurance for medical care. Yet, two and a half billion people around the world do not have access to the kinds of financial services that you and I rely on every day. As a result, millions of families, farmers and entrepreneurs must use informal means to make sure they have cash when they need it.

Now, these informal financial tools are time consuming and expensive. And, they are not always adequate to meet the needs of the people. We see this especially after unexpected events such as a flood that destroys crops and homes. And, in many poor communities, some risks affect whole communities so neighbors are not available to help each other out. So, too often, people sell productive assets, pull children out of school or take an expensive loan so they can replant and rebuild. This affects current consumption and has long-term consequences. In fact, illness or a physical accident is one of the main reasons why people in the developing world fall into poverty.

And that is exactly insurance's very reason for existence. To protect people against this. So, we need to provide proper insurance products. The issue is how can we create an inclusive insurance market that is sustainable and that creates the impact we are looking for.

In the Netherlands, $90 \%$ of the population is covered by private health insurance. So we can say that here and across Europe, the issue is not really access but better usage. In developing countries, however, access is a first concern. In Africa, only $2 \%$ of the population has private health insurance. But also payments and banking services in general have huge access problems.

Together, these can present even more challenges as they depend on each other. Even if we bring a good insurance product to market, how do we collect frequent premiums or pay benefits quickly if each requires the client to travel on a bus for hours and wait in line with cash? 
The good news is that there is already a lot of innovation changing this situation. While only one-fourth of Africans have a bank account, in some countries already more than $90 \%$ have access to a mobile phone. People are using phones to pay insurance premiums easily and cheaply. And insurance companies are partnering with mobile phone operators, microfinance institutions and others to provide insurance through existing infrastructure.

After access, how do we get to take up usage? This is not only an issue in poor countries. One of the papers for this conference points out that $80 \%$ of households in the United Kingdom have property insurance. But among the poorest $10 \%$ of the population, only half of them have it. Why is this?

I think we can all agree it is not because a poor person values his home any less. In fact, research shows us that around the world, people in lower income segments are very aware of risks. This is logical because the consequences can be harder on them. But then, why don't they buy an insurance product?

Although it can be difficult for us to understand, low-income people have good reasons for their choices. For example, in Brazil, poor households frequently choose to spend more money in buying better quality goods or move to a more secure house before spending it on insurance. Or in Rio, an insurer discovered that homes were owned by a whole group of living in family members. So the insurer had to sign a contract with the whole family instead of just one family member. Ever since, the use of insurance started to take off. This shows us that knowledge of the local context is very important to design fitting products for usage.

This brings me to my next point. Well-informed customers are best able to choose the right products for their needs. And when this happens, we get increased demand. Basic knowledge begins with knowing that insurance is available and how it can help. One CEO realized that his poor clients in new markets associated life insurance with attracting death, rather than protecting the widow from debt. Their only experience of a benefit came when someone died. In comparison, indemnity for a visit to a hospital, which people experience throughout their lives, is proving highly educational for the whole community.

But basic knowledge is not always sufficient. Trust is a key factor for lower-income clients in developing countries. And this depends on experience and also information. The more a person understands the insurance, the more his expectations will match the actual experience. Being well-informed is thus not only knowing about available options but understanding obligations, costs and benefits as well.

This is why financial education efforts are so important, especially in developed countries where access already exists. In the Netherlands, the national Money-Wise Platform is effectively raising financial awareness and increasing capability through outreach, including a Money Week, free pension education and education for youth. I am thrilled that so many members of Insurance Europe are also engaged in national literacy efforts. For example, the Dutch Insurance Association supports our Money- 
Wise Platform and provides guest lectures in schools and instructive board games, among other activities. I encourage all of you to see what more you can do in your own countries to deepen similar efforts. I am also encouraged that the OECD has proposed financial education to be part of its PISA educational assessment going forward. This will of course help to get financial education in the curricula of schools.

Finally, to get the impact that we desire, we need products that offer value by meeting the needs of lower income clients. There are many exciting innovations. Like flexible premium schedules that respond to unpredictable incomes. Business processes that review claims in two days to provide the benefit when it is most needed. Or, combining insurance with other financial products. In Sri Lanka, weather-based index insurance together with credit makes the farmer a more attractive candidate for a loan and reduces the cost of the loan. In Brazil, a small savings account with insurance helps customers pay their premiums.

By value, I also mean contribution to social-economic welfare. Sometimes things that are highly demanded have no real impact. And things that are not demanded can have a very big impact. Like preventative health care. This is one reason why countries including Brazil and Mexico are making cash transfers to poor households conditional on visits to health clinics. And as all of you know, insurance and prevention go hand in hand. This is an area where public-private partnerships can be especially effective.

In closing, if we want to build inclusive insurance markets that have impact, the challenge is to understand clients in their local contexts very well. To do so, I believe insurance providers should work closely with governments, civil society and communities. Building this understanding and building client trust in products takes effort and time. But it is worth it, as you all know.

I think we have a tremendous opportunity to make a difference in the lives of poor people and whole communities around the world. This should be done through the right insurance products, delivered at the right price and in the right place. We can do this by building access, fostering demand through trust and financial literacy, and creating impact through products with real value.

Thank you." 


\section{Her Royal Highness Princess Máxima of the Netherlands UN Secretary General's Special Advocate for Inclusive Finance for Development and Chair of the Prince Claus Curatorium Speech at Access to Health Insurance Conference Rotterdam, 5 June 2012}

“Good morning, Excellencies, Ladies and Gentlemen.

How wonderful it is to see so many practitioners, policy makers, academics and also students, our next generation, gathered for this conference. I am happy to welcome those of you coming from abroad to the Netherlands. A special welcome goes to Stella Quimbo, the current holder of the Prince Claus Chair on Development and Equity - a chair honoring my father-in-law's legacy in development. Also, I would like to thank the Erasmus University Rotterdam, the International Institute of Social Studies, the Dutch Ministry of Foreign Affairs, the Rotterdam Global Health Initiative and PharmAccess International for facilitating this conference which I consider so timely.

As UN Special Advocate, I look closely at the factors that influence development and health is of course a very important one. Health affects all of us. Health is an especially pressing concern for poor families. This is even more so in developing countries, where health care and financial safety mechanisms may be limited. When poor people get sick, they commonly sell productive assets, pull children out of school or take expensive loans in order to get the care they need. Or they just simply do without. As a result, daily priorities such as food and shelter suffer. And there are long-term consequences. In fact, about 100 million people around the world fall into poverty every year due to health expenses.

So protecting poor people from these devastating financial impacts should be a concern for all of us. Today, we will explore some of the ways that health insurance can help. But health insurance is somewhat different than other financial products. For example, it involves a big element of public good. It is linked to broader, complex issues that require national leadership and diverse partnerships. So, this issue is about financial inclusion, but also about so much more.

One of the responsibilities of government is to address the availability of health care for everybody needing it. Some countries do so through a totally government-run health system. Others do it through a combination of public and private health providers. Some finance health mostly through tax revenues, some through insurance schemes and some through diverse financing mechanisms. The Philippines, Thailand, Colombia and Mexico are among countries that have introduced nation-wide health insurance. The point I would like to stress is that there is no single approach. Whatever we do to do this successfully, it will entail a combination of coverage and quality care that is accessible and affordable.

In the best cases, health insurance works in combination with public health goals to reinforce or even change behavior. But this can present some challenges. Why? Typically, insurance generally covers infrequent events and large losses. Health 
insurance that covers regular clinic visits and medication is just the reverse - high frequency, low risk and small amounts. This can make it very expensive and complicated for an insurance provider. So, knowing that prevention is the most effective means of improving health outcomes and reducing costs, this issue needs to be addressed. Moreover, health insurance is no use if there are no good doctors, clinics and hospitals. We must also consider the availability of care as well. So as you can see we will have lots to talk about in the breakout sessions.

Now, we are here today because we would like people to be healthy. But for health insurance to contribute to public health goals, it must be used on an on-going basis, it must be trusted and it must be sustainable for providers. We can learn a lot from experiences in Brazil, India, Kenya and other countries where health insurance is increasingly available. There, we see that despite the availability, low-income families still do not often purchase or renew health insurance. How can we understand this? Maybe it is because there are no clinics nearby. Or because of the competing necessities on available cash against other priorities like food or school fees. Or, perhaps the product is just not right.

So, we must understand client needs and local context very well. From that, we can design products that add real value. Value comes from the kind of benefits that are provided. Value also comes from convenient premium payments through mobile phones or flexible premiums that allow for uneven incomes. The claims process must also be very easy. It must pay benefits in a matter of days, not weeks, if it is going to prevent debts. These factors, and many more, may explain why health insurance products that work for higher income populations do not always succeed with lower-income groups.

I am especially encouraged by innovations that go beyond insurance to support client needs and social goals. For example, in Brazil, a company is designing a small savings to go with its insurance. This can be used to pay premiums when money is tight. And in Indonesia, another company is piloting a savings account for education. This account comes with small life insurance and hospital cash coverage as a benefit, thus protecting the family's educational goal. I would be remiss in my duties as Special Advocate if I did not point out that we also need to make basic savings accounts much more widely available. After all, savings is the simplest form of insurance.

Now, knowledge is of course a factor. Low-income families are often not aware of health insurance or they do not understand precisely how it can help. But basic knowledge is not always sufficient. Trust matters. And trust results from experience as well as knowledge. The more a person understands the obligations, costs and benefits, the more his expectations will match the actual experience. For these reasons, financial education is very important and something everyone should help to provide.

This leads me to my final topic. What can each of us do to increase access to health?

National governments have the most important role. We see many examples of national commitment and leadership to expand national health systems, provide access and build medical and nursing capacity. I am thrilled that we have policymakers with us today to 
share their experiences and priorities. Donors and other partners are also key. I am proud of the support that the Netherlands along with many other countries has given in the past years to global health. This has brought tangible benefits and, importantly, fostered so many national initiatives. But to make sure that all the efforts have positive outcomes, it is all the more urgent that we together share what we know about what works and what does not.

What is certainly important is to ensure that health care reaches the poorest and most marginalized families. Subsidies of premiums and supplemental support conditional on regular visits to health clinics are all proving effective.

It should go without saying that providers have a lead role in product design. Donors and academics can also help, for example with research to understand client needs. Or to evaluate the impact of specific products. There is so much more that we would like to understand. When it comes to sustainability, providers are also best placed. We have seen lots of good projects that have not succeeded due to costs. This and reaching the poor are two areas where public-private partnerships are essential to get the scale needed to be able to pool risks.

I am so happy that this conference is taking place, with so many diverse stakeholders coming together. I think the day will be successful if as a result of the discussions we continue to address the following four issues:

Identify knowledge gaps. Where is there consensus and enough said? What needs to be studied more?

Prioritize where we need more pilots and on what aspects.

Agree, more or less, on some successes and also failures, so that we can communicate this clearly to policy makers and practitioners

Call attention to the importance of this subject. Of course, not only today, but as you return home and in months to come.

In closing, I would like to remind everyone that investments in health pay very high dividends. If through insurance we can help people to become more healthy and productive and prevent impoverishment when they get sick, then we really need to focus on what is stopping us from doing so.

Thank you." 


\section{Samenvatting}

\section{Inleiding en probleemstelling}

Microverzekeringen kunnen arme mensen in ontwikkelingslanden, die vaak weinig of geen financiële reserves hebben, ondersteunen bij het omgaan met de consequenties van natuurrampen. Onverzekerde risico's hebben gevolgen voor de welvaart van huishoudens die niet alleen maar betrekking hebben op korte termijn consumptie maar ook gevolgen hebben voor blijvende armoede (Townsend, 1994; Dercon, 2004; Carter, Little, Mogues, Negatu, 2007). Accumulatie, innovatie en ontwikkeling van een samenleving kunnen bemoeilijkt worden als mensen geen mogelijkheden hebben voor het management van risico's (Fafchamps, 2003: 146).

Recentelijk worden microverzekeringen geïntroduceerd om het risicomanagement van arme mensen te ondersteunen. Aangenomen wordt dat, als er perfecte informatie is, mensen risicomijdend zijn en als er een verzekering was met een premie die gelijk was aan de verwachtte uitkomsten (verlies maal kans op het verlies), dan zouden mensen zich volledig verzekeren omdat het hun nut zou optimaliseren. Daarentegen hebben arme mensen vaak al bestaande strategieën waarmee ze risico's managen zoals diversificatie van risico's, lenen, het gebruiken van spaargeld, het verkopen van productiemiddelen en informeel verzekeren. Dergelijke activiteiten, net als verzekeren, hebben als doel om inkomen en consumptie af te vlakken (Alderman and Paxson, 1994 and Morduch, 1995). Uit onderzoek blijkt dat huishoudens die worden geconfronteerd met idiosyncrate risico's op basis van die bestaande activiteiten onvoldoende in staat zijn om hun consumptie af te vlakken. Daar komt bij dat natuurrampen vaak gecorreleerd zijn en dit impliceert, voornamelijk omdat huishoudens risicomijdend zijn, dat er gelegenheid is voor een complementair mechanisme voor risicomanagement, zoals microverzekeringen.

Echter, zelfs als microverzekeringen aangeboden worden tegen een redelijke prijs, dan is het niveau van de vraag naar microverzekeringen door arme mensen in ontwikkelingslanden laag in vergelijking met de verwachte vraag op basis van nutstheorie. Een toenemend aantal empirische studies waarin de vraag naar microverzekeringen wordt onderzocht concluderen dat risicomijdend gedrag niet tot meer maar juist tot minder opname van verzekeringen leidt (Giné et. al., 2008; Cole et al., 2010; Ito and Kono, 2010; Clarke and Kalani, 2011; Dercon, Gunning and Zeitlin, 2011). Dit is in tegenspraak met voorspellingen op basis van nutstheorie, namelijk dat de vraag naar verzekeringen hoger is voor risicomijdende individuen die verzekeringen nemen om het risico op verliezen te verkleinen (e.g. Arrow, 1963, 1965; Pratt, 1964; Mossin, 1968; Feldstein, 1973; Schlesinger and Doherty, 1985). Hoe kan het relatief lage niveau van de vraag naar microverzekeringen en het omgekeerde effect van risicomijdend gedrag verklaard worden?

Microverzekeringen kunnen complementair zijn aan bestaande consumptie-afvlakkende activiteiten maar zouden deze ook kunnen vervangen (Arnott and Stiglitz, 1991). Als 
microverzekeringen actuarieel fair waren en bestaande consumptie-afvlakkende activiteiten volledig zouden vervangen, dan zou er geen verandering zijn in het bereikte niveau van verzekering. Er zouden dan ook geen veranderingen zijn in het verwachtte nut voor één enkele nutmaximaliserende beslissing. Het zou echter wel zo kunnen zijn dat het vervangen van bestaande consumptie-afvlakkende activiteiten nut oplevert voor toekomstige nutmaximaliserende beslissingen.

\section{Onderzoeksvraag}

Ondanks de mogelijke bijdrage van microverzekeringen aan welvaartsverbeteringen door toegenomen consumptie is de vraag relatief laag. Dit kan resulteren in suboptimale welvaartsniveaus en verdelingseffecten voor huishoudens met bepaalde kenmerken. Bovendien maken arme huishoudens in ontwikkelingslanden al gebruik van bestaande inkomens en consumptie-afvlakkende activiteiten. Op deze manier kunnen microverzekeringen complementair of vervangend zijn en dit kan niet alleen gevolgen hebben voor een huidige nutmaximaliserende beslissing maar ook voor nutmaximaliserende beslissingen in de toekomst. Daarom wordt in deze dissertatie de volgende onderzoeksvraag gesteld:

Waarom nemen huishoudens met lage inkomens in ontwikkelingslanden microverzekeringen en hebben microverzekeringen effecten voor armoedebestrijding?

Om deze vraag te beantwoorden is deze dissertatie in twee delen opgesplitst: Het eerste deel gaat over de vraag waarom huishoudens microverzekeringen nemen en het tweede deel gaat over het effect op armoedebestrijding.

\section{Resultaten}

In Hoofdstuk 2 is eerst theorie besproken over de keuze voor microverzekeringen. Daarna, op basis van een algemeen theoretisch kader, zijn 31 empirische studies naar de vraag naar microverzekeringen vergeleken. Het theoretische kader is gebaseerd op nutstheorie omdat deze theorie normaalgesproken wordt gebruikt om beslissingen over verzekeringen te begrijpen. Kritische aannames, gebaseerd op de toepassing van nutstheorie, zijn vergeleken met de daadwerkelijke situatie in microverzekeringsmarkten. De volgende factoren die de vraag naar microverzekeringen zouden kunnen verklaren zijn geïdentificeerd: prijs, subsidies en kortingen, het verzekerde risico en de risicosituatie van het huishouden, kredietbeperkingen, preventief handelen en informele verzekeringen, kenmerken van de marketing van de verzekering, risicopreferenties, begrip van de verzekering en sociaal kapitaal, netwerken en vertrouwen.

De eerste conclusie is dat veel studies de keuze om een verzekering te nemen vergelijken met de keuze om geen verzekering te nemen. Dit zou logisch zijn als alle huishoudens op de hoogte waren van de verzekering en voldoende waren geïnformeerd over de verzekering. Daarentegen, als mensen met de verzekering vergeleken worden met mensen zonder de verzekering terwijl de mensen zonder de verzekering niet op de hoogte zijn van de verzekering of nog niet aan een keuze over het nemen van de 
verzekering zijn toegekomen, is het onduidelijk waaraan geobserveerde effecten moeten worden toegeschreven.

De studie laat ook zien dat er consistent bewijs is dat een hogere verzekeringspremie leidt tot een lagere vraag naar de verzekering. Additionele transactiekosten, zoals kosten voor vervoer hebben hetzelfde effect. Subsidies en kortingen hebben een positief effect op de vraag. Echter, zelfs als de netto verzekeringspremie beneden de actuarieel faire verzekeringspremie ligt, is de vraag laag. Dit suggereert dat andere factoren dan de prijs een belangrijke rol spelen bij het verklaren van de vraag.

Huishoudens die meer dan gemiddeld risico lopen nemen vaker de verzekering. Dit impliceert dat dit kan leiden tot moral hazard en adverse selectie als producten niet zodanig ontworpen worden dat ze deze problemen kunnen voorkomen.

De resultaten van de empirische studies suggereren dat risico vermijding leidt tot minder in plaats van meer vraag naar de verzekering. Dit is in tegenstelling tot voorspellingen op basis van nutstheorie die normaalgesproken gebruikt wordt om de keuze voor verzekeringen te voorspellen. Alhoewel het negatieve effect in meerdere studies is gevonden is in de meeste studies geen rekening gehouden met de mogelijkheid dat arme huishoudens de verzekering beschouwen als een verlies. Dit zou kunnen betekenen dat Prospect Theorie een beter begrip van de keuze voor verzekeringen geeft. Dit moet verder worden onderzocht.

Een andere verklaring die in sommige studies wordt gegeven voor het negatieve effect van risico vermijding is de onzekerheid over de verzekering. In deze studies wordt gesuggereerd dat huishoudens er wellicht niet zeker van zijn dat de verzekering daadwerkelijk uitbetaald als het verzekerde risico optreedt terwijl deze huishoudens wel een premie hebben betaald. Factoren die zijn onderzocht omdat ze de potentie hebben dat ze deze onzekerheid kunnen verminderen zijn financiële geletterdheid en educatie en vertrouwen. Het bewijs voor het effect van financiële geletterdheid en educatie is niet consistent. Sommige studies vinden een positief effect terwijl anderen geen effect vinden op de vraag.

Vertrouwen wordt vaak genoemd in kwalitatieve studies als verklaring voor de vraag naar de microverzekeringen: vertrouwen in verzekeringen, vertrouwen in de verzekeraar, vertrouwen in het management van de verzekering en vertrouwen in weten regelgeving worden genoemd. Slechts twee kwantitatieve studies hebben het effect van vertrouwen onderzocht maar de manier waarop ze vertrouwen hebben geoperationaliseerd en de methode van onderzoek verschillen erg van elkaar. Dit impliceert dat verder onderzoek nodig is om te begrijpen hoe en waarom en in welke mate onzekerheid over de verzekering een rol speelt bij de vraag naar microverzekeringen en hoe deze onzekerheid kan worden verminderd.

Het effect van sociaal kapitaal en netwerkkenmerken op de vraag naar microverzekeringen is in veel studies significant. Het is echter onduidelijk hoe en waarom deze effecten optreden. Sommige studies bieden als verklaring dat sociaal kapitaal en netwerken bijdragen aan het vergroten van het begrip van de verzekering en op deze manier de onzekerheid over de verzekering helpen verminderen. Een andere verklaring is dat sociaal kapitaal en netwerken de overtuigingen over verzekeringen 
veranderen en dat dus gedragselementen het effect verklaren. Sociaal kapitaal en netwerken kunnen ook een effect hebben omdat ze leiden tot schaalvergroting of collectieve actie of doordat dat ze een indicatie zijn van informele verzekeringen en daardoor de vraag naar verzekeringen verminderen. Tot slot kunnen verzekeringen ook de vraag beïnvloeden omdat ze het vertrouwen in de verzekering of verzekeraar vergroten.

Om de mechanismen te begrijpen die het effect van sociaal kapitaal, netwerken en vertrouwen op de vraag naar microverzekeringen verklaren is er in Hoofdstuk 3 een empirisch onderzoek gedaan naar het effect van vertrouwen dat door ervaringen van buren (mensen in lokale netwerken) met uitbetaling van claims wordt vergroot.

Het wordt veronderstelt dat vertrouwen belangrijk is bij het begrijpen van de vraag naar microverzekeringen in ontwikkelingslanden omdat ervaringen met verzekeringen vaak ontbreken of gekenmerkt worden door opportunisme aan de kant van verzekeraars, dan wel door verminderde solvabiliteit of door slechte intenties. Bovendien is de beslissing om een verzekering te nemen op zichzelf een risico omdat huishoudens het gevaar lopen dat ze vooraf een premie betalen, het risico meemaken maar vervolgens geen claim krijgen uitbetaald. Op basis van Gambetta's definitie van vertrouwen is vertrouwen in de verzekering in deze studie gedefinieerd als: de perceptie van de kans dat de verzekeraar de claim uitbetaald wanneer het arme huishouden het verzekerde risico meemaakt is groot genoeg voor het arme huishouden om het verzekeringscontract aan te gaan en de verzekeringspremie te betalen. In deze studie is daarom de volgende onderzoeksvraag gesteld: Hoe en in welke mate beïnvloed vertrouwen de vraag naar microverzekeringen? Deze vraag is met name van belang voor arme huishoudens in rurale gebieden waar vaak geen verzekeringservaringen zijn of faillissementen en fraude veel voorkomen. Instituties die verzekeringscontracten en markten reguleren zijn ook vaak ontoegankelijk, onbetrouwbaar of bestaan simpelweg niet. Bovendien doen herhaalde transacties zich niet vaak voor omdat verzekeringen een preventieve werking hebben en de verzekerde risico's en dus ook uitbetaling van de claims niet vaak voorkomen. Volgens Rogers (2003: 177) zijn positieve ervaringen met microverzekeringen van betrouwbare buren in lokale netwerken van belang om bij dit soort 'preventieve innovaties' vertrouwen op te bouwen. Daarom is in dit hoofdstuk onderzocht of het kennen van mensen met uitbetaalde claims een manier is waarop vertrouwen in microverzekeringen vergroot kan worden.

De volgende hypothese is daarom in Hoofdstuk 3 getest:

Vertrouwen, opgebouwd door bekenden met uitbetaalde claims heeft een positief effect op de vraag naar microverzekeringen.

Om dit te onderzoeken is een model getest waarin het kennen van mensen met uitbetaalde claims de onafhankelijke variabele was en de vraag de afhankelijke. De factoren die in Hoofdstuk 2 zijn geïdentificeerd zijn gebruikt als controles. De primaire data zijn verzameld tijdens een veldonderzoek waarin elf focusgroepen en 200 arme mensen, met en zonder verzekeringen, in de Filippijnen zijn geïnterviewd. Naast risico vermijding en het hebben van consumptiemiddelen was het kennen van mensen met uitbetaalde claims de belangrijkste factor die van invloed was op de vraag naar 
microverzekeringen. Een andere belangrijke bevinding was dat het effect van vertrouwen significant lager was voor huishoudens met een lage mate van risicovermijding in vergelijking met huishoudens met hoge risicovermijding. Voor huishoudens met een hoge mate van risicovermijding had het kennen van mensen met uitbetaalde claims een positief effect op de vraag. Dit suggereert dat vertrouwen inderdaad de onzekerheid over de verzekeringstransactie kan verminderen. Andere mogelijke verklaringen voor het effect van bekenden met uitbetaalde claims, zoals toegang tot de verzekering, het begrijpen van de verzekering, imitatie, de kans op het risico en marketing effecten zijn onderzocht maar geen significante effecten zijn gevonden. De uitgebreide testen voor alternatieve verklaringen maken het aannemelijk dat het effect van bekenden met uitbetaalde claims een indicatie is van vertrouwen. Het effect van lokaal sociaal kapitaal en netwerken op de vraag naar microverzekeringen kan dus (deels) verklaard worden doordat lokale netwerken een rol spelen bij het kennen van mensen met uitbetaalde claims.

In Hoofdstuk 2 en 3 lag de nadruk op het begrijpen van de vraag naar microverzekeringen vanuit de aanname dat risico vermijdende huishoudens die proberen hun nut te maximaliseren microverzekeringen willen nemen om hun consumptie af te vlakken en zich te beschermen tegen risico's. Empirische studies die de vraag naar micro-verzekeringen hebben onderzocht werden vergeleken om te begrijpen welke factoren een rol kunnen spelen bij deze vraag. Vertrouwen werd empirisch onderzocht. Het kennen van deze factoren is van belang voor het vergroten van de vraag naar microverzekeringen. In Hoofdstuk 4 en 5 is deze benadering uitgebreid en is ook gekeken naar de huidige impact van microverzekeringen op armoedebestrijding.

In Hoofdstuk 4 zijn eerst theorieën over de impact van microverzekeringen besproken. Microverzekeringen vlakken consumptie af doordat de verzekering leidt tot een uitbetaling als er een risico optreedt. Echter, microverzekeringen zouden ook een effect kunnen hebben, anders dan consumptie afvlakking, door te voorkomen dat huishoudens belangrijke bezittingen kwijtraken die ze nodig hebben voor toekomstige inkomensstrategieën. Bovendien kunnen microverzekeringen effecten hebben voorafgaand aan het optreden van een risico door zekerheid te bieden ex-ante en daardoor mensen te stimuleren om te investeren in activiteiten met een hoger risico maar ook een hogere winst.

Naast deze lange en korte termijn effecten voor inkomen en consumptie zijn verdelingseffecten van verzekeringen besproken. Factoren die van invloed zijn op de vraag kunnen implicaties hebben voor de impact van microverzekeringen op huishoudens met bepaalde kenmerken zoals risicovermijding, een lage mate van vertrouwen in de verzekering en kredietbeperkingen.

$\mathrm{Na}$ de discussie van de theorieën in Hoofdstuk 4 zijn onderzoeksontwerpen besproken die gebruikt kunnen worden voor het evalueren van de impact van microverzekeringen. Randomized Control Trials (RCTs) zijn eerst besproken omdat ze door veel wetenschappers worden beschouwd als de gouden standaard voor impactevaluatie. RCTs kunnen waardevol zijn omdat ze vertekening van onderzoeksresultaten, door het weglaten van variabelen, kunnen vermijden doordat aangenomen wordt dat deze weggelaten variabelen random verdeeld zijn over de treatment en controle groepen. RCTs kunnen hierdoor leiden tot onderzoeksresultaten met een hoge mate van interne 
validiteit. Echter, door de randomisatie geven RCTs informatie over gemiddelde effecten en zeggen niets over verdeeleffecten van de interventie voor huishoudens met bepaalde kenmerken.

RCTs adresseren niet automatisch externe, construct en statistische conclusie validiteit. De mechanismen die leiden tot toegang tot de verzekering en het hebben van de verzekering worden nog niet goed begrepen. Hierdoor is het nog maar de vraag of het random toewijzen van de verzekering aan bepaalde groepen, zonder de vraag naar verzekeringen te begrijpen, leidt tot de benodigde informatie over impact van microverzekeringen. Daarnaast kunnen praktische overwegingen zoals de kosten van RCTs of het feit dat veel risico's niet regelmatig voorkomen de toepassing van RCTs bemoeilijken.

In huidig onderzoek naar de impact van microverzekeringen wordt vaak de impact op out-of-pocket betalingen en het gebruik van gezondheidszorg geanalyseerd terwijl de impact van verzekeringen voor natuurrampen op consumptie afvlakkende activiteiten nog nauwelijks is onderzocht. In de rest van Hoofdstuk 4 zijn voordelen en nadelen van verschillende onderzoeksontwerpen voor het onderzoeken van de impact van verschillende typen microverzekeringen besproken. Goed doordachte theorieën over de impact van microverzekeringen, die zowel toegang tot de verzekering als de daadwerkelijke keuze om de verzekering wel of niet te nemen, in overweging nemen zijn van belang voor het begrijpen van impact voor verschillende typen huishoudens. Observatiestudies met aandacht voor externe en construct validiteit zouden gecombineerd moeten worden met (gerandomiseerde) experimentele onderzoeksontwerpen om valide causale uitspraken te doen over constructen die van belang zijn voor beleid.

In Hoofdstuk 4 is aan de orde gekomen dat ex-post effecten van microverzekeringen, in het bijzonder voor risico's met een lage waarschijnlijkheid, nog niet zijn onderzocht in de huidige literatuur. Er is ook besproken dat microverzekeringen zowel complementair kunnen zijn aan als een vervanging kunnen zijn voor bestaande consumptie afvlakkende activiteiten die arme huishoudens gebruiken. Als microverzekeringen een vervangend effect hebben dan is het voor de toekomstige welvaart van arme huishoudens van belang welke typen activiteiten de microverzekering vervangt. Echter, het gebruik van bepaalde activiteiten kan negatievere gevolgen hebben voor de toekomst dan het gebruik van andere.

Daarom is in Hoofdstuk 5 de volgende hypothese getest:

Huishoudens met microverzekeringen gebruiken minder vaak stressvolle consumptie afvlakkende activiteiten dan huishoudens zonder microverzekeringen.

Voor het testen van deze hypothese is dezelfde dataset van elf focusgroepen en 200 arme mensen, met en zonder verzekeringen, in de Filippijnen gebruikt. Het doel van deze studie was om te begrijpen waarom huishoudens bepaalde consumptie afvlakkende activiteiten gebruiken en te analyseren wat het effect is van microverzekeringen op deze activiteiten. De kenmerken van het verzekeringsproduct maakten het onmogelijk om de verzekering te randomiseren en te wachten totdat de natuurramp, zoals de typhoon, gebeurde. Omdat de factoren die de vraag naar de verzekering beïnvloeden ook nog niet 
duidelijk zijn (zie Hoofdstuk 2) was het niet mogelijk om goede instrumenten te vinden waardoor 'matching' geen optie was. Daarom is een observatiestudie gedaan waarin het model voor de verklaring van de vraag zoals gebruikt in Hoofdstuk 3 een belangrijke rol heeft gespeeld om mogelijke problemen met endogeneiteit en zelfselectie uit te sluiten. Andere theoretisch relevante factoren die gebruikt zijn om hiervoor te controleren zijn eerdere ervaringen met hulp van nationale en internationale organisaties na schade door typhoons en het gebruik van andere inkomens- en consumptie-afvlakkende activiteiten.

De schattingsmodellen zijn eerst voor iedere consumptie afvlakkende activiteit apart geschat, met controles voor de andere activiteiten. Daarnaast is getracht om op basis van bestaande theorieën over coping strategieën, consumptie-afvlakkende strategieën en de specifieke informatie van de focus groepen, een variabele te construeren die de activiteiten indeelt in meer en minder stressvolle activiteiten voor de toekomstige welvaart.

Op basis van de resultaten van alle schattingen kan geconcludeerd worden dat het algemene patroon is dat verzekeringen de kans verlagen dat huishoudens andere stressvolle consumptie-afvlakkende activiteiten gebruiken. Dit effect is significant voor het verkopen van productiemiddelen, het uitvoeren van extra werkzaamheden naast de vaste inkomensbron en voor het gebruiken van het spaargeld van het huishouden. Ook kan geconcludeerd worden dat de ex-ante situatie van huishoudens een grote rol speelt bij de keuze voor specifieke activiteiten. Het effect van de verzekering op de gecombineerde variabele is dat het de kans op het gebruik van stressvolle activiteiten significant en aanzienlijk verminderd. Zelfs voor alternatieve constructies van de afhankelijke variabele, zoals een andere indeling in de mate van stress en constructies waarbij het aantal activiteiten zijn geteld, blijft het effect robuust. Dit leidt tot de conclusie dat microverzekeringen de kans verkleinen dat huishoudens stressvolle consumptie-afvlakkende activiteiten gebruiken die een negatief effect hebben voor het toekomstige inkomen en de toekomstige productiviteit.

\section{Conclusies en discussie}

Een van de bevindingen is dat meerdere studies nutstheorie gebruiken voor het begrijpen van de vraag naar microverzekeringen terwijl ze in hun analyse mensen met de verzekering vergelijken met mensen zonder de verzekering. Nutstheorieën zijn beslistheorieën en zouden gebruikt moeten worden voor de keuze tussen het wel of niet nemen van de verzekering. Literatuur over de diffusie van innovaties (Tarde, 1903; Ryan and Gross, 1943; Katz, 1961; Coleman, 1966; Rogers, 2003; Banerjee, Chandrasekhar, Duflo and Jackson, 2012) bevat interessante informatie over de stadia die aan de daadwerkelijke keuze vooraf gaan.

Een andere bevinding is dat factoren die oorspronkelijk onderdeel zijn van nutstheorieën vaak een significant effect hebben maar een groot deel van de variantie in de vraag onverklaard laten. Tegelijkertijd hebben locatie dummies, sociaal kapitaal, netwerken en vertrouwen vaak een groot effect op het verklaren van de vraag. Echter, de mechanismen waardoor deze factoren effect hebben zijn nog onduidelijk en moeten verder onderzocht worden. Deze studie heeft één mechanisme, vertrouwen door het kennen van mensen in lokale netwerken met uitbetaalde claims, toegevoegd. 
In deze dissertatie is vertrouwen onderzocht in een context met een gegeven wet- en regelgeving (Philippines), product (PAID plan) en aanbieder van de verzekering (CARD). In de Filipijnen zijn verzekeringen relatief bekend omdat er een gezondheidsverzekering is van de overheid, ook voor de arme bevolking. Aan de ene kant zou dit kunnen betekenen dat het begrip van verzekeringen groot is en de onzekerheid over verzekeringen daardoor laag. Aan de andere kant zijn er in de laatste jaren regelmatig berichten in de media geweest over faillissementen van verzekeraars. Dit zou een laag niveau van vertrouwen kunnen impliceren. Het zou kunnen zijn dat in een markt zonder negatieve ervaringen het opbouwen van vertrouwen minder belangrijk is dan in de Filippijnen. In dit geval zal het effect van het kennen van mensen met uitbetaalde claims minder groot zijn. Daarentegen werd de aanbieder CARD door alle respondenten als betrouwbaar beschouwd. Ondanks dit is het effect van vertrouwen door ervaringen van bekenden toch nog groot. De voorspelling is dat als de aanbieder minder betrouwbaar is, het effect van de bekenden met ervaringen met uitbetaalde claims groter zal worden.

Deze dissertatie bediscussieert ook de praktische evaluatie van interventies gericht op armoede bestrijding zoals voorgesteld door Banerjee and Duflo (2009). Het gebrek aan het structureel gebruiken van theorie om alle mogelijke impacts te overwegen kan leiden tot onderzoeken die alleen praktisch haalbare of wetenschappelijk interessante impacts analyseren. Dit kan schadelijk zijn als andere impacts worden gemist.

Bovendien, zelfs al kunnen RCTs bijdragen aan intern valide conclusies, zijn ze niet de beste methode om externe en construct valide conclusies te trekken. Deze laatste twee zijn met name van belang voor beleid. Externe validiteit beschouwt de generaliseerbaarheid van de conclusies en stelt dus bijvoorbeeld vragen over het effect van een interventie voor huishoudens met verschillende kenmerken. Door construct validiteit kan bijvoorbeeld de vraag geadresseerd worden of de indicatoren die worden onderzocht wel daadwerkelijk leiden tot armoedebestrijding. Impactonderzoek zou gebruik moeten maken van verschillende onderzoeksontwerpen die de verschillende validiteiten adresseren; het zou gebaseerd moeten zijn op een sterk theoretisch kader ; en het zou uitvoerbaar moeten zijn in termen van de onderzoeksvraag.

\section{Aanbevelingen voor beleid en praktijk}

Traditionele factoren zoals de hoogte van de premie en de kans op het risico hebben effect op de vraag naar microverzekeringen. Sociaal kapitaal, netwerken en vertrouwen hebben ook een groot effect en zijn manipuleerbaar en kunnen dus door beleid en in de praktijk worden beïnvloed. Echter, de mechanismen waardoor ze kunnen worden beïnvloed zijn nog niet goed begrepen. Aangezien veel arme mensen nog onvoldoende verzekerd zijn (door informele dan wel formele verzekeringen) is het voor normatief beleid van groot belang om te begrijpen waarom de vraag van een laag niveau is. Daarbij komt dat factoren moeten worden geïdentificeerd die deze vraag beïnvloeden maar ook kunnen worden gemanipuleerd.

In de begin stadia van de levenscyclus van microverzekeringen, is het van belang om de vraag naar microverzekeringen beter te begrijpen. Momenteel investeren echter veel donoren, overheden en beleidsmakers in impactonderzoek. Aangezien nog niet goed wordt begrepen welke producten precies waardevol zijn voor arme mensen en hoe ze 
kunnen worden aangeboden is het effectiever om te investeren in het begrijpen van de vraag.

De wijze waarop verzekeringsgeletterdheid een bijdrage levert aan het verminderen van onzekerheid over de verzekeringstransactie is nog onduidelijk en moet verder worden onderzocht. Tegelijkertijd wordt er veel geld geïnvesteerd in educatie op het gebied van verzekeringen in ontwikkelingslanden. Alhoewel dit belangrijk kan zijn vanuit andere overwegingen is er geen overtuigend bewijs dat educatie de vraag naar verzekeringen vergroot. Vertrouwen is, naast verzekeringsgeletterdheid, een andere manier om onzekerheid weg te nemen en een aantal onderzoeken bevestigen dit. Verder onderzoek moet gedaan worden om de afzonderlijke en gecombineerde effecten van educatie en vertrouwen te begrijpen.

Een andere uitkomst van deze studie is dat vertrouwen opgebouwd wordt door informele mechanismen na afloop van uitbetaling van claims. Omdat dit pas na afloop van het optreden van het verzekerde risico gebeurd en de kans op het optreden van het risico klein is impliceert dit dat de vraag langzaam zal toenemen. Informele mechanismen kunnen echter vervangen worden door formele mechanismen voor het opbouwen van vertrouwen (wet- en regelgeving, standaarden). Dit betekent dat investeringen in wet- en regelgeving op de langere termijn tot gevolg kunnen hebben dat de vraag sneller toeneemt omdat formele mechanismen vertrouwen bieden voordat het risico optreedt. 


\section{About the author}

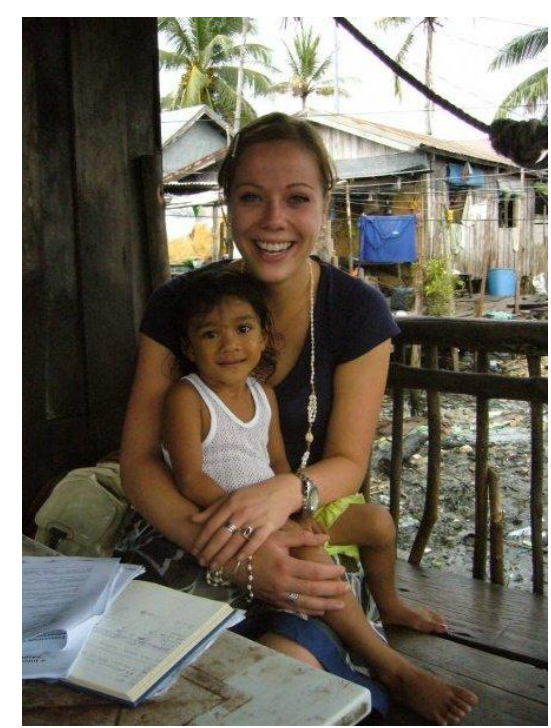

During her bachelor and master Karlijn Morsink has conducted more than a year of field work in rural areas of India and Kenya investigating the adoption of innovations by low-income households and small enterprises. During her PhD at the Twente Centre for Studies in Technology and Sustainable Development (CSTM) at the University of Twente her research focused on the collection of primary data on the demand for and impact of microinsurance by low-income households in the Philippines and Ethiopia. Her research interests include risk, uncertainty, microinsurance, development and behavioral and experimental economics. She has done consultancy work for the International Labour Organization Microinsurance Innovation Facility, the Microinsurance Network and the United Nations Secretary General's Special Advocate for Inclusive Finance for Development H.R.H. Princess Máxima of the Netherlands. Since 2012 Karlijn has been working as advisor on insurance to the Dutch Ministry of Foreign Affairs and since May 2012 she has been a visiting scholar at the University of Oxford's Centre for the Study of African Economies (CSAE). 
